Prepared in cooperation with Rockland County, New York, and New York State Department of Environmental Conservation

\title{
Hydrogeology and Simulation of Groundwater Flow in Fractured Rock in the Newark Basin, Rockland County, New York
}

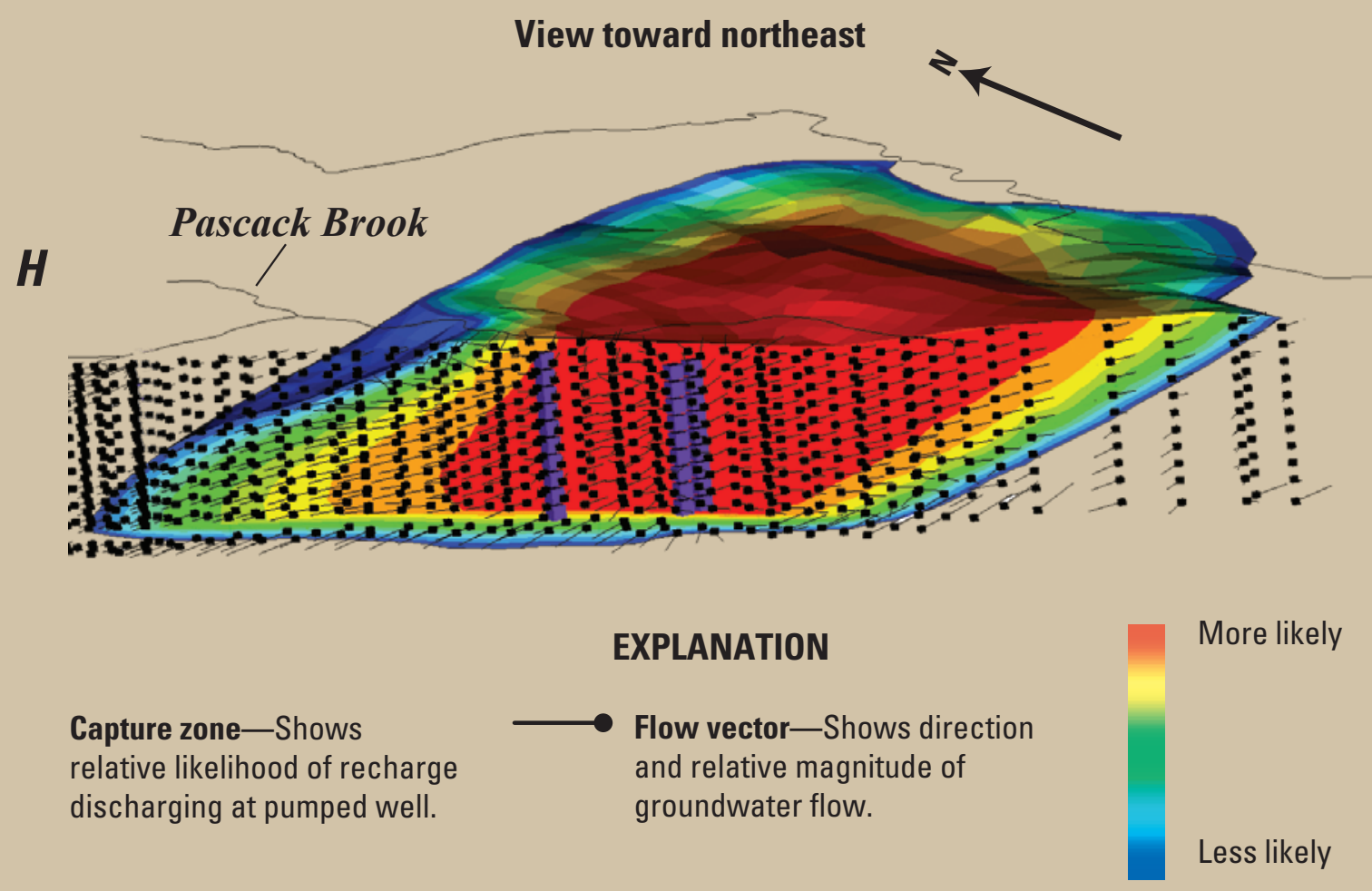

Scientific Investigations Report 2010-5250

U.S. Department of the Interior

U.S. Geological Survey 
Cover. Three-dimensional perspective view of capture zone for Spring Valley well field in Rockland County NY, viewed to northeast parallel to strike of bedding. 


\section{Hydrogeology and Simulation of Groundwater Flow in Fractured Rock in the Newark Basin, Rockland County, New York}

By Richard M. Yager and Nicholas M. Ratcliffe

Prepared in cooperation with Rockland County, New York, and

New York State Department of Environmental Conservation

Scientific Investigations Report 2010-5250 


\section{U.S. Department of the Interior \\ KEN SALAZAR, Secretary \\ U.S. Geological Survey \\ Marcia K. McNutt, Director}

U.S. Geological Survey, Reston, Virginia: 2010

For product and ordering information:

World Wide Web: http://www.usgs.gov/pubprod

Telephone: 1-888-ASK-USGS

For more information on the USGS — the Federal source for science about the Earth,

its natural and living resources, natural hazards, and the environment:

World Wide Web: http://www.usgs.gov

Telephone: 1-888-ASK-USGS

Any use of trade, product, or firm names is for descriptive purposes only and does not imply endorsement by the U.S. Government.

Although this report is in the public domain, permission must be secured from the individual copyright owners to reproduce any copyrighted material contained within this report.

Suggested citation:

Yager, R.M., and Ratcliffe, N.M., 2010, Hydrogeology and simulation of groundwater flow in fractured rock in the Newark basin, Rockland County, New York: U.S. Geological Survey Scientific Investigations Report 2010-5250, 139 p. 


\section{Contents}

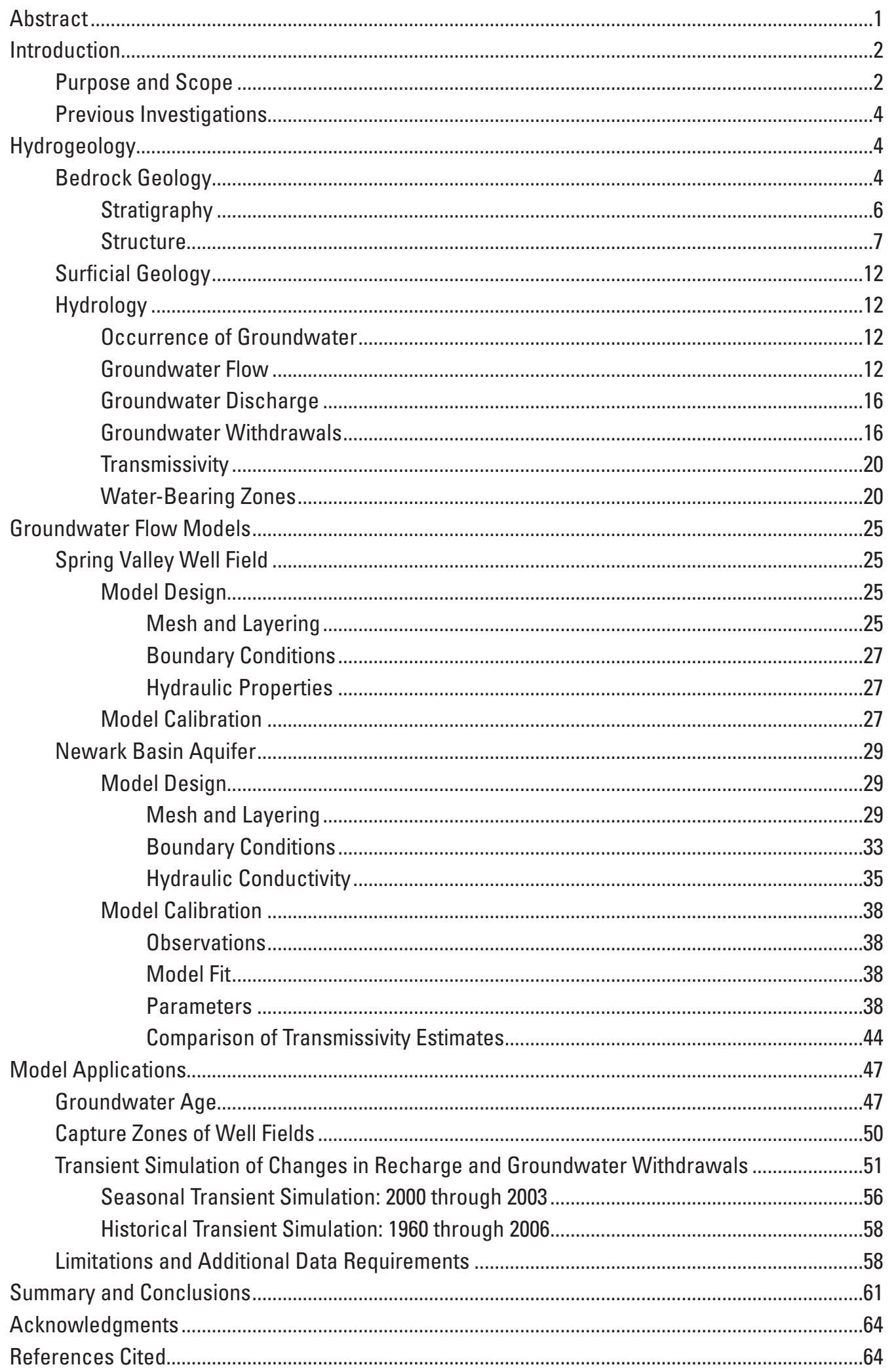


Appendix 1. Generalized bedrock geology of northern Newark basin .............................................68

Appendix 2. Modifications to SUTRA ................................................................................ Link

Appendix 3. Input data for the Time-Dependent Sources and Boundary Conditions Files

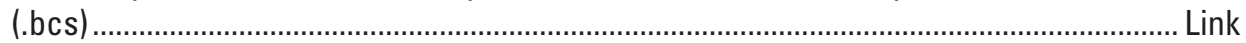

Appendix 4. Selected SUTRA Subroutines ........................................................................... Link

\section{Figures}

1. Map showing generalized bedrock stratigraphy and geographic features near Rockland County, NY, and extent of model domain. 3

2. Graph showing population growth, 1940 through 2006, and annual groundwater use in Rockland County, NY, 1960 through 2006.

3. Map showing well fields in operation in Rockland County, NY, and average groundwater withdrawals, 1995 through 2005

4. Generalized geologic sections showing sedimentary rock units and diabase intrusions in Newark basin, Rockland County, NY .8

5. Shaded relief and aeromagnetic map of Rockland County, NY, and adjacent parts New Jersey and New York

6. Structure map of Newark basin in Rockland County, NY, showing measurements of strike and dip, and form lines and major folds of bedding .....

7. Map showing bedrock zones in the Newark basin aquifer in Rockland County, NY, interpolated strike of bedding, and distribution of alluvium, outwash, and lacustrine sediments

8. Generalized section showing bedrock zones, groundwater level and depths of production wells

9. Map showing average groundwater levels (potentiometric surface) measured from 2005 through 2007 in the Newark basin aquifer in Rockland County, NY.

10. Water-level hydrographs for two production wells in the Newark basin aquifer in Rockland County, NY

11. Map showing watersheds, precipitation gages, and streamgage stations where base flow was estimated in and near Rockland County, NY

12. Map showing transmissivity of Newark basin aquifer in Rockland County, NY, showing values estimated at bedrock wells from aquifer test and specific capacity data

13. Map showing high and low transmissivity $(T)$ zones in the Newark basin aquifer in Rockland County, NY, delineated on the basis of kriged interpolation

14. Boxplots showing distribution of transmissivity in bedrock wells using zones based on $(A)$ kriged interpolation and $(B)$ interpretation of Heisig (2010)

15. Geologic section showing distribution of water-bearing zones in the Passaic Formation at Fair Lawn, New Jersey.

16. Perspective diagram of block of inclined sedimentary rock showing hydraulic conductivity directions at upper edge of block

17. Grid showing water-level recovery following 5-day cessation of pumping from the Spring Valley well field, NY. 
18. Schematic design showing distribution of simulated water-level recovery in model $\mathrm{B}(A)$ plan view, and $B$ ) perspective three-dimensional view along section $\mathrm{F}-\mathrm{F}^{\prime}$..

19. Graphs showing observed and simulated water-level recovery in deep wells in model $B$ at $(A)$ well Ro1308 (PTPN-20D), (B) well Ro1298 (PTPN-8D), (C) well Ro1305 (PTPN-19D), (D) well Ro1318 (PTPN-24D), (E) well Ro1324 (SRI-2D), and ( $F$ well Ro1326 (SRI-3D).

20. Graph showing measured and simulated water-level recovery in shallow wells in model B at $(A)$ well Ro1310 (PTPN-20S), (B) well Ro1299 (PTPN-8S), (C) well Ro1307 (PTPN-19S), (D) well Ro1319 (PTPN-24S), (E) well Ro1325 (SRI-2S), and ( $F$ well Ro1327 (SRI-3S)

21. Graph showing residual plots (observed minus simulated values) for simulated water-level recovery in model $\mathrm{B}:(A)$ relation between simulated and observed values, and $(B)$ relation between simulated values and residuals.

22. Map showing finite-element mesh and bedrock zones used to assign thickness of active groundwater flow in Newark basin in Rockland County, NY

23. Block diagram cropped along section G-G' showing thickness of units and hydraulic conductivity zones within model domain.

24. Graphs showing relations defining factors used to compute recharge assigned to nodes in finite-element mesh $(A)$ pervious area factor, and $(B)$ thickness factor for unconsolidated deposits

25. Map showing distribution of simulated recharge specified in steady-state simulations of 2006 conditions in Newark basin in Rockland County, NY

26. Map showing potentiometric surface simulated for 2006 conditions in Newark basin in Rockland County, NY, using model B and distribution of residuals

27. Block diagram cropped along section G-G' showing spatial distribution of simulated hydraulic head with model $B$ and locations of potential flowing and cascading wells

28. Graphs showing residual plots for simulated water levels in model $B(A)$ relation between simulated and observed values, and $(B)$ relation between simulated values and weighted residuals

29. Bar chart comparing simulated base flows for selected streams in model B with base flows estimated from streamflow hydrographs 2004 to 2007, and low flows in July 2006

30. Graphs showing simulated change in head produced by wells pumping from isotropic and anisotropic materials $(A)$ fully penetrating well, and $(B)$ partially penetrating well

31. Schematic design and graph showing effect of angle between strike of bedding and hydraulic gradient $(\theta)$ and bedding declination $(\varphi)$ on flow through a block of inclined anisotropic material $(A)$ simulated head distribution with $\theta=50^{\circ}$ and $\varphi=10^{\circ}$, and $(B)$ simulated flow through block

32. Graph showing comparison of simulated ages of groundwater withdrawn from production wells with those estimated on the basis of tritium/helium age dating ..........47

33. Map showing spatial distribution of groundwater age in Newark basin in Rockland County, NY, as simulated using $(A)$ model $A$, and $(B)$ model $B$

34. Map showing plan views of capture zones of well fields in Rockland County, NY, delineated after 10-year travel time with $(A)$ model $A$, and $(B)$ model $B$

35. Schematic design showing three-dimensional perspective views of capture zones for Spring Valley well field in Rockland County, NY, delineated using model $B:(A)$ view to northeast parallel to strike of bedding, and $(B)$ view to northwest perpendicular to strike of bedding. 
36. Schematic design showing sensitivity of capture-zone delineation to changes in model B: $(A) K_{\max }: K_{\min }$ anisotropy reduced to 70:1 (ratio parallel to bedding: perpendicular to bedding), $(B)$ recharge rate reduced by 40 percent (1966 rate), and $(C)$ withdrawal rates increased by 30 percent.

37. Water-level hydrographs simulated using model $B$ with monthly distribution of recharge and groundwater withdrawals, 2000 through 2003: $(A)$ well Ro647, (B) well Ro1272, (C) well Ro106, (D) well Ro1234, (E) well Ro58, and ( $F$ ) well Ro1278

38. Graphs showing groundwater discharge to streams (base flow) simulated using model $B$ with $(A)$ monthly distribution of recharge and groundwater withdrawals, 2000 through 2003, and $(B)$ annual distribution of recharge and groundwater withdrawals, 1960 through 2006

39. Water-level hydrographs simulated using model B with annual distribution of recharge and groundwater withdrawals, 1960 through 2006: $(A)$ well Ro647, $(B)$ well Ro1272, (C) well Ro106, (D) well Ro1234, $(E)$ well Ro58, and (F) well Ro1278.

\section{Tables}

1. Base flow and basin area for streamgage stations in and near, Rockland County, NY

2. Well fields supplying water from the Newark basin aquifer in 2005, Rockland County, NY......

3. Parameter values in alternative models of recovery test at Spring Valley well field in 1992, Rockland County, NY

4. Simulated water budget for Newark basin aquifer in model B

5. Parameter values in alternative models of regional groundwater flow specified or estimated through nonlinear regression

6. Values of unsaturated flow properties specified in unconfined transient simulations

\section{Conversion Factors}

Inch/Pound to SI

\begin{tabular}{lcl}
\hline Multiply & \multicolumn{1}{c}{ By } & To obtain \\
\hline & \multicolumn{1}{c}{ Length } & \\
\hline inch (in.) & 2.54 & centimeter $(\mathrm{cm})$ \\
inch (in.) & 25.4 & millimeter $(\mathrm{mm})$ \\
foot (ft) & 0.3048 & meter $(\mathrm{m})$ \\
mile (mi) & 1.609 & kilometer $(\mathrm{km})$ \\
\hline & \multicolumn{1}{c}{ Area } & \\
\hline square foot $\left(\mathrm{ft}^{2}\right)$ & 929.0 & square centimeter $\left(\mathrm{cm}^{2}\right)$ \\
square foot $\left(\mathrm{ft}^{2}\right)$ & 0.09290 & square meter $\left(\mathrm{m}^{2}\right)$ \\
square mile $\left(\mathrm{mi}^{2}\right)$ & 259.0 & hectare (ha) \\
square mile $\left(\mathrm{mi}^{2}\right)$ & 2.590 & square kilometer $\left(\mathrm{km}^{2}\right)$ \\
\hline
\end{tabular}




\begin{tabular}{|c|c|c|}
\hline \multicolumn{3}{|c|}{ Volume } \\
\hline gallon (gal) & 3.785 & liter (L) \\
\hline gallon (gal) & 0.003785 & cubic meter $\left(\mathrm{m}^{3}\right)$ \\
\hline million gallons (Mgal) & 3,785 & cubic meter $\left(\mathrm{m}^{3}\right)$ \\
\hline cubic foot $\left(\mathrm{ft}^{3}\right)$ & 0.02832 & cubic meter $\left(\mathrm{m}^{3}\right)$ \\
\hline \multicolumn{3}{|c|}{ Flow rate } \\
\hline foot per day (ft/d) & 0.3048 & meter per day $(\mathrm{m} / \mathrm{d})$ \\
\hline cubic foot per second $\left(\mathrm{ft}^{3} / \mathrm{s}\right)$ & 0.02832 & cubic meter per second $\left(\mathrm{m}^{3} / \mathrm{s}\right)$ \\
\hline cubic foot per day $\left(\mathrm{ft}^{3} / \mathrm{d}\right)$ & 0.02832 & cubic meter per day $\left(\mathrm{m}^{3} / \mathrm{d}\right)$ \\
\hline $\begin{array}{l}\text { cubic foot per second per square mile } \\
{\left[\left(\mathrm{ft}^{3} / \mathrm{s}\right) / \mathrm{mi}^{2}\right]}\end{array}$ & 0.01093 & $\begin{array}{l}\text { cubic meter per second per square } \\
\text { kilometer }\left[\left(\mathrm{m}^{3} / \mathrm{s}\right) / \mathrm{km}^{2}\right]\end{array}$ \\
\hline gallon per minute (gal/min) & 0.06309 & liter per second $(\mathrm{L} / \mathrm{s})$ \\
\hline million gallons per day (Mgal/d) & 0.04381 & cubic meter per second $\left(\mathrm{m}^{3} / \mathrm{s}\right)$ \\
\hline inch per year (in/yr) & 25.4 & millimeter per year (mm/yr) \\
\hline \multicolumn{3}{|c|}{ Specific capacity } \\
\hline $\begin{array}{l}\text { gallon per minute per foot } \\
[(\mathrm{gal} / \mathrm{min}) / \mathrm{ft})]\end{array}$ & 0.2070 & liter per second per meter $[(\mathrm{L} / \mathrm{s}) / \mathrm{m}]$ \\
\hline \multicolumn{3}{|c|}{ Hydraulic conductivity } \\
\hline foot per day $(\mathrm{ft} / \mathrm{d})$ & 0.3048 & meter per day $(\mathrm{m} / \mathrm{d})$ \\
\hline \multicolumn{3}{|c|}{ Hydraulic gradient } \\
\hline foot per mile ( $\mathrm{ft} / \mathrm{mi})$ & 0.1894 & meter per kilometer (m/km) \\
\hline \multicolumn{3}{|c|}{ Transmissivity* } \\
\hline foot squared per day $\left(\mathrm{ft}^{2} / \mathrm{d}\right)$ & 0.09290 & meter squared per day $\left(\mathrm{m}^{2} / \mathrm{d}\right)$ \\
\hline
\end{tabular}

Temperature in degrees Celsius $\left({ }^{\circ} \mathrm{C}\right)$ may be converted to degrees Fahrenheit $\left({ }^{\circ} \mathrm{F}\right)$ as follows:

$$
{ }^{\circ} \mathrm{F}=\left(1.8 \times^{\circ} \mathrm{C}\right)+32
$$

Temperature in degrees Fahrenheit $\left({ }^{\circ} \mathrm{F}\right)$ may be converted to degrees Celsius $\left({ }^{\circ} \mathrm{C}\right)$ as follows:

$$
{ }^{\circ} \mathrm{C}=\left({ }^{\circ} \mathrm{F}-32\right) / 1.8
$$

Vertical coordinate information is referenced to the North American Vertical Datum of 1988 (NAVD 88).

Horizontal coordinate information is referenced to the North American Datum of 1983 (NAD 83).

Altitude, as used in this report, refers to distance above the vertical datum.

*Transmissivity: The standard unit for transmissivity is cubic foot per day per square foot times foot of aquifer thickness [( $\left.\left.\mathrm{ft}^{3} / \mathrm{d}\right) / \mathrm{ft}^{2}\right] \mathrm{ft}$. In this report, the mathematically reduced form, foot squared per day $\left(\mathrm{ft}^{2} / \mathrm{d}\right)$, is used for convenience. 



\title{
Hydrogeology and Simulation of Groundwater Flow in Fractured Rock in the Newark Basin, Rockland County, New York
}

\author{
By Richard M. Yager and Nicolas M. Ratcliffe
}

\section{Abstract}

Groundwater in the Newark basin aquifer flows primarily through discrete water-bearing zones parallel to the strike and dip of bedding, whereas flow perpendicular to the strike is restricted, thereby imparting anisotropy to the groundwater flow field. The finite-element model SUTRA was used to represent bedrock structure in the aquifer by spatially varying the orientation of the hydraulic conductivity tensor to reflect variations in the strike and dip of the bedding. Directions of maximum and medium hydraulic conductivity were oriented parallel to the bedding, and the direction of minimum hydraulic conductivity was oriented perpendicular to the bedding. Groundwater flow models were prepared to simulate local flow in the vicinity of the Spring Valley well field and regional flow through the Newark basin aquifer.

The Newark basin contains sedimentary rocks deposited as alluvium during the Late Triassic and is one of a series of basins that developed when Mesozoic rifting of the super continent Pangea created the Atlantic Ocean. The westwarddipping basin is filled with interbedded facies of coarsegrained to fine-grained rocks that were intruded by diabase associated with Jurassic volcanism. The Newark basin aquifer is bounded to the north and east by the Palisades sill and to the west by the Ramapo Fault. Although the general dip of bedding is toward the fault, mapping of conglomerate beds indicates the rocks are folded into broad anticlines and synclines. An alternative, more uniform pattern of regional structure, based on interpolated strike and dip measurements from a number of sources, has also been proposed. Two groundwater flow models (A for the former type of bedrock structure and B for the latter type) were developed to represent these alternative depictions of bedrock structure.

Transient simulations were calibrated to reproduce measured water-level recoveries in a $9.3 \mathrm{mi}^{2}$ area surrounding the Spring Valley well field during a 5-day aquifer test in 1992. The models represented a 330-ft thick rock mass divided vertically into 10 equally spaced layers and were calibrated through nonlinear regression. Results of model $\mathrm{B}$ best matched the observed water-level recoveries with an estimated hydraulic conductivity of $9.5 \mathrm{ft} /$ day, specific storage of $7.6 \times 10^{-6} \mathrm{ft}^{-1}$, and $K_{\max }: K_{\min }$ anisotropy ratio (hydraulic conductivity parallel to bedding: perpendicular to bedding) of 72:1. Model error was 50 percent greater in model A because the assumed structure did not match the actual strike of bedding in this area.

Steady-state simulations of regional flow through the 85.4- $\mathrm{mi}^{2}$ modeled extent of the Newark basin aquifer represented both the alluvial aquifer beneath the Mawah River and the fractured bedrock. The rock mass was divided into two aquifer units: an upper 500-ft thick unit divided into 10 equally spaced layers through which most groundwater is assumed to flow and a lower unit divided into 7 layers with increasing thickness. Models were calibrated through nonlinear regression to average water levels measured in 140 wells from August 2005 through April 2007. Water levels simulated using the two models were similar and generally matched those observed, and the average recharge rate estimated using both models was 19 inches/year for the simulated period. Estimated transmissivity parallel to the strike of bedding $\left(1,100 \mathrm{ft}^{2} / \mathrm{d}\right)$ was uniform in two transmissivity $(T)$ zones in model A, but in model B the transmissivity of a high $T$ zone $\left(1,600 \mathrm{ft}^{2} / \mathrm{d}\right)$, delineated on the basis of aquifer test data, was slightly greater than in a low $T$ zone $\left(1,300 \mathrm{ft}^{2} / \mathrm{d}\right)$. The $K_{\max }: K_{\min }$ anisotropy was estimated to be $58: 1$ in model A and 410:1 in model B, so the proportion of flow perpendicular to bedding is less in model $\mathrm{B}$ than in model $\mathrm{A}$.

Distributions of groundwater age simulated with models $\mathrm{A}$ and $\mathrm{B}$ are similar and indicate that most shallow groundwater ( $225 \mathrm{ft}$ below the bedrock surface) is 5 to 20 years old, with younger water (5 years or less) near upland recharge areas and older water (more than 100 years) in lowland discharge areas near the Hackensack River and Saddle River. The two simulated distributions differ in some areas where younger water is simulated with model A. Effective porosity $\left(2 \times 10^{-2}\right)$ was estimated by comparing simulated groundwater ages with those calculated previously on the basis of tritium/ helium $\left({ }^{3} \mathrm{H} /{ }^{3} \mathrm{He}\right)$ dating. Well-field capture zones delineated for major well fields are generally elongated parallel to the assumed strike of bedding and are affected by the simulated potentiometric surface, the drainage network of stream channels, and capture zones of adjacent well fields. Sizes of capture zones range from $1.9 \mathrm{mi}^{2}$ (1,200 acres) for well fields with 
Hydrogeology and Simulation of Groundwater Flow in Fractured Rock in the Newark Basin, Rockland County, New York

the largest average withdrawal rates $(1,300 \mathrm{gal} / \mathrm{min})$ to less than $0.04 \mathrm{mi}^{2}$ ( 25 acres) for well fields with the smallest rates (80 gal/min). Base flows in Pascack Brook and Nauraushaun Brook probably have been decreased by groundwater withdrawals because capture zones of several well fields overlap these watersheds.

The effects of annual and monthly changes in recharge and groundwater withdrawals on water levels and discharges to streams were assessed through transient flow simulations of two periods: a 47-year period from January 1960 through December 2006 and a 3-year period from January 2000 through December 2003. The simulations included an orderof-magnitude range in specific storage $\left(S_{s}\right)$ and both saturated and variably saturated conditions. Monthly water levels simulated with the smallest $S_{s}$ value $\left(7.6 \times 10^{-6} \mathrm{ft}^{-1}\right.$ from simulation of the Spring Valley water-level recovery test) fluctuated by about $15 \mathrm{ft}$ in lowlands and $85 \mathrm{ft}$ in uplands, and by about $3 \mathrm{ft}$ and $20 \mathrm{ft}$ using the largest $S_{s}$ value, whereas measured water-levels fluctuated by $7 \mathrm{ft}$ and $13 \mathrm{ft}$, respectively. The hydrographs of simulated annual groundwater levels indicate a trend of decreasing groundwater levels from 1960 through 2006 in upland areas where water levels decreased by 15 to $20 \mathrm{ft}$. Although the groundwater flow models described in this report are sufficiently accurate to estimate the water budget and delineate capture zones of pumped wells, smaller-scale higher-resolution models would be needed to more accurately simulate contaminant movement, interference between adjacent wells, and local effects of pumping on stream discharge.

\section{Introduction}

Groundwater provided an average 21 million gallons per day (Mgal/d) or about 60 percent of the public water supply for about 300,000 people in Rockland County, New York, from 1985 through 2005. Of this amount, nearly one-half (10 Mgal/d) was withdrawn from fractured sedimentary rocks of the Newark basin that underlie an $85.4 \mathrm{mi}^{2}$ area in the southeastern part of the county that is bounded by the New Jersey State line and the Palisades sill (fig. 1). The population of Rockland County increased steadily from the 1950s through the 1970s because of its proximity to New York City (U.S. Census Bureau, 2007), and water use followed a similar trend (fig. 2) (Legette, Brashears and Graham, Inc, written commun., 2007). Groundwater withdrawals from the Newark basin provided nearly the entire water supply until the 1960s when the commercially owned water provider augmented the supply by including groundwater from unconsolidated aquifers adjacent to the Ramapo and Mahwah Rivers and surface water from the Lake DeForest Reservoir. Despite these additional sources, groundwater from the Newark basin remains a substantial component of the public water supply, and 32 well fields were in operation in 2005 (fig. 3). As early as 1979 , there was concern that utilization of the Newark basin aquifer was near capacity and that withdrawals equaled 60 percent of recharge (Legette, Brashears and Graham, Inc., 1979). In more recent years (2000 to 2010), withdrawals from individual well fields were sometimes curtailed during periods of high demand in the summer when water levels were too low to sustain pumping. Contamination of groundwater has also necessitated closure or additional treatment at some well fields (Heisig, 2010).

Because of the importance of groundwater to the Rockland County water supply and concerns regarding the sustainability and quality of water in the Newark basin aquifer, the U.S. Geological Survey (USGS) began a 5-year study of this resource in 2003 in cooperation with Rockland County and New York State Department of Environmental Conservation. This comprehensive investigation, documented in a companion report (Heisig, 2010) included (1) measurement of groundwater levels, (2) borehole geophysical surveys in selected wells, (3) evaluation of streamflow, and (4) analysis of groundwater chemistry. An additional component of the study was the development of a groundwater flow model of the Newark basin aquifer, described herein, to facilitate estimation of recharge and delineation of capture zones that supply water to well fields. A further benefit of the development of a groundwater flow model was the assessment of the effects of more than 40 years of withdrawals on water levels in the Newark basin aquifer.

\section{Purpose and Scope}

This report describes the hydrogeology of the Newark basin aquifer in Rockland County, NY, and the development and application of groundwater flow models. The bedrock geology is discussed, including stratigraphy and structure, and glacial geology. Bedrock stratigraphy is illustrated through sections and maps, two of which depict alternate interpretations of the regional strike of bedding. The first is more detailed and reflects minor structures (folds) in the rock, while the second is more generalized and depicts a more uniform structure with less folding. A conceptual model of the groundwater flow system is discussed, including estimates of transmissivity for the fracture network that transmits water through the aquifer, and information regarding groundwater discharge and withdrawals is presented.

The report documents the design and calibration of threedimensional models used to simulate the pattern and rate of groundwater flow, and to estimate the hydraulic properties of the aquifer. Applications of model simulations used to estimate groundwater age and to delineate capture zones of well fields in operation in 2005 are described. Additional simulations that show changes in water levels in response to changes in recharge and withdrawals, including monthly changes from 2000 through 2003 and annual changes from 1960 through 2006, also are presented. Finally, the limitations of the models and the need for additional information are discussed. 


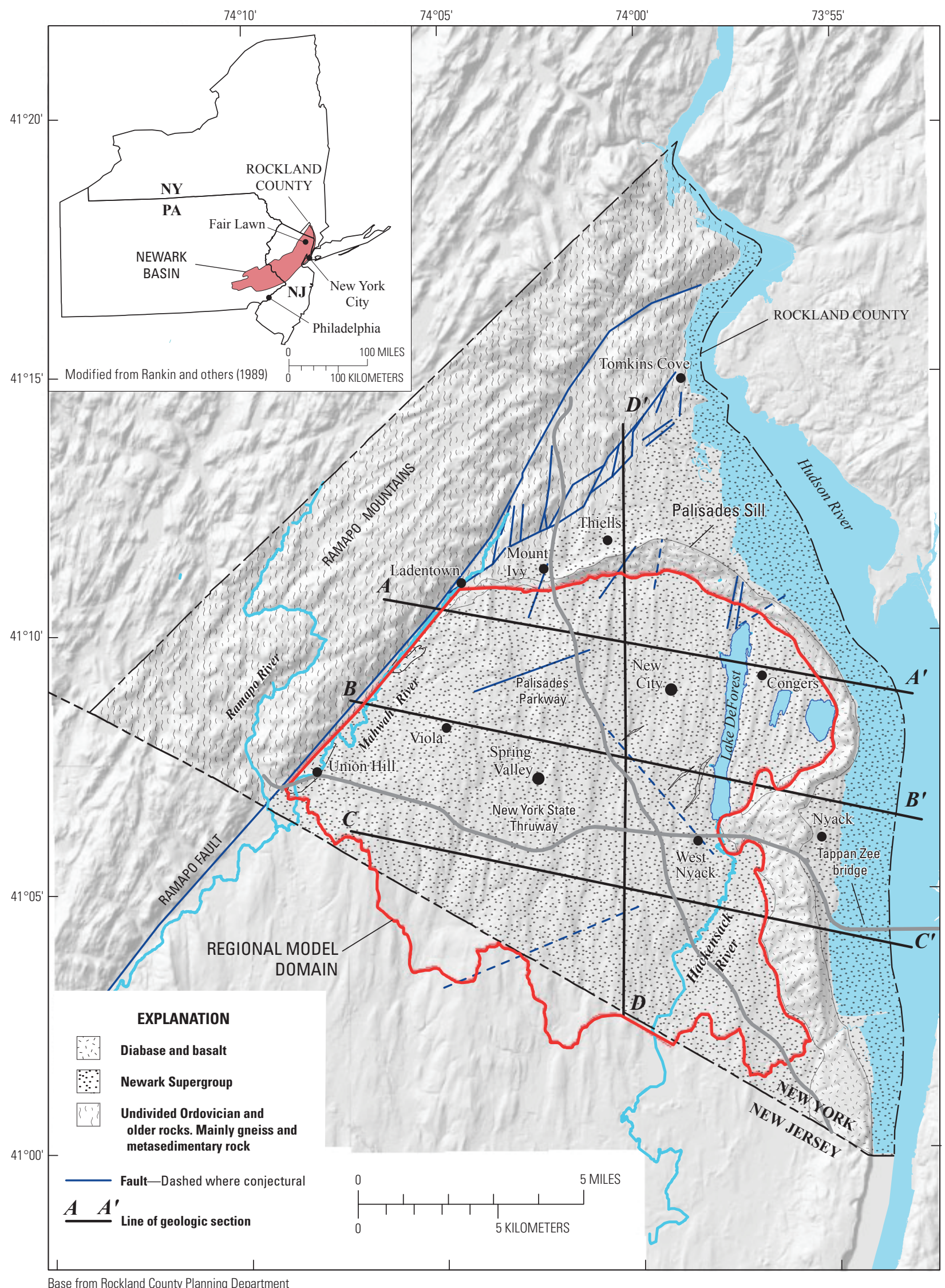

Figure 1. Generalized bedrock stratigraphy and geographic features near Rockland County, NY, and extent of model domain. Bedrock stratigraphy based on Ratcliffe (1988). 


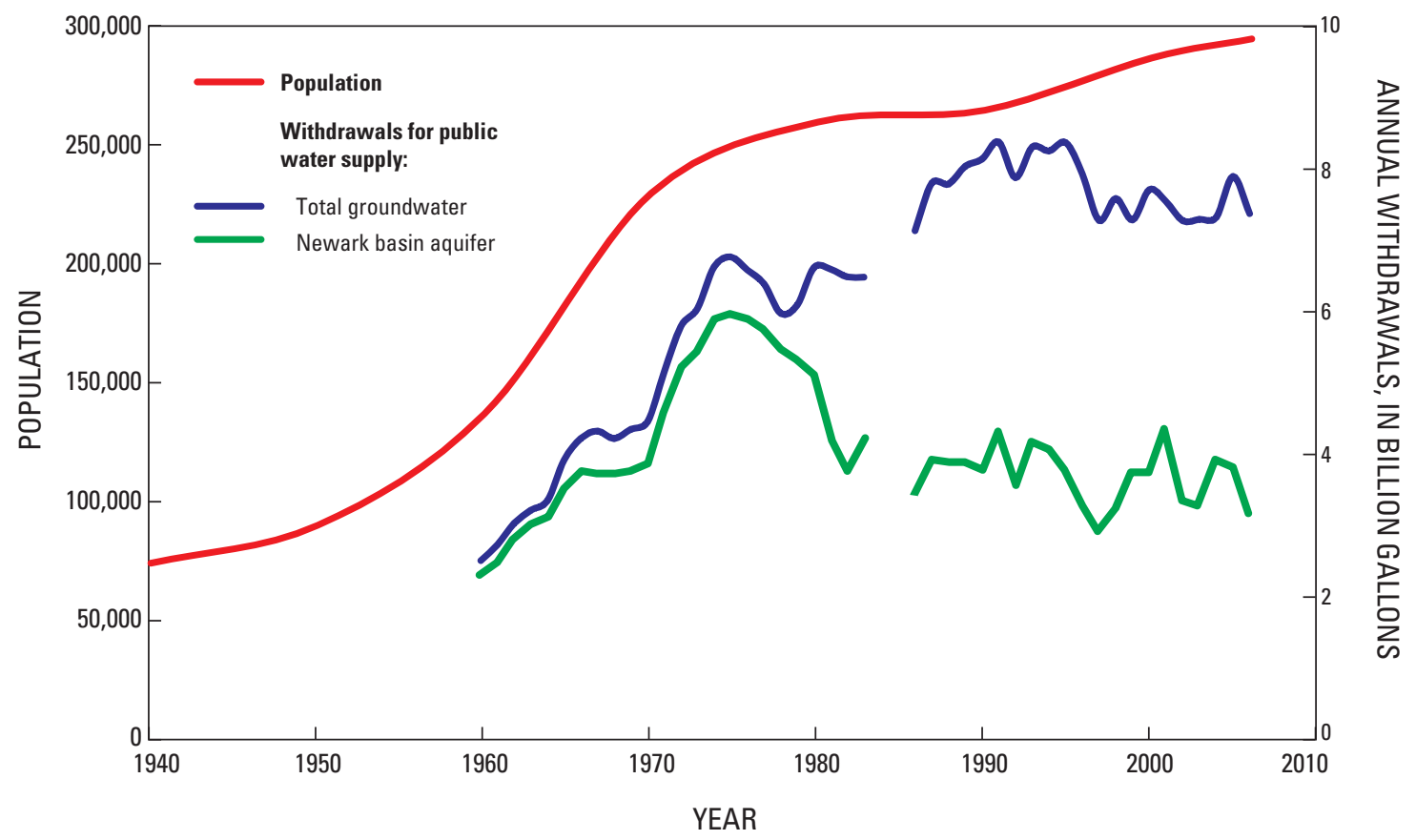

Figure 2. Population growth, 1940 through 2006, and annual groundwater use in Rockland County, NY, 1960 through 2006.

\section{Previous Investigations}

A comprehensive summary of hydrologic and geologic studies that pertain to the Newark basin aquifer in Rockland County is presented in Heisig (2010). The geology of the sedimentary rocks, including stratigraphy and structure, is described by Kummel (1899), Savage (1967), and Ratcliffe (1988). The geology of intrusive igneous rock (diabase) within Rockland County is discussed by Lowe (1959) and Ratcliffe (1988). The structure of the Ramapo Fault and adjacent areas was investigated by Ratcliffe $(1980,1982)$ and Ratcliffe and Burton (1985). A hydrogeologic study by Perlmutter (1959) of the Newark basin aquifer in Rockland County described the bedrock and glacial geology, the waterbearing properties of the aquifer, and water use. Perlmutter (1959) also compiled water levels, yields, and water-quality data. Leggette, Brashears, and Graham, Inc. (1979) conducted a hydrogeologic assessment of the aquifer and estimated water availability by computing water budgets for the largest watersheds. Leggette, Brashears, and Graham, Inc. (1992) conducted a 5-day aquifer test at the Spring Valley well field using 4 production wells and 32 observation wells. Aeschbach-Hertig and others (1998) estimated the age of groundwater in the Newark basin aquifer in Rockland County using tritium-helium age dating.

\section{Hydrogeology}

The Newark basin aquifer in Rockland County lies within eroded Upper Triassic to Lower Jurassic rocks of the Newark Supergroup at the northern end of the Newark basin, which extends $150 \mathrm{mi}$ from New York State southwest across New Jersey into Pennsylvania. The Newark basin is one of a series of such continental rift basins in eastern North and South America, and western Africa, and Europe that developed during the Mesozoic rifting of the super continent Pangea and creation of the Atlantic Ocean (Pittman and Talwani, 1972; Olsen 1997). The cumulative width of the opposing rift basins on both sides of the present Atlantic Ocean is as much as $300 \mathrm{mi}$, making these basins first-order tectonic features of the Earth.

\section{Bedrock Geology}

The Newark basin in Rockland County is a fault-bounded half graben that consists of a 2.5 to 3 mi-thick sequence of westward dipping continental red beds and lake deposits, and intrusive sheets of diabase and basaltic lava flows, that collectively make up the Newark Supergroup. These rocks unconformably overlie much older metamorphic rocks of 


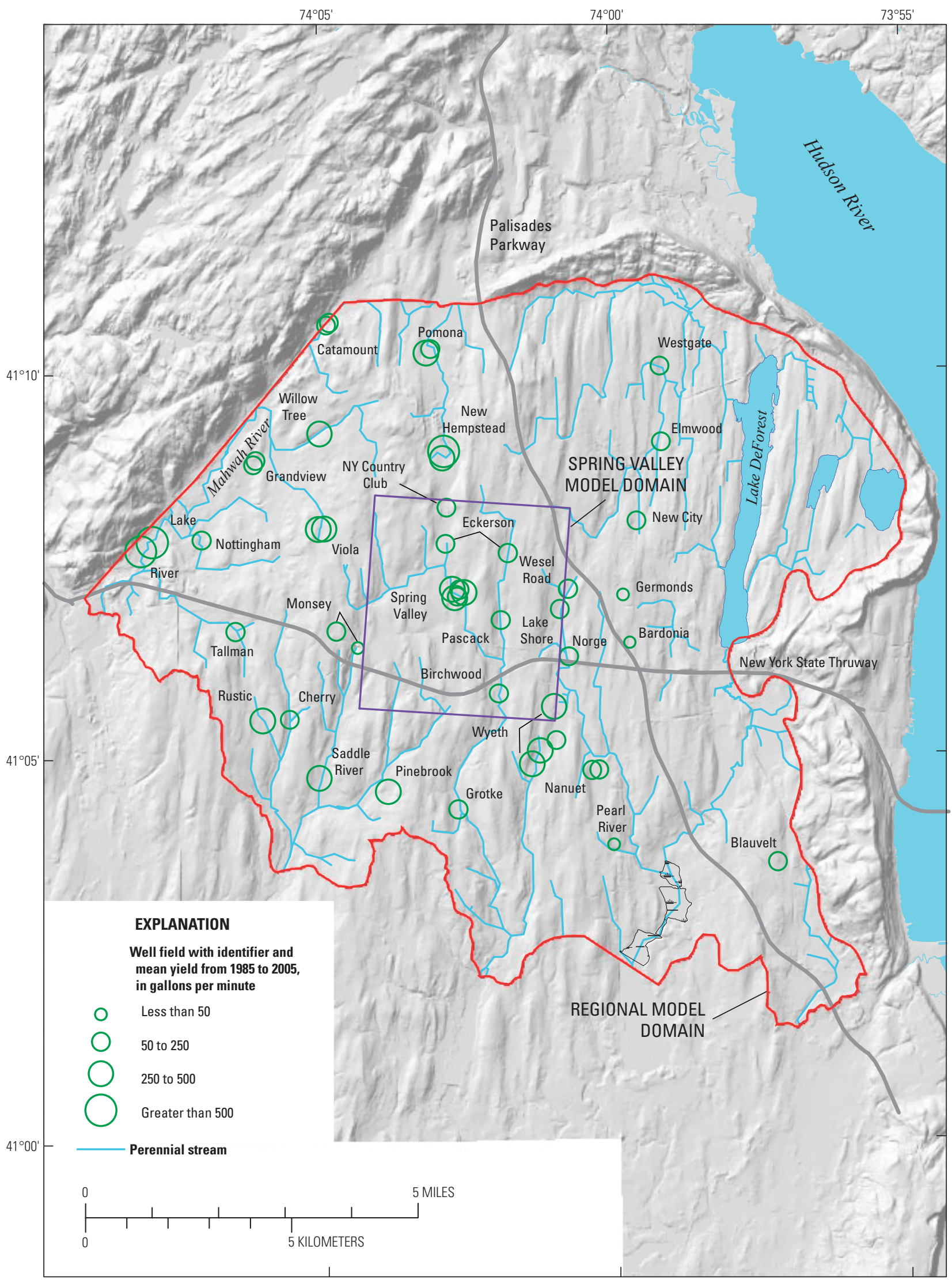

Base from Rockland County Planning Department

Figure 3. Well fields in operation in Rockland County, NY, and average groundwater withdrawals, 1995 through 2005. 
the Hudson Highlands and Manhattan Prong that extend under the basin from the west, north, and east. The floor of the basin extends beneath the Hudson River, as determined during drilling for the Tappan Zee bridge (Worzel and Drake, 1957), and is locally exposed only at Tomkins Cove, NY (fig. 1). Several miles of basin sediments were removed by erosion after deposition, and the total sediment thickness is as much as 3.6 mi near the center of the basin in Pennsylvania. The Ramapo Fault bounds the Newark basin to the west in Rockland County and is inclined about 55 degrees to the southeast (Ratcliffe, 1980 and 1982). Cumulative movement along the Ramapo Fault caused basin sediments and diabase to drop as much as 2.5 mi during the Mesozoic Era. Although the last movements are more recent than about 200 mega-annum (Ma), no evidence supports further reactivation of this thrust fault (Ratcliffe, 1980).

The resistance of rocks in Rockland County to erosion is variable and has resulted in the present land-surface topography. Highlands underlain by Proterozoic gneiss to the west of the Newark basin in Rockland County form a distinct eroded scarp that marks the location of the Ramapo Fault (fig. 1). A highland within the basin near Ladentown and Viola is underlain by gently folded layers of resistant lava flows and thick beds of coarse conglomerate. The topography in eastern and northern parts of the basin is dominated by a resistant northsouth trending ridge underlain by the diabase of the Palisades sill that curves and trends east-west and terminates at Mount Ivy. In the central part of the basin, from New City to West Nyack, the topography is lower and less affected by erosion and is dominated by north-south trending drumlins formed by molding of glacial drift during Pleistocene glaciation. Pleistocene and Holocene alluvial gravels and sands underlie swampy areas along the valley of the Mahwah River and near Thiells and Mount Ivy.

\section{Stratigraphy}

Sedimentary rocks of the Newark Supergroup in Rockland County range in age from Late Triassic Period to Early Jurassic Period. The age, grain size, texture, and bedding characteristics of rocks vary, depending upon the location and the former depositional environments within the subsiding basin (Smoot, 1991; Olsen and Rainforth, 2003). The Stockton Formation (fig. 4 and Appendix 1) consists of arkosic sandstones, pebbly sandstones, and feldspar containing conglomerate. These Triassic sediments were deposited in the basin by many small rivers and streams before the present drainage system was developed. Coarse- to fine-grained alluvial deposits and coarse-grained alluvial fans were deposited as interfingering facies and are interbedded with lacustrine deposits of the Lockatong Formation, which is well developed closer to the center of the basin in New Jersey but present only locally in Rockland County (Appendix 1).

The Passaic Formation directly overlies the Stockton Formation where the Lockatong Formation is absent and consists of interbedded coarse-grained to fine-grained arkosic sandstones, siltstones, and shales. The fine-grained rocks crop out in the eastern part of the basin, whereas the coarse-grained rocks are present at higher stratigraphic levels to the west. The lower part of the Passaic Formation consists of interbedded arkosic sandstone, mudstone, and silty shales. A distinctive polymictic quartz conglomerate in the lower Passaic Formation is cut by the Palisades sill and serves as a marker horizon north of the sill. Braided streams near the western margin of the basin in Rockland County deposited fine sands and clay into shallow ephemeral lakes in this area as part of a major south-draining river system, forming an "axial alluvial facies" in the upper and middle part of the Passaic Formation that has been identified by Smoot (2010). Parker and others (1988) and Parker (1993) determined that cross bedding in these alluvial deposits is highly variable, but the cross bedding in general indicates south to southeast transport and deposition. The orientation of individual foreset beds in these deposits is variable, and dip directions range from east-northeast to south-southwest. Strike measurements based on cross bedding observed in geophysical logs, therefore, may not reflect the generalized regional strike of bedding in the Passaic Formation. Rocks with these characteristics also are present in the middle and lower parts of the Passaic Formation in central and eastern Rockland County.

The middle and upper parts of the Passaic Formation consist of coarse-grained to medium-grained quartz-pebble sandstone and conglomerate with less mudstone and shale. Smoot (2010) interprets these deposits as alluvial braidedstream deposits within the axial alluvial facies. Six continuous conglomerate layers have been identified by Ratcliffe (1980) in the middle and upper Passaic Formation (Appendix 1). The conglomerate layers in the middle of the Passaic Formation contain pebbles and cobbles that are predominantly clasts of the Devonian Green Pond Conglomerate (Ratcliffe, 1980). The conglomerate layers at higher stratigraphic levels also contain boulders with cobbles of Mesoproterozoic gneiss and clasts of rhyodacite dikes from the Rosetown pluton and dike swarm (Ratcliffe, 1980) that crop out several miles north and west of the basin margin. In the northwestern part of the basin, coarse limestone and dolostone fanglomerates (coarse material in an alluvial fan) in the upper part of the Passaic Formation are abundant at land surface and in drill cores (Ratcliffe, 1980; 1982; 1988). The conglomerates thicken westward towards the Ramapo Fault and replace the sandstone and sandstone alluvial facies (fig. 4) of the Passaic Formation.

The earliest lava flows in the Newark basin mark the approximate boundary between Triassic and Jurassic rocks. Where the lavas are thin or flowed over irregular topography this boundary is difficult to discern, however, so deposition of the Passaic Formation could have extended into the Jurassic Period in some areas near Ladentown (fig. 1 and Appendix 1) (Ratcliffe, 1980; 1988). An episode of magmatism produced voluminous intrusions of basalt and lava flows in the Newark basin during a brief period in the Lower Jurassic at about 201Ma (Dunning and Hodych, 1990). The Feltville Formation, the only sedimentary rocks within the basin known to overlie 
the basalt, is present near Ladentown (Ratcliffe,1988) and overlies the Orange Mountain Basalt (Olsen and Rainforth, 2003).

The Palisades sill intrudes the Stockton and Lockatong Formations from Nyack northward to Verdrietege Hook, where the sill is about $1,000 \mathrm{ft}$ thick and generally concordant to sedimentary rock layers. On the basis of aeromagnetic mapping, the top and base of the sill are slightly discordant and may also consist of buried tongues of diabase that intrude into the Stockton Formation (fig.4). The Palisades sill thins and is strongly discordant from Verdrietege Hook westward through Hi Tor to Mount Ivy (Appendix 1). Sedimentary rock within about $30 \mathrm{ft}$ of the Palisades sill was recrystallized by heat from the slow-cooling magma, producing a dense, finegrained dark rock called hornfels. The thickness of hornfels decreases westward as the depth of intrusion also decreases, and little or no hornfels is present between Mount Ivy and Ladentown. A diabase dike extends upward through about $2.4 \mathrm{mi}$ of sedimentary rocks and surfaces near Ladentown as a fissure flow complex (Ratcliffe, 1980 and 1988) that was first recognized by Kummel (1899). Recent geochemical studies (Puffer and others, 2009) indicate that lava flows at Ladentown and the diabase of the feeder dike (Ratcliffe, 1980, 1982 and 1988) correlate with successive magma pulses of the Palisades sill injected over a 10,000- to 20,000-year period and were the source of widespread Orange Mountain Basalt flows of New Jersey and the Preakness Basalt (Olsen and Rainforth, 2003). It is uncertain, however, whether lava flows at Ladentown correlate solely with the Orange Mountain Basalt or whether the upper flow is derived from the Preakness Basalt.

The New City dike (Frimpter, 1967) is a part of the Palisades sill that extends west to New City and correlates with a positive aeromagnetic anomaly (fig. 5) (Andreason, 1962). Although shown as a continuous feature at land surface by Frimpter (1967) and Fisher and others (1971), there are few exposures of diabase along this trend. Where exposed, the diabase forms small north-east trending dikes at a high angle to the aeromagnetically defined intrusion (fig. 5), and it is likely that the New City dike is largely a subsurface feature.

The four detailed sections in figure 4 show the subsurface configuration of major lithofacies in upper Triassic to lower Jurassic sedimentary rocks of the Newark Supergroup (Trs, Trl and Trps) and lower Jurassic intrusive diabase (Jd) and basalt (Jb) in Rockland County. Sections A-A', B-B', and C-C' are drawn normal to the Ramapo Fault, and section D-D' is drawn north to south and intersects the other three. The subsurface interfingering of lithic units is conjectural at depth but agrees with surface observations along the lines of section. The sedimentary rocks dip to the west and unconformably overlie much older (Ordovician to Precambrian) metamorphic rocks of Manhattan Prong and Hudson Highlands. In general, the sedimentary rocks are coarsest near the base in the Stockton Formation (Trs) and in the western and upper parts of the Passaic Formation (Trplc). Medium-grained sandstone containing beds of quartz-pebble to -cobble conglomerate $(\operatorname{Trpc})$ is predominant in the middle part of the Passaic
Formation and is underlain by a fine-grained sequence of siltstone and shale that contains few conglomerate beds. The actual number of conglomerate beds is probably greater than illustrated in the sections owing to incomplete exposure at land surface. Dark gray lacustrine shales of the Lockatong Formation are limited in extent and are present immediately above and below the Palisades sill near Congers and northern Nyack (Appendix 1).

Subsurface intrusive diabase (Jd) of the Palisades sill and New City dike extend westward toward Ladentown where the fissure-feeder flow complex is present at land surface within a thin section of Jurassic sedimentary rocks. The intrusive rocks are present in a saucer-shaped form with two south- to southwest-dipping flanges and a broad sub-horizontal floor, as shown in section D-D'. The New City dike is exposed at the surface in several places as northeast-trending dikes that resemble "fins" emanating from a general northwest-trending feature; the dike is well-defined by a positive aeromagnetic anomaly (fig. 5). A steep negative gradient along the northeast border of the New City aeromagnetic anomaly and lesser gradient to the southwest indicate a southwest-dipping lower contact that mimics that of the Palisades sill to the north. The irregular pattern of the New City anomaly indicates the top of the dike is uneven and that protrusions extend closer to the surface in some places than in others. The top of the dike in section B-B' is shown to be generally within 500 to $600 \mathrm{ft}$ of land surface and crops out at land surface near the Hudson River in the eastern part of the basin. The dike may be continuous at land surface, although this is not shown, and the depth of the dike below land surface is uncertain because maps of the outcrops are limited in extent. Previous maps (Fisher and others, 1971) show the New City dike as a continuous feature on the basis of mapping by Frimpter (1967). The apparent sub-horizontal attitude of the dike in section B-B' is the result of the orientation of the section line at a low angle to the trend of the dike.

\section{Structure}

The general dip of the bedding in the Newark Supergroup throughout the Newark basin is westward to northwestward to border faults, such as the Ramapo Fault. The rocks are folded regionally and locally into broad anticlines and synclines that vary in amplitude. The folding is attributed to differential motion between blocks along the irregular basin margins as a result of changes in the regional stress field following the end of rifting and the opening of the Atlantic Ocean (Schlische, 2002). Some of these structures are illustrated on a structure map (fig. 6) that traces individual conglomerate beds and form lines that outline the more prominent folds. The folds are open, broad structures that have low plunges and slight variations in strikes as the folds diminish eastward. Abrupt changes in strikes occur north and south of the Palisades sill and adjacent to some mapped faults, as illustrated by form lines drawn parallel to the generalized regional strike of bedding in figure 6 . Offsets in form lines from Verdrietege Hook west to Mount Ivy 

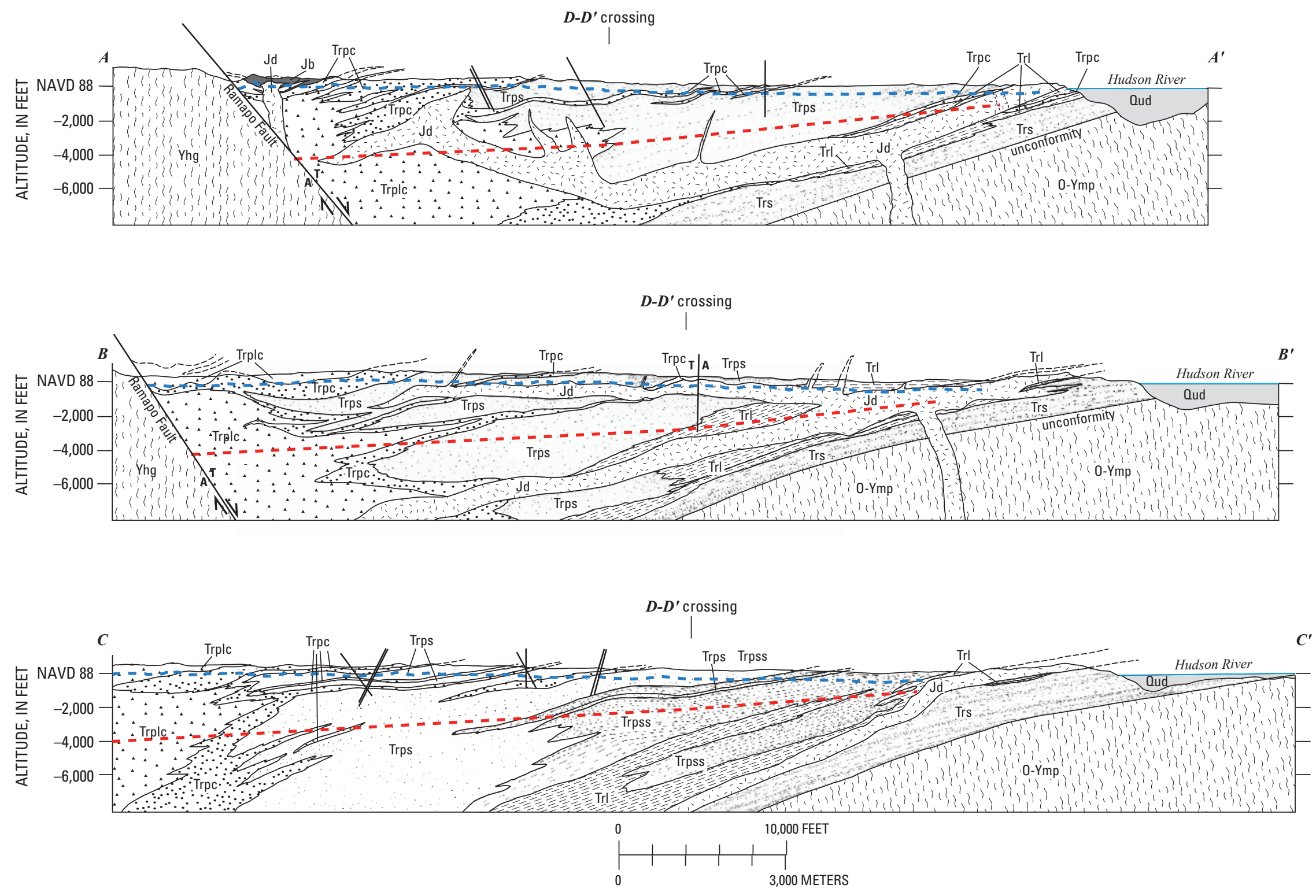

Figure 4. Generalized geologic sections showing sedimentary rock units and diabase intrusions in Newark basin, Rockland County, NY. Location of sections shown in figure 1. 


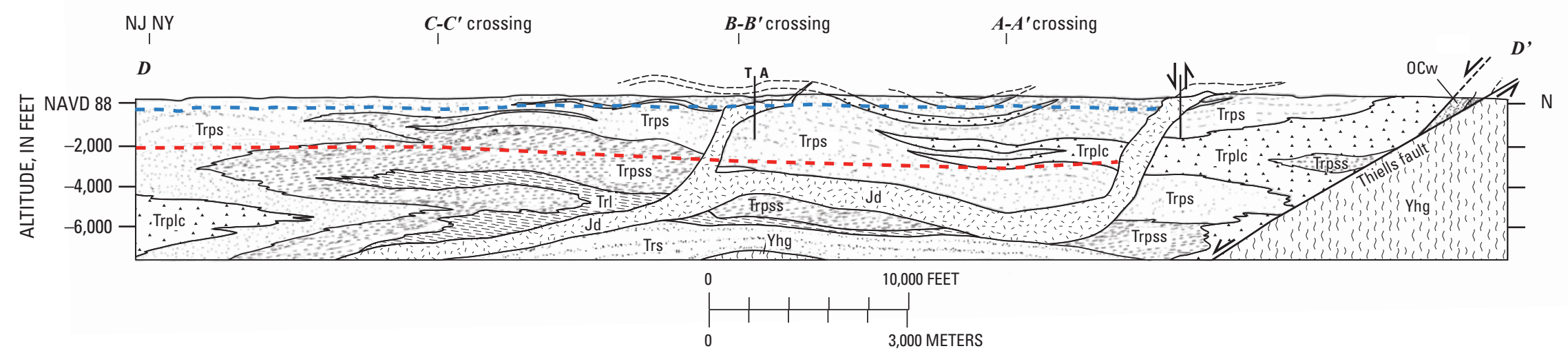

EXPLANATION

Vertical datum is NAVD 88. No vertical exaggeration.

\section{Quaternary deposits}

Qud-Unconsolidated deposits

\section{Rocks of Newark Supergroup in Rockland County}

Jd-Diabase intrusions (Lower Jurassic)

$\mathrm{Jb}-$ Basalt lava flows and intercalated sedimentary rocks-(lower Jurassic) Exposed at Ladentown fissure flow eruptive center

Passaic Formation (Upper Triassic)

Major lithofacies patterns show interbedding of rock types

Trplc-Limestone conglomerate

Trpc-Quartz-cobble and -pebble conglomerate

Trps—Arkosic sandstone and minor pebbly arkose

Trpss-Arkosic siltstone and shale
Trl—Lockatong Formation-(Upper Triassic)—black and gray shale

Trs-Stockton Formation-(Upper Triassic)—gray, red arkosic, thick-bedded sandstone, light colored sandstone and polymict conglomerate. Unconformity

OCw - Carbonate rocks of the Wappinger Group (Ordovician and Cambrian) Shown only in section $\boldsymbol{D}-\boldsymbol{D}$

प? 1 -Ymp-Metamorphic rocks of the Manhattan prong (Ordovician to Mesoproterozoic)

13, Yhg - Gneisses of the Hudson Highlands (Mesoproterozoic)

A PFault-arrows show dip slip component of motion, A/T shows motion away and towards observer

\section{- - - Assumed depth of active flow}

- - - Lower extent of regional flow model

Figure 4. Generalized geologic sections showing sedimentary rock units and diabase intrusions in Newark basin, Rockland County, NY—Continued. Location of sections shown in figure 1. 


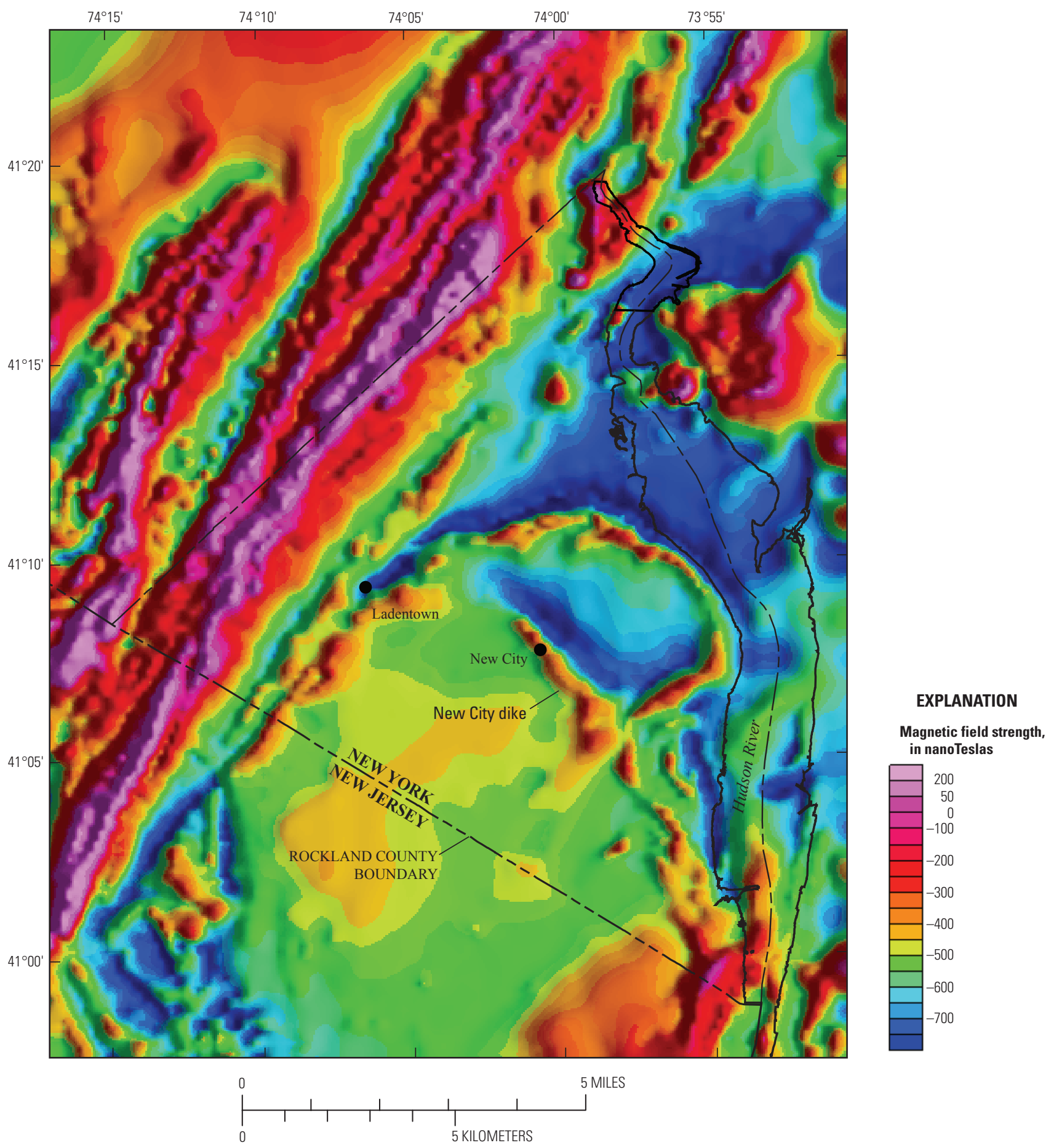

Figure 5. Shaded relief and aeromagnetic map of Rockland County, NY, and adjacent parts New Jersey and New York. (Steve Snyder, USGS, written commun., 2009, after Bond and Phillips, 1988) 


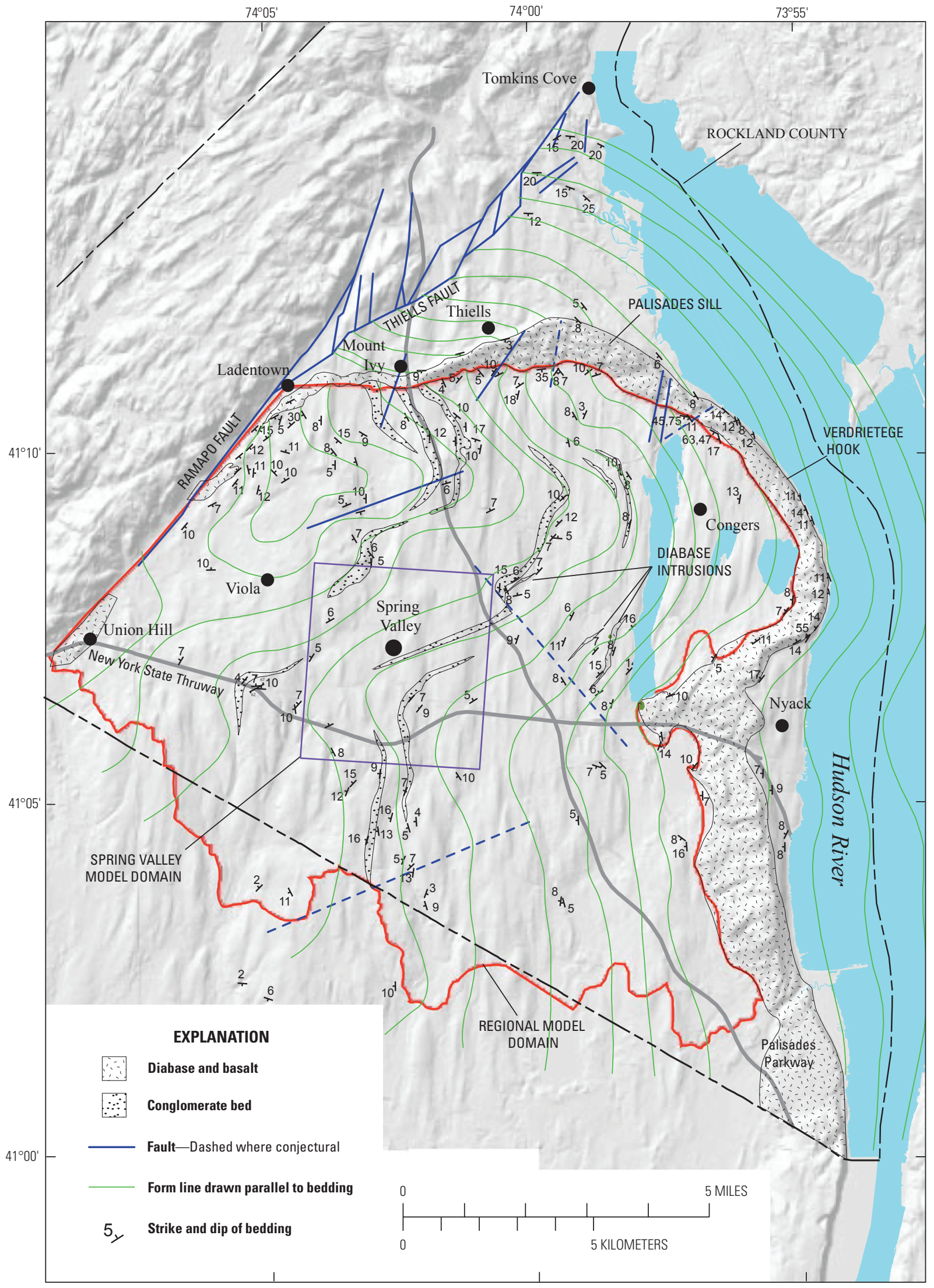

Base from Rockland County Planning Department

Figure 6. Structure map of Newark basin in Rockland County, NY, showing measurements of strike and dip, and form lines and major folds of bedding. 
indicate that this section of the Palisades sill intruded along a fault similar to another mapped fault near Viola (fig. 6). Form lines trend east-west north of the Palisades sill to the northern end of the basin and define a broad south-plunging syncline.

The Ramapo and Thiells Faults are major faults associated with dropping and tilting of basin sediments and are part of a wide zone of Mesozoic faulting referred to as the Ramapo Fault zone (Ratcliffe, 1980). These faults affected a broad area in the western part of the Newark basin and produced uplifted blocks that contributed to alluvial fans feeding the basin.

Brecciation is extensive along these faults, along with a welldeveloped system of conjugate normal faults and subvertical extension fracture fillings of zeolites, quartz, and carbonate. The fractured zone is approximately $300 \mathrm{ft}$ thick along the Ramapo Fault (Ratcliffe, 1980; 1982).

Heisig (2010) interpolated strike and dip measurements from multiple published sources. New data were obtained from borehole optical and acoustic televiewer logs, and a bedding structure map was produced that depicts a more parallel orientation of bedding strike in the sedimentary bedrock than that of figure 6. Heisig (2010) also divided the sedimentary bedrock of the Newark basin in Rockland County into four zones on the basis of lithology, natural-gamma log activity, and relation to the Ramapo Fault and the Palisades sill (fig. 7). Zone A is adjacent to the Ramapo Fault and areas underlain by intrusive diabase and contains fanglomerates that have low natural-gamma activity. Zone B underlies the western part of the Newark basin in Rockland County and contains conglomerate and conglomerate sandstone that have low natural-gamma activity. Zone $\mathrm{C}$ underlies the central part of the basin and contains sandstone with interbeds of fine-grained rocks that increase in abundance and thickness eastward. Natural gamma activity in these rocks is generally low with higher peaks that correspond to the fine-grained beds. Zone D underlies the eastern part of the basin and contains siltstone, mudstone, and arkosic sandstone with high natural-gamma activity. Parts of this zone have been thermally altered by intrusion of diabase.

\section{Surficial Geology}

Unconsolidated deposits of glacial, lacustrine, and alluvial origin mantle the bedrock throughout most of the Newark basin in Rockland County. The thickness of the unconsolidated deposits generally ranges from 5 to $20 \mathrm{ft}$ but is much thicker beneath some stream valleys (Heisig, 2010, fig. 7). The unconsolidated deposits are mainly till, which is unsorted material deposited directly by glacial ice. Although two types of till with differing clay contents have been mapped elsewhere in the Newark basin, no attempt to distinguish these tills has been made in Rockland County. Coarse-grained outwash and alluvium were deposited along the Mahwah River, Saddle River, Pascack Brook, and Minisceongo Creek (fig. 7). Fine-grained lacustrine sediments as much as $100 \mathrm{ft}$ thick were deposited along the Hackensack River in the eastern part of Rockland County (fig. 7).

\section{Hydrology}

\section{Occurrence of Groundwater}

Groundwater in Rockland County flows primarily through the sedimentary rocks of the Newark basin aquifer. Water enters the aquifer by infiltration through unconsolidated deposits (primarily till) that overlie the bedrock and discharges from the bedrock aquifer to stream channels and pumped wells. Water also leaks to and from the sewer and water distribution networks that service this highly developed area. Most of the groundwater in the Newark basin aquifer in Rockland County is assumed on the basis of the distribution of well yields to flow within the upper $500 \mathrm{ft}$ of the fractured bedrock (Heisig, 2010). For the Newark basin rocks in New Jersey, Lewis-Brown and others (2005) assumed most groundwater flows within the upper $400 \mathrm{ft}$ of bedrock. This assumption is based on well-completion records and the observed decline in the number of water-bearing zones with depth. Borehole geophysical logs by Morin and others (2000) indicate that flow is within the upper $260 \mathrm{ft}$ of bedrock.

The Newark basin aquifer is generally confined where the water table lies within the unconsolidated deposits in lowland areas. The water table is below the bedrock surface in uplands and near pumped wells, however, so the aquifer is generally unconfined in these areas (fig. 8). Artesian (flowing) wells have been drilled at several well fields, commonly in low-lying stream valleys, where the aquifer is confined by low-permeability glacial and lacustrine sediments.

In much of the study area, groundwater in the unconsolidated deposits provides little water to wells or streams. The relatively low permeability of till and lacustrine sediments that cover most of the Newark basin aquifer restricts water movement, and these sediments constitute a confining layer above the bedrock aquifer in lowland areas. Thick lacustrine sediments beneath the Hackensack River valley limit recharge. Permeable outwash and alluvium enhance the exchange of water between the bedrock aquifer and the overlying streams in some valleys, but the outwash aquifer that underlies the Mahwah River along the western edge of the Newark basin aquifer is the only productive sand and gravel aquifer (figs. 3 and 7).

\section{Groundwater Flow}

Groundwater in the Newark basin aquifer in Rockland County generally flows from upland areas towards watersheds of the Mahwah River to the west, the Hackensack River to the east, and the Saddle River and Pascack Brook to the south (fig. 9). Groundwater withdrawals from well fields have altered this pattern locally, especially in the central part of the aquifer where withdrawals are concentrated. Water-level data collected since 1989 do not indicate widespread areas of water-level decline, however (Heisig, 2010). Water-level hydrographs for two production wells near the Spring Valley well field (fig. 3 ) in one of the most heavily pumped parts of 


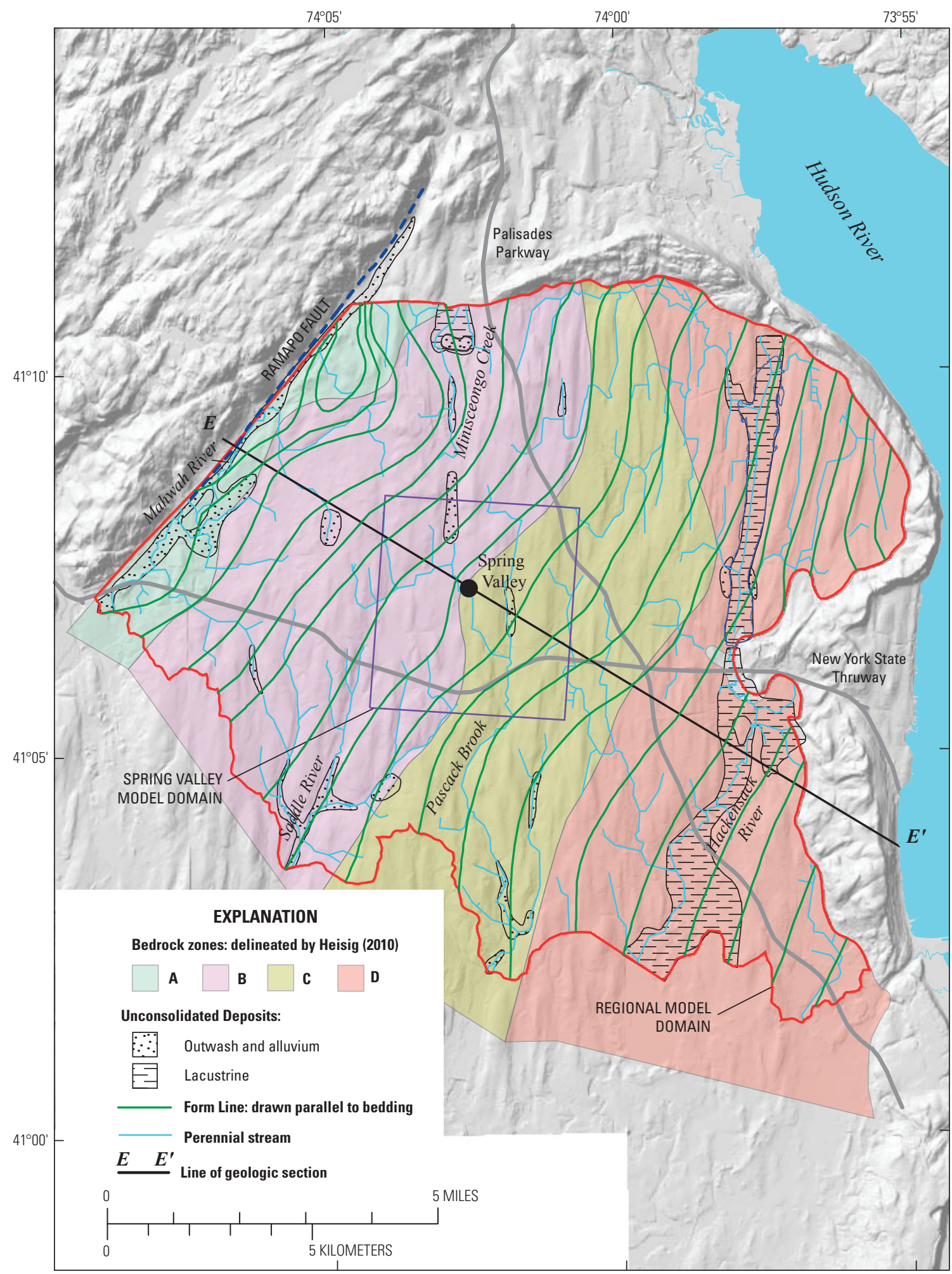

Base from Rockland County Planning Department

Figure 7. Bedrock zones in the Newark basin aquifer in Rockland County, NY, delineated by Heisig (2010), interpolated strike of bedding, and distribution of alluvium, outwash, and lacustrine sediments. (Modified from Heisig, 2010) 


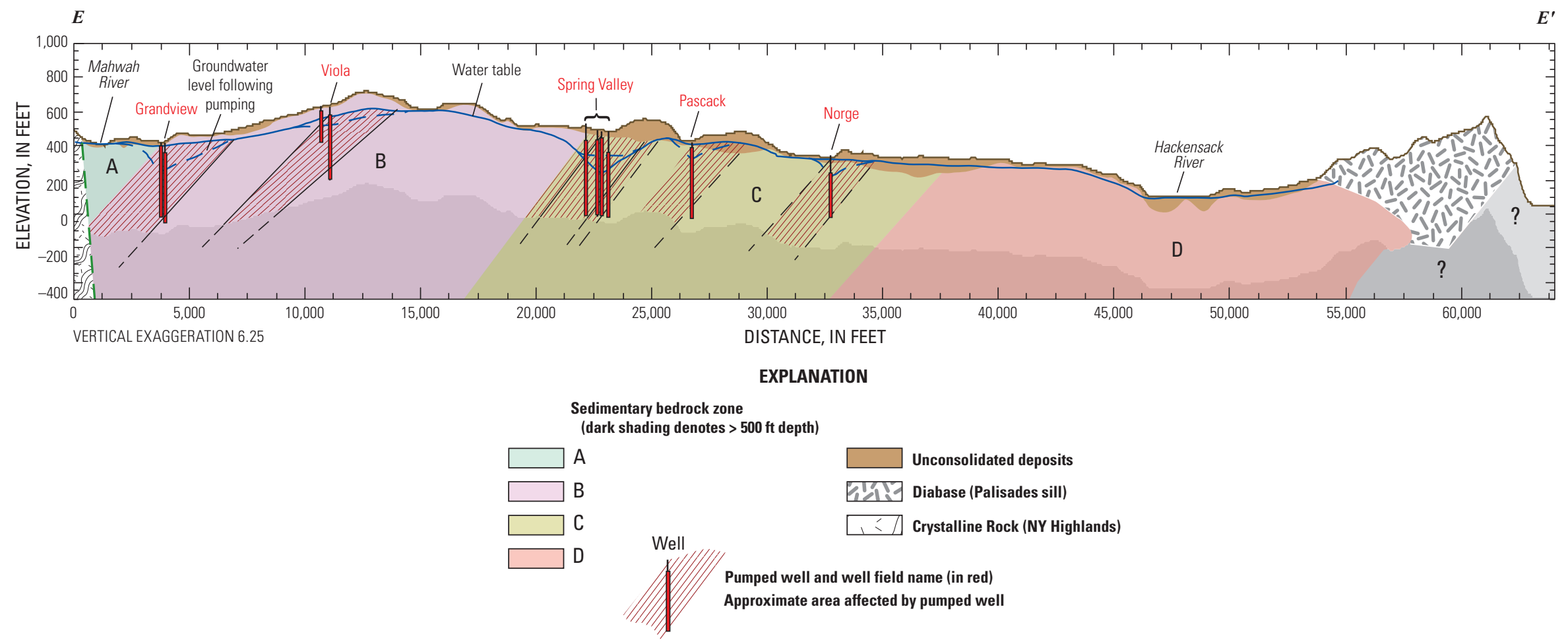

Figure 8. Generalized section showing bedrock zones, groundwater level and depths of production wells. (Modified from Heisig, 2010) Location of section shown in figure 7. 


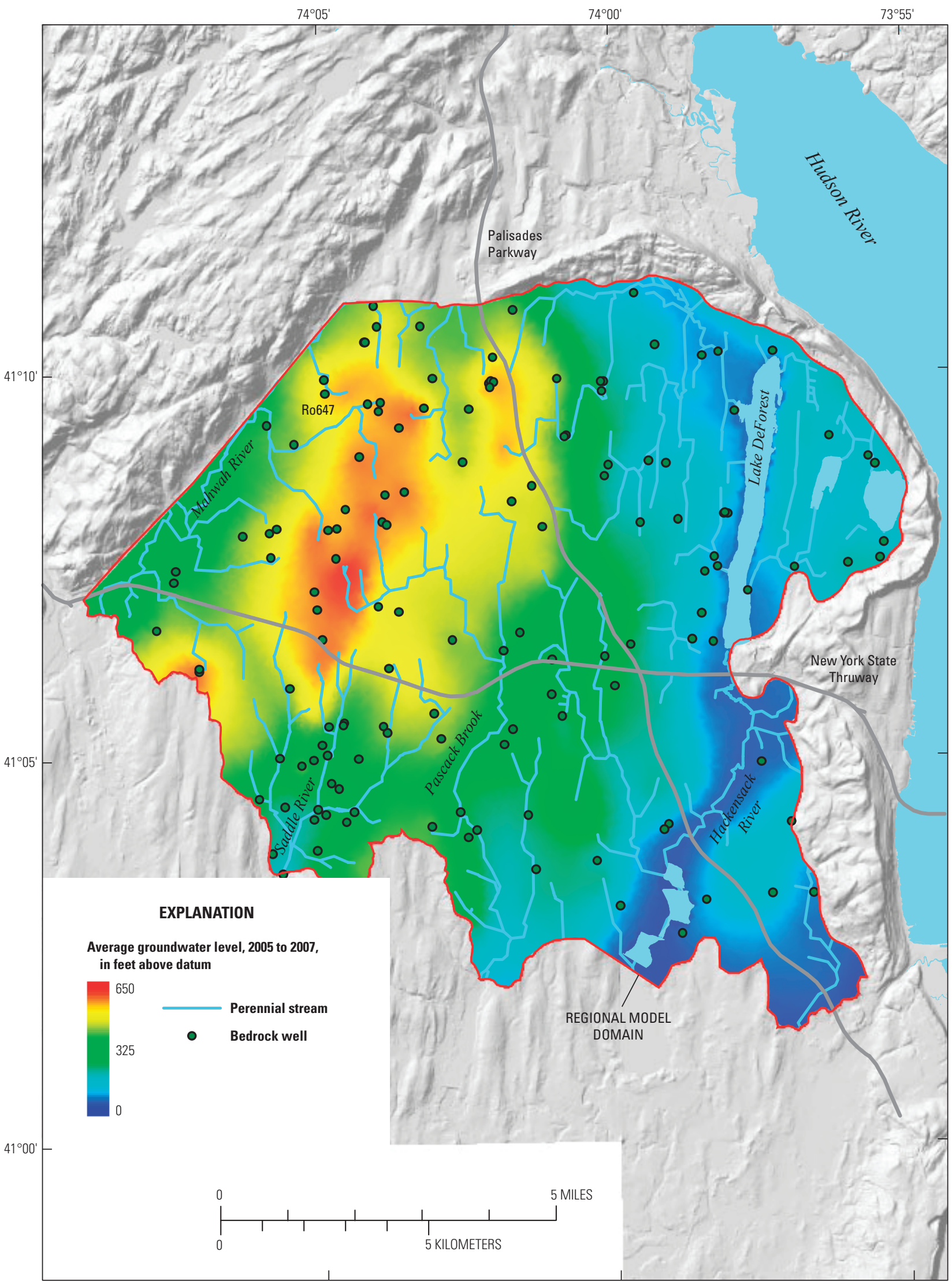

Base from Rockland County Planning Department

Figure 9. Average groundwater levels (potentiometric surface) measured from 2005 through 2007 in the Newark basin aquifer in Rockland County, NY. 
the aquifer are shown in figure 10. The hydrographs indicate steady water levels at the Pascack well field (fig. 10A) where the average withdrawal rate has been constant and rising levels at the Eckerson well field (fig. 10B) where the withdrawal rate has declined.

\section{Groundwater Discharge}

Groundwater from the Newark basin aquifer discharges to stream channels throughout Rockland County and sustains streamflow during periods with little or no precipitation. Mean annual groundwater discharge (base flow) was estimated for seven watersheds (fig. 11) from measured daily streamflow using a hydrograph-separation method (Rutledge, 1998). Four of the records were for 1961, a year in which precipitation was nearly equal to the 60 -year median value. The base-flow estimates are approximate because the periods of record are 4 years or less, except for the 35-year period of record for the streamgage station on the Mahwah River near Suffern. Nearly one-half of the watershed for this streamgage station is underlain by igneous and metamorphic rocks, however, and the 2-mi reach of the Mahwah River upstream from the station overlies coarse-grained alluvial material. Discharges measured at this station, therefore, may not represent conditions elsewhere in the Newark basin aquifer.

Estimated mean annual base flow ranges from 13.2 to $19.2 \mathrm{in} / \mathrm{yr}$ on the basis of area for the seven watersheds and accounts for 50 to 80 percent of the total streamflow (table 1).
These estimates correspond to flows ranging from 1.0 to $1.4 \mathrm{ft}^{3} / \mathrm{s}$ per $\mathrm{mi}^{2}$ for the three stations with more than one year of data. These values were exceeded during 60 percent of the period of record in the Saddle River and Pascack Brook watersheds and during 40 percent of the period of record in the Mahwah River watershed. These base-flow estimates for Rockland County are higher than those computed for the southern part of the Newark basin, where an average base flow of $9 \mathrm{in} / \mathrm{yr}$ (40 percent of streamflow) was computed for seven watersheds in southeastern Pennsylvania (Risser and others, 2005). Annual precipitation is larger and evapotranspiration is smaller in Rockland County than in southeastern Pennsylvania, however. These factors would cause increased infiltration to the water table (recharge) and, therefore, increased base flow. More accurate estimates of base flow require longer periods of record than those available for watersheds that drain different areas of the Newark basin. More precise hydrograph-separation methods using chemical tracers to partition base flow from stormflow could also be used to provide better estimates.

\section{Groundwater Withdrawals}

Groundwater withdrawals from the Newark basin aquifer in Rockland County peaked in 1975 at a rate of $18.6 \mathrm{Mgal} / \mathrm{d}$. From 1985 through 2005 withdrawals averaged $10.7 \mathrm{Mgal} / \mathrm{d}$ (with about 90 percent of the water used for the public supply), an amount equivalent to $2.6 \mathrm{in} / \mathrm{yr}$ or about 5 percent

Table 1. Base flow and basin area for streamgage stations in and near, Rockland County, NY.

$\left[\mathrm{mi}^{2}\right.$, square miles; in/yr, inches per year]

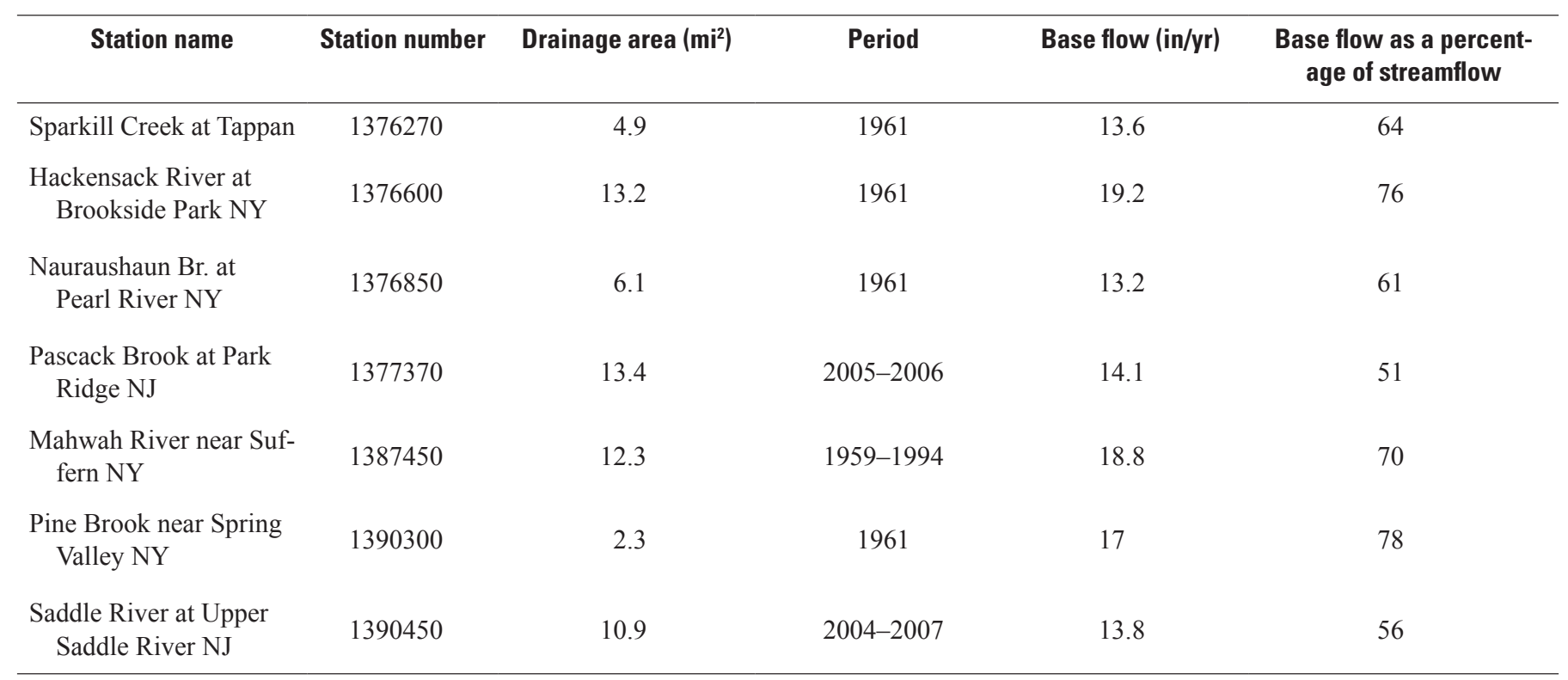


A Well Ro552 (UW-65) Pascack well field

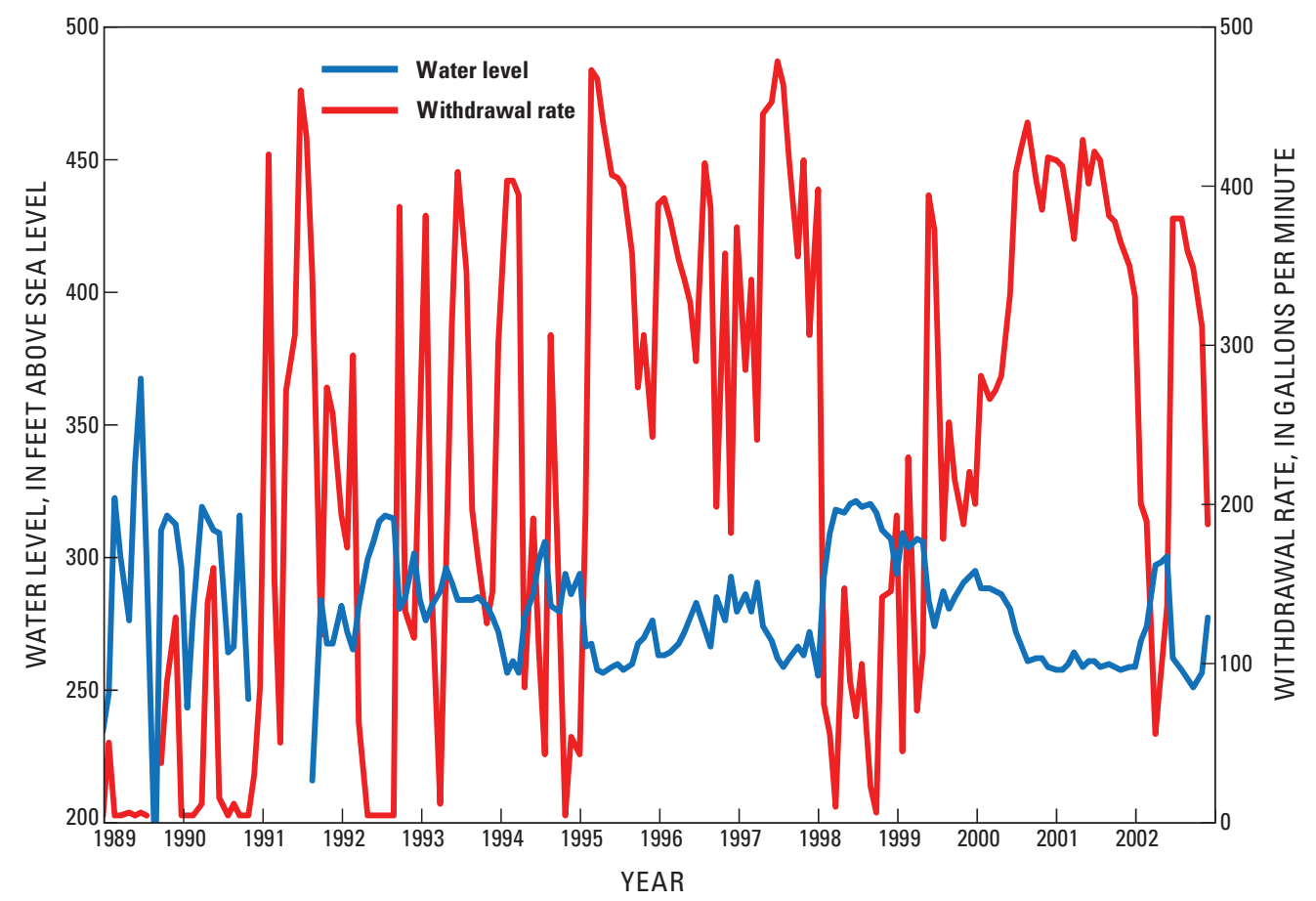

$B$ Well Ro563 (UW-82) Eckerson well field

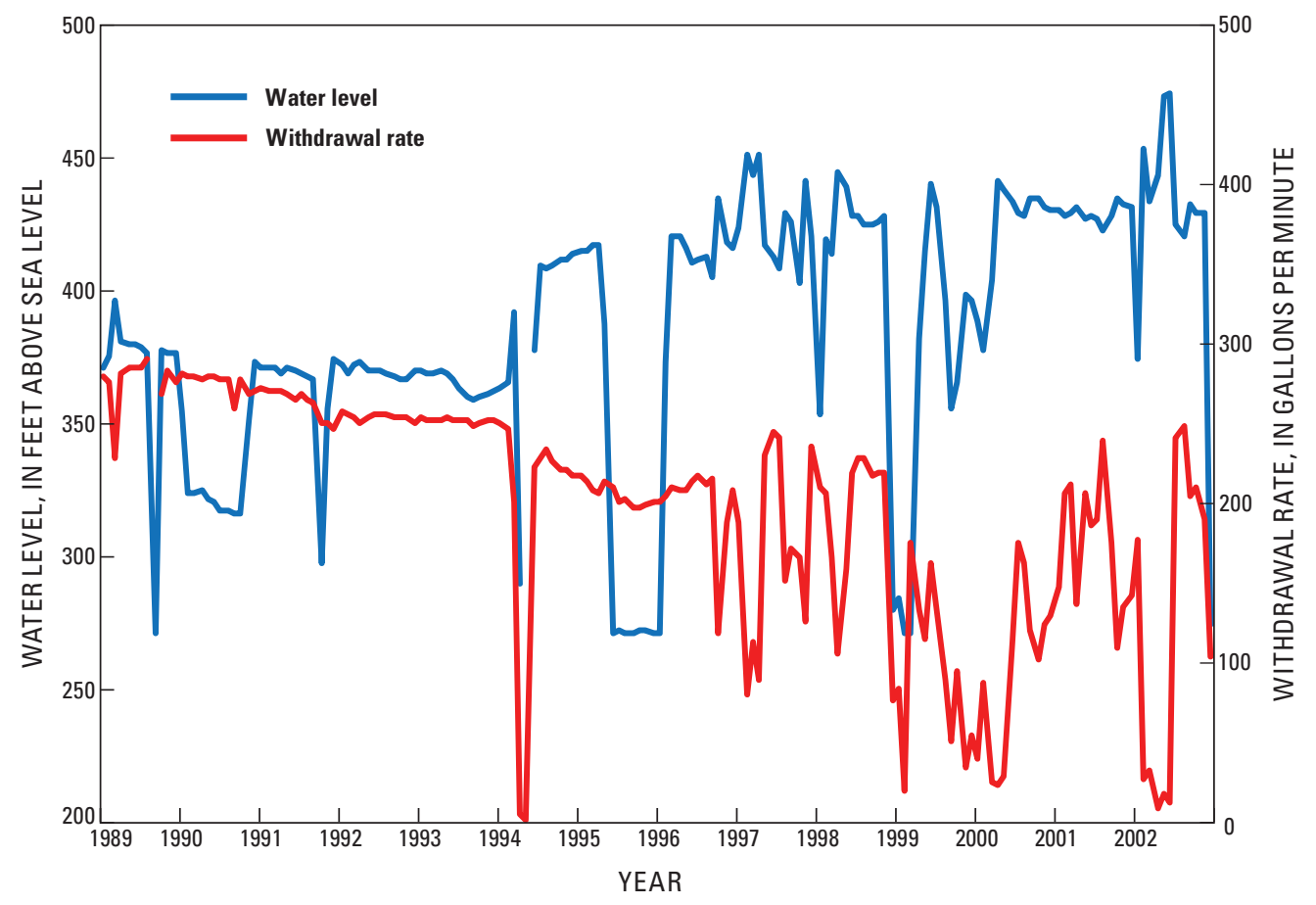

Figure 10. Water-level hydrographs for two production wells in the Newark basin aquifer in Rockland County, NY. Well locations shown in figure 3. 


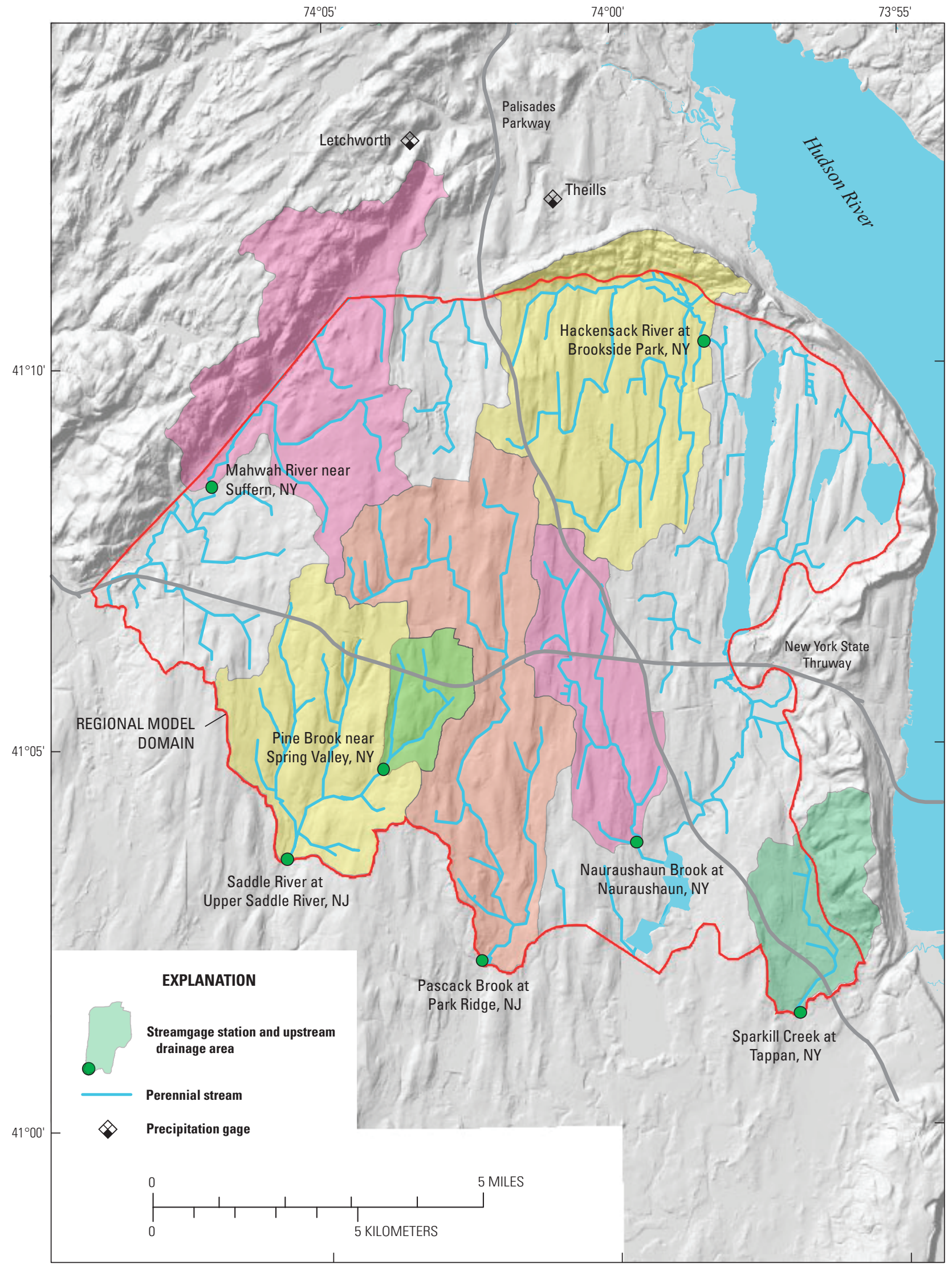

Base from Rockland County Planning Department

Figure 11. Watersheds, precipitation gages, and streamgage stations where base flow was estimated in and near Rockland County, NY. 
Table 2. Well fields supplying water from the Newark basin aquifer in 2005, Rockland County, NY.

$[-$, no data $]$

\begin{tabular}{|c|c|c|c|}
\hline Well field & Number ${ }^{\mathrm{a}}$ & $\begin{array}{l}\text { United Water New York well } \\
\text { identifier }\end{array}$ & $\begin{array}{l}\text { Average withdrawal rate from } 1985 \text { through } \\
\text { 2005, in gallons per minute }\end{array}$ \\
\hline Bardonia & 1 & 19 & 9 \\
\hline Birchwood & 2 & 70 & 52 \\
\hline Blauvelt & 3 & 15 & 81 \\
\hline Catamount $^{\mathrm{b}}$ & 4 & $42 \mathrm{~A}, 54 \mathrm{~A}$ & 452 \\
\hline Cherry & 5 & 68 & 172 \\
\hline Eckerson & 6 & 71,82 & 320 \\
\hline Elmwood & 7 & 66 & 81 \\
\hline Germonds & 8 & 21 & 8 \\
\hline Grandview & 9 & 67,78 & 188 \\
\hline Grotke & 10 & 83 & 142 \\
\hline Lake Shore & 11 & 73 & 234 \\
\hline Monsey & 12 & $30,31 \mathrm{~A}$ & 179 \\
\hline Nanuet & 13 & 13,14 & 175 \\
\hline New City & 14 & 23 & 65 \\
\hline New Hempstead & 15 & 18,24 & 828 \\
\hline Norge & 16 & 64 & 228 \\
\hline Nottingham & 17 & 55 & 187 \\
\hline Golf course $e^{c}$ & 18 & - & 200 \\
\hline Pascack & 19 & 65 & 200 \\
\hline Pearl River & 20 & 22 & 22 \\
\hline Pinebrook & 21 & 69 & 289 \\
\hline Pomona & 22 & 37,38 & 523 \\
\hline River/Lake ${ }^{b}$ & 23 & $27,29 \mathrm{~A}$ & 1392 \\
\hline Rustic & 24 & 72 & 283 \\
\hline Saddle_River & 25 & 53 & 287 \\
\hline Spring Valley & 26 & $1 \mathrm{~A}, 3,4,6,17$ & 1,277 \\
\hline Tallman & 27 & 26 & 175 \\
\hline Viola & 28 & 28,106 & 574 \\
\hline Wesel & 29 & 32 & 75 \\
\hline Westgate & 30 & 79 & 113 \\
\hline Willow Tree & 31 & 56 & 422 \\
\hline Pharmaceutical Company ${ }^{\mathrm{c}}$ & 32 & - & 1177 \\
\hline Total & & & 10,409 \\
\hline
\end{tabular}

${ }^{a}$ Number used in figure 3.

${ }^{\mathrm{b}}$ Alluvial aquifer.

${ }^{\mathrm{c}}$ Private supply. 
of the mean annual precipitation. For the period from 1985 through 2005, average withdrawal rates for individual well fields producing from the Newark basin aquifer ranged from 8 to $1,400 \mathrm{gal} / \mathrm{min}$ (table 2). Production wells completed in the bedrock aquifer typically are about $400 \mathrm{ft}$ deep and cased to $70 \mathrm{ft}$ below land surface; the yield of an individual well can be as much as $800 \mathrm{gal} / \mathrm{min}$. Production wells completed in the sand and gravel aquifer adjacent to the Mahwah River are 65 to $105 \mathrm{ft}$ deep and yield up to $1,400 \mathrm{gal} / \mathrm{min}$.

Most water withdrawn by pumping does not re-enter the aquifer because essentially all wastewater in areas of Rockland County overlying the Newark basin aquifer is discharged through sanitary sewers to either the Ramapo River or the Hudson River. However, about 16 percent of the pumped groundwater is lost through conveyance and returned to the bedrock aquifer (Heisig, 2010). Groundwater also discharges through leakage into sanitary sewers that carry wastewater to treatment plants on the Mahwah and Hudson Rivers. Leakage into sewers is evident in hydrographs of effluent flows from wastewater-treatment plants in 2005 that depict increased infiltration following rainfall (Heisig, 2010, fig. 63). The mean low flow (excluding storm flow) in the Rockland County sewer system was $35.8 \mathrm{Mgal} / \mathrm{d}$ in 2005 , as estimated through hydrograph separation. Direct discharge to the sewer system is estimated to be $29.4 \mathrm{Mgal} / \mathrm{d}$ (equal to the total water use of $35 \mathrm{Mgal} / \mathrm{d}$ minus losses through conveyance). Groundwater discharged through leakage into sewers is, therefore, 6.4 Mgal/d or $1.6 \mathrm{in} / \mathrm{yr}$. Leakage to and from the sewer and water infrastructure, therefore, results in a net loss of $0.8 \mathrm{Mgal} / \mathrm{d}$ of groundwater from the Newark basin aquifer.

\section{Transmissivity}

The transmissivity of the Newark basin aquifer was estimated from records of single-hole aquifer tests conducted at 55 wells. Changes in water levels through time (drawdown) were recorded for tests of 34 production wells, and specific capacity (the ratio of well yield to drawdown) was available for the other 21 wells tested. Drawdown data were analyzed with the commonly applied semi-logarithmic approximation to the Theis equation (Cooper-Jacob method), and transmissivity was computed from specific capacity using an equation given in Todd and Mays (2005). The transmissivity values span four orders of magnitude (fig. 12), ranging from 17 to $10,000 \mathrm{ft}^{2} / \mathrm{d}$ with a median value of $620 \mathrm{ft}^{2} / \mathrm{d}$. Transmissivity values commonly varied within a factor of two at well fields where multiple wells were tested; however, transmissivity varied by factors ranging from four to six at the three well fields (Elmwood, Grandview, and Pinebrook) labeled on figure 12.

A kriged interpolation of the log-transformed values of transmissivity was computed using an assumed exponential variogram with a variance (sill) of $2.7\left(\mathrm{ft}^{2} / \mathrm{d}\right)^{2}$ and a range of $6,600 \mathrm{ft}$ (fig. 13). The distribution of transmissivity $(T)$ indicates larger values in the central and western parts of the aquifer and smaller values in the eastern and northwestern parts. The larger values generally correlate with the presence of coarse-grained rocks that contain conglomerate, whereas the smaller values correlate with the presence of fine-grained rocks and diabase. High and low $T$ zones were delineated on the basis of the kriged interpolation with median values of 800 and $260 \mathrm{ft}^{2} / \mathrm{d}$, respectively. Box plots showing the distribution of values within each krige-based zone indicate a significant difference in transmissivity between these zones because the middle quartile values of the high- and low- $T$ groups do not overlap (fig. 14A).

The transmissivity values were compared using three of the four aquifer zones (zones B, C, and D) delineated by Heisig (2010) (fig. 7). Only two tests were conducted in zone A, so these results were not evaluated. Box plots indicate no significant difference in transmissivity between zones B and C (fig. 14B). Transmissivity values are slightly lower in zone $\mathrm{D}$ and an analysis of variance indicates a significant difference between zones $\mathrm{B}$ and $\mathrm{D}$, but no difference between zones $\mathrm{C}$ and $\mathrm{D}$.

\section{Water-Bearing Zones}

Groundwater in the Newark basin aquifer flows primarily through discrete water-bearing zones because the rocks that constitute the aquifer have little interconnected primary porosity. These water-bearing zones include fractures that developed parallel and perpendicular (joints) to bedding and widened through chemical dissolution of minerals within the rocks. The water-bearing zones comprise fractures that developed in zones of weakness in the rock in response to various stresses, including extension associated with the opening of the Atlantic Ocean in the Mesozoic Period, intrusion of diabase in the Jurassic Period, and erosional uplift that continued through the Cretaceous Period to the present.

Field studies in the Newark basin in New Jersey have been used to describe geologic controls (primarily the dipping bed structure) on the interconnection of fracture zones, which may include multiple discrete fractures. Twelve water-bearing units were delineated in a $15-\mathrm{mi}^{2}$ area of the Passaic Formation near Fair Lawn in Bergen County, New Jersey, 15 mi south of Rockland County (fig. 1) on the basis of borehole geophysical logs and hydraulic packer tests (Lewis-Brown and others, 2005). The water-bearing units parallel the $8^{\circ}$ dip of the bedding range from 20 to $90 \mathrm{ft}$ thick, and are seprated by low-permeability confining units that range from 20 to $250 \mathrm{ft}$ thick (fig. 15). This distribution of water-bearing units provides hydraulic connection between pairs of wells at similar depths that are aligned along the strike of the bedding. Pairs of wells that are aligned perpendicular to the strike of bedding are connected only if the separation distance is less than $4,000 \mathrm{ft}$ and if the wells intersect the same waterbearing unit. The confining units contain two orthogonal sets of fractures (joints) that cut across the bedding and provide limited hydraulic connection between adjacent water-bearing units (Michalski and Britton, 1997; Carleton and others, 1999). This three-dimensional (3D) geometry imparts asymmetry or anisotropy to the groundwater flow field, so that 


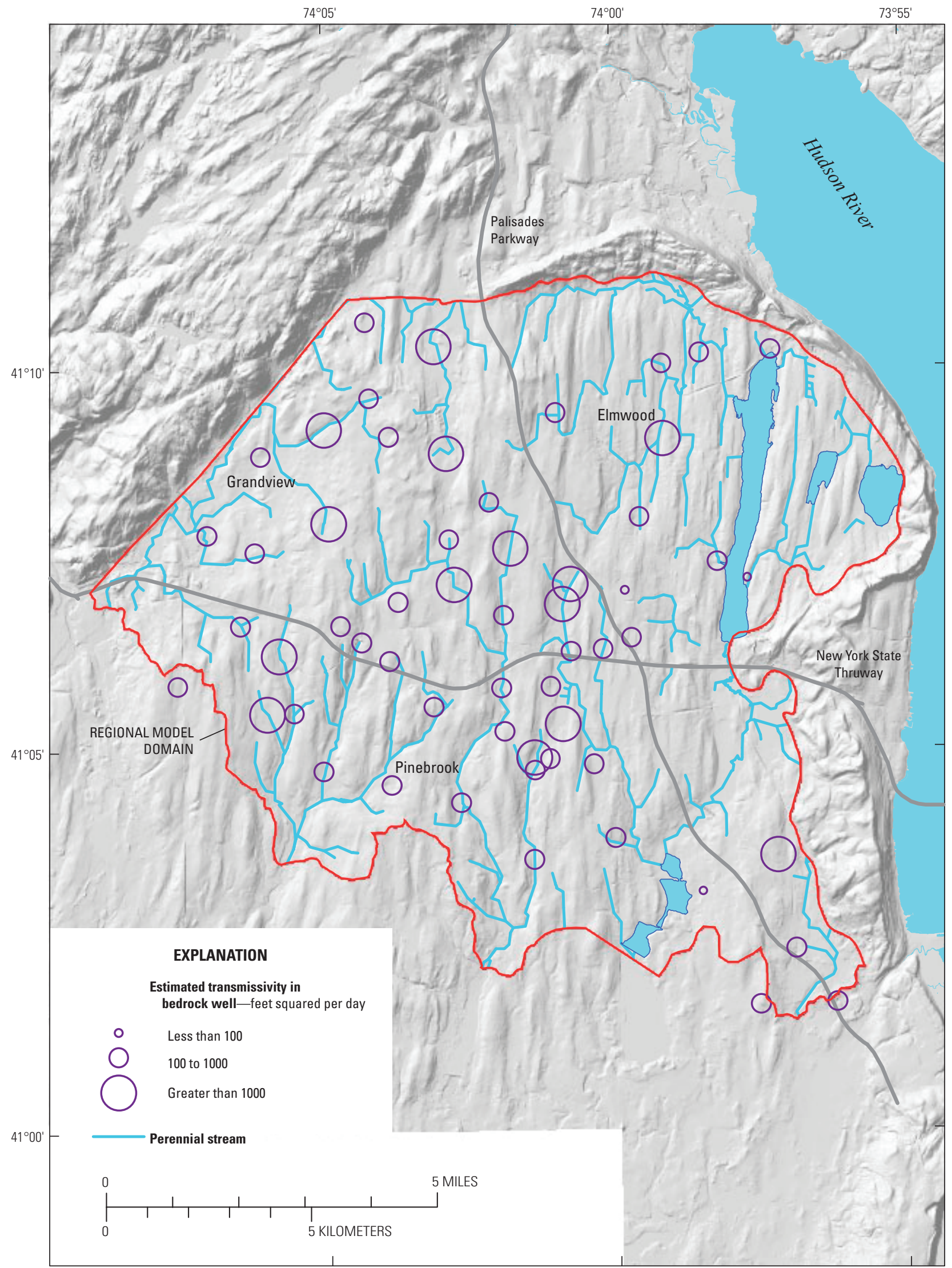

Base from Rockland County Planning Department

Figure 12. Transmissivity of Newark basin aquifer in Rockland County, NY, showing values estimated at bedrock wells from aquifer test and specific capacity data. 


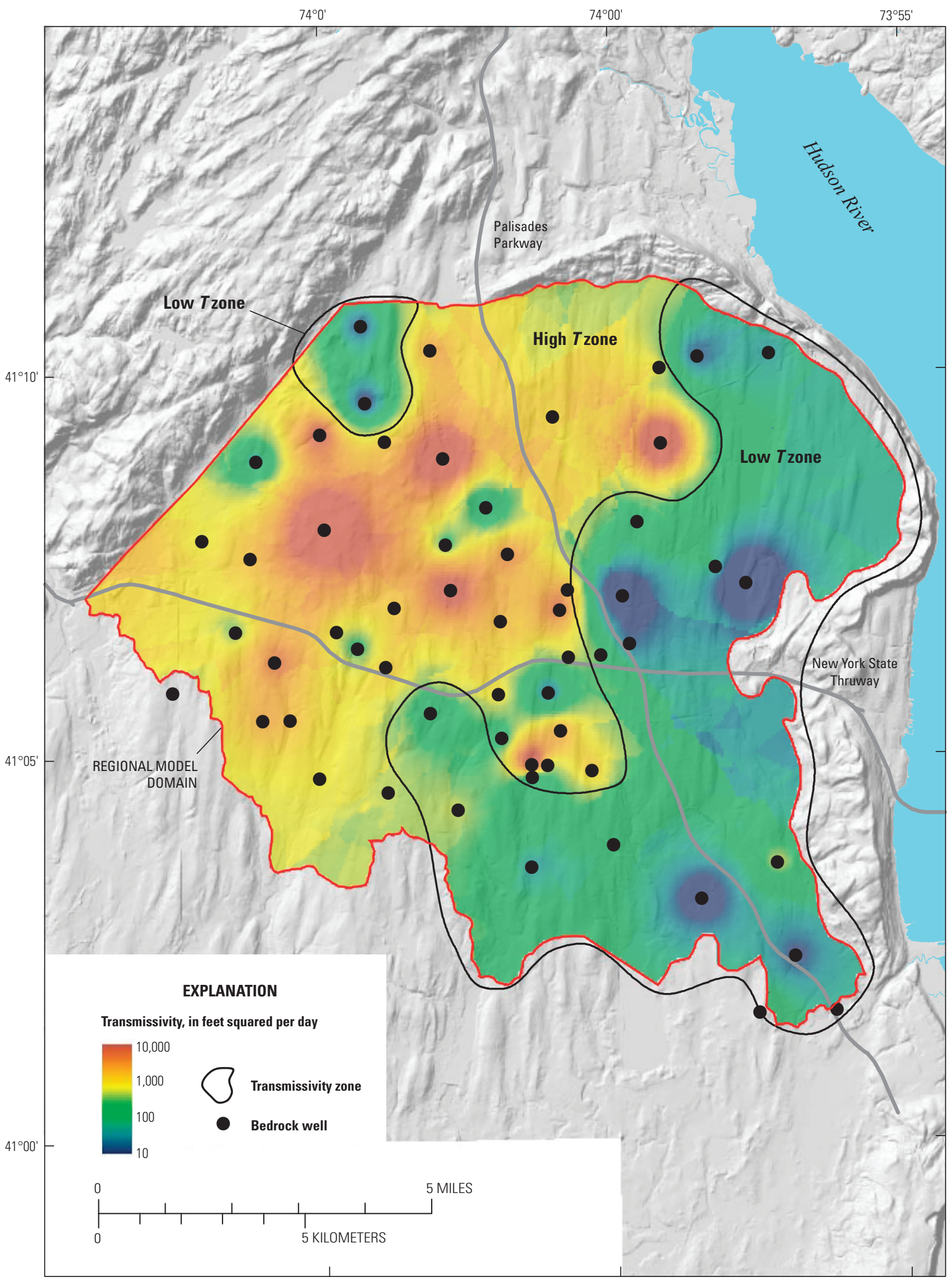

Base from Rockland County Planning Department

Figure 13. High and low transmissivity $(T)$ zones in the Newark basin aquifer in Rockland County, NY, delineated on the basis of kriged interpolation. 


\section{$A$ Kriged-based zones}

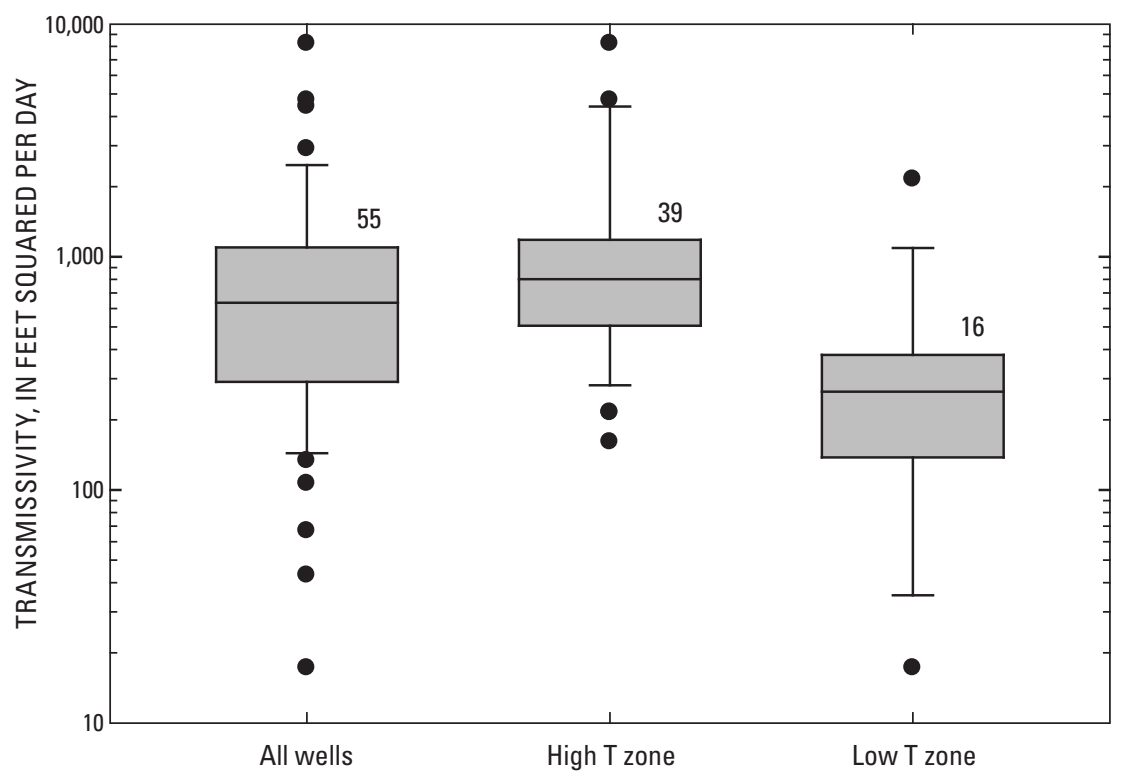

B Zones delineated by Heisig (2010)

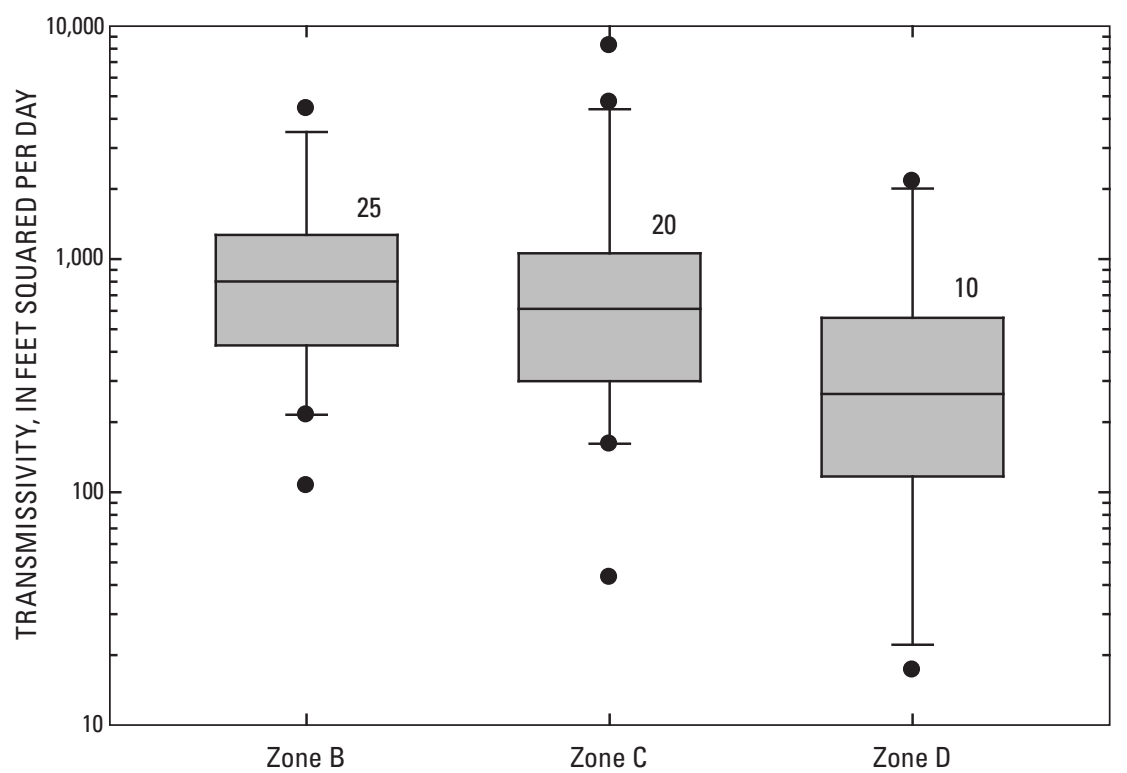

EXPLANATION

\section{Percentile}

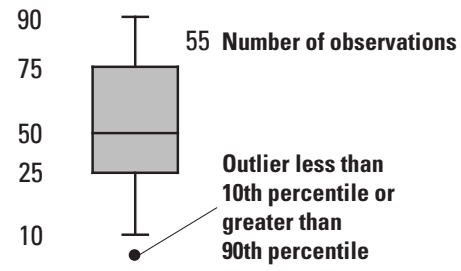

Figure 14. Boxplots showing distribution of transmissivity $(T)$ in bedrock wells using zones based on (A) kriged interpolation and (B) interpretation of Heisig (2010). 


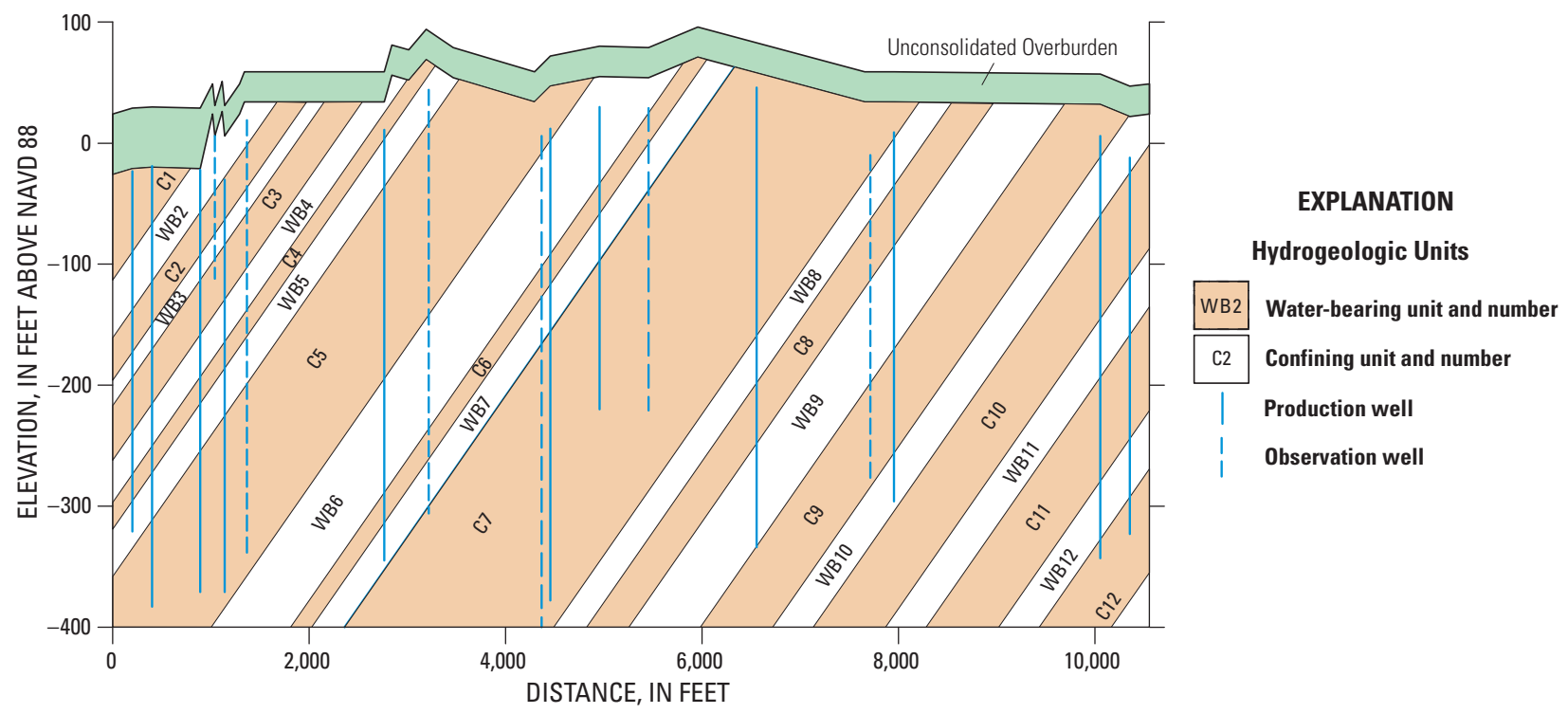

Figure 15. Geologic section showing distribution of water-bearing zones in the Passaic Formation at Fair Lawn, New Jersey. (After Lewis-Brown and others, 2005)

water flows preferentially parallel to the strike of bedding, and flow perpendicular to the strike is restricted. Such asymmetric patterns have been observed elsewhere in the Newark basin, in the distribution of drawdown (Vecchioli and others, 1969) and in groundwater discharge to streams (Lewis, 1992). A 3D groundwater flow model that represented preferential flow within the water-bearing units connected by leakage through confining layers separating adjacent units reproduced the anisotropic behavior observed in the Fair Lawn site and was used to trace the migration of contaminants through the flow system (Lewis-Brown and others, 2005).

In Rockland County, water-bearing zones are assumed to generally parallel the regional $10^{\circ}$ dip of the sedimentary bedrock toward the $\mathrm{N} 40^{\circ} \mathrm{E}$-striking Ramapo Fault. The depth of most active groundwater flow in the Newark basin aquifer is estimated to range from 200 to $400 \mathrm{ft}$ on the basis of the distribution of well yields with depth (Heisig, 2010), although some flow probably occurs above and below those depths. Borehole geophysical surveys (including caliper, optical and flow-meter logs) conducted in 23 wells in Rockland County provided information on water-bearing zones in local areas (Heisig, 2010). The borehole logs indicate the rock is generally well-indurated and contains discrete, water-bearing fracture zones that range from less than 0.1 to $2 \mathrm{ft}$ thick. Spacing of water-bearing zones within boreholes ranged from 10 to $100 \mathrm{ft}$, with an average spacing of $40 \mathrm{ft}$. The dip of the water-bearing fractures is variable. At the Spring Valley well field, for example, the dip angle of nine water-bearing fractures ranged from $11^{\circ}$ to $23^{\circ}$ within a $400-\mathrm{ft}$ section of rock. The dip direction was more variable; seven of the nine fractures dipped to the west or northwest (azimuth $250^{\circ}$ to $340^{\circ}$ ), but two fractures dipped to the east. This variability may reflect cross bedding within the bedrock sediments that resulted from the alluvial depositional environment.

Water-bearing zones identified at a local scale (hundreds of feet) are clearly connected at a regional scale (several miles) because the Newark basin aquifer in Rockland County has supplied thousands of gallons of water per minute to well fields for more than 40 years. Although it may be possible to delineate hydraulic connections between closely spaced boreholes, it is not possible to delineate connections between locations separated by thousands of feet or more. The approach of dividing the bedrock into water-bearing units and confining units, used by Lewis-Brown and others (2005) in the local scale Bergen County study, is not applicable in this study because of lack of detailed stratigraphic information and possible discontinuity of units at the regional scale. Also, the bedrock lithology in Rockland County is different and contains thickly bedded sandstones and conglomerates, rather than finer grained and more thinly bedded rocks as in Bergen County. An alternative approach for characterizing water-bearing units was employed in this study that is similar to that used by Yager and others (2008) in representing groundwater flow through folded fractured rock in the Shenandoah Valley, VA. This approach, which allowed for the comparison of model results for different depictions of the orientation of bedding, was chosen for the development of groundwater flow models for the Newark basin aquifer, described in the next section. 


\section{Groundwater Flow Models}

Groundwater flow through the Newark basin aquifer was simulated using SUTRA (Voss and Provost, 2002), a three-dimensional finite-element (FE) model. In SUTRA, the principal directions of the hydraulic conductivity tensor (herein referred to as conductivity tensor) can be specified independently of the model coordinate axes and the FE mesh and can vary throughout the model domain. Anisotropy in the flow system can be represented by orienting the conductivity tensor in each element, with the directions of maximum and medium hydraulic conductivity oriented parallel to the bedding and the minimum hydraulic conductivity oriented perpendicular to the bedding (fig. 16). As a result, SUTRA is particularly applicable to the simulation of flow in the Newark basin, where the bedding is inclined. In this study, two alternative models were developed for different representations of the directions of strike and dip, corresponding to the two depictions of the strike of bedding presented earlier (figs. 6 and 7). Two separate model domains were delineated to simulate the 1992 water-level recovery test conducted at the Spring Valley well field and regional flow through the Newark basin aquifer (fig. 3).

\section{Spring Valley Well Field}

An extensive water-level recovery test was conducted at the Spring Valley well field in January 1992 after pumping from four wells was temporarily halted for 5 days (Legette, Brashears and Graham, Inc., 1992). Water-level recovery was recorded in 32 observation wells, including nested wells of

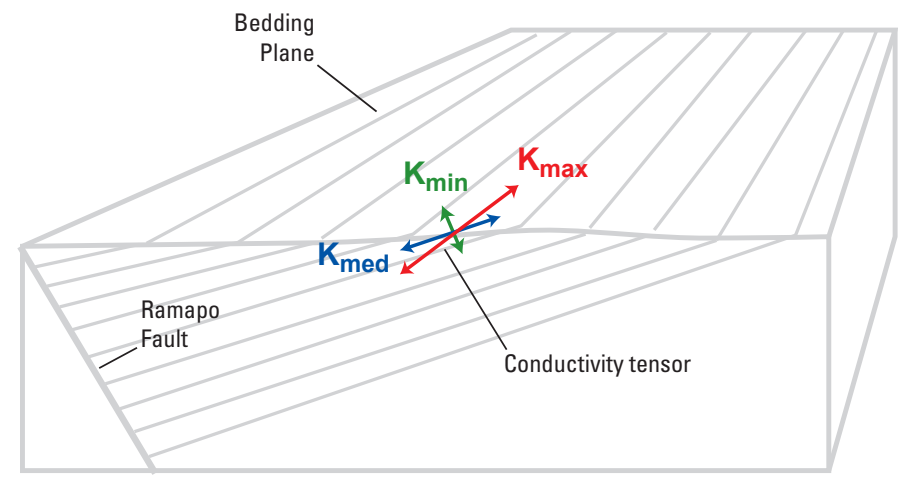

Figure 16. Perspective diagram of block of inclined sedimentary rock showing hydraulic conductivity directions at upper edge of block. $K_{\max }$ is the maximum hydraulic conductivity parallel to the strike direction, $K_{m e d}$ is the medium hydraulic conductivity parallel to the dip direction and $K_{\min }$ is the minimum hydraulic conductivity perpendicular to bedding. Gray form lines are drawn parallel to bedding different depths at 14 locations. Prior to the cessation of pumping, the withdrawal rate was held constant at $1,470 \mathrm{gal} / \mathrm{min}$ for 5 days. Water-level recoveries after 5 days ranged from 51 to $4.1 \mathrm{ft}$ at wells Ro1308 and Ro1326, located 1,000 ft and $4,600 \mathrm{ft}$ from the center of the well field, respectively (fig. 17). About 0.7 in of rain fell on the second day of the test, but plots of water-level recovery do not indicate the effects of either recharge or barrier boundaries, so infiltration of water from rainfall or streamflow through the overburden to the bedrock aquifer is assumed to be negligible. The distribution of waterlevel recovery in wells farthest from the well field displayed an anisotropic pattern with the maximum recoveries aligned subparallel to the strike of the Ramapo Fault $\left(\mathrm{N} 40^{\circ} \mathrm{E}\right)$. Conventional analytical techniques could not be used to determine the hydraulic properties of the aquifer from the water-level recovery data because withdrawals occurred at several wells rather than at a single well (New York State Department of Environmental Conservation, 1992).

A three-dimensional (3D) model of a $9.3-\mathrm{mi}^{2}$ area around Spring Valley was constructed to simulate water-level recovery after withdrawals from the well field were suspended. A transient flow simulation using the principle of superposition was calibrated to measured water-level recoveries to obtain estimates of maximum and minimum hydraulic conductivity and specific storage. The transient flow simulation represented a 5.5-day period with time steps ranging from 1 to $1,000 \mathrm{~min}$. A similar approach using superposition was applied to the simulation of the temporary cessation of withdrawals from a site in the Newark basin near Trenton, NJ (Tiedeman and others, 2010).

\section{Model Design}

The model represents the aquifer in the upper part of the bedrock with a constant saturated thickness of $330 \mathrm{ft}$, the assumed depth of active flow near Spring Valley based on a borehole flowmeter survey in well Ro82 (fig. 17) (Heisig, 2010). The top surface of the model represents the bedrock surface computed from altitudes of land surface using a $30-\mathrm{ft}$ digital-elevation model (DEM) and overburden thickness as interpolated by Heisig (2010). Time-series plots of water-level recovery indicate that negligible downward leakage occurred from either low-permeability glacial sediments or Pascack Brook during the 5-day test, so these features are not represented in the model.

\section{Mesh and Layering}

The model domain is discretized using an irregularly connected FE mesh that is extended vertically to the bottom of the model domain. Areally, the mesh appears as a set of quadrilateral elements with maximum lateral lengths of $330 \mathrm{ft}$; smaller elements (33 to $160 \mathrm{ft}$ ) were used to better represent the area within 1,400 ft of the well field (fig. 17). The 330-ft rock mass is divided vertically into 10 equally spaced layers of elements. The resulting mesh contains 74,500 elements and 83,138 nodes. 


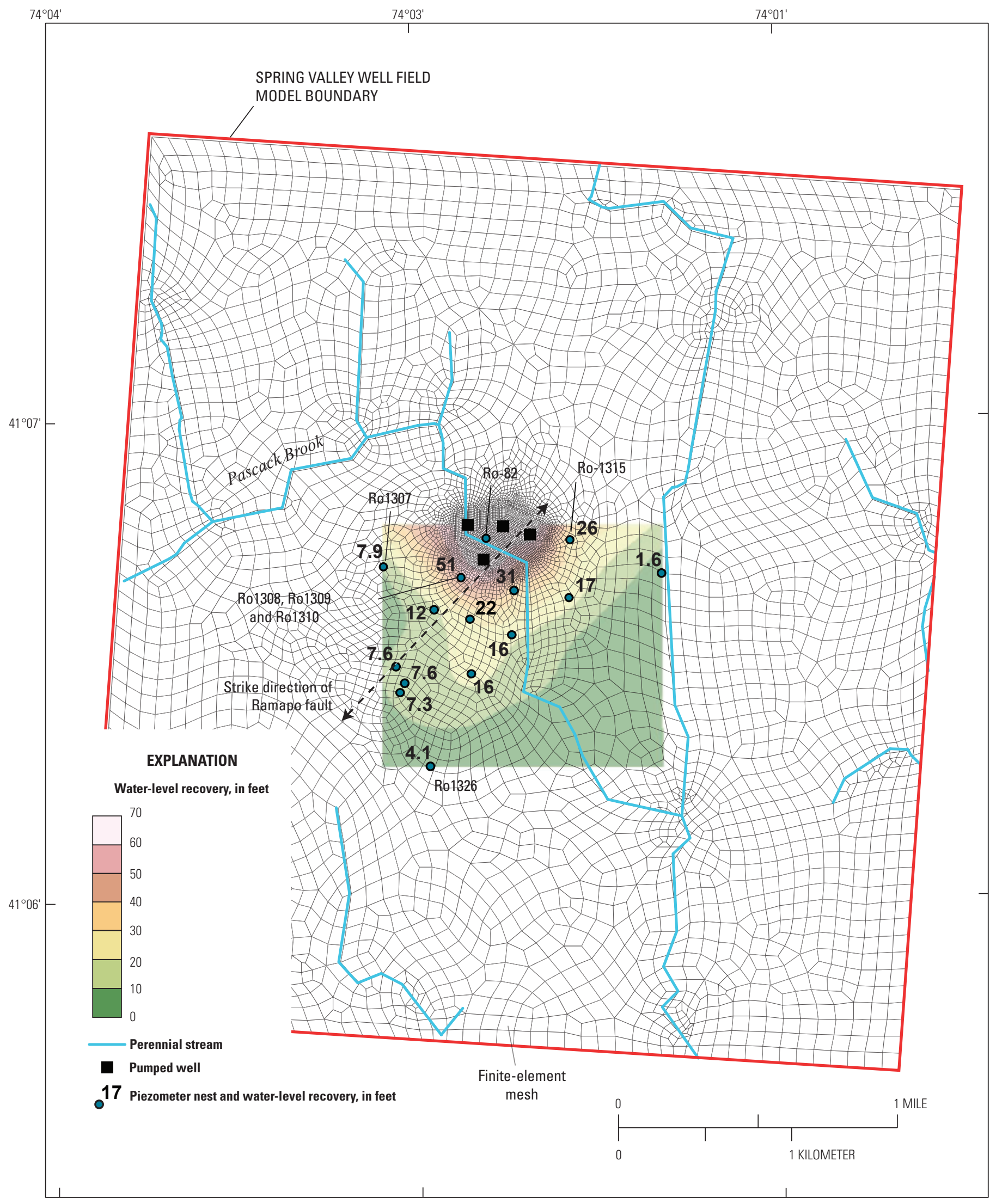

Figure 17. Water-level recovery following 5-day cessation of pumping from the Spring Valley well field, NY. 


\section{Boundary Conditions}

The principle of superposition states that for linear systems, such as flow in a confined aquifer, solutions to individual parts of a problem can be added to solve composite problems (Reilly and others, 1984). In a simple application of this principle, the water-level drawdowns produced by pumping from two adjacent wells can be computed as the sum of the drawdown produced by each well. In the context of the Spring Valley simulation, the change in water level resulting from pumping at a constant rate followed by a 5-day shutdown is equivalent to the change in water level caused by a 5-day period of injection at the same constant rate. In this simulation, the four production wells in the Spring Valley well field are represented as injection wells, and water-level recovery is computed as the change in water level above an arbitrary datum after 5 days of injection. External model boundaries, specified as no-flow (impervious to flow), were specified about $1 \mathrm{mi}$ from the well field and have little effect on the flow solution.

\section{Hydraulic Properties}

Hydraulic conductivity $(K)$ and specific storage $\left(S_{s}\right)$ values were estimated for the bedrock aquifer through model calibration. The hydraulic conductivity values were computed for each element in the FE mesh using a conductivity tensor defined by three scalar values (herein referred to as conductivity) and two angles. ${ }^{1}$ The scalar values $K_{\text {max }}, K_{\text {med }}$, and $K_{\min }$ correspond to the directions of maximum, medium, and minimum conductivity, respectively (fig. 16). Values of $K_{\max }$ and $K_{\min }$ were estimated through calibration, and the value of $K_{\text {med }}$ was set equal to $K_{\max }$ because the water-bearing zones were assumed to be isotropic.

The orientations of conductivity tensors specified for each model element were variable and assumed to be aligned with the strike and dip of the bedding, as depicted by form lines in figure 6 and figure 7. The maximum conductivity $\left(K_{\max }\right)$ is oriented along the direction of strike, the medium conductivity $\left(K_{\text {med }}\right)$ is oriented along the direction of dip, and the minimum conductivity $\left(K_{\min }\right)$ is perpendicular to the bedding. Two angles are required to define the conductivity tensor: the first angle defines the strike of bedding as measured counterclockwise from east (from the $+X$ coordinate direction), and the second angle is the inclination of bedding as measured from the horizontal plane in the dip direction (the direction perpendicular to strike). Two alternative models (A and $\mathrm{B}$ ) were constructed to assess the different depictions of the strike of bedding. Model A represents form lines presented in figure 6, whereas model B represents the interpolated strike presented in figure 7 . The declination of the bedding was set to a constant value of $10^{\circ}$ in both models on the basis of the areal distribution of dip reported in Heisig (2010).

\footnotetext{
${ }^{1}$ Although in general, three angles are required, only two are required here because it is assumed that the $\mathrm{K}_{\max }$ direction is parallel to the horizontal plane, so the third angle is always zero (see Voss and Provost, 2002).
}

\section{Model Calibration}

The groundwater flow models were calibrated by adjusting values of maximum and minimum conductivity $\left(K_{\max }\right.$ and $K_{\text {min }}$, respectively) and specific storage $\left(S_{s}\right)$ to minimize the difference in water-level recovery simulated by the model and that observed in wells during the 1992 recovery test. Optimum parameter values were obtained through nonlinear regression using UCODE 2005 (Poeter and others, 2005), a computer program that uses weighted least squares to minimize model residuals (difference between observed and simulated data).

The nonlinear regression was used to compare simulated recoveries with water levels measured in 32 bedrock wells at 14 locations. Depths of shallow wells ranged from 75 to $145 \mathrm{ft}$, and depths of deep wells ranged from 170 to $270 \mathrm{ft}$. The water-level measurements were interpolated from plots of water-level recoveries presented in Legette, Brashears and Graham, Inc. (1992). The measurement depth was assumed to be midway between the top and bottom of the screened interval, which ranged from 2 to $5 \mathrm{ft}$ in length. All measurements were weighted equally in the regression, with the exception of those recorded for the set of nested wells closest to the well field (wells Ro1308, Ro1309, and Ro1310; fig. 17) that were omitted. Regressions that closely matched the measured recoveries at this location resulted in significant error at the remaining locations farther from the well field, possibly for reasons discussed farther on.

Water-level recoveries simulated with model B best matched the observed values, likely because the interpolated strike was based, in part, on borehole data obtained from the well field. The standard error of recovery is $1.7 \mathrm{ft}$ or about 6 percent of the $30-\mathrm{ft}$ measured range (table 3 ). The simulated distribution of recovery extends about $1 \mathrm{mi}$ north and south of the well field and is slightly elongated along Heisig's (2010) assumed $\mathrm{N} 25^{\circ} \mathrm{E}$ strike of bedding in this area (fig. 18A). This strike direction is more northerly than that of the Ramapo Fault $\left(\mathrm{N} 40^{\circ} \mathrm{E}\right)$ and the strike directions depicted in figure 6 . The three-dimensional (3D) perspective view of the simulated distribution of recovery clearly reflects the assumed $10^{\circ}$ dip of bedding (fig. 18B). Time-series plots for deep and shallow wells (figs. 19 and 20) indicate that the simulated recovery matches the observed data reasonably well, with the exception of wells Ro1308 and Ro1310, as noted above. Simulated water-level recovery is overpredicted for shallow wells where little recovery was observed, however. Residual plots show that the overall model fit is good, with a slight bias in underprediction (positive residuals) for deep wells and overprediction (negative residuals) for shallow wells (fig. 21).

Three parameter values $\left(K_{\max }, K_{\min }\right.$, and $\left.S_{s}\right)$ were optimized through nonlinear regression, all with coefficients of variation less than 1 percent, indicating that the regression is sensitive to the parameters and that the values are well estimated (table 3). Estimated values for $K_{\max }, S_{s}$, and the $K_{\max }: K_{\min }$ anisotropy for model B are $9.5 \mathrm{ft} / \mathrm{d}, 7.6 \times 10^{-6} \mathrm{ft}^{-1}$, and 72:1, respectively. Values estimated for $K_{\max }$ and $S_{s}$ with model A are similar (table 3), but the value estimated for 

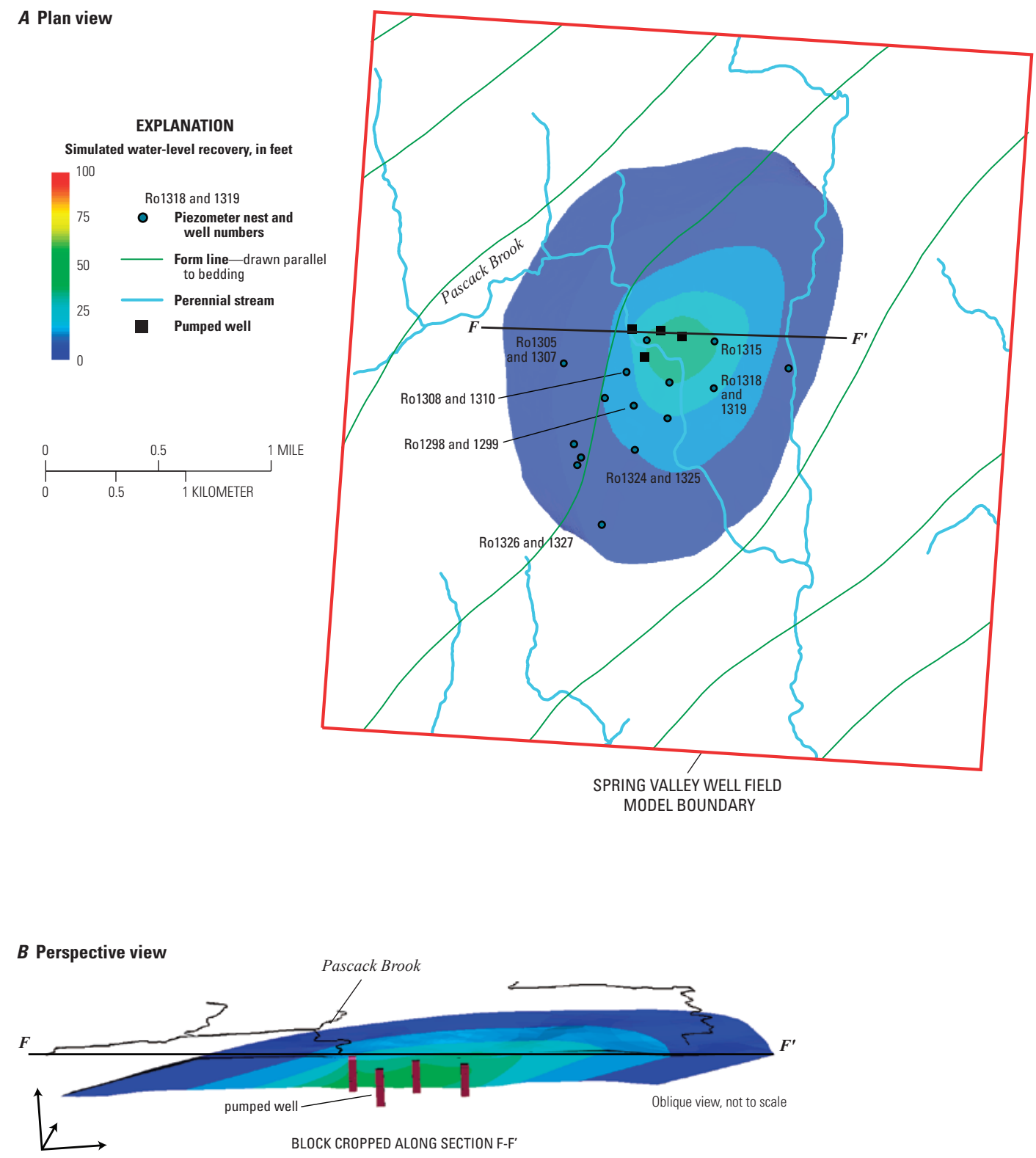

Figure 18. Distribution of simulated water-level recovery in model $B(A)$ plan view, and $(B)$ perspective three-dimensional view along section F-F'. Coordinate axes shown indicate rotation of perspective view. 
Table 3. Parameter values in alternative models of recovery test at Spring Valley well field in 1992, Rockland County, NY.

[ft, feet; $\mathrm{ft} / \mathrm{d}$, feet per day; $\mathrm{ft}^{-1}$, inverse feet; $\mathrm{ft}^{2}$, square feet]

\begin{tabular}{lccc}
\hline & Model A & Model B \\
\hline Parameter & Value & Value & Approximate individual confidence interval \\
\hline Maximum hydraulic conductivity ${ }^{\mathrm{a}}, \mathrm{ft} / \mathrm{d}$ & 10.2 & 9.5 & 8.8 to 10.2 \\
Maximum:minimum anisotropy & & $72: 1$ & $63: 1$ to $82: 1$ \\
Specific storage, $\mathrm{ft}^{-1}$ & 17 & $7.6 \times 10^{-6}$ & $7.4 \times 10^{-6}$ to $7.8 \times 10^{-6}$ \\
\hline Model fit & $7.3 \times 10^{-6}$ & & 88.2 \\
\hline Sum of squared errors, $\mathrm{ft}^{2}$ & & 1.7 & \\
Standard error, $\mathrm{ft}$ & 252.8 & 2.9 & \\
\hline
\end{tabular}

a Parallel to strike.

${ }^{\mathrm{b}}$ Ratio parallel to bedding: perpendicular to bedding.

$K_{\max }: K_{\min }$ anisotropy is much less, $17: 1$, than found for model B (72:1). The standard error is 50 percent greater for model A because the assumed distributions of strike of bedding do not match the actual strike as well as those from model B. The nonlinear regression compensated for this disparity in model A with a larger $K_{\min }$ value in order to match observed water-level recoveries in areas updip and downdip of the pumped wells.

Simulations of the 1992 recovery test at the Spring Valley well field indicate a significant degree of anisotropy in the hydraulic conductivity with preferential flow parallel to the bedding and restricted flow perpendicular to the bedding. Because the bedding is inclined, the degree of anisotropy is not apparent in the plan view of the distribution of waterlevel recovery (fig. 18A) and is only accurately reflected by the $3 \mathrm{D}$ view (fig. 18B). The estimated $K_{\max }: K_{\min }$ anisotropy from model B is $72: 1$, and the simulated strike of bedding in this area is consistent with the strike interpolated by Heisig (2010). The model B simulation provides an acceptable fit to the measured water-level recoveries but cannot reproduce the recovery data at all wells because the hydraulic properties and dip of bedding are assumed to be uniform throughout the model domain. The actual degree of $K_{\max }: K_{\min }$ anisotropy is probably greater in some areas because the simulated results underpredict the water-level recoveries measured in some shallow wells east (updip) of the well field (Ro1315) and overpredict water-level recoveries in shallow wells west (downdip) of the well field (Ro1307). The effect of heterogeneity in the distribution of $K$ and $S_{s}$ is particularly apparent in the results for the deep and shallow nested wells closest to the well field (Ro1308 and Ro1310) where recovery is underpredicted and overpredicted, respectively. These results indicate that the hydraulic conductivity and (or) $K_{\max }: K_{\min }$ anisotropy of waterbearing zones and (or) fractures that connect the deep well (Ro1308) to the production wells are greater than corresponding values in surrounding areas.

\section{Newark Basin Aquifer}

Two alternative 3D models $\mathrm{A}$ and $\mathrm{B}$ were constructed to estimate the hydraulic-head distribution and rate of groundwater flow throughout the Newark basin aquifer in Rockland County. As was the case for the Spring Valley models, the alternative county-wide models used the representations of the bedding strike presented in figure 6 and figure 7. Steady-state simulations for the alternative models were calibrated to water levels measured in bedrock wells from 2005 through 2007 when groundwater withdrawals were relatively constant and the aquifer system was assumed to be near equilibrium.

\section{Model Design}

The model domain covers an area of $85.4 \mathrm{mi}^{2}$ and is bounded to the west by the Ramapo Fault, to the north and east by the Palisades sill, and to the south by drainage divides of the gaged streams that drain the area (fig. 11). The model represents the fractured-bedrock aquifer with a constant saturated thickness, and downward flow from the saturated overburden is represented as recharge to the underlying bedrock aquifer. Flow through the outwash aquifer that underlies the Mahwah River along the western boundary of the model domain also is represented.

\section{Mesh and Layering}

The model domain is discretized using a 3D FE mesh consisting of an irregularly connected mesh in the areal plane that is extended vertically to the bottom of the model domain. Areally, the mesh appears as a set of quadrilateral elements with maximum lateral lengths of $500 \mathrm{ft}$ (fig. 22). Smaller elements with maximum lateral lengths of $40 \mathrm{ft}$ were used to better represent junctions of the stream network that was used to constrain the mesh generation and the area near the Spring Valley well field. 
$A$ Well Ro1308 (PTPN 20D)
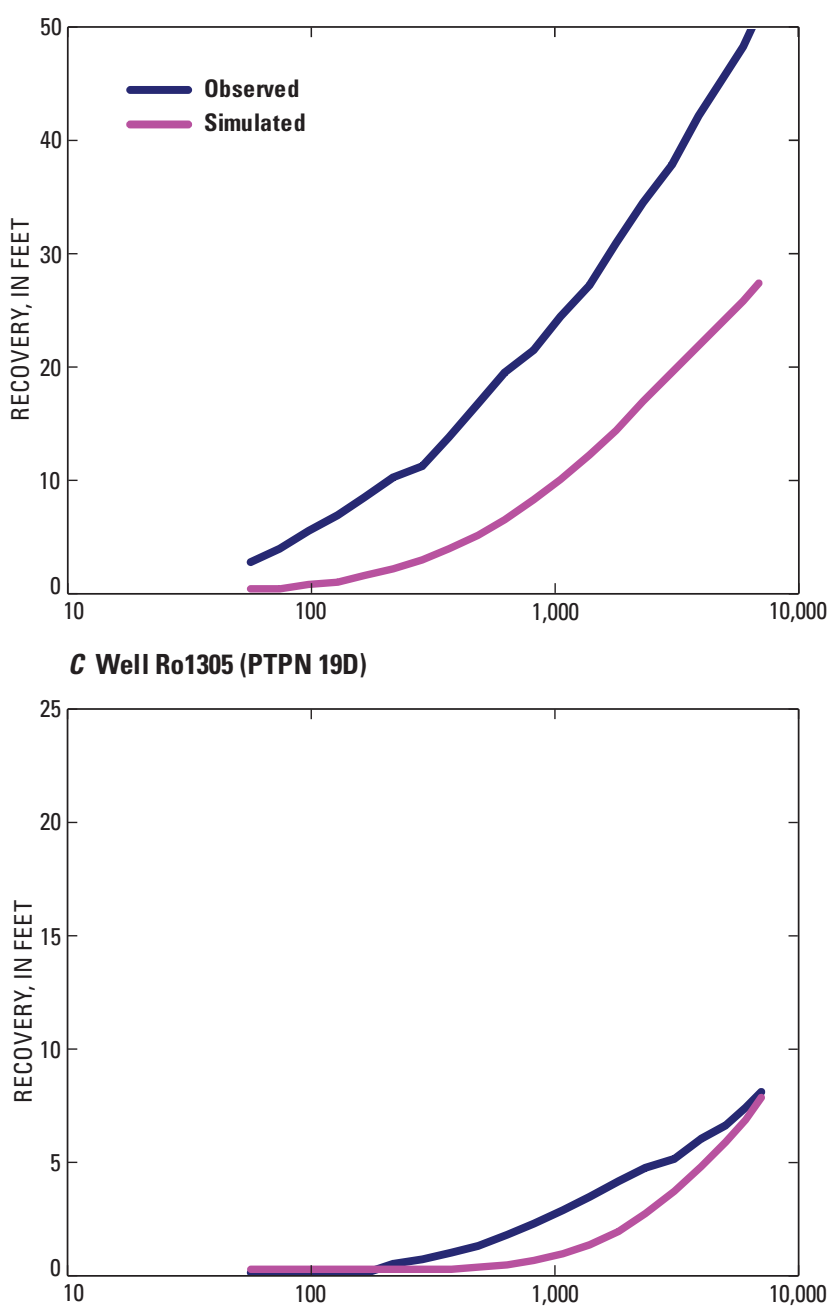

E Well Ro1324 (SRI 2D)

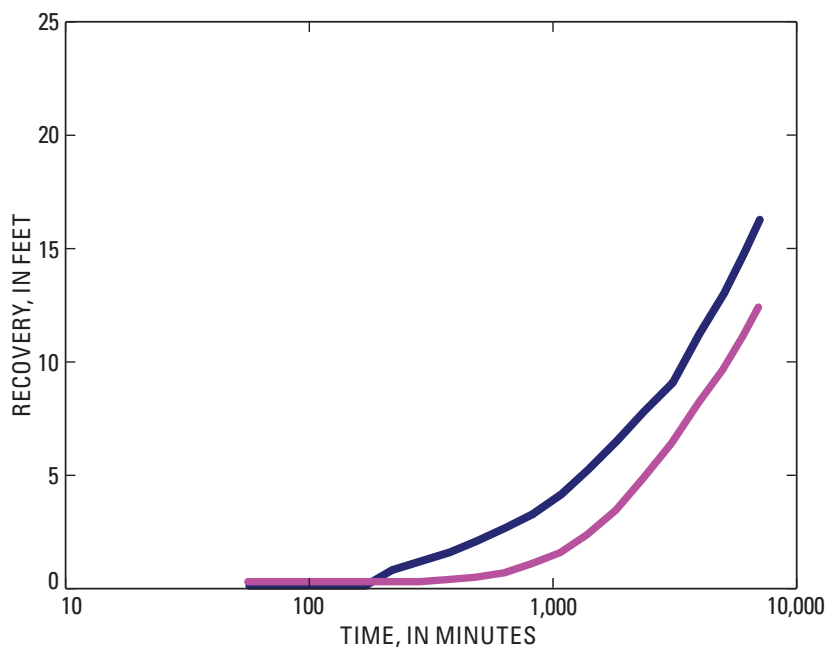

$B$ Well Ro1298 (PTPN 8D)
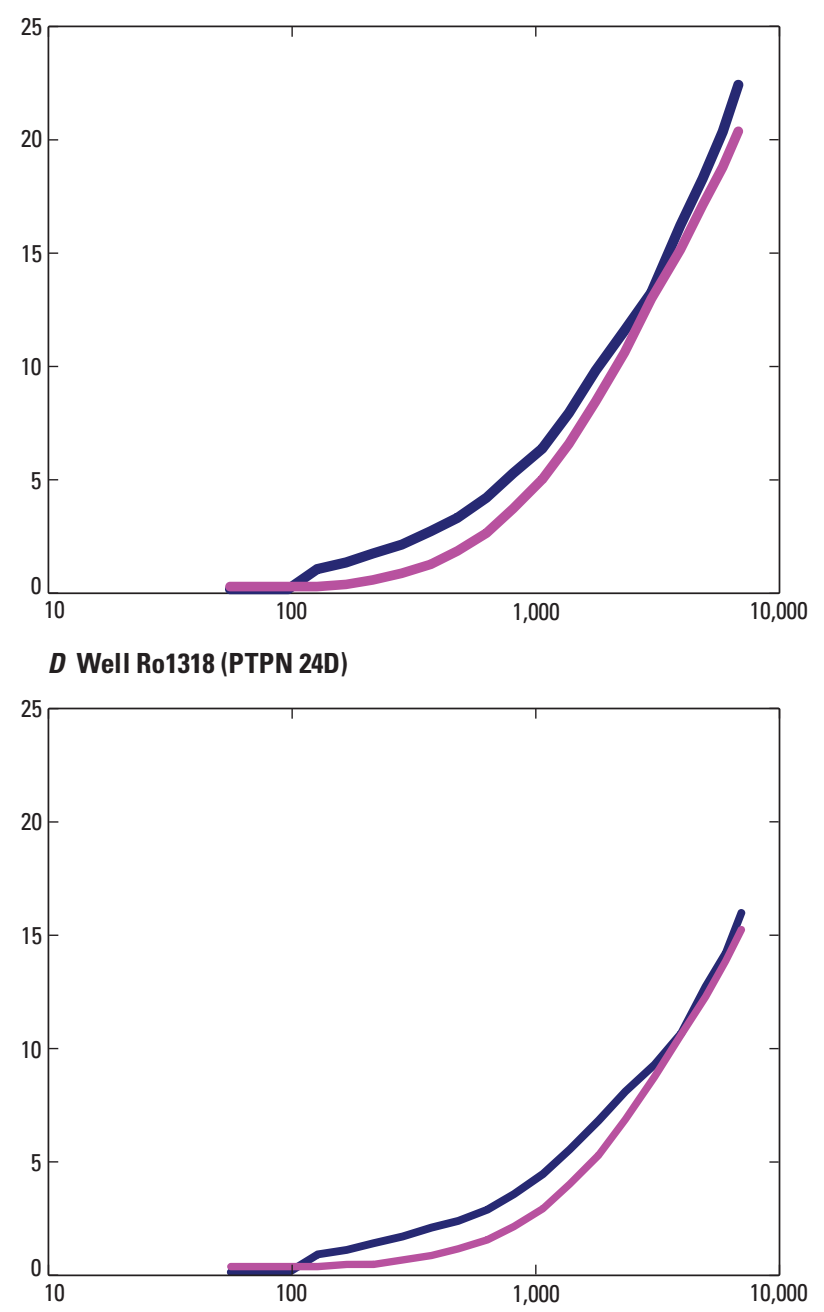

F Well Ro1326 (SRI 3D)

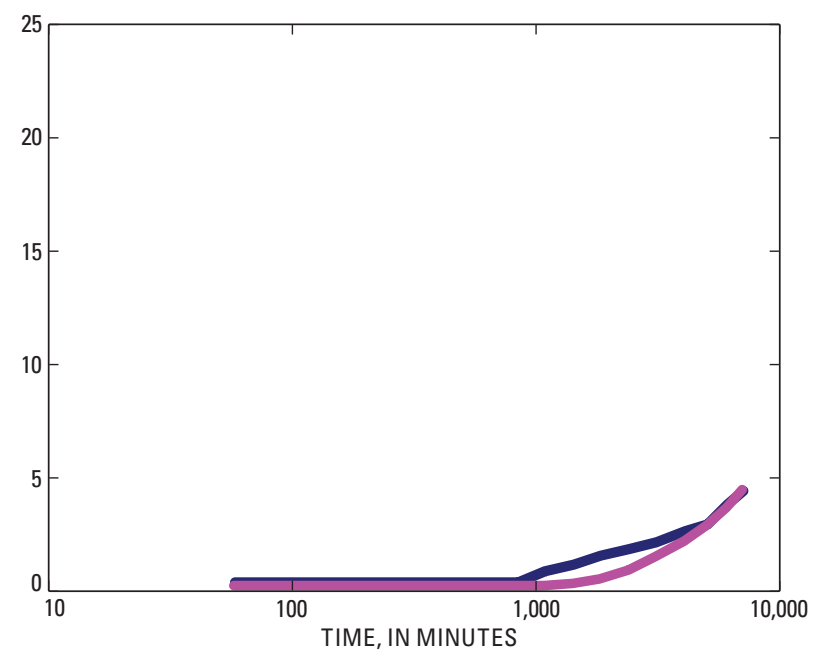

Figure 19. Observed and simulated water-level recovery in deep wells in model $B$ at $(A)$ well Ro1308 (PTPN-20D), (B) well Ro1298 (PTPN-8D), (C) well Ro1305 (PTPN-19D), (D) well Ro1318 (PTPN-24D), (E) well Ro1324 (SRI-2D), and (F) well Ro1326 (SRI-3D). (Well locations shown in figure 18.) 


\section{A Well Ro1310 (PTPN 20S)}

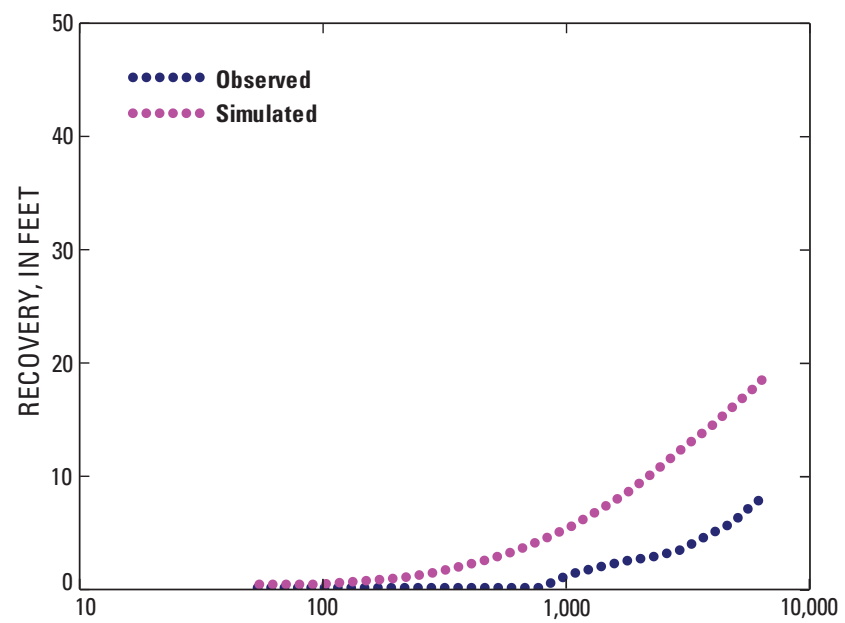

C Well Ro1307 (PTPN 19S)

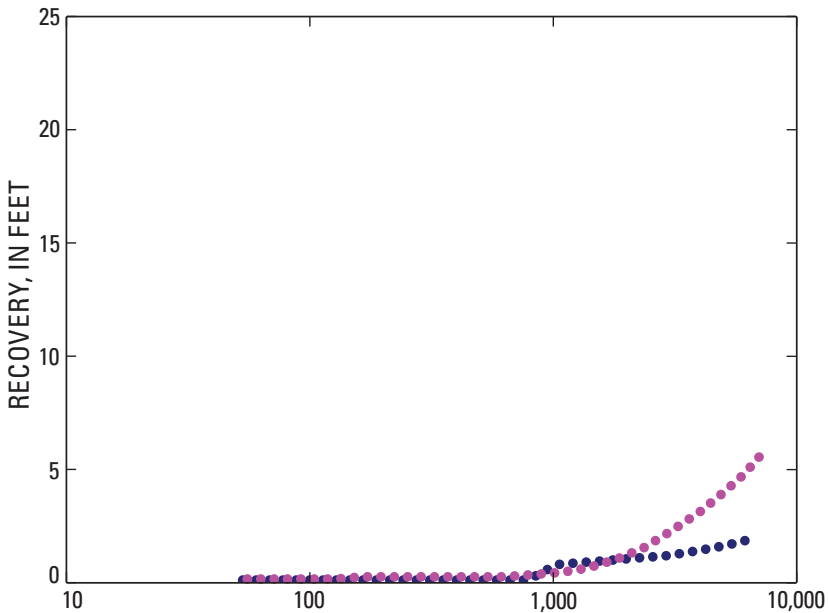

E Well Ro1325 (SRI 2S)

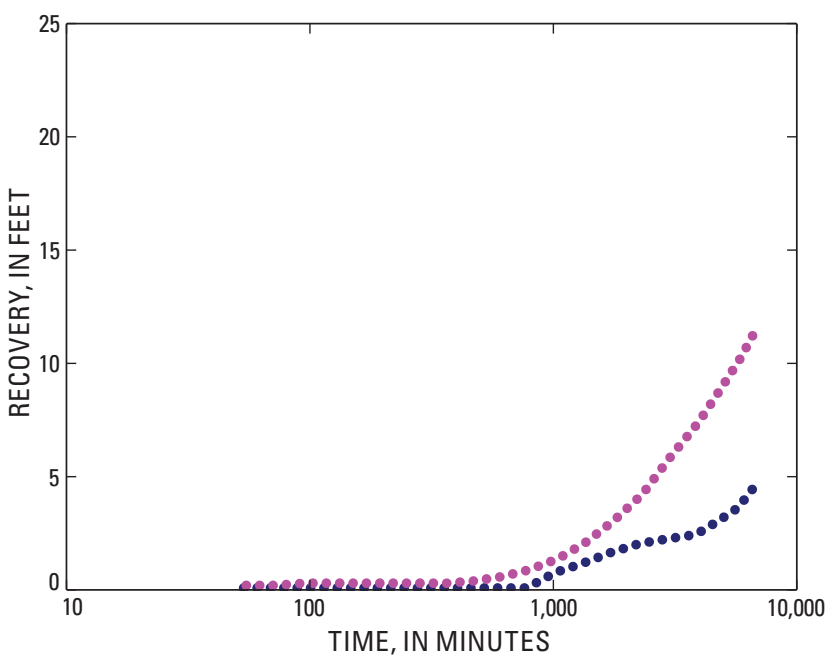

$B$ Well Ro1299 (PTPN 8S)

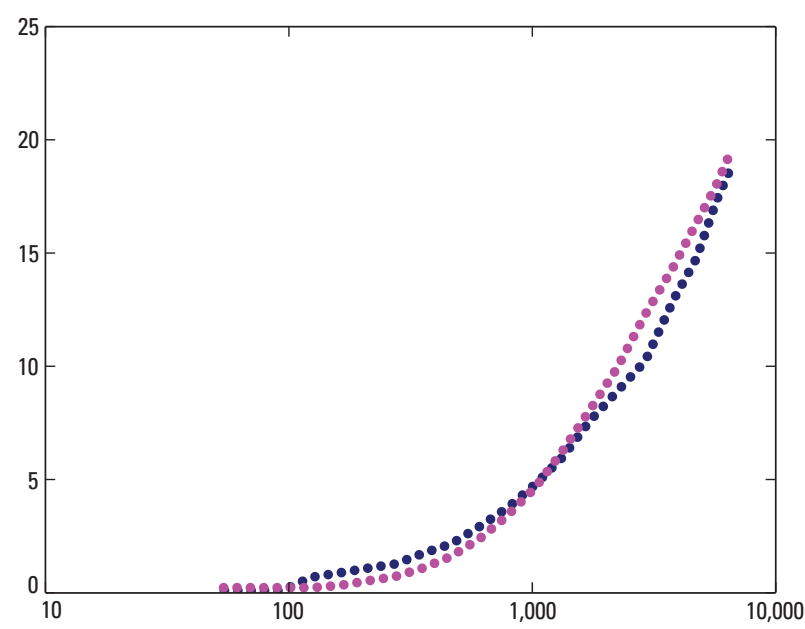

D Well Ro1319 (PTPN 24S)

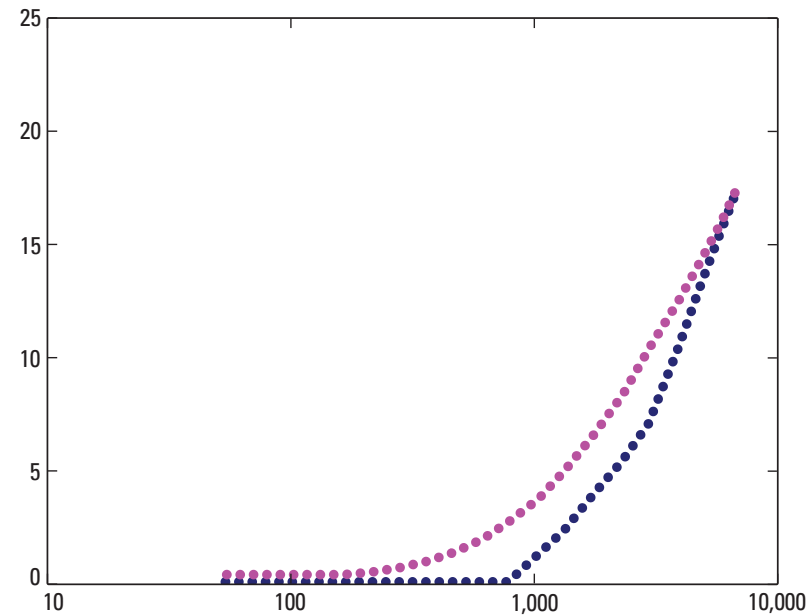

F Well Ro1327 (SRI 3S)

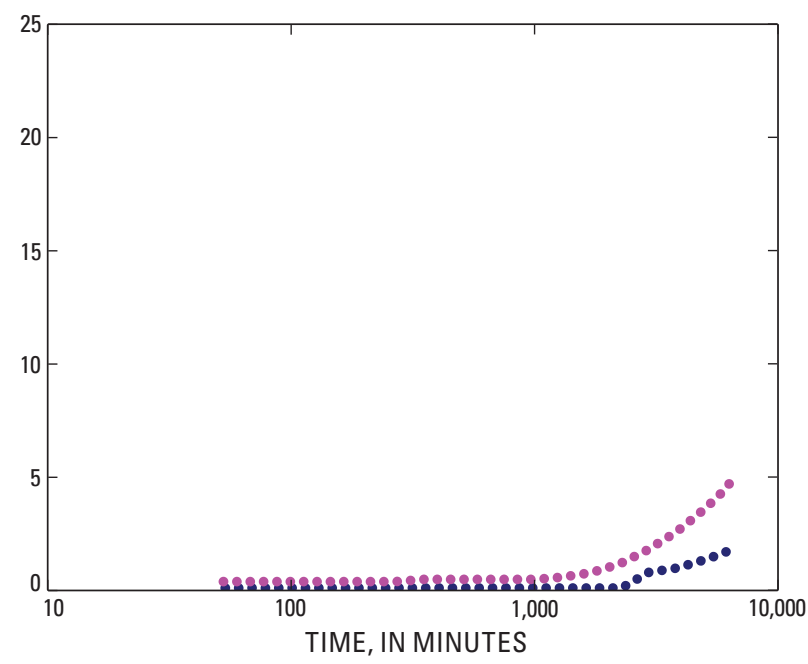

Figure 20. Measured and simulated water-level recovery in shallow wells in model $B$ at $(A)$ well Ro1310 (PTPN-20S), $(B)$ well Ro1299 (PTPN-8S), (C) well Ro1307 (PTPN-19S), (D) well Ro1319 (PTPN-24S), (E) well Ro1325 (SRI-2S), and (F) well Ro1327 (SRI-3S). (County and local well numbers are noted and well locations shown in figure 18.) 
A Simulated and observed values
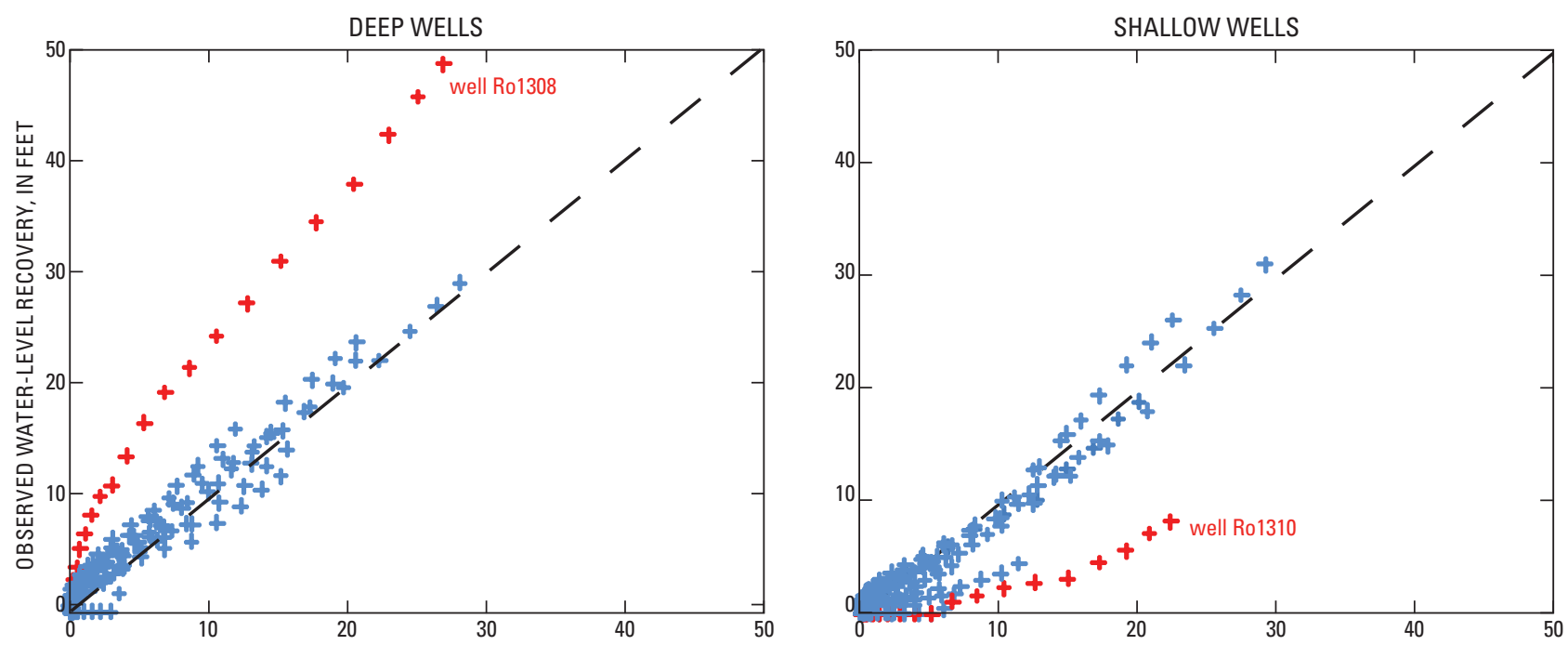

$B$ Simulated values and residuals (wells Ro1308 and Ro1310 omitted)
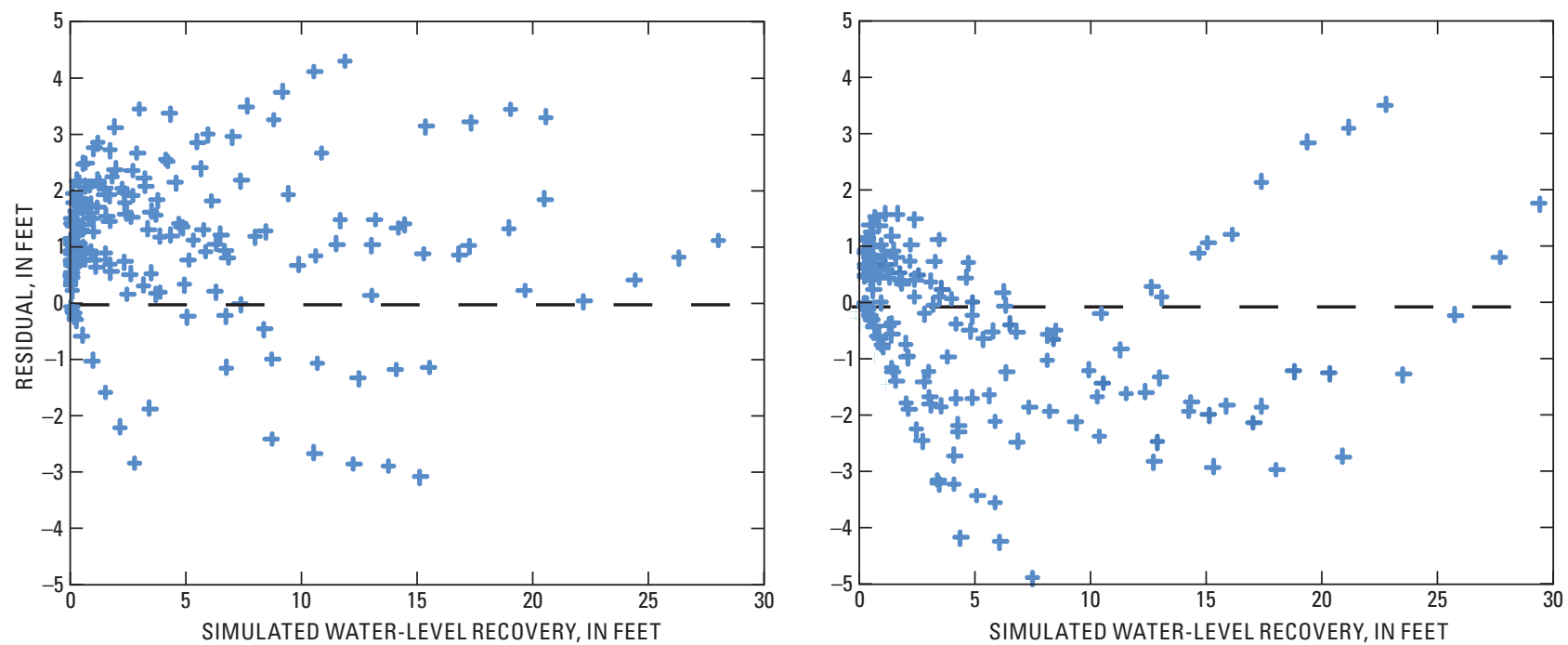

Figure 21. Residual plots (observed minus simulated values) for simulated water-level recovery in model B: $(A)$ relation between simulated and observed values, and $(B)$ relation between simulated values and residuals. (Note that data for wells Ro1308 and Ro1310 are omitted in B.) 
The top surface of the model was initially set equal to the bedrock surface as computed from altitudes of land surface using a 30-ft DEM minus the overburden thickness interpolated by Heisig (2010). As a result, the model-computed transmissivity was too large in upland areas where the water table is below the bedrock surface. In subsequent simulations, the top model boundary was replaced by water levels (hydraulic heads) computed by the calibrated models A and B; then the parameter values were reoptimized. In areas where the outwash aquifer is present, the top surface corresponds to the 2006 water table mapped by Heisig (2010). The bottom surface of the model roughly parallels the base of the Newark basin sedimentary rocks (fig. 4); the model domain represents a wedge of rock that thickens from about $1,000 \mathrm{ft}$ at the eastern edge to nearly $5,000 \mathrm{ft}$ at the western edge (fig. 23). The bedrock is divided into two units. The upper unit in the flow model corresponds to an assumed 500-ft thick zone of active flow that is divided into 10 equally spaced layers of elements. The outwash aquifer is represented by either the top one or top two layers of the upper unit, depending on the combined thickness of the alluvium and outwash. The lower unit in the model represents underlying rock deeper than $500 \mathrm{ft}$ and is represented by a lower unit that is divided into 7 layers of elements using a factor of 1.5 to increase the layer thickness with depth. The resulting mesh contains 17 layers with 436,118 elements and 470,106 nodes.

\section{Boundary Conditions}

All the lateral and bottom boundaries of the model domain are assumed to be no-flow (impervious to flow) with the exception of the southern boundary which is specified pressure (referred to as specified head for the uniform density simulations described herein). The southern boundary represents underflow to and from New Jersey and was assigned hydraulic-head altitudes based on the 2005-2007 potentiometric surface mapped by Heisig (2010). Open waters (lakes and marshes) are also represented by specified head boundaries.

Stream channels are represented by head-dependent flow boundaries that use a modification of the specified-head boundary provided in SUTRA, as described in Appendix 2 (provided by A.M. Provost, U.S. Geological Survey, written commun., 2009). Head-dependent flow boundaries require definition of a conductance term $C$ :

$$
C=\frac{K L W}{l},
$$

where $K$ is hydraulic conductivity [L/T],

$L$ is length of stream reach [L],

$W$ is width of stream reach [L], and

$l$ is thickness of the unconsolidated deposits underlying the stream [L], assumed to be equivalent to the overburden thickness.

Stream widths range from 5 to $30 \mathrm{ft}$, and thicknesses range from 3 to $100 \mathrm{ft}$. Different $C$ values are used in the model to reflect the three types of unconsolidated deposits that underlie streambeds: (1) alluvium or outwash, (2) till, and (3) lacustrine (fig. 7; areas in the figure not underlain by alluvium, outwash, or lacustrine sediments are assumed to be underlain by till). The modification to SUTRA allows the specified-head boundary to function in a manner similar to a drain boundary in MODFLOW (Harbaugh and others, 2000) by preventing inflow from the boundary. Outflow from a drain boundary can occur only when the head at the node is larger than the specified head and is proportional to the conductance term $C$; when the head at the node is lower than the specified head, the drain boundary has no effect. While groundwater withdrawals probably induce infiltration of streamwater to the bedrock aquifer in some areas, this process was not represented in the models because the quantity and spatial distribution of these flows has not been mapped.

The top model boundary represents recharge from the unconsolidated deposits and is specified as a fluid source applied to nodes on the boundary, except those nodes that represent stream and open-water boundaries, and areas underlain by lacustrine sediments (fig. 7). The recharge rate at each node $(R c h)$ was computed from a calibrated maximum recharge rate $\left(R c h_{\max }\right)$ adjusted by three factors using the equation

$$
R c h=R c h_{\max } \times \text { Precip } \mathrm{x} \text { Perv } \mathrm{x} \text { Thick, }
$$

where Precip is a precipitation factor,

Perv is a pervious area factor, and

Thick is a factor related to overburden thickness.

The Precip factor accounted for the spatial distribution of precipitation, which is based on measured precipitation at nine gages (Heisig, 2010, fig. 3). Mean annual precipitation was normalized by dividing the precipitation at each node location by the weighted mean for the entire model domain (50.8 in/yr). The Perv factor reduced recharge in areas with impervious cover (for example, pavement), which is based on maps of existing buildings and roadways in 2000 (Rockland County Department of Planning, written commun., 2007) and an assumed relation between recharge and the percentage of pervious area surrounding each nodal location (fig. 24A). The Thick factor reduced recharge in areas covered by till according to the equation (fig. 24B)

$$
\text { Thick }=10^{-\kappa b} \text {, }
$$

where $b$ is the thickness of till [L] below a threshold depth

$(10 \mathrm{ft})$ and

$\kappa$ is a decay factor $\left[\mathrm{L}^{-1}\right]$ estimated through model calibration.

The Thick factor was assigned a value of 1.0 for nodes representing areas underlain by alluvium and outwash.

Simulated recharge rates to the bedrock aquifer in the southern part of the model domain are lower than those computed for the northern part where annual precipitation is higher and the till is thinner (fig. 25). Less recharge to the bedrock aquifer also is computed for stream valleys where the till is thicker than surrounding areas. Recharge rates estimated through model calibration include conveyance losses 


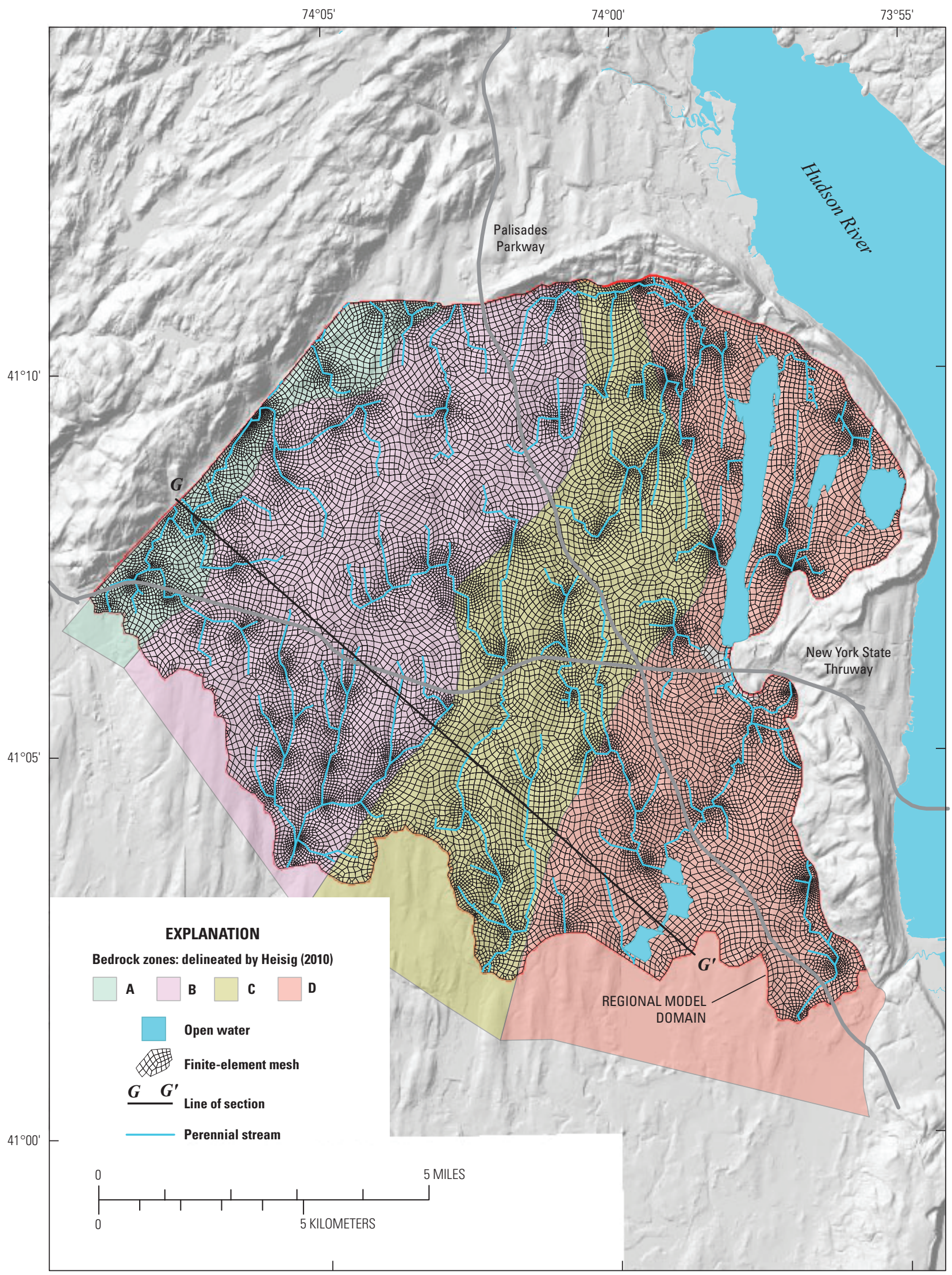

Base from Rockland County Planning Department

Figure 22. Finite-element mesh and bedrock zones used to assign thickness of active groundwater flow in Newark basin in Rockland County, NY. 


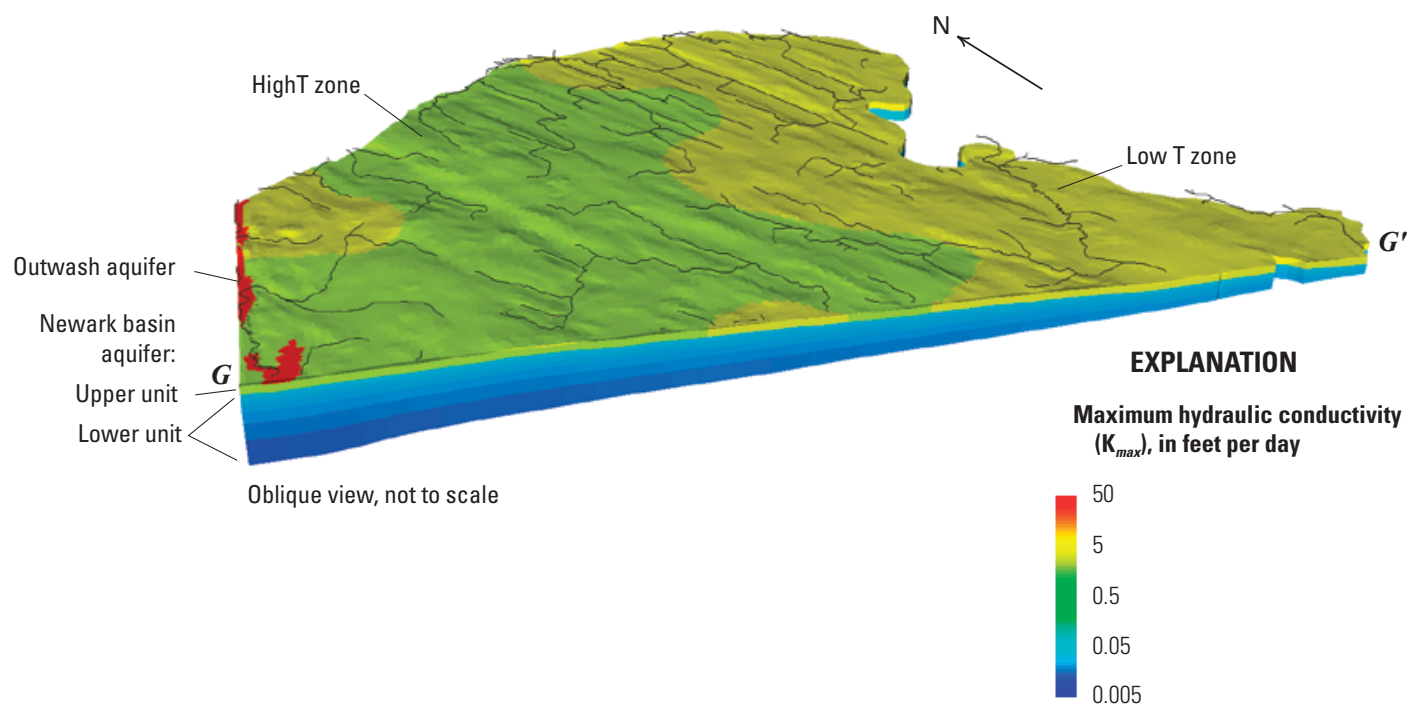

Figure 23. Block diagram cropped along section G-G' showing thickness of units and hydraulic conductivity zones within model domain. Location of section shown in figure 22.

through the delivery of public water, which are not represented explicitly in model simulations. The effect of impervious areas mapped in 2000 reduces recharge to the Newark basin aquifer by about 5 percent.

Groundwater withdrawals from 48 wells are represented by fluid sinks assigned to nodal locations that are nearest to each well using average withdrawal rates from 1985 through 2005. At each node location, the withdrawal is distributed over a vertically stacked set of nodes that corresponds to the open interval of the well. Two well fields containing closely grouped wells (Grandview and Pomona; fig. 3) are represented as combined withdrawal from a single well that is represented by a column of nodes in the FE mesh.

\section{Hydraulic Conductivity}

Hydraulic conductivity values are computed for elements in the FE mesh using a conductivity tensor and a function that decreased hydraulic conductivity with increasing depth below the bedrock surface. The conductivity tensors are aligned with the strike and dip of the bedding, as in the Spring Valley model described earlier, and tensor orientations are assumed to remain constant with depth. Maximum conductivity $\left(K_{\max }\right)$ is oriented along the direction of strike, the medium conductivity $\left(K_{\text {med }}\right)$ is oriented along the direction of dip, and the minimum conductivity $\left(K_{\min }\right)$ is perpendicular to the bedding. Values of $K_{\max }$ and
$K_{\min }$ were estimated through calibration, and the value of $K_{\text {med }}$ was set equal to $K_{\max }$ because the water-bearing zones were assumed to be isotropic. The same two structural models used for the Spring Valley well field are represented. The dip of bedding in model $\mathrm{A}$ is assumed to be uniform with a declination of $10^{\circ}$ towards the Ramapo Fault, and the dip of bedding in model $\mathrm{B}$ is based on the delineation by Heisig (2010).

A power function similar to that applied in the groundwater flow model of the Shenandoah Valley by Yager and others (2008) is used to relate the decrease in hydraulic conductivity $K$ below a threshold depth $D$ below the bedrock surface:

$$
K_{\text {depth }}=K 10^{-\lambda d} \text {, }
$$

where $K_{\text {depth }}$ is the hydraulic conductivity [L/T] at depth $d[\mathrm{~L}]$ below a threshold depth $D$ and

$\lambda$ is a decay factor $\left[\mathrm{L}^{-1}\right]$.

Threshold depths $D$ were assigned for each bedrock zone (fig. 7) on the basis of depths of active flow estimated by Heisig (2010) from borehole geophysical surveys. The depth decay factor $\lambda$ was not a sensitive model parameter and was assigned a value of $3 \times 10^{-4} \mathrm{ft}^{-1}$ on the basis of values estimated by Yager and others (2008) for the Shenandoah Valley. The minimum value of $K_{\text {depth }}$ was limited to $10^{-3} \mathrm{ft} / \mathrm{d}$.

Hydraulic conductivity values were estimated through model calibration for the high and low $T$ zones presented 

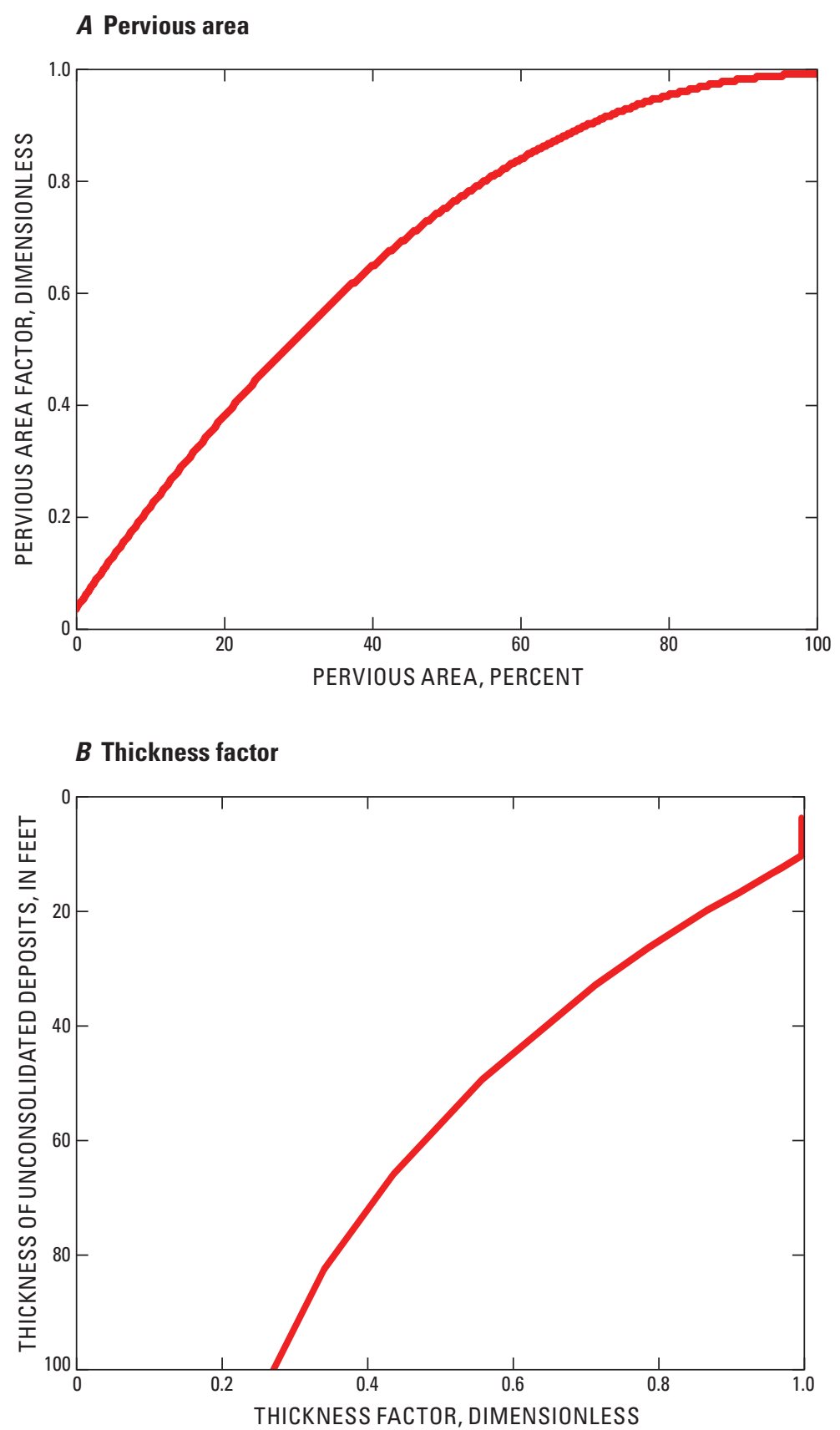

Figure 24. Relations defining factors used to compute recharge assigned to nodes in finite-element mesh $(A)$ pervious area factor (Perv), and $(B)$ thickness factor for unconsolidated deposits (Thick). 


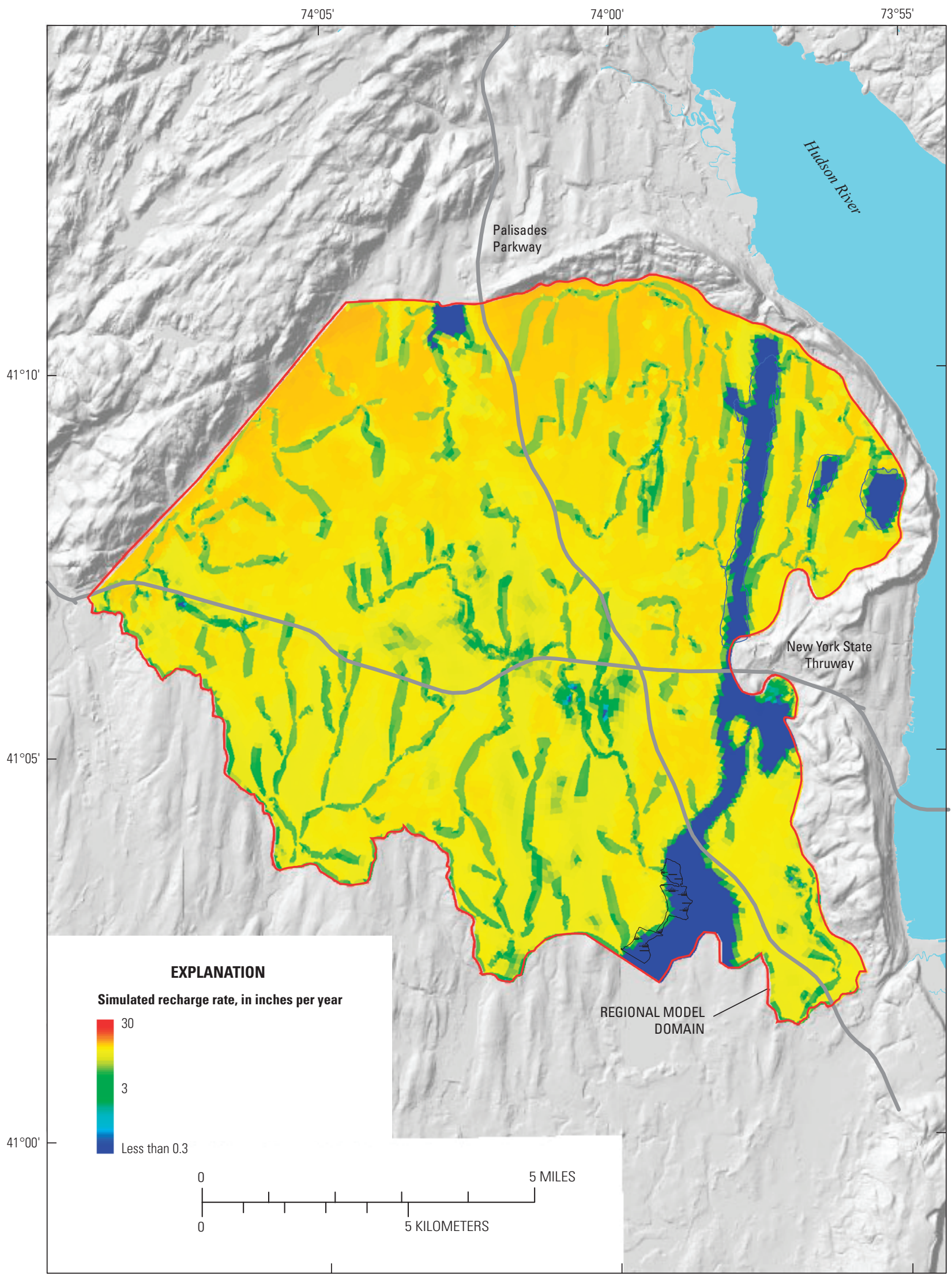

Base from Rockland County Planning Department

Figure 25. Distribution of simulated recharge specified in steady-state simulations of 2006 conditions in Newark basin in Rockland, NY. 
earlier (fig. 13). Two alternative hydraulic conductivity patterns also were considered in model calibration-a continuous distribution of $T$ based on kriging (fig. 13) and zones that correspond to the bedrock zones mapped on the basis of natural-gamma activity surveys conducted by Heisig (2010) (fig. 7). These alternative distributions either resulted in poorer model fits or had little effect on model results, as described below.

\section{Model Calibration}

Both groundwater flow models A and B were calibrated by adjusting hydraulic conductivity and recharge values to minimize the difference between simulated groundwater levels and those observed in wells. Optimum parameter values were obtained through nonlinear regression using UCODE 2005 (Poeter and others, 2005), as described previously for the Spring Valley model.

\section{Observations}

The nonlinear regression was used to compare simulated water levels with the average of water levels measured in 140 bedrock wells from August 2005 through April 2007. The open interval of many of these wells is not known, but drilled wells in the Newark basin aquifer are typically cased to bedrock. The assumed measurement depth was computed as midway between the bottom of the well and the estimated bedrock surface or the measured water level, whichever was lower. The median well depth is $155 \mathrm{ft}$, and the median measurement depth is $82 \mathrm{ft}$. Weights assigned to the waterlevel measurements were chosen to reflect measurement error and were based on the number of measurements made. Wells for which two to four measurements were made were assigned weights equivalent to a 6.5 -ft standard deviation in measurement error. Wells that were measured only once were assigned weights equivalent to a $10-\mathrm{ft}$ standard deviation in error, slightly less than the 11.5 - $\mathrm{ft}$ mean range in water-level fluctuation observed during the measurement period.

Although mean annual base flow has been estimated at seven streamgage stations, as discussed previously, only one station (Mahwah River near Suffern, fig. 11) has period of record longer than 3 years, so base-flow data were not used in model calibration. The volume of groundwater withdrawals applies a sufficiently large stress on the bedrock aquifer to allow the estimation of recharge without including the base-flow data. Simulated base flows were compared with the only available data measured during the simulated period, low flows in July 2006.

\section{Model Fit}

The potentiometric surfaces simulated with both models A and B (fig. 26) are similar and provide a reasonable match to that observed, but simulated heads are underpredicted in the uplands north and west of Spring Valley. A perspective 3D view illustrates that heads are propagated downdip through the aquifer, creating areas with upward and downward gradients northwest of uplands and lowlands, respectively (fig. 27). Artesian flow has been observed and upward flow measured in wells located in areas of upward gradient. Cascading flow has been observed and downward flow measured in wells located in areas of downward gradient. In general, vertical gradients (upward or downward) can be expected throughout the aquifer as a result of the topography and the inclined bedding, as indicated in figure 27. In this setting, individual water-bearing zones function as separate confined aquifers.

Residual (observed minus simulated value) plots for heads indicate that both models A and B simulate the groundwater flow system reasonably well (fig. 28). The standard error in head in model A is $12.6 \mathrm{ft}$, while the standard error in model B is $12.2 \mathrm{ft}$, indicating a slightly better model fit. These standard errors are less than 3 percent of the $535-\mathrm{ft}$ measured range of head and are comparable to the mean 11.5 -ft fluctuation in measured water levels. There is a slight bias towards overprediction (fig. 28) with a mean residual of $-2.5 \mathrm{ft}$. Heads are overpredicted (negative residuals) in the Saddle River watershed and west of Lake DeForest and are underpredicted (positive residuals) in the uplands west of Spring Valley (fig. 26). In general, the simulated hydraulic gradient is flatter than that measured. The wide scatter in the residuals for measured heads greater than $480 \mathrm{ft}$ indicates that water levels in these upland areas are controlled by local conditions not represented in the model (fig 28).

Simulated stream base flows from models A and B are similar and closely match the low flows observed in July 2006, with the exception of the Hackensack and Saddle Rivers (fig. 11) where simulated flows are higher (fig. 29). Groundwater discharge to the Hackensack River is estimated to account for nearly 30 percent of discharge from the aquifer (table 4), so additional information concerning the volume of base flow is important for improving the model fit. Decreasing simulated flows to the Saddle River would likely increase model error because simulated heads in this watershed are overpredicted, as noted above. Simulated flows are less than estimated base flows in the Mahwah River and Pascack Brook, indicating possible additional sources of water in these watersheds. Groundwater withdrawals account for about 19 percent of discharge from the aquifer.

\section{Parameters}

A total of 14 parameter values were specified in the models, five of which were optimized through nonlinear regression (table 5). Coefficients of variation (cv) for the hydraulic conductivity parameters are less than 2 percent. The $\mathrm{cv}$ for the $R c h_{\max }$ recharge parameter is larger (15 percent), and the $\kappa$ recharge parameter is more than 100 percent. These $\mathrm{cv}$ values indicate that the regression is sensitive to most of the parameters and that the values are reasonably well estimated, with the exception of $\kappa$. Values for the hydraulic conductivity $(K)$ of unconsolidated deposits underlying streams were estimated through regressions that improved overall measures of model fit, but values did not converge because the sensitivity of the 


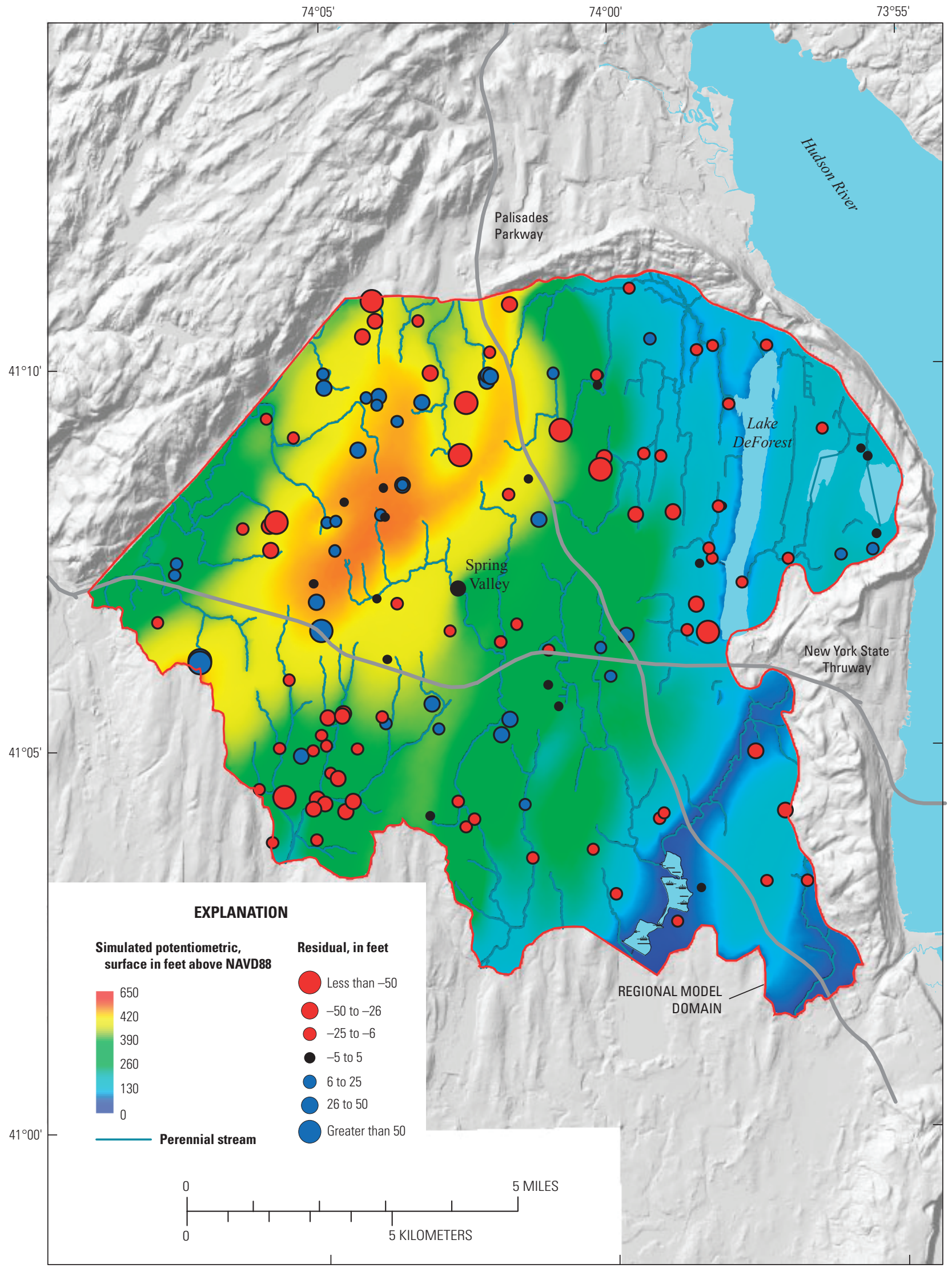

Base from Rockland County Planning Department

Figure 26. Potentiometric surface simulated for 2006 conditions in Newark basin in Rockland County, NY, using model B and distribution of residuals (observed minus simulated values). 
Table 4. Simulated water budget for Newark basin aquifer in model B.

$\left[\mathrm{ft}^{3} / \mathrm{s}\right.$, cubic feet per second]

\begin{tabular}{|c|c|c|c|c|c|}
\hline Source & $\begin{array}{l}\text { Inflow volume } \\
\qquad\left(\mathrm{ft}^{3} / \mathrm{s}\right)\end{array}$ & Percent & Discharge & $\begin{array}{l}\text { Outflow volume } \\
\left(\mathrm{ft}^{3} / \mathrm{s}\right)\end{array}$ & Percent \\
\hline \multirow[t]{2}{*}{$\begin{array}{l}\text { Recharge from precipitation } \\
\text { and conveyance losses }\end{array}$} & 118.2 & 98.9 & Streams & & \\
\hline & & & Hackensack River & 35.1 & 29.4 \\
\hline \multirow[t]{6}{*}{ Underflow from New Jersey } & 1.3 & 1.1 & Mahwah River & 13.4 & 11.3 \\
\hline & & & Pascack Brook & 8.6 & 7.2 \\
\hline & & & Saddle River & 10.7 & 8.9 \\
\hline & & & Sparkill Creek & 1.8 & 1.5 \\
\hline & & & Open water and small drainages & 15.0 & 12.5 \\
\hline & & & Water withdrawals & 23.0 & 19.2 \\
\hline
\end{tabular}

${ }^{a}$ Estimated to be 16 percent of water withdrawals.

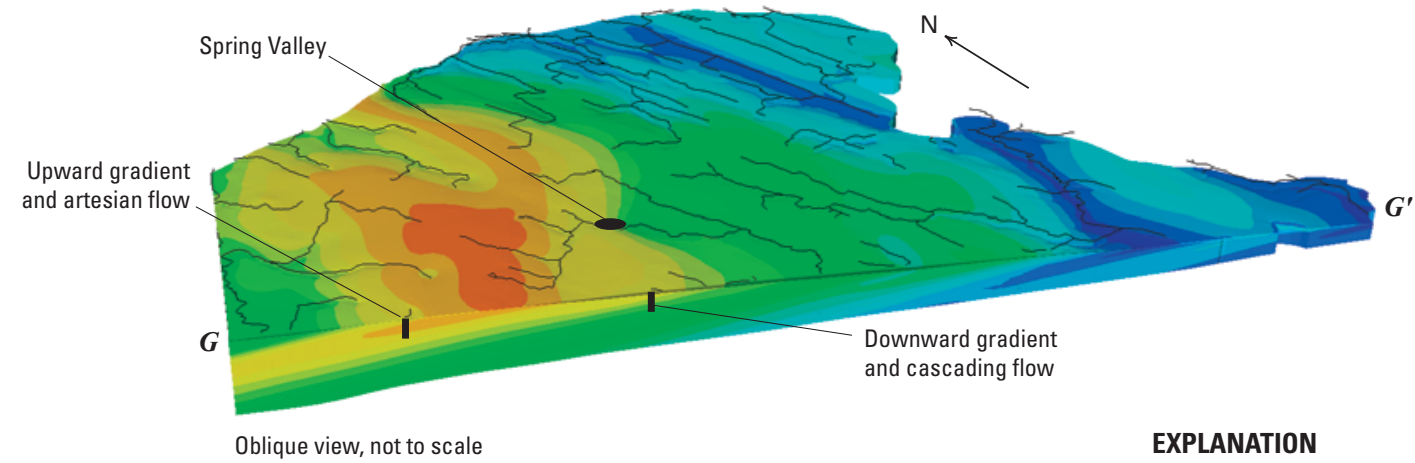

Water level, in feet

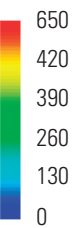

Figure 27. Block diagram cropped along section G-G' showing spatial distribution of simulated hydraulic head with model $B$ and locations of potential flowing and cascading wells. 


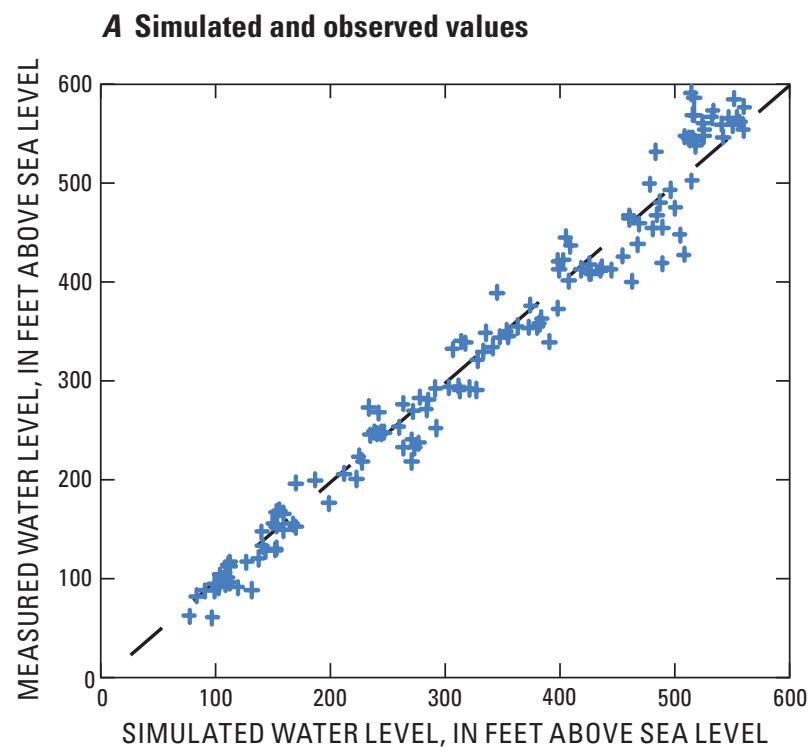

$B$ Simulated values and weighted residuals

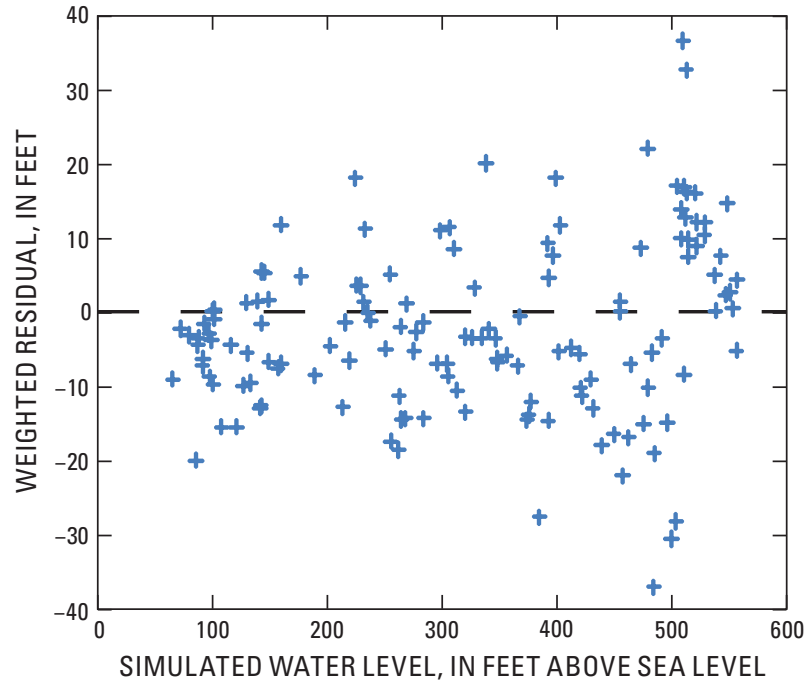

Figure 28. Residual plots for simulated water levels in model $B(A)$ relation between simulated and observed values, and $(B)$ and relation between simulated values and weighted residuals. 


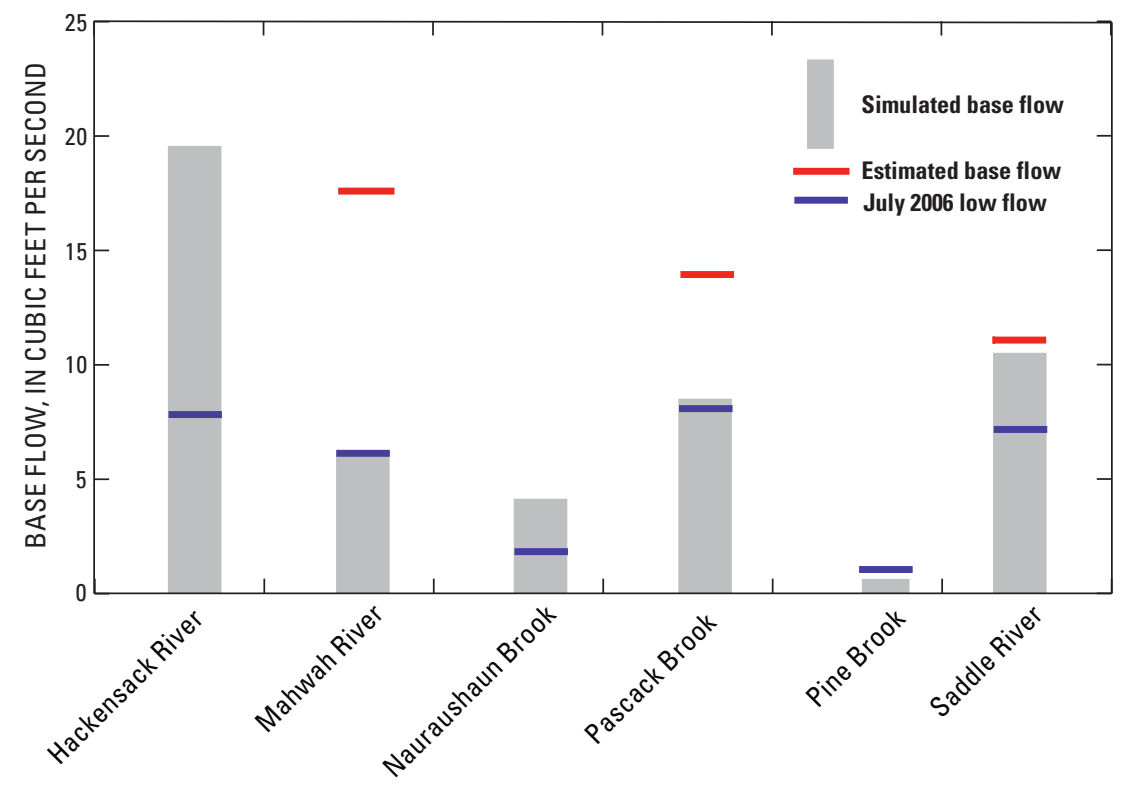

Figure 29. Bar chart comparing simulated base flows for selected streams in model B with base flows estimated from streamflow hydrographs 2004 to 2007, and low flows in July 2006. Locations of streamgage stations shown in figure 12.

regression to these parameters was too low. The estimated $K$ values for till and lacustrine sediments are greater than expected (10 and $2 \mathrm{ft} / \mathrm{d}$, respectively, table 5), but lower $K$ values resulted in overprediction of groundwater levels and increased model error. One possible explanation for the large values is that the drainage network represented in the model does not include groundwater discharge (by infiltration) to sewers that is estimated to be $7.6 \mathrm{Mgal} / \mathrm{d}$, or about 10 percent of the simulated water budget. The large overburden $K$ values of the unconsolidated deposits in the models increase the simulated discharge and lower the simulated water levels but do not represent the spatial distribution of the sewer network.

The average recharge rates estimated with both models A and $\mathrm{B}$ are 20 and $19 \mathrm{in} / \mathrm{yr}$, respectively (table 5), corresponding to maximum recharge rates of 28 and $24 \mathrm{in} / \mathrm{yr}$, respectively. The average recharge rates are comparable to rates computed by Heisig (2010) for 2006 from base-flow data for the Saddle River and Pascack Brook (19 and 18 in/yr) and from annual water-level fluctuation in well Ro647 (21 in/yr, well location shown in figure 9). These recharge rates are lower than the rate estimated by Heisig (2010) for the Mahwah River watershed ( $27 \mathrm{in} / \mathrm{yr}$ ), however, consistent with the fact that part of the base flow in the river is derived from the highlands west of the model domain. The uncertainty in the recharge estimate is $\pm 6 \mathrm{in} / \mathrm{yr}$, which is based on the approximate 95-percent confidence interval. The precipitation in 2006 was 18 percent greater than average precipitation from 1960 through 2006, so the mean long-term recharge rate is probably less than $19 \mathrm{in} / \mathrm{yr}$.
Optimized $K_{\max }$ values in model A result in equal transmissivity values parallel to the strike of bedding in both the high and low $T$ zones $\left(1,100 \mathrm{ft}^{2} / \mathrm{d}\right)$. These $K_{\max }$ values are both within the approximate 95-percent individual confidence intervals associated with model B. Optimized $K_{\max }$ values for the two $T$ zones in model B are nearly identical, but the corresponding transmissivity values (assuming $T=K b$ ) are slightly higher in the high $T$ zone $\left(1,600 \mathrm{ft}^{2} / \mathrm{d}\right)$ than in the low $T$ zone $\left(1,300 \mathrm{ft}^{2} / \mathrm{d}\right)$ where the depth of active flow is thinner. The $K_{\max }: K_{\min }$ anisotropy was estimated to be 58:1 in model A and 410:1 in model B. As a result, the proportion of the total flow that is perpendicular to bedding is less in model B than in model A.

Additional nonlinear regressions were conducted using model B to assess the effects of alternative distributions of $T$ and specified $K_{\max }: K_{\min }$ anisotropy ratios. The first regression employed a continuous transmissivity distribution based on kriged $\log T$ values from aquifer test data. The estimated $K_{\max }$ values using nonlinear regression techniques were 60 percent greater than those estimated with model B but preserved the nearly three-fold difference between the high and low $T$ zones observed in aquifer tests. The average recharge rate estimated using regression is $36 \mathrm{in} / \mathrm{yr}$, and the model error is 27 percent greater than the model B error, indicating a poor model fit. The second regression estimated $T$ for the four bedrock zones (fig. 7) delineated by Heisig (2010) and produced parameter estimates that were nearly identical to those produced by model B. Together, these results indicate that a nearly uniform 
Table 5. Parameter values in alternative models of regional groundwater flow specified or estimated through nonlinear regression.

[Optimized values are shaded. $\mathrm{ft} / \mathrm{d}$, feet per day; $\mathrm{ft}$, feet; in/yr, inches per year; $T$, transmissivity; $\mathrm{ft}^{-1}$, inverse feet]

\begin{tabular}{cllll}
\hline & \multicolumn{2}{c}{ MODEL } & \\
\hline Parameter & A & B & Approximate individe \\
\cline { 2 - 3 } & Value & Value & \\
confidence inten & & & $2.7-6.0$ \\
Maximum hydraulic conductivity, ft/d: & 2.8 & 4 & $2.9-6.2$
\end{tabular}

Anisotropy ratios:

Maximum:medium ${ }^{\mathrm{a}}$

Maximum:minimum ${ }^{\mathrm{b}}$

Power function:

Decay factor, $\mathrm{ft}^{-1}$

Depth threshold, $\mathrm{ft}$

$$
\begin{aligned}
& \text { Zone A } \\
& \text { Zone B } \\
& \text { Zone C } \\
& \text { Zone D }
\end{aligned}
$$

Recharge:

Maximum rate, in/yr

Thickness factor, $\mathrm{ft}^{-1}$

Average rate, in $/ \mathrm{yr}$

$\begin{array}{rr}1 & 1 \\ 58 & 410\end{array}$

$180-940$

Streambed hydraulic conductivity, $\mathrm{ft} / \mathrm{d}$ :

$\begin{array}{lcc}\text { Alluvial sediments } & 300 & 300 \\ \text { Till } & 10 & 10 \\ \text { Lacustrine sediments } & 2 & 2 \\ \text { andard error, ft } & \mathbf{1 2 . 6} & \mathbf{1 2 . 2}\end{array}$

${ }^{a}$ Strike-parallel to dip-parallel conductivity.

${ }^{\mathrm{b}}$ Strike-parallel to cross-bedding conductivity.

${ }^{\mathrm{c}}$ Computed from simulated water budget.

${ }^{\mathrm{d}}$ Not meaningful, coefficient of variation $=100$ percent. 
distribution of transmissivity yields the best fit to the waterlevel data obtained from 2005 to 2007. In the third regression, the anisotropy ratio was fixed at the value obtained from the simulation of Spring Valley water-level recovery test (70:1). In comparison to those used with model $\mathrm{B}$, the $K_{\max }$ values estimated in this regression are 34 percent lower, the average recharge rate is similar (18 in/yr), and model error is 13 percent greater. In the fourth regression, the bedrock aquifer was specified as isotropic (anisotropy ratio 1:1). This regression produced the best model fit with a 15 percent reduction in error, with $K_{\max }$ values 70 percent less than in model B and a comparable average recharge rate (19 in/yr). Results from the Spring Valley water-level recovery test and borehole geophysical logs indicate that the bedrock aquifer is not isotropic, however. All of the water-level data used in model calibration were measured in wells that are open boreholes. Each measurement is a composite of hydraulic heads in fracture zones intersected by each well (weighted by the transmissivity of each zone) and likely does not reflect the effects of the dipping bedrock structure, as represented by the models. The model calibration could be improved if a better observation set based on water levels measured in piezometers open to isolated water-bearing zones were available.

\section{Comparison of Transmissivity Estimates}

Comparison of $K_{\max }$ values estimated through model calibration with transmissivity values estimated from aquifer tests in the field is not straightforward. Model-derived $K$ values are converted to transmissivity $(T)$ using knowledge of the saturated thickness $b(T=K b)$. Saturated thickness is commonly assigned to the length of open boreholes in the analysis of aquifer tests and to the depth of active flow in the analysis of model results. For anisotropic aquifers, comparison of modelderived $T$ values with those obtained using analytical methods (such as the Cooper-Jacob semi-logarithmic method) poses an additional complication because, for the latter, it is assumed that either isotropic material or a few limited configurations of horizontally bedded anisotropic material are present. In contrast, the transmissivity of inclined fractured bedrock in the Newark basin aquifer was represented in model simulations with a 3D hydraulic conductivity tensor.

For the case of flow to a fully penetrating pumped well (borehole length equivalent to the saturated aquifer thickness), $T$ values estimated through simulation and by analytical methods for isotropic material are similar. The model-derived and analytically-derived $T$ values for the Spring Valley water-level recovery test are 3,100 and 2,900 $\mathrm{ft}^{2} / \mathrm{d}$, respectively, assuming a saturated thickness of $330 \mathrm{ft}$. The two values are similar because a fully penetrating well in fractured rock with a shallow dip induces two-dimensional radial flow that is parallel to bedding and well approximated by isotropic flow (fig. 30A). Results derived from simulations of a $1,770 \times 1,770 \times 330 \mathrm{ft}^{3}$ block of anisotropic material with hydraulic properties equivalent to those estimated for the Newark basin aquifer $\left(K_{\max }=4.5 \mathrm{ft} / \mathrm{d}, K_{\max }: K_{\min }=410: 1\right)$ illustrate that differences in predicted flows to production wells in isotropic and anisotropic materials become significant, however, when the dip of bedding is steep $\left(30^{\circ}\right.$, fig. $\left.30 \mathrm{~A}\right)$ or if the well is partially penetrating (fig. 30B). In both these cases, more of the water pumped from the well flows through water-bearing zones that do not intersect the open interval. As a result, the component of flow perpendicular to bedding increases, and the effect of anisotropy becomes important.

Estimated $T$ values derived from regional simulations can be very different for isotropic and anisotropic aquifers. The estimated $T$ values represent the bulk transmissivity of a volume of rock that encompasses both highly transmissive water-bearing zones and the network of less transmissive fractures that connect them (Shapiro and others, 2007). The bulk transmissivity is the coefficient of proportionality between the hydraulic gradient and the volumetric flow rate through a volume of the rock. In the case of an inclined anisotropic aquifer, the bulk transmissivity is less than the transmissivity parallel to bedding (corresponding to $K_{\max }$ ) because regional flow paths are both parallel and perpendicular to bedding. Bulk $T$ values for isotropic and anisotropic aquifers can be compared by computing the volumetric flow rate through each system under a specified hydraulic gradient. This computation was performed for the Newark basin aquifer by replacing the top model boundaries (recharge and drains) with specified heads computed using model B (fig. 26) and then calculating groundwater discharge to the top model boundary through steady-state simulation. This process was repeated for an isotropic aquifer by specifying the anisotropy ratio as $1: 1$.

The $K_{\max }$ value of the isotropic aquifer was then adjusted to produce a volumetric flow rate equivalent to that through the anisotropic aquifer. The equivalent bulk $K$ value of the isotropic aquifer was about 16 percent of $K_{\max }$ in the anisotropic aquifer, corresponding to a bulk $T$ value of $290 \mathrm{ft}^{2} / \mathrm{d}$. This value is less than 75 percent of the values computed from analysis of aquifer tests, assuming isotropic conditions (300 to $1,000 \mathrm{ft}^{2} / \mathrm{d}$; fig. 14) and indicates that regional flow through the Newark basin aquifer is controlled by networks of waterbearing zones that are overall less transmissive than those surrounding the pumped well fields.

In general, the bulk $T$ value of an inclined anisotropic aquifer depends on (1) the angle between the direction of the hydraulic gradient and the strike of bedding $(\theta)$ and (2) the declination of bedding $(\varphi)$. This relation is demonstrated by simulation results, which are based on the same block of anisotropic material described above. In these simulations, inflow and outflow head boundaries were specified at the top edges of the block to produce a uniform hydraulic gradient (fig. 31A). The orientation of the strike of bedding (direction of $K_{\max }$ ) was varied between $0^{\circ}$ and $90^{\circ}$, relative to the direction of the hydraulic gradient, and the flow through the block was simulated. Two bedding declination angles were considered, $10^{\circ}$ and $30^{\circ}$. Simulation results are presented as percentages of flow through an equivalent block of isotropic material (fig. 31B). Flow through the block of anisotropic material inclined at $10^{\circ}$ decreased from 28 to 5 percent as 
A Fully penetrating well

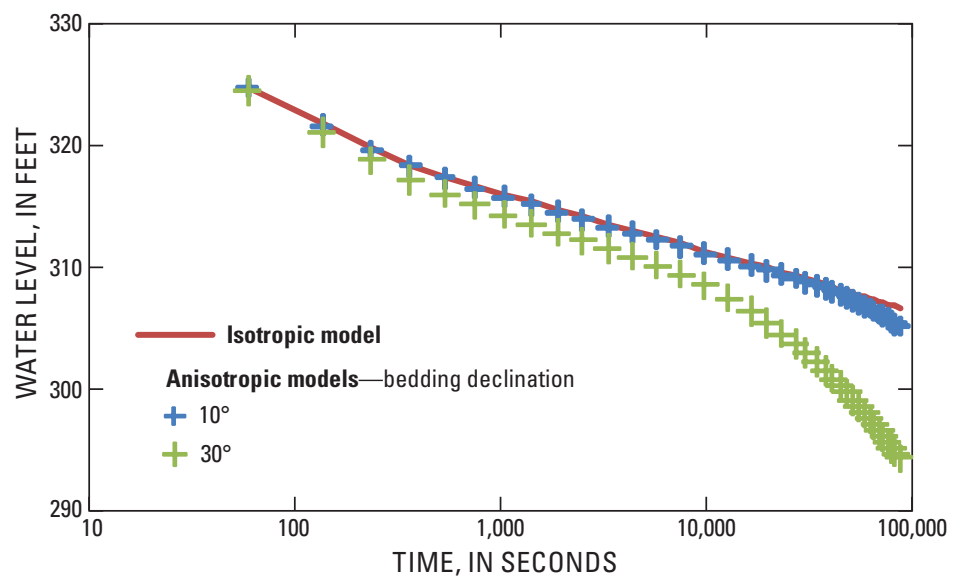

B Partially penetrating well

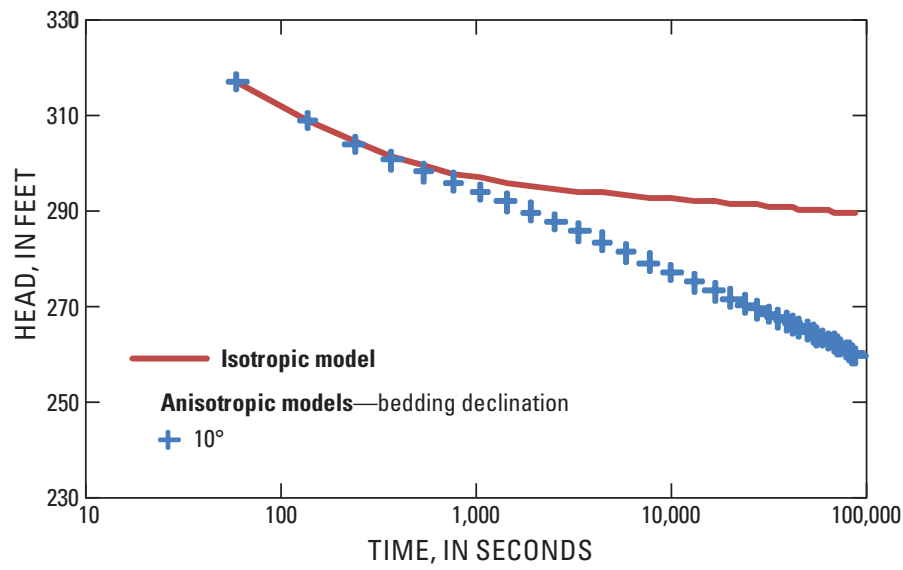

Figure 30. Simulated change in head produced by wells pumping from isotropic and anisotropic materials $(A)$ fully penetrating well, and $(B)$ partially penetrating well. 


\section{A Simulated head distribution}

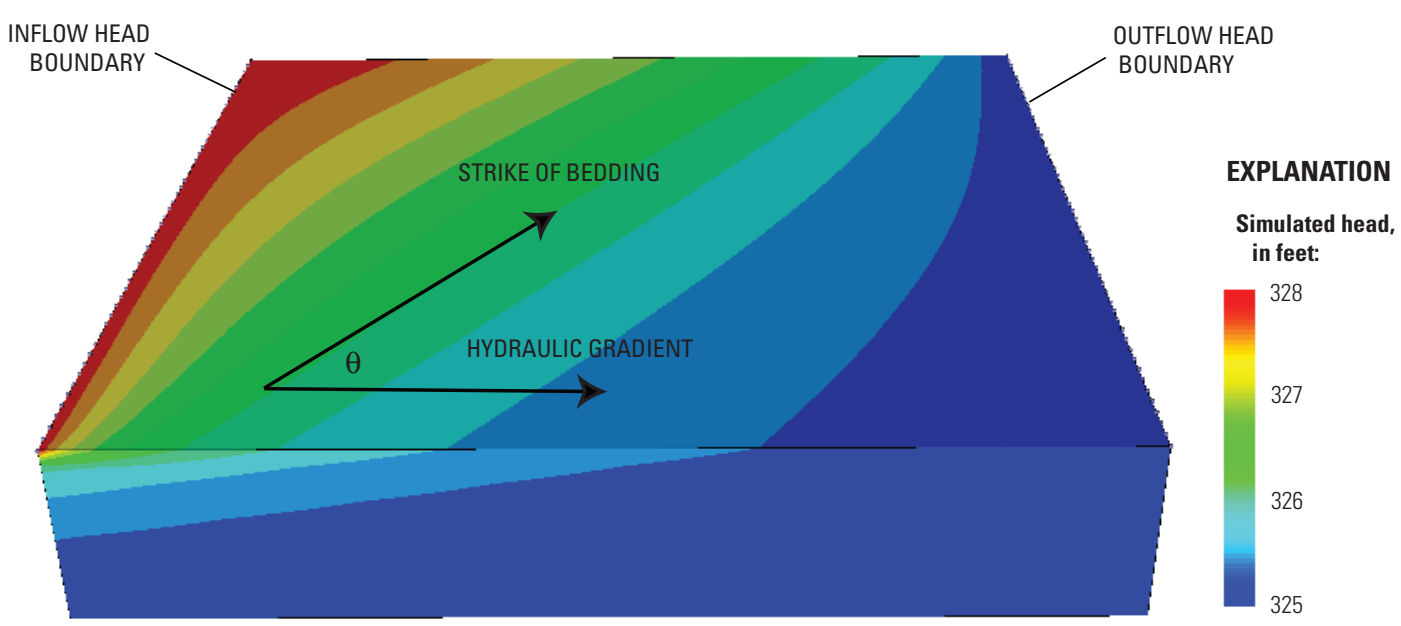

$B$ Simulated flow through block

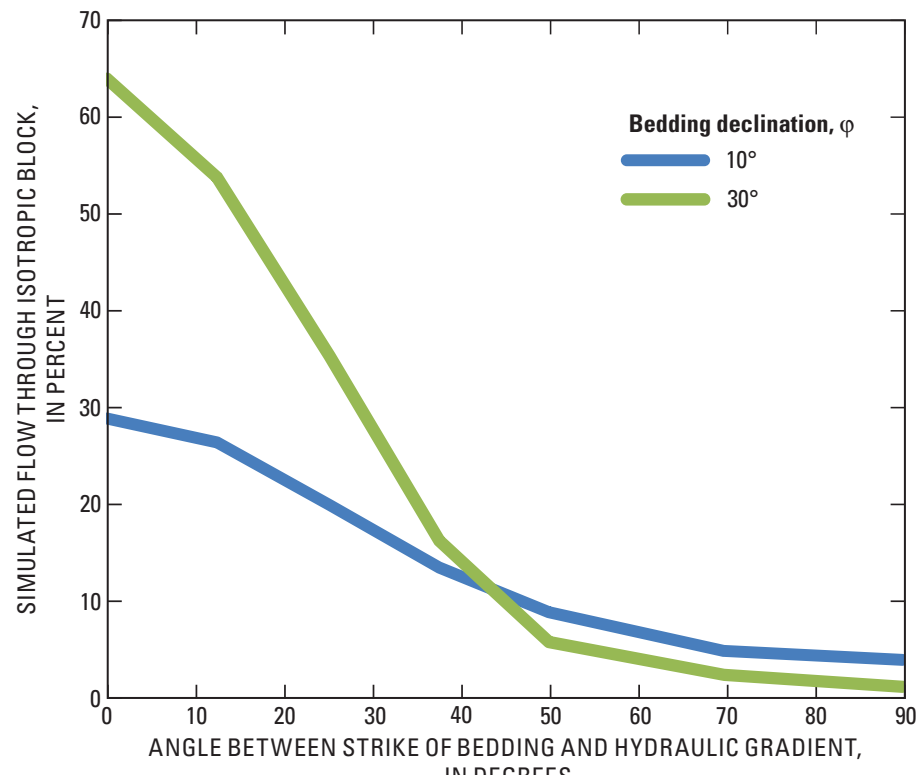

Figure 31. Effect of angle $(\theta)$ between strike of bedding and hydraulic gradient and bedding declination $(\varphi)$ on flow through a block of inclined anisotropic material $(A)$ simulated head distribution with $\theta=50^{\circ}$ and $\varphi=10^{\circ}$, and $(B)$ simulated flow through block. 
the angle $\theta$ between the strike of bedding and the hydraulic gradient increased from $0^{\circ}$ and $90^{\circ}$. The simulated decrease in flow is larger (60 to 2 percent) for the steeper declination angle $\left(\varphi=30^{\circ}\right)$. The flow rate is larger for the steeper angle because water penetrated deeper into the block and effectively increased the thickness of active flow. These results can be interpreted as the decrease in equivalent bulk $T$, which is proportional to the simulated flow, corresponding to different angles of $\theta$ and $\varphi$.

\section{Model Applications}

Conservative solute-transport simulations were conducted with alternative models A and B to estimate the groundwater age distribution in the flow system of groundwater of various ages and to delineate capture zones of production wells. Longitudinal and transverse dispersivities in the transport simulations were specified as $1,000 \mathrm{ft}$ and $100 \mathrm{ft}$, respectively, to facilitate convergence of the numerical solution and reduce numerical oscillations.

\section{Groundwater Age}

Groundwater age was computed through steady-state simulations in which the solute concentration was interpreted as age. The initial solute concentrations (age) in groundwater and recharge were specified as zero, and a zero-order (linear increase in time) production of solute of unit strength (1 concentration unit/year) was used to represent aging. The simulated ages are inversely proportional to the value of effective porosity specified in the models. An effective porosity value of $2 \times 10^{-2}$ was estimated by comparing the simulated age of groundwater withdrawn from 12 well fields to ages of water from the well fields calculated on the basis of tritium/helium $\left({ }^{3} \mathrm{H} /{ }^{3} \mathrm{He}\right.$ ) age dating (Aeschbach-Hertig and others, 1998). Groundwater ages simulated with models A and $\mathrm{B}$ compare favorably with the ${ }^{3} \mathrm{H} /{ }^{3} \mathrm{He}$ ages (fig. 32). The estimate of effective porosity compares favorably with the range of values $\left(1.7 \times 10^{-2}\right.$ to $\left.2.2 \times 10^{-2}\right)$ estimated by Heisig (2010) on the basis of water-table fluctuations measured in well Ro647 in the Newark basin aquifer. This value is useful when considering movement of environmental tracers on a

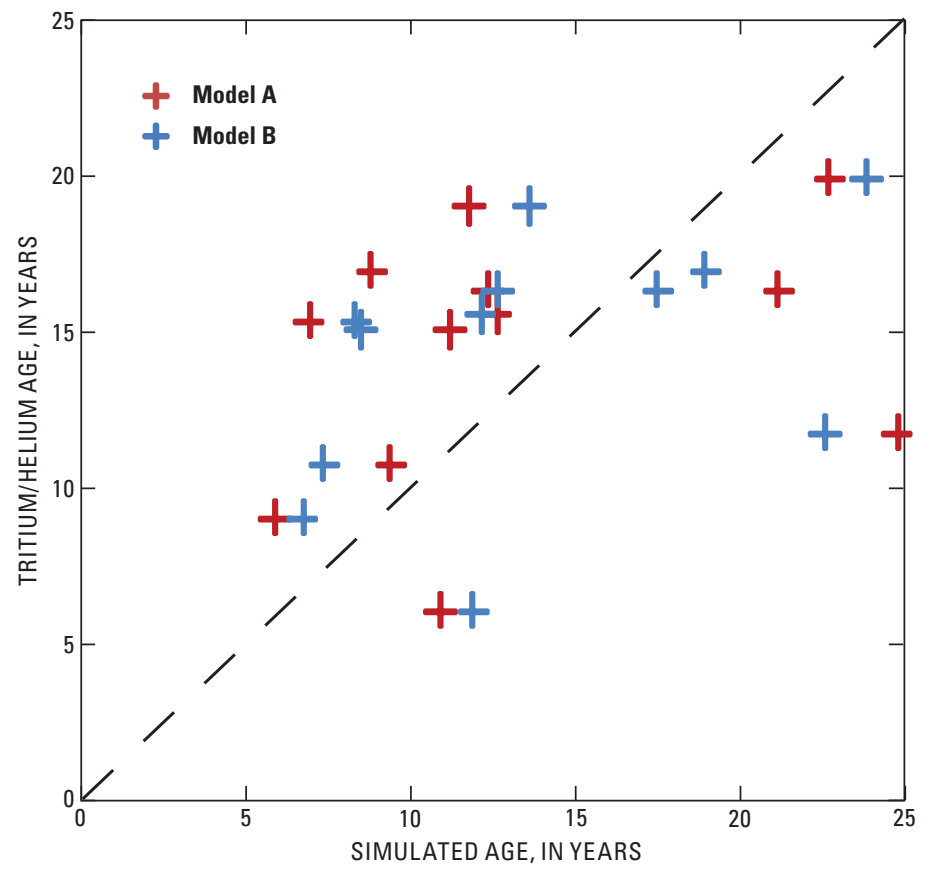

Figure 32. Comparison of simulated ages of groundwater withdrawn from production wells with those estimated on the basis of tritium/helium age dating. 


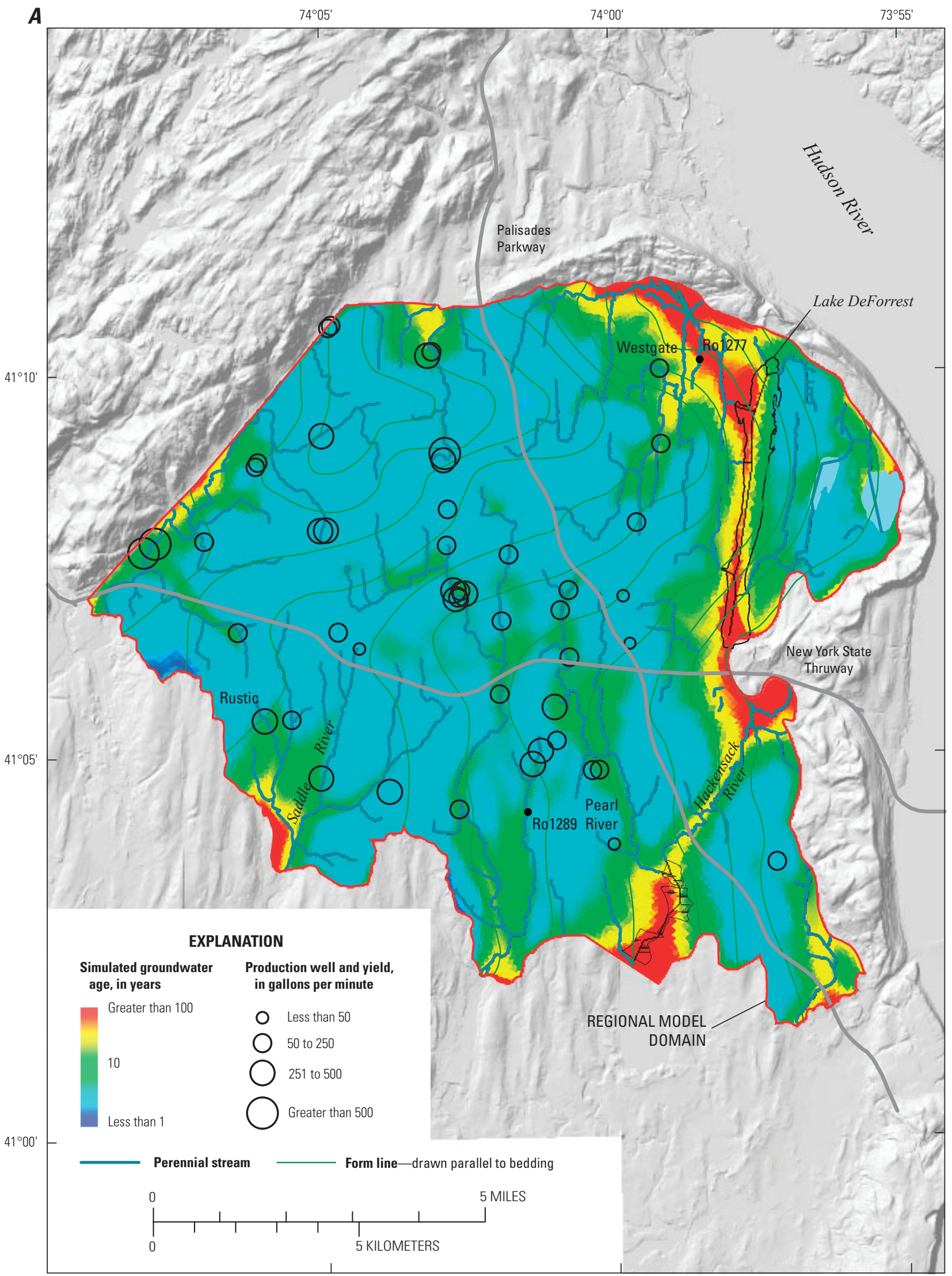

Base from Rockland County Planning Department

Figure 33. Spatial distribution of groundwater age in Newark basin in Rockland County, NY, as simulated using $(A)$ model $A$, and $(B)$ model $B$. 


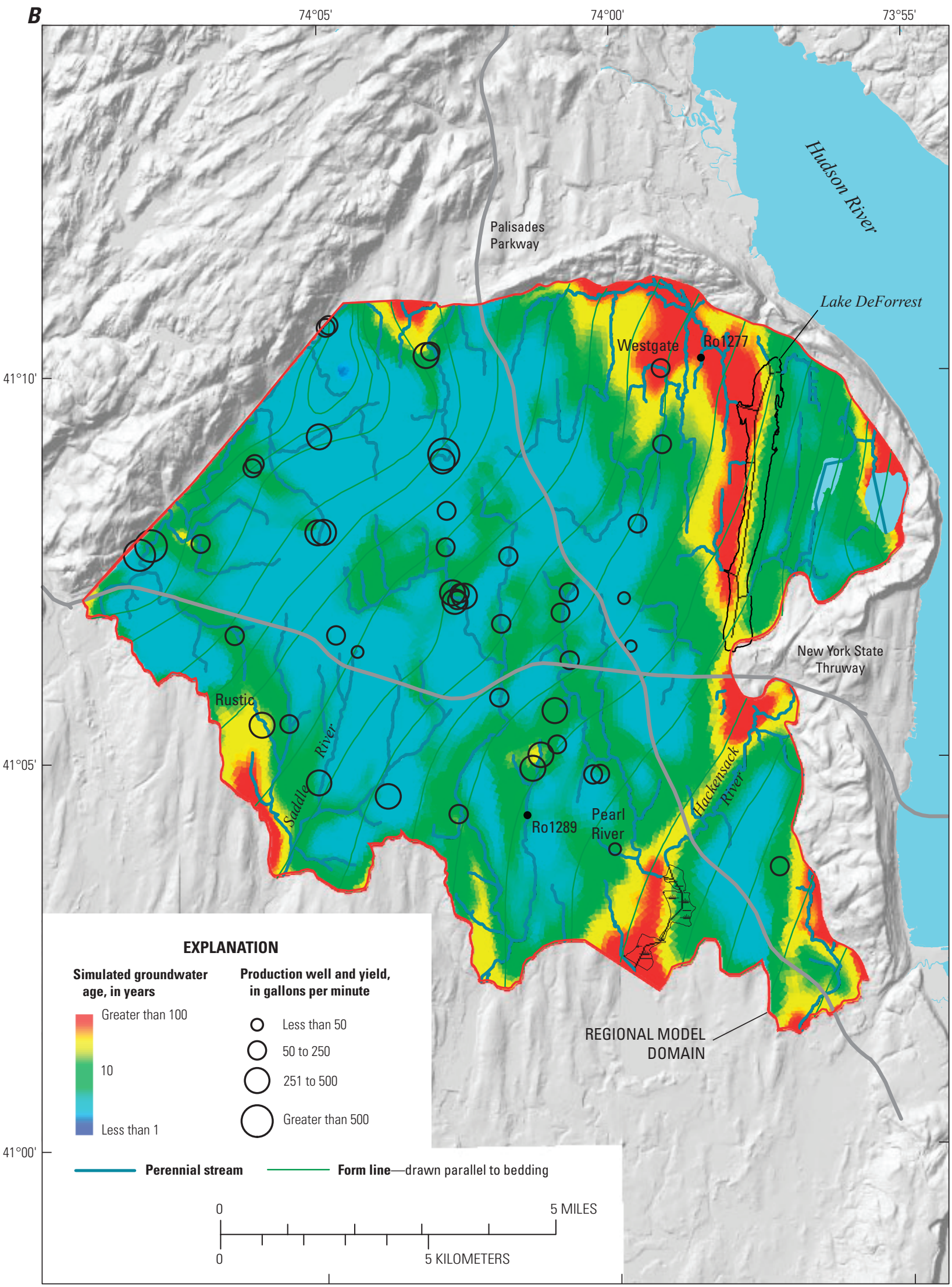

Base from Rockland County Planning Department

Figure 33. Spatial distribution of groundwater age in Newark basin in Rockland County, NY, as simulated using $(A)$ model A, and $(B)$ model B-Continued. 
regional scale (miles) but is not necessarily applicable to the prediction of contaminant migration at the local scale (hundreds of feet).

The distributions of simulated groundwater age in models $\mathrm{A}$ and $\mathrm{B}$ are similar and indicate that most groundwater at a depth of $225 \mathrm{ft}$ below the bedrock surface (one-half the assumed thickness of the zone of active flow) is 5 to 20 years old (fig. 33). Simulated ages are youngest (5 years or less) near recharge areas in uplands and oldest (more than 100 years) in lowlands near the Hackensack River and Saddle River. The youngest ages (2 to 3 years) simulated with model A are located in some upland areas and east of the Palisades Parkway near the northern model boundary (fig. 33A). In these areas, the assumed strike of bedding in model A provides shorter paths for groundwater discharge to tributary streams than those in model B.

The median age of water from the 45 well fields simulated using both models is about 12 years, although water older than 100 years was simulated by both models for the Pearl River well and for the Westgate well in model B (fig. 33B). Aeschbach-Hertig and others (1998) note that water from the Westgate well is probably a mixture that contains water older than 50 years, so it cannot be accurately dated from the available data. Groundwater ages simulated with the two models generally differ by less than 2 years at most wells but differ by more than 10 years at 8 of the 45 wells. The standard error in age in model A is 6.6 years, while the standard error in model B is 5.7 years, indicating a slightly better model fit. Both models predicted groundwater ages that were more than twice as old as that estimated for water in observation well Ro1277 (19 years) and less than one-half as old as estimated for water in observation well Ro1289 (23 years). Groundwater ages of water from observation wells could reflect local conditions, however, and may differ from those of water from pumped wells that sample a larger volume of groundwater flow.

\section{Capture Zones of Well Fields}

The 3D capture zones of 30 well fields that tap the Newark basin aquifer with an average withdrawal rate more than $70 \mathrm{gal} / \mathrm{min}$ were delineated through reverse-flow, transient transport simulations using both models A and B. In the reverse-flow simulations, flow was routed through a steadystate simulation in a reverse direction from inflow points at production wells and along streams to discharge points at land surface. The transient transport represented a 10-year period with time steps ranging from 1 to 365 days. Reverseflow simulations track migration of a tracer solute injected at the production wells backwards to discharge points at land surface; the tracking is achieved by multiplying all specified heads and all sources by negative one $(-1)$. This means that production wells become injection wells in the reverse-flow simulation, and recharge rates are specified as negative values. The average withdrawal rates from 1985 through 2005 used in model calibration were specified for each well field. Drain boundaries were modified in reverse-flow simulations to only allow inflow of water from streams. One exception was the Mahwah River that was treated as a head-dependent boundary to represent the potential exchange of water (inflow and outflow) between the river and the underlying outwash aquifer.

This procedure is similar to backward tracking using particles (for example, Zheng and Bennett, 2002) and was used to delineate capture zones to well fields in the Shenandoah Valley, VA (Yager and others, 2008). Simulation of dispersion using reverse-flow simulations results in larger delineated areas than those using particle tracking methods, and the dispersion coefficient represents heterogeneity of hydraulic conductivity in the aquifer that creates uncertainty in the position of the capture zone. Qualitatively, the simulated distribution of concentration of tracer solute presented herein can be interpreted as areas within which water recharging the bedrock aquifer has a 50-percent probability of reaching the well. Water recharging at locations with higher concentrations of tracer solute is more likely to reach the well at the field site than water recharging at locations of lower concentrations.

Plan views of the capture zones delineated using models A and B (fig. 33B) are shown in figure 34. The plan views were delineated by truncating each $3 \mathrm{D}$ capture zone at a depth of $225 \mathrm{ft}$ below the bedrock surface (one-half the assumed thickness of the zone of active flow) and projecting the remaining volume to the piezometric (water-level) surface; the plans are analogous to contributing recharge areas typically delineated by other studies. The resulting plan views are conservative because they depict an area downdip of the wells that is larger than actually intercepted at land surface. Although the capture zones depict recharge areas within a 10-year travel time of the wells, the zones were relatively stable at this point in the simulation and were expanding only slightly. Some delineated capture zones are contiguous in the central part of the model area, so adjacent capture zones are distinguished with different colors.

Capture zones for bedrock wells range from $1.9 \mathrm{mi}^{2}$ for the Spring Valley well field and $1.0 \mathrm{mi}^{2}$ for the pharmaceutical company well field, which have the largest withdrawal rates $(1,300$ and $1,200 \mathrm{gal} / \mathrm{min}$, respectively), to less than $0.04 \mathrm{mi}^{2}$ ( 25 acres) for well fields with the smallest withdrawal rates $(80 \mathrm{gal} / \mathrm{min})$. The combined area of capture zones for all the well fields represented is $13.6 \mathrm{mi}^{2}$ or 16 percent of the model domain. The delineated capture zones for two well fields that produce water from the outwash aquifer underlying the Mahwah River (Catamount and River) are approximate. Although the reverse-flow simulations did account for possible induced infiltration from the river, the outwash aquifer was not the primary focus of the modeling effort, and the model mesh was not designed to provide a high degree of resolution in these areas.

The shapes of the delineated capture zones are generally elongated parallel to the assumed strike of bedding (shown 
by form lines on fig. 34) but are affected by the assumed anisotropy ratio $\left(K_{\max }: K_{\min }\right)$, the simulated potentiometric surfaces, and the drainage network of stream channels, as well as by capture zones of adjacent well fields. Differences in the assumed strike of bedding are reflected by the different shapes of capture zones delineated by models A and B, but the areas of the capture zones are similar. Capture zones generally extend beneath adjacent streams and collect recharge from both sides of the streams. Portions of the capture zones of several well fields lie within the watersheds of Pascack Brook and Nauraushaun Brook (fig. 34A and B). The watersheds of these two brooks account for the largest portions of watershed area overlapped by capture zones, indicating that the reduction of base flow by groundwater withdrawals is greatest for these streams.

Areas affected by groundwater withdrawals were delineated by Heisig (2010) by mapping the range and orientation of hydraulic connections emanating from selected well fields, as measured from water-level changes induced by pumping. The areas affected by groundwater withdrawals (fig. 34B) are generally consistent with the delineated capture zones but are larger for some well fields because areas that are affected by pumping do not necessarily contribute water to the pumped well. In addition, the average withdrawal rates from 1985 through 2005 used to delineate the capture zones are typically lower than the increased rates of pumpage during the summer seasons when the hydraulic connections were measured. This is especially true for the Viola well field where an additional well increased withdrawal rates by about 80 percent from 2001 through 2005. Finally, the capture zones were delineated by a porous-media model, whereas water in the fracturedbedrock aquifer flows through discrete fractures. Actual hydraulic connections along preferential paths within the fracture network could, therefore, extend further than the distances predicted by the model simulations.

The 3D perspective views of the capture zone of the Spring Valley well field delineated by model B are shown in figure 35 . The colors of the capture zone indicate the relative likelihood that water in the capture zone will flow to the well. Simulated flow vectors drawn on the plots are projected onto vertical planes and show the direction and relative magnitude of groundwater flow near the well field. The capture zone extends to the simulated base of active flow in the bedrock aquifer ( $500 \mathrm{ft}$ below the bedrock surface) and conforms to the dip of the bedding. Flow vectors indicate that water flows downdip to the wells from the southeast and updip to the wells from the northwest (fig. 35A). Flow from the northeast and southwest parallels the assumed strike of bedding and is generally horizontal (fig. 35B).

Uncertainty in the delineation of capture zones was assessed by changing specified aquifer properties and boundary conditions in three reverse-flow simulations conducted using model $\mathrm{B}$. In the first simulation, the $K_{\max }: K_{\min }$ anisotropy ratio was fixed at the lower value (70:1) obtained from the simulation of the Spring Valley recovery test. The capture zones delineated with this simulation (fig. 36A) are similar to those shown previously (fig. 34B) but are less elongated parallel to bedding and more affected by the potentiometric surface. In the second simulation the recharge rate was specified as $11 \mathrm{in} / \mathrm{yr}$ estimated for 1966, the lowest rate estimated for the period 1960 through 2006 and about 60 percent of the calibrated rate estimated for 2006. These delineated capture zones (fig. 36B) are only slightly larger than those originally delineated with model B (fig. 34B), but the combined area of capture zones for all the well fields was $18.3 \mathrm{mi}^{2}$, or 35 percent larger than originally estimated by model B. Finally, a third simulation was conducted in which the largest annual withdrawal rates from 1975 were specified (30 percent larger than the average rate from 1985 through 2005). Some of the delineated capture zones in this simulation are larger than those delineated with model B (such as the Rustic well field), and the combined capture-zone area was $19 \mathrm{mi}^{2}$ or 40 percent larger. In summary, none of the changes considered had a marked effect on the delineated area that contributes recharge to wells.

\section{Transient Simulation of Changes in Recharge and Groundwater Withdrawals}

Transient simulations were conducted using model B to assess the effect of changes in recharge and groundwater withdrawals on water levels and discharges to streams. Two simulation periods were considered: a 47 -year period that represented annual changes from January 1960 through December 2006 and a 3-year period that represented monthly changes from January 2000 through December 2002. A steady-state simulation that used recharge and withdrawal rates estimated for 1960 provided the initial head distribution for the 47-year simulation, which in turn provided the initial head distribution in January 2000 for the 3-year simulation. Values of aquifer properties that were specified in the transient simulations included those estimated through calibration with model B (table 5) and the effective porosity value (0.02) estimated using simulations of groundwater age. The sensitivity of the simulated water levels and discharges was assessed by considering an order-of-magnitude range of values of specific storage $S_{s}$ with the lowest value $7.6 \times 10^{-6} \mathrm{ft}^{-1}$ equal to that estimated through transient simulation of the Spring Valley recovery test.

The Newark basin aquifer was initially assumed to remain confined during the transient simulations, so changes in the volume of water stored in the aquifer and the water levels were determined by the value of specific storage. About one-half the area of the aquifer is unconfined, however, as evidenced by measured water levels that are below the bedrock surface. In these unconfined areas, the volume of stored water is determined by the value of specific yield $\left(S_{y}\right)$, which is assumed to be equivalent to the estimated effective porosity (0.02). In unconfined aquifers the volume of water released from unsaturated storage per unit area under a unit 


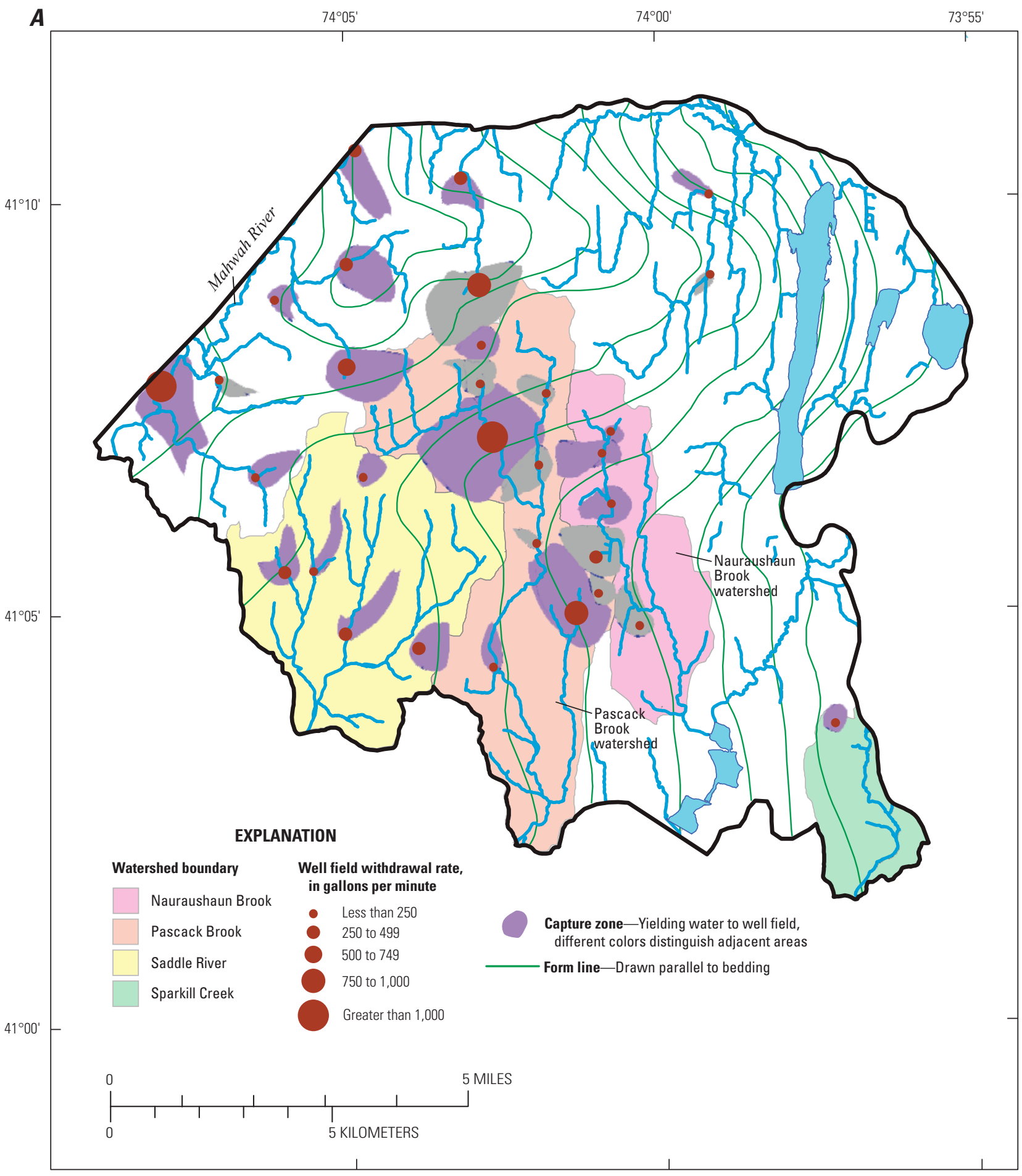

Base from Rockland County Planning Department

Figure 34. Plan views of capture zones of well fields in Rockland County, NY, delineated after 10-year travel time with (A) model $A$, and $(B)$ model $B$. 


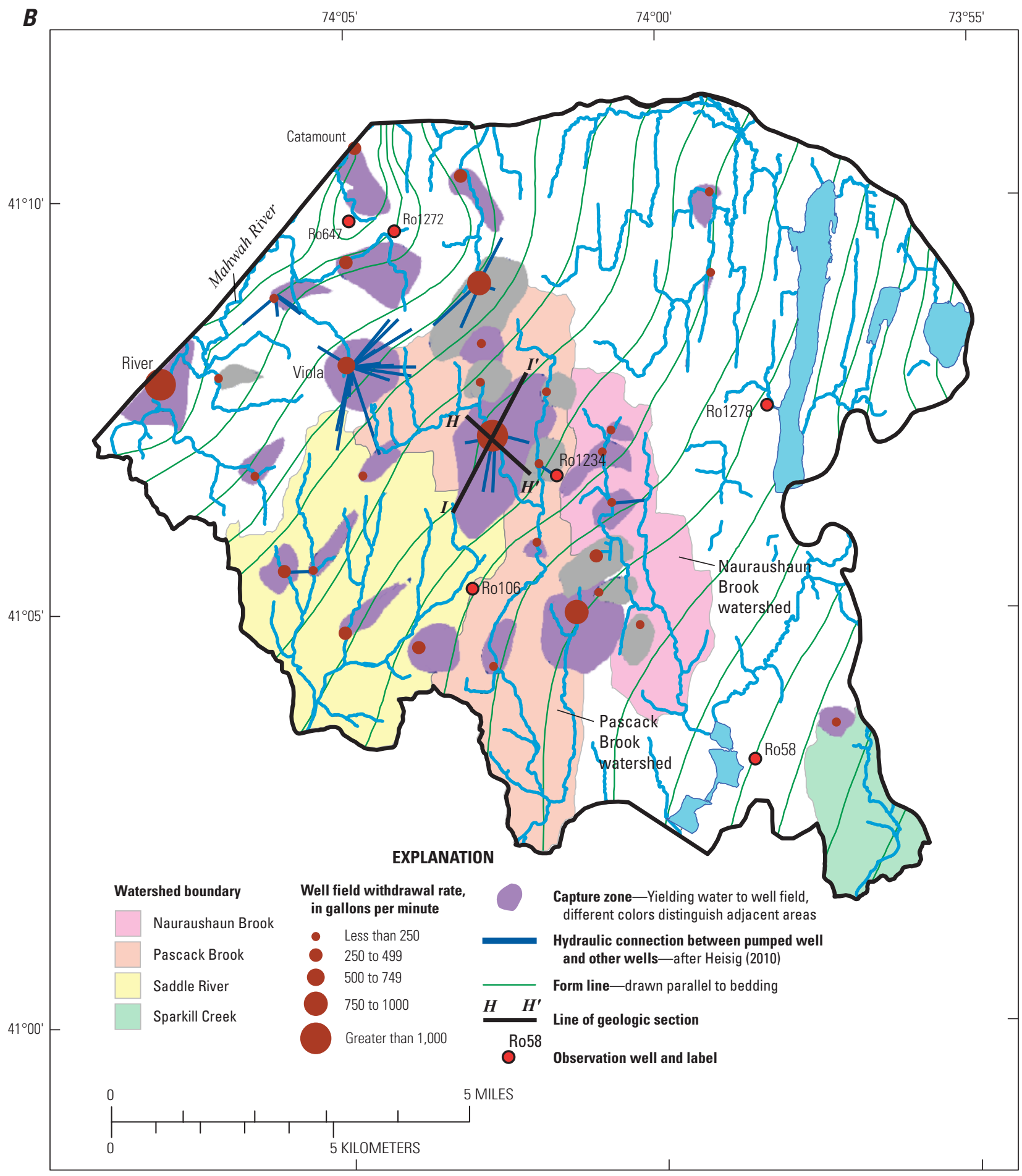

Base from Rockland County Planning Department

Figure 34. Plan views of capture zones of well fields in Rockland County, NY, delineated after 10-year travel time with $(A)$ model $\mathrm{A}$, and $(B)$ model $\mathrm{B}$-Continued. 


\section{$A$ View toward northeast}
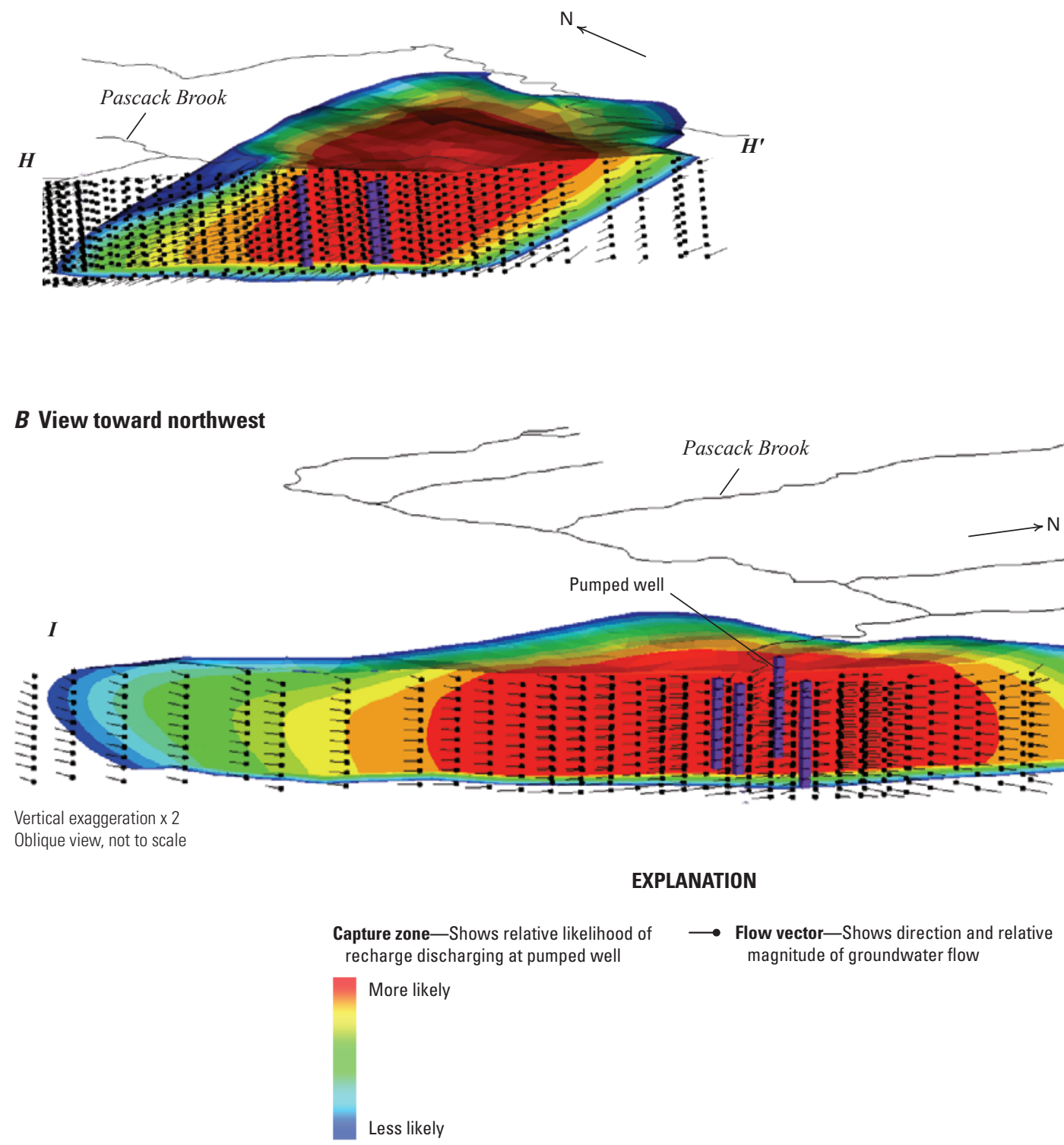

Figure 35. Three-dimensional perspective views of capture zones for Spring Valley well field in Rockland County, NY, delineated using model B: $(A)$ view to northeast parallel to strike of bedding, and $(B)$ view to northwest perpendicular to strike of bedding. Vertical slices along sections $\mathrm{H}-\mathrm{H}^{\prime}$ and $\mathrm{I}-\mathrm{I}$ '. Locations of sections shown in figure 34B. Rounded tips of vectors denote direction and relative magnitude of groundwater flow. 


\section{$A \mathrm{~K}_{\max }: \mathrm{K}_{\min }$ anisotropy 70:1}

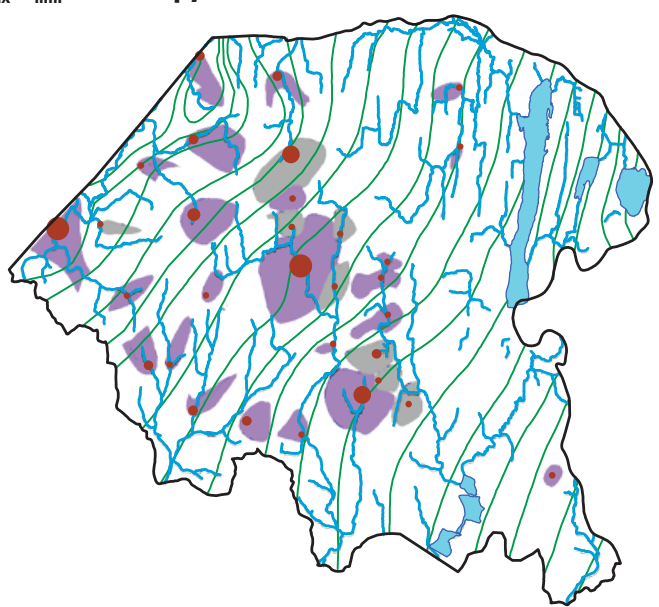

$B$ Recharge reduced 40 percent

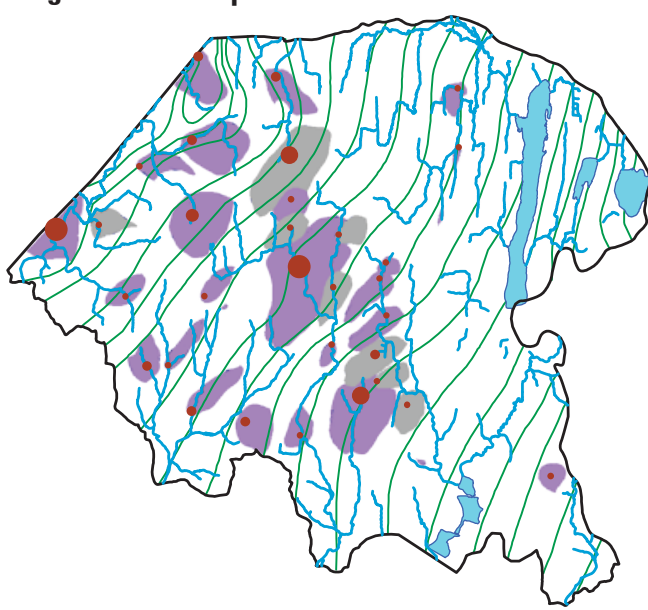

C 1975 groundwater withdrawals

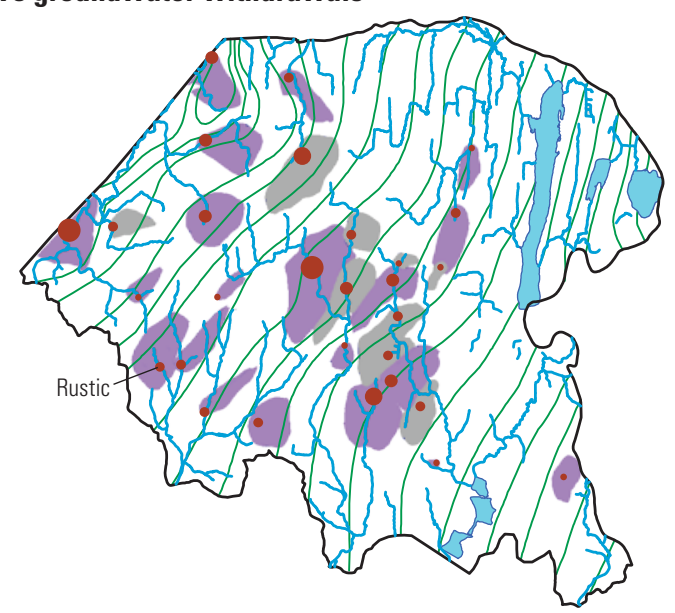

\section{EXPLANATION}

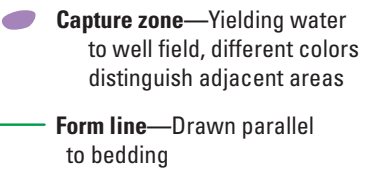

Well field-groundwater withdrawal

rate, in gallons per minute

- Less than 250

- 250 to 499

- 500 to 749

750 to 1,000

Greater than 1,000

Figure 36. Sensitivity of capture-zone delineation to changes in model B:

(A) $K_{\max }: K_{\min }$ anisotropy reduced to 70:1 (ratio parallel to bedding: perpendicular to bedding), $(B)$ recharge rate reduced by 40 percent (1966 rate), and $(C)$ withdrawal rates increased by 30 percent (1975 rates). 
decline in hydraulic head equals $S_{\gamma}$. An equivalent volume of water would be released from a saturated storage in a confined aquifer if

$$
S_{\mathrm{s}} b=S_{y}
$$

where $b$ is the saturated thickness of the aquifer.

A specific storage value of $4.0 \times 10^{-5} \mathrm{ft}^{-1}=0.02 / 500 \mathrm{ft}$ was, therefore, used to represent unsaturated storage in the confined transient simulations. This value is about five times the value estimated from the Spring Valley recovery test simulation.

Alternatively, unconfined transient simulations that incorporate both storage values also were used to represent variable saturation throughout the aquifer. These simulations were more difficult to conduct because representation of variably saturated conditions adds nonlinearity to the solution of groundwater flow because (1) in the saturated zone, transmissivity is a function of hydraulic head and (2) in the unsaturated zone, hydraulic conductivity is a function of saturation, which is, in turn, a function of pressure (tension). Relations (characteristic curves) are specified for the unsaturated zone that relate hydraulic conductivity to saturation, and saturation to pressure (Voss and Provost, 2002). Unconfined transient simulations were conducted for both the 47-year and 3-year periods to indicate qualitatively the effect of variable saturation on simulated water levels and discharges. The simplified (linear) characteristic curves of properties specified for the Newark basin aquifer were based on laboratory values reported for glass beads (Tindall and Kunkel, 1999) (table 6) and caused rapid changes in storage in areas that were variably saturated. The top $50-\mathrm{ft}$ model layer was replaced by five 10 - $\mathrm{ft}$ layers in the simulations for an unconfined aquifer to better represent changes in saturation within the variably saturated zone in response to changes in recharge and groundwater withdrawals.

Table 6. Values of unsaturated flow properties specified in unconfined transient simulations.

\begin{tabular}{lc}
\hline \multicolumn{1}{c}{ Property } & Value \\
\hline Residual saturation, percent & 0.085 \\
Air entry pressure, feet & -2 \\
Residual saturation pressure, feet & -330 \\
Relative permeability, percent & 0.1 \\
\hline
\end{tabular}

\section{Seasonal Transient Simulation: 2000 through 2003}

The 3-year transient simulation was divided into 36 monthly periods to reflect seasonal changes in groundwater withdrawals and recharge. Monthly withdrawals were based on reported rates for 44 well fields that provide water for public and industrial supplies. Monthly recharge was estimated by apportioning annual recharge using a monthly distribution computed by Heisig (2010, fig. 56) on the basis of groundwater levels measured from 1998 through 2007 in a monitoring well completed in an outwash aquifer in Morris County, New Jersey, 20 mi southwest of Rockland County. Simulated water levels were compared with those measured in two observation wells in the Newark basin aquifer in Rockland County (wells Ro1272 and 1278, fig. 34B). Simulated hydrographs also were prepared at four other well locations for which data were not available for the period simulated to assess the potential range of water-level fluctuations in these areas (fig. 37).

The simulated hydrographs are arranged in figure 37 by altitude, with the two wells located in lowlands (Ro58 and Ro1278) at the bottom and the two wells located in uplands (Ro647 and Ro1272) at the top. All six hydrographs are shown with the same scale to facilitate comparison; monthly recharge is included on all plots and referenced on the right axis. Results of four simulations are shown; three simulations represented different values of $S_{s}$ : (1) $7.6 \times 10^{-6} \mathrm{ft}^{-1}$ from the simulation of the Spring Valley recovery test, (2) $4.0 \times 10^{-5} \mathrm{ft}^{-1}$ calculated with eq. 5 , and (3) $7.6 \times 10^{-5} \mathrm{ft}^{-1}$, one order of magnitude greater than the smallest value considered. The fourth simulation used the smallest value of $S_{s}$ but also represented variably saturated flow so that changes in storage in unsaturated areas were computed using $S_{y}(0.02)$.

The simulated hydrographs reflect monthly changes in recharge, which ranged from 0.6 to 2.9 inches per month during the simulated period. Simulated water levels were highest during spring and lowest during the summer, and water levels were higher in 2002 as a result of relatively high recharge during the spring. Upland wells display the most water-level fluctuation (fig. 37A and B), and lowland wells display the least (fig. 37E and F). The simulated ranges in water levels are sensitive to the value of specific storage. The ranges of simulated water levels computed with the smallest $S_{s}$ value vary from 10 to $20 \mathrm{ft}$ in lowlands and from 80 to $90 \mathrm{ft}$ in uplands. Water-level fluctuations computed with the largest $S_{s}$ value were about $3 \mathrm{ft}$ and $20 \mathrm{ft}$, respectively. For comparison, waterlevel fluctuations measured in the lowland and upland wells were $7 \mathrm{ft}$ and $13 \mathrm{ft}$, respectively. Representation of variably saturated flow with the smallest $S_{s}$ value resulted in less waterlevel fluctuation, from 10 to $16 \mathrm{ft}$ in lowlands and from 40 to $47 \mathrm{ft}$ in uplands. The $S_{s}$ value probably varies by location in the Newark basin aquifer but is larger than the value estimated from the Spring Valley water-level recovery test because the simulation of the variably saturated aquifer with the smallest $S_{s}$ value predicted higher water-level fluctuations than were measured. Additional simulations of a variably saturated 


\section{A Ro647}

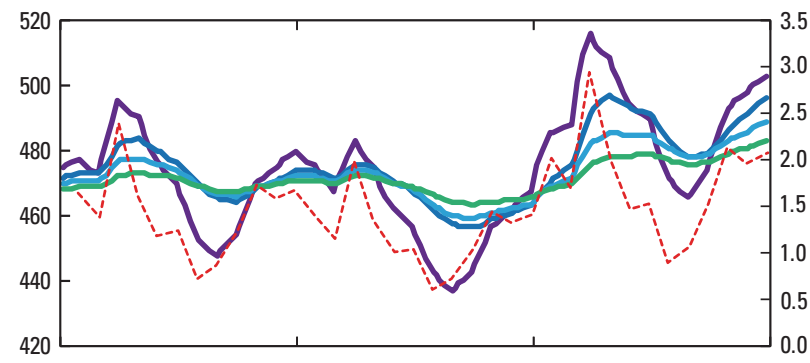

岃

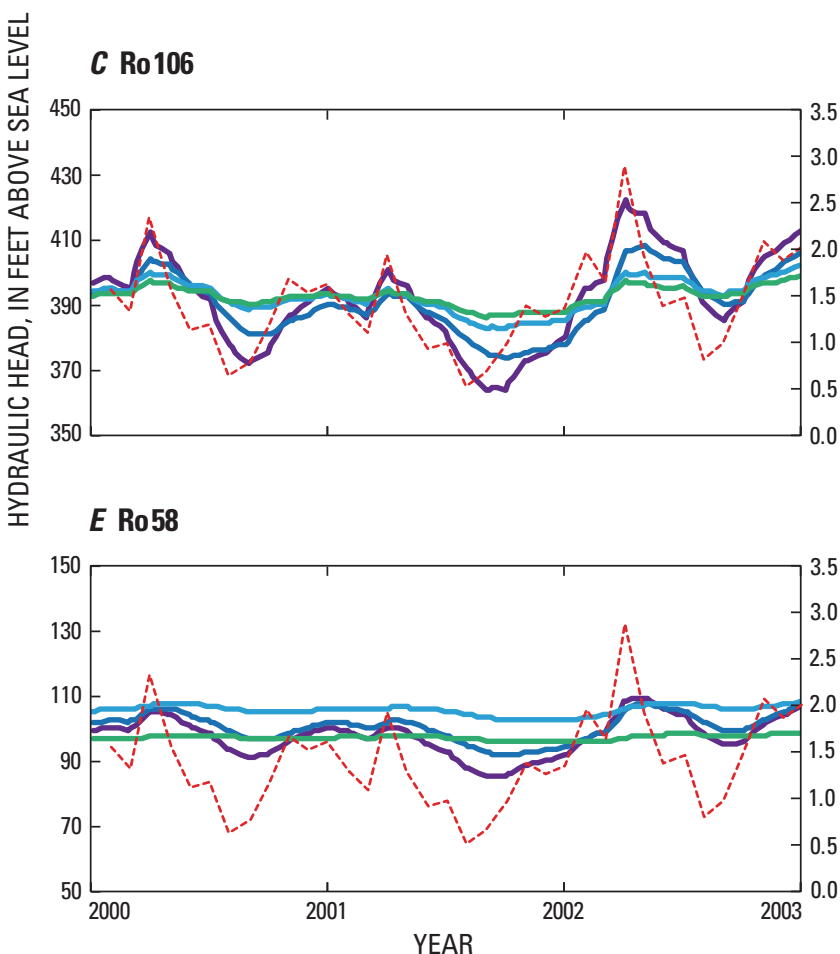

B Ro1272
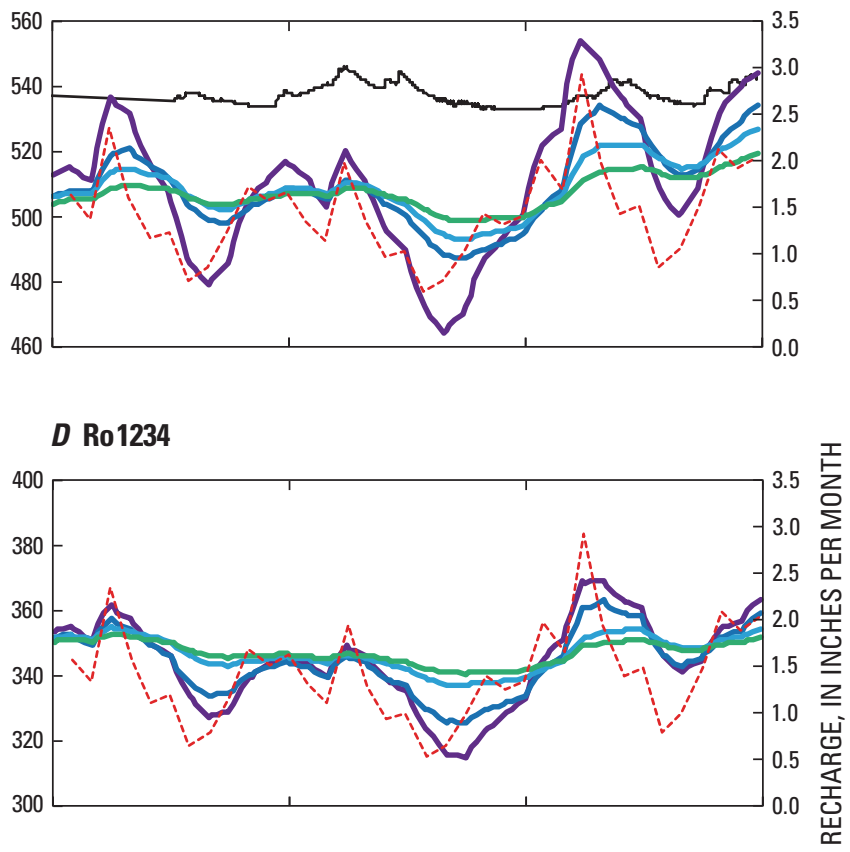

F Ro 1278

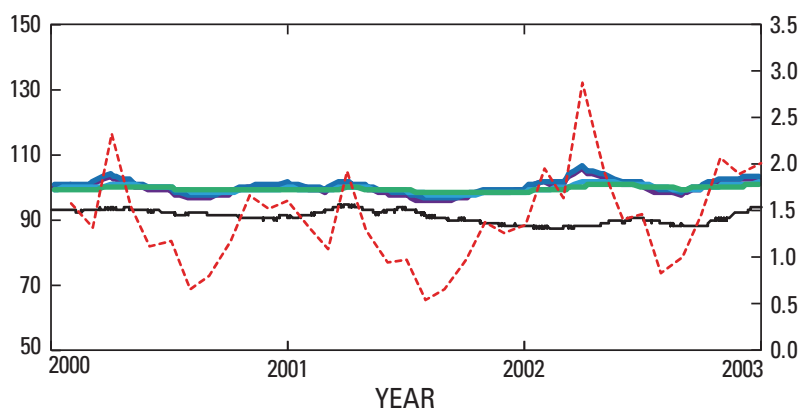

\section{EXPLANATION}

Water-level hydrograph, in feet above datum

Measured

Simulation and value of specific storage $\left(\boldsymbol{S}_{\mathrm{s}}\right)$

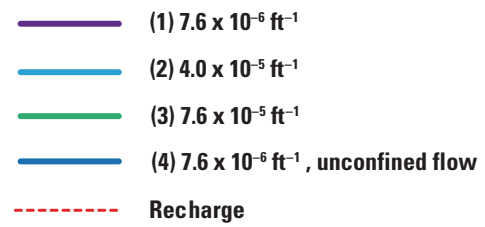

Figure 37. Water-level hydrographs simulated using model B with monthly distribution of recharge and groundwater withdrawals, 2000 through 2003: $(A)$ well Ro647, $(B)$ well Ro1272, $(C)$ well Ro106, $(D)$ well Ro1234, $(E)$ well Ro58, and $(F)$ well Ro1278. Well locations in figure 34B. 
aquifer could be conducted with other $S_{s}$ values, but those simulations were not conducted because of limited data.

Simulated discharges to streams (base flow) are also sensitive to the assumed $S_{s}$ value and largely reflect changes in monthly recharge (fig. 38A). Simulated monthly base flows range from 44 to $160 \mathrm{ft}^{3} / \mathrm{s}$ with the smallest $S_{s}$ value and from 67 to $104 \mathrm{ft}^{3} / \mathrm{s}$ with the largest $S_{s}$ value. Groundwater withdrawals ranged from 16 to $30 \mathrm{ft}^{3} / \mathrm{s}$ during the simulated period; withdrawals are inversely correlated to recharge because withdrawal rates are greater in the summer when recharge is lower and lower in the spring when there is more recharge. Simulated mean annual base flow is about $90 \mathrm{ft}^{3} / \mathrm{s}$ for all simulations, which is about four times the mean groundwaterwithdrawal rate.

\section{Historical Transient Simulation: 1960 through 2006}

The 47-year transient simulation was divided into annual periods to reflect historical changes in groundwater withdrawals and recharge. Annual withdrawals were based on reported rates for 59 well fields that provided water for public and industrial supplies. Annual recharge was estimated by scaling the 2005-2007 recharge rate estimated through model calibration (19 in/yr) by a factor that accounted for differences in annual precipitation measured from 1960 through 2006 at a gages in Letchworth, NY, and Theills, NY (fig. 11). Simulated water-level hydrographs were prepared for the same six locations presented for the 3-year transient simulations and are displayed in a similar manner (fig. 39). Four simulations were conducted using the same $S_{s}$ values as presented earlier and considered both saturated and variably saturated flow.

Simulated water levels display the same sensitivity to the assumed $S_{s}$ value in the 47-year simulations as in the 3 -year simulations, but the differences among the simulations are less apparent because changes in annual recharge rates (11.3 to $24.8 \mathrm{in} / \mathrm{yr}$ ) are less than the five-fold changes in monthly rates from 2000 through 2003 . There is little trend in simulated water levels in the lowlands, except at Ro58 where water levels increased following the decrease in groundwater withdrawals in 1970 (fig. 39E). A trend of declining water levels is apparent in other areas (fig. 39A-D) where simulated water levels decreased by 15 to $20 \mathrm{ft}$ during the 43 -year period from 1960 through 2002. Water levels increased sharply after 2002, however, in response to increased recharge after 2002. Simulated mean annual base flow ranged from about 60 to $120 \mathrm{ft}^{3} / \mathrm{s}$ during the simulated period (fig. 38B), with a mean value of $80 \mathrm{ft}^{3} / \mathrm{s}$ that is about four times the mean groundwater-withdrawal rate. The variability of simulated base flow was greater for simulations with smaller $S_{s}$ values.

\section{Limitations and Additional Data Requirements}

The groundwater flow models described in this report were designed to simulate regional flow and utilize a near uniform distribution of transmissivity that represents interconnections along flow paths that are 1 mile or more in length. This representation is sufficiently accurate to estimate the water budget for the Newark basin aquifer and to delineate the extents of capture zones associated with well fields. The actual distribution of transmissivity in the aquifer is heterogeneous (fig. 12), however, and reflects differences in the numbers and connectivity of fractures within local areas. This heterogeneity likely affects the pattern of flow in the vicinity of pumped wells. As a result, smaller-scale higher-resolution flow models would be required to more accurately represent contaminant movement, interference from adjacent wells, and local effects of pumping on streamflow.

The connection between the Newark basin aquifer and streams is represented by drains in the flow models described herein, so that only groundwater discharge is simulated. As a result, the models do not represent induced infiltration of water from streams to pumped wells and, thereby, overestimate the extents of capture zones of well fields located along perennial streams, such as the Spring Valley well field. These drain boundaries could be replaced by more general head-dependent boundaries that simulate induced infiltration, but additional data would be needed to estimate streamflow losses in the vicinity of pumped wells and calibrate the conductance terms (C) that determine rates of infiltration.

Additional data that extend the period of record for water-level and streamflow hydrographs would be valuable in improving the calibration of the groundwater flow models. Hydrographs constructed from long-term water levels and streamflow data could be analyzed to improve estimates of average recharge and to quantify annual and seasonal variability. In addition, concentrations of chemical tracers in streamflow could be measured during and between storms to better quantify the contribution of groundwater to stream discharge using a mass balance method (Stewart and others, 2007). Additional water-level hydrographs would also provide more information concerning saturated and unsaturated storage in the aquifer and could be used to better estimate the value of $S_{s}$. Historical records of groundwater levels during the period 1960 through 2006 would provide valuable information concerning long-term trends and could be used to calibrate the transient simulations. Additional streamflow data for several streams that drain the modeled area would allow estimation of base flows, which would provide information regarding the hydraulic connections between streams and the bedrock aquifer. The present models are not intended to accurately predict the transient behavior of the bedrock aquifer but rather to indicate the potential range of water levels that could result from changes in stress.

Uncertainty exists concerning the pattern of bedrock structure in the Newark basin aquifer and its relation to the fracture network. Two depictions of form lines that indicate the strike of bedding in the aquifer have been proposed - in model A, based on the geologic map presented in this report (fig. 6), the bedding strike reflects broad folds in the bedrock, whereas model B, based on the structure map of Heisig (2010) (fig. 7), depicts a more parallel orientation of bedding strike. 

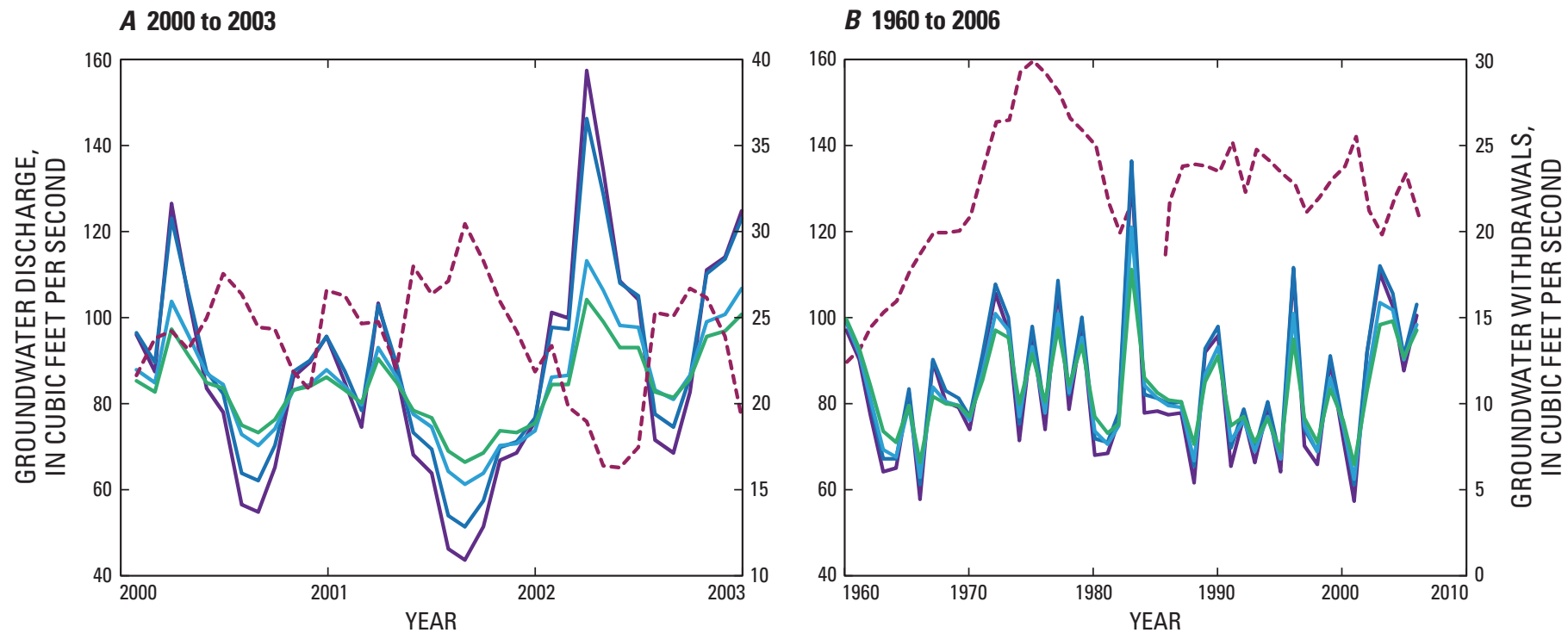

EXPLANATION

Simulation and value of specific storage $\left(S_{s}\right)$

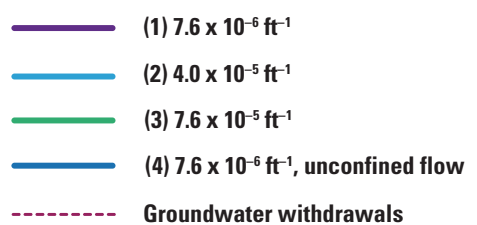

Figure 38. Groundwater discharge to streams (base flow) simulated using model $B$ with $(A)$ monthly distribution of recharge and groundwater withdrawals, 2000 through 2003, and $(B)$ annual distribution of recharge and groundwater withdrawals, 1960 through 2006. 

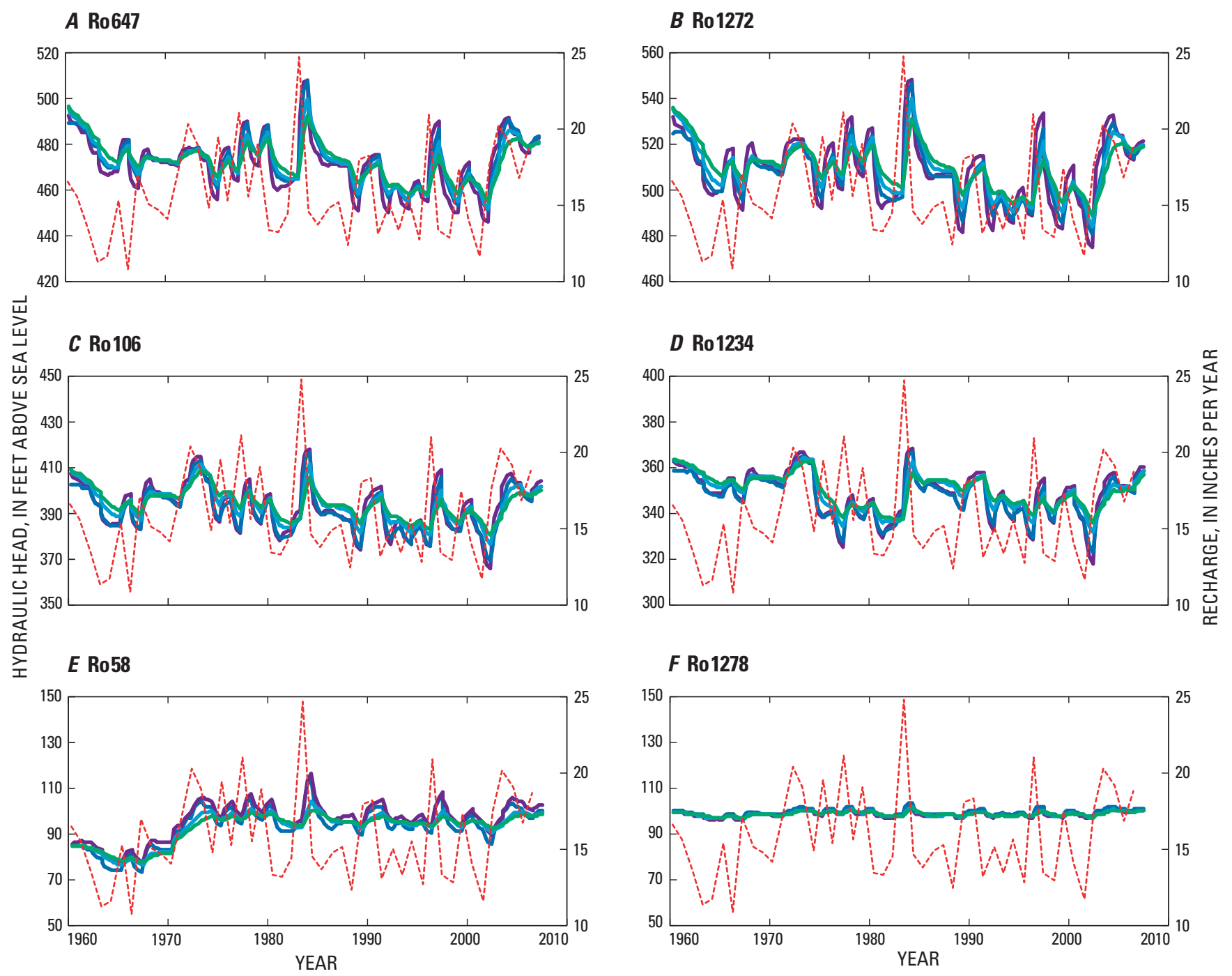

EXPLANATION

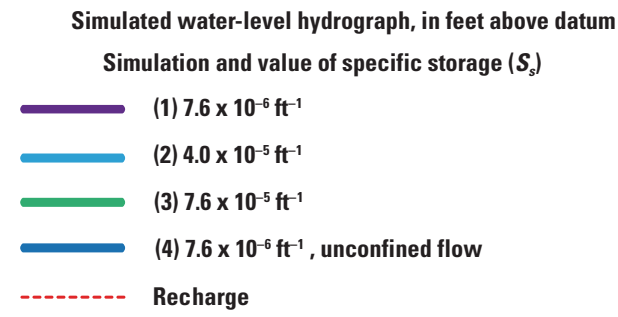

Figure 39. Water-level hydrographs simulated using model $B$ with annual distribution of recharge and groundwater withdrawals, 1960 through 2006: $(A)$ well Ro647, $(B)$ well Ro1272, $(C)$ well Ro106, $(D)$ well Ro1234, $(E)$ well Ro58, and $(F)$ well Ro1278. (Well locations shown in figure $34 \mathrm{~B})$. 
Model B provides a better match to water levels measured following the water-level recovery test at the Spring Valley well field and throughout the Newark basin aquifer from 2005 through 2007, as well as a better match to groundwater ages previously estimated with tritium/helium dating. Model A predicts shorter groundwater flow paths and younger ages than model B in some areas, so additional age data could provide the information required to determine which structure model better matches aquifer conditions. The combined area affected by groundwater withdrawals is the same in both models, although the shapes of capture zones associated with individual well fields differ slightly. A conservative approach would consider the combined area delineated by both models as the likely area contributing recharge to wells.

Additional geologic mapping of bedrock stratigraphy and fracture orientation could be conducted in areas where the structure models differ to assess the accuracy of each model. Information concerning the direction of groundwater flow from the observed movement of chemical tracers could also be used to accept or reject predictions of either model. Finally, test holes could be cored and completed with piezometers installed at different depths to collect more detailed information within the aquifer concerning the pressure distribution and differences in groundwater chemistry. Sets of three wells would be required to determine the strike and dip of waterbearing fracture zones at each location. This information could yield a more refined understanding of the relation between the fracture network and bedrock lithology.

\section{Summary and Conclusions}

A hydrogeologic study was undertaken by the U.S. Geological Survey, in cooperation with Rockland County and New York State Department of Environmental Conservation, to assess groundwater resources of the Newark basin aquifer, which currently (2009) provides 30 percent of the water supply for Rockland County, NY. Groundwater flows through fractures in sedimentary rocks within the Newark basin, which extends $150 \mathrm{mi}$ southwest from New York into New Jersey and Pennsylvania. The sedimentary rocks are part of the Newark Supergroup and were deposited as alluvium during the Late Triassic age into a westward dipping basin that is one of a series of such continental rift basins in eastern North and South America, western Africa and Europe. These basins developed during the Mesozoic rifting of the super continent Pangea that created the Atlantic Ocean.

Sedimentary rocks of the Newark basin generally consist of interbedded facies of coarse-grained to fine-grained arkosic sandstones, siltstones, and shales. Rocks of the older Stockton Formation are exposed in the eastern part of the basin and are overlain by younger rocks of the Passaic Formation in the western part of the basin. Lacustrine shales of the Lockatong Formation separate in the Passaic Formation from the Stockton Formation in some areas. Cross bedding in alluvial deposits in the Passaic Formation is highly variable and dip directions range from east-northeast to south-southwest. Coarse-grained limestone and dolostone fanglomerates are present in the upper part of the Passaic Formation in the northwestern part of the basin.

The sedimentary rocks were intruded by diabase associated with Jurassic volcanism and are bounded to the north and east by the Palisades sill, which parallels the Hudson River. Diabase and lava flows are present near Ladenton, NY, and were part of a fissure flow complex that was the source of widespread Orange Mountain Basalt flows in New Jersey and the Preakness Basalt. The largely buried New City dike has been mapped by aeromagnetic surveys and extends from the Palisades sill northwest toward Ladenton.

The general dip of bedding in the Newark basin is westward toward the Ramapo Fault, but mapped structures, observed variations in the strike and dip of bedding and tracing of stratigraphic maker beds by Ratcliffe (1988) indicate that rocks are folded into broad anticlines and synclines, possibly as a result of differential motion between bedrock blocks along the irregular basin margin. Form lines drawn parallel to bedding indicate the folds are open broad structures with low plunges and slight variations in strikes. The folds diminish eastward. An alternative, more uniform structure with beds generally striking parallel to the northeastward strike of the Ramapo Fault, is depicted by Heisig (2010), who interpolated bedding strike and dip measurements from a number of sources that included field mapping and borehole geophysical surveys. The latter, more uniform model does not reflect all the folds mapped by Ratcliffe (1988) in areas near the Ramapo Fault at the north end of the Newark basin at Tompkins Cove and in northern New Jersey, as shown on the geologic map (Appendix 1).

The Newark basin aquifer is generally overlain by till sediments and is confined in lowland areas but is unconfined in upland areas and near pumped wells. Most groundwater is assumed on the basis of the distribution of well yields to flow within the upper $500 \mathrm{ft}$ of the fractured bedrock. Base flow in streams is sustained by groundwater discharge from the bedrock aquifer. Coarse-grained alluvium and outwash is present in some stream valleys and enhance the exchange of water between the aquifer and streams. Outwash beneath the Mahwah River forms a productive aquifer that supplies groundwater to production wells.

Groundwater in Rockland County generally flows from upland areas towards major drainages of the Mahwah River, Hackensack River, Saddle River, and Pascack Brook, although pumping has altered this pattern in the central part of the aquifer where groundwater withdrawals are concentrated. Available data do not indicate widespread areas of long-term water-level decline, however. Estimated groundwater discharges to streams range from 13.2 to $19.2 \mathrm{in} / \mathrm{yr}$. Groundwater withdrawals from the Newark basin aquifer have declined from a high of $16.3 \mathrm{Mgal} / \mathrm{d}$ (4 in/yr) in 1975 to recent (2006) withdrawals that averaged $10.7 \mathrm{Mgal} / \mathrm{d}$ or $2.6 \mathrm{in} / \mathrm{yr}$. Although essentially all wastewater is discharged through sanitary sewers in areas of Rockland County overlying the Newark basin 
aquifer, about 16 percent of the water pumped is lost through conveyance and returned to the aquifer. Groundwater discharged through leakage into sanitary sewers is estimated to total $7.6 \mathrm{Mgal} / \mathrm{d}$ or $1.9 \mathrm{in} / \mathrm{yr}$.

The transmissivity $(T)$ of the Newark basin aquifer as estimated from aquifer tests ranges from 17 to $10,000 \mathrm{ft}^{2} / \mathrm{d}$ with a median value of $620 \mathrm{ft}^{2} / \mathrm{d}$. High and low $T$ zones in the aquifer (median values of 800 and $260 \mathrm{ft}^{2} / \mathrm{d}$, respectively) were delineated from a kriged interpolation of $\log T$. Box plots of the $\log T$ distribution and analysis of variance indicate a significant difference in transmissivity between the high and low $T$ zones, and two of the three bedrock zones (zones B and D) delineated by Heisig (2010).

Groundwater in the Newark basin aquifer flows primarily through discrete water-bearing zones that parallel the strike and dip of bedding. This distribution of water-bearing zones provides hydraulic connection between pairs of wells at similar depths that are aligned along the strike of the bedding, whereas pairs of wells that are aligned perpendicular to the strike of bedding are connected only if the wells intersect the same water-bearing zone. This geometry imparts anisotropy to the groundwater flow field because water flows preferentially parallel to the strike of bedding, while flow perpendicular to the strike is restricted. Borehole geophysical surveys indicate that the water-bearing zones are from 0.1 to $2 \mathrm{ft}$ thick and spaced from 10 to $100 \mathrm{ft}$ apart, with an average spacing of $40 \mathrm{ft}$. The water-bearing zones are assumed to generally parallel the average $10^{\circ}$ regional dip of bedrock sediments toward the Ramapo Fault, which strikes $\mathrm{N} 40^{\circ} \mathrm{E}$, but locally the strike and dip of fracture zones are variable and reflect bedding structure, as depicted in figures 6 and 7.

Separate groundwater flow models were prepared to simulate the 1992 water-level recovery test conducted at the Spring Valley well field and regional flow through the Newark basin aquifer. The finite-element program SUTRA was used to represent two alternate depictions of bedrock structure in each model by spatially varying the orientation of the hydraulic conductivity tensor to reflect variations in the strike and dip of the bedding. Directions of maximum and medium hydraulic conductivity were oriented parallel to the bedding, and the minimum hydraulic conductivity was oriented perpendicular to the bedding. Model A represented the bedrock structure presented in this report, while model B represented the structure of Heisig (2010).

Transient simulations using the principle of superposition reproduced water-level recovery in a $9.3-\mathrm{mi}^{2}$ area surrounding the Spring Valley well field. Four production wells were represented as injection wells, and recovery was computed as the change in water level above an arbitrary datum after 5 days of injection. Models A and B were calibrated through nonlinear regression using UCODE 2005 to optimize values of maximum and minimum hydraulic conductivity $\left(K_{\max }\right.$ and $K_{\min }$, respectively) and specific storage using the measured waterlevel recoveries in 32 wells at 14 locations during the Spring Valley 1992 recovery test. Results from model B best matched the measured values, largely because the assumed strike of bedding was based, in part, on data from the water-level recovery test. Residual plots indicate good model fit, with a standard error of $1.7 \mathrm{ft}$, about 6 percent of the $30-\mathrm{ft}$ measured range. A slight bias was noted in underprediction of waterlevel recovery at deep wells and overprediction of recovery at shallow wells. Model error was greatest for a pair of deep and shallow wells closest to the Spring Valley well field, where recovery is underpredicted and overpredicted, respectively, indicating that the transmissivity and (or) $K_{\max }: K_{\min }$ anisotropy of water-bearing zones that connect the deeper well to the pumped wells are greater than corresponding values in surrounding areas. The estimated transmissivity obtained by nonlinear regression $\left(3,100 \mathrm{ft}^{2} / \mathrm{d}\right)$ was slightly larger than the value of $2,900 \mathrm{ft}^{2} / \mathrm{d}$ obtained by analyzing the recovery data, whereas estimated values for specific storage and the $K_{\max }: K_{\min }$ anisotropy were $7.6 \times 10^{-6} \mathrm{ft}^{-1}$ and $72: 1$, respectively. The standard error is 50 percent greater for model A than for model $\mathrm{B}$ because the assumed distribution of strike did not match the actual strike of bedding in this area.

Regional flow through an 85.4- $\mathrm{mi}^{2}$ area of the Newark basin aquifer bounded by the Ramapo Fault, the Palisades sill, and New Jersey was simulated to represent steady-state conditions from 2005 through 2007. Models A and B were calibrated through nonlinear regression using UCODE 2005 to optimize hydraulic conductivity and recharge values using average water levels measured in 140 wells from August 2005 through April 2007. Potentiometric surfaces simulated with models A and B were similar and closely matched measured surfaces, but simulated heads were underpredicted in upland areas. Standard errors for models A and B were $12.6 \mathrm{ft}$ and $12.2 \mathrm{ft}$, respectively, less than 3 percent of the $535-\mathrm{ft}$ measured range and comparable to the mean 11.5 -ft fluctuation in measured water levels. Simulated flows from models A and B were similar and closely matched low flows observed in July 2006, with the exception of the Hackensack and Saddle Rivers where simulated flows were much higher than those estimated using hydrograph separation methods.

Values of both recharge and hydraulic conductivity were reasonably well estimated, but computed coefficients of variation indicate that the hydraulic-conductivity values were better estimated. The average recharge rates estimated with models A and B were 20 and $19 \mathrm{in} / \mathrm{yr}$, respectively, which are comparable to rates estimated by Heisig (2010, 18 to $21 \mathrm{in} / \mathrm{yr})$. Mean long-term recharge is probably less than $19 \mathrm{in} / \mathrm{yr}$, however, because precipitation for the period of calibration (2006) was 18 percent greater than the average precipitation from 1960 through 2006. Estimated transmissivities parallel to the strike of bedding in the high and low $T$ zones in model A were equal $\left(1,100 \mathrm{ft}^{2} / \mathrm{d}\right)$, but in model B the transmissivity of the high $T$ zone $\left(1,600 \mathrm{ft}^{2} / \mathrm{d}\right)$ was slightly greater than that of the low $T$ zone $\left(1,300 \mathrm{ft}^{2} / \mathrm{d}\right)$. The $K_{\max }: K_{\min }$ anisotropy (ratio parallel to bedding: perpendicular to bedding) was estimated to be $58: 1$ in model A and 410:1 in model B. As a result, the proportion of the total flow that is perpendicular to bedding is less in model $\mathrm{B}$ than in model A. Four additional nonlinear regressions conducted using model B to assess the effects of alternative 
patterns of $T$ zones and specified $K_{\max }: K_{\min }$ anisotropy ratios resulted in either little change in model error and estimated parameter values or much greater model error. One exception was the nonlinear regression in which the bedrock aquifer was specified as isotropic (anisotropy ratio 1:1), which resulted in less model error and lower hydraulic-conductivity values. This model is not considered realistic, however, because both the Spring Valley recovery test and borehole geophysical logs indicate that the bedrock aquifer is not isotropic.

Transmissivities estimated for the Spring Valley waterlevel recovery test using analytical methods and model simulation are similar $\left(2,900\right.$ and $3,100 \mathrm{ft}^{2} / \mathrm{d}$, respectively) because a fully penetrating well in fractured rock with a shallow bedding dip induces two-dimensional radial flow parallel to bedding. The effect of anisotropy is more important for a partially penetrating well or at steeper bedding dips where the component of flow perpendicular to bedding is larger. In these cases, different transmissivity values would be estimated using an analytical method that assumes isotropic flow than by a simulation that represents flow using a fully 3D conductivity tensor.

Regional simulations of flow through isotropic aquifers and inclined anisotropic aquifers yield different estimates of transmissivity. The bulk transmissivity of an aquifer is the coefficient of proportionality between the hydraulic gradient and the volumetric flow rate through the system. In the case of an inclined anisotropic aquifer, the bulk $T$ is less than the transmissivity parallel to bedding because regional flow follows paths that are both parallel and perpendicular to bedding. Bulk $T$ values for the Newark basin aquifer were computed for both isotropic and anisotropic conditions using steady-state simulations that estimated groundwater discharge with the top model boundaries (recharge and drains) replaced by specified heads estimated using model $\mathrm{B}$. The equivalent bulk $T$ of an isotropic aquifer required to produce a volumetric flow rate equivalent to that through an anisotropic aquifer was $290 \mathrm{ft}^{2} / \mathrm{d}$, about 16 percent of the estimated transmissivity parallel to strike of bedding in model $\mathrm{B}$. This value is less than 75 percent of the values computed from analysis of aquifer tests (300 to $1,000 \mathrm{ft}^{2} / \mathrm{d}$ ) and indicates that regional flow through the Newark basin aquifer is generally controlled by networks of waterbearing zones that are less transmissive than those surrounding the pumped well fields.

Distributions of groundwater age from models A and B were computed through steady-state simulations in which solute concentration was interpreted as age. Longitudinal and transverse dispersivities in transport simulations were specified as $1,000 \mathrm{ft}$ and $100 \mathrm{ft}$, respectively, to facilitate convergence of the solution and reduce numerical oscillations. An effective porosity value $\left(2 \times 10^{-2}\right)$ was estimated by comparing the simulated ages with the calculated ages of groundwater withdrawn from 12 well fields on the basis of tritium/helium $\left({ }^{3} \mathrm{H} /{ }^{3} \mathrm{He}\right)$ dating. The effective porosity compares favorably with the range of values $\left(1.7 \times 10^{-2}\right.$ to $\left.2.2 \times 10^{-2}\right)$ estimated on the basis of measured water-level fluctuations. Distributions of groundwater age simulated by models A and B are similar and indicate that most shallow groundwater ( $225 \mathrm{ft}$ below the bedrock surface) is 5 to 20 years old with younger water ( 5 years or less) near upland recharge areas and older water (more than 100 years) in lowlands near the Hackensack River and Saddle River. The simulated distributions differ in some upland areas, east of the Palisades Parkway near the northern model boundary, where younger water is simulated by model A.

Three-dimensional capture zones for 30 well fields with average withdrawal rates of more than $70 \mathrm{gal} / \mathrm{min}$ were delineated using both models A and B through 10-year reverse-flow, transient simulations. Reverse-flow simulations track migration of a tracer solute injected at the production wells backwards to discharge points at land surface, and tracer-concentration distributions can be interpreted as relative certainties that water recharging parts of the capture zone will reach each well. The two-dimensional projections of the delineated capture zones at land surface (obtained by taking a horizontal slice through each $3 \mathrm{D}$ capture zone at a depth of $225 \mathrm{ft}$ below the bedrock surface), in general, are elongated parallel to the assumed strike of bedding but were affected by the simulated potentiometric surface, the $K_{\max }: K_{\min }$ anisotropy, the drainage network of stream channels, and capture zones of adjacent well fields. The sizes of delineated capture zones range from $1.9 \mathrm{mi}^{2}$ for the Spring Valley well field (1,300 gal/min withdrawal rate) to less than $0.04 \mathrm{mi}^{2}$ (25 acres) for well fields with the smallest withdrawal rates $(80 \mathrm{gal} / \mathrm{min})$. The capture zones of several well fields overlap the watersheds of Pascack Brook and Nauraushaun Brook and indicate that the reduction of base flow caused by groundwater withdrawals is greatest for these streams. Uncertainty in the delineation of capture zones was assessed by changing specified aquifer properties and boundary conditions in reverse-flow simulations using model $\mathrm{B}$, but none of the changes considered had a marked effect on the delineated areas. The combined recharge area of all well fields is $13.6 \mathrm{mi}^{2}$ or 16 percent of the model domain.

Transient simulations were conducted using model B to assess the effect of changes in recharge and groundwater withdrawals on water levels and discharges to streams. Four simulations were conducted for each of two periods - a 47-year period representing annual changes from January 1960 through December 2006, and a 3-year period representing monthly changes from January 2000 through December 2002. Three of the simulations represented confined (saturated) aquifer conditions with an order-of-magnitude range of values of specific storage $\left(S_{s}\right)$, with the lowest value $\left(7.6 \times 10^{-6} \mathrm{ft}^{-1}\right)$ equal to that estimated from the Spring Valley water-level recovery test. The fourth simulation represented unconfined (variably saturated) conditions with the minimum $S_{s}$ value and specific yield $\left(S_{y}\right)$ equivalent to the estimated effective porosity (0.02). Annual and monthly withdrawals were based on reported rates for well fields that provide water for public and industrial supplies. Annual recharge was estimated by scaling the estimated 2005 to 2007 recharge rate $(19 \mathrm{in} / \mathrm{yr}$ ) by a factor that accounted for differences in precipitation measured from 1960 through 2006 at a gages in Letchworth and Theills, NY. Monthly recharge was estimated by the apportioning annual 
recharge using the distribution of recharge computed from measured water-level fluctuations in a monitoring well in New Jersey, 20 mi southwest of Rockland County.

Simulated monthly hydrographs reflect changes in recharge, which is highest during spring and lowest during summer, and water levels rose in 2002 when recharge was high. Monthly water levels simulated with the smallest $S_{s}$ value fluctuated by about $15 \mathrm{ft}$ in lowlands and $85 \mathrm{ft}$ in uplands, and by about $3 \mathrm{ft}$ and $20 \mathrm{ft}$ with the largest $S_{s}$ value. Corresponding values of measured water levels in two wells were $7 \mathrm{ft}$ and $13 \mathrm{ft}$ in the lowlands and uplands, respectively. The simulated annual hydrographs indicate a trend of declining water levels from 1960 through 2002 in upland areas where water levels decreased by 15 to $20 \mathrm{ft}$. Results indicate that the $S_{s}$ value varies by location and is likely larger than the value estimated from the Spring Valley water-level recovery test. Simulated groundwater discharges to streams (base flow) are sensitive to the assumed $S_{s}$ value and also reflect changes in recharge. Mean monthly base flows simulated with the smallest $S_{s}$ value range from 44 to $160 \mathrm{ft}^{3} / \mathrm{s}$, and from 67 to $104 \mathrm{ft}^{3} / \mathrm{s}$ with the largest $S$ value. Simulated mean annual base flow ranged from 60 to $120 \mathrm{ft}^{3} / \mathrm{s}$, with a mean value $\left(80 \mathrm{ft}^{3} / \mathrm{s}\right)$ about four times the mean groundwater-withdrawal rate.

Groundwater flow models of the Newark basin aquifer described in this report simulate regional flow along paths that are longer than 1 mile and are sufficiently accurate to estimate the water budget and delineate capture zones of pumped wells. Capture zones of wells that induce water from streams are overestimated, however, because the connection between the aquifer and streams is represented by drains. The models utilize a near uniform, homogeneous distribution of transmissivity, which is actually heterogeneous, so smaller-scale higher-resolution flow models would be needed to more accurately simulate contaminant movement, interference between adjacent wells, and local effects of pumping on stream discharge. Longer duration water-level and streamflow hydrographs would provide improved estimates of average recharge and better quantify annual and seasonal variability. These additional records also would provide information for further model calibration and could be used to improve estimates of aquifer storage properties and the hydraulic connection between the aquifer and streams, and to document long-term trends in water levels.

Uncertainty exists concerning the pattern of bedrock structure in the Newark basin aquifer and its relation to the fracture network; two structure maps depicting the strike of bedding are presented. Simulation results from the groundwater flow models based on both maps are similar, but the model based on structure presented in Heisig (2010) provides a better fit to estimated groundwater ages and better matches average water levels measured from 2005 through 2007 and during the Spring Valley water-level recovery test. Additional groundwater-age data could be used to determine which structure map better represents aquifer conditions because the simulated distributions of groundwater age differ slightly. The accuracy of each structure map could be assessed by conducting additional geologic mapping and by using chemical tracers to determine the direction of groundwater flow in areas where the models differ. The relation between the fracture network and bedrock lithology could be refined by coring test holes at several locations to enable the collection of pressure and water-quality data at different depths within the aquifer.

\section{Acknowledgments}

The authors thank Paul Heisig of the USGS (Troy, NY) who aided in the design of the groundwater flow models and collected nearly all of the data used in this report to design and calibrate the models, Alden Provost (USGS, Reston, VA) who wrote Appendices 2, 3 and 4 describing his modifications to SUTRA, and Richard Winston (USGS, Reston, VA) who wrote procedures for SutraGUI that generated the strike directions used to define conductivity tensors specified in the groundwater flow models. The authors also thank David Daniels and Stephen Snyder of the USGS (Reston, VA) for preparing the aeromagnetic map of Rockland County for this report.

\section{References Cited}

Aeschbach-Hertig, W., Schlosser, P., Stute, M., Simpson, H. J., Ludin, A., and Clark, J. F., 1998, A ${ }^{3} \mathrm{H} /{ }^{3} \mathrm{He}$ study of ground water flow in a fractured bedrock aquifer: Ground Water, v. 36 , no. 4 , p. 661-670.

Andreason, G.E., 1962, Aeromagnetic map of the Thiells Quadrangle Rockland and Orange Counties, New York: U.S. Geological Survey Geophysical Investigations map GP-342, scale 1:31,680.

Bond, K. R., and Phillips, J.D., 1988, Aeromagnetic imagery with geologic correlations for some Early Mesozoic basins of the Eastern United States, in Froelich, A.J., and Roninson, G.R., Jr, eds., Studies of the Early Mesozoic basins of the Eastern United States: U.S. Geological Survey Bulletin 1776, p. 253-264.

Carleton, G.B., Welty, Claire, and Buxton, H.T., 1999, Design and analysis of tracer tests to determine effective porosity and dispersivity in fractured sedimentary rocks, Newark basin, New Jersey: U.S. Geological Survey WaterResources Investigations Report 98-4126A, 80 p.

Dunning, G.R., and Hodych, J.P., 1990, U/Pb, zircon and baddelyite ages for the Palisades and Gettysburg sills of the northeastern United States: Implications for the age of the Triassic/Jurassic boundary: Geology, v. 18, p.795-798.

Fisher, D.W., Isachsen, Y.W., and Rickard, L.V., 1971, Geologic map of the State of New York: New York State Museum and Science Service Map and Chart Series, no.15, 5 sheets, 1:250,000. 
Frimpter, M.H., 1967, Geology of the Thiells Quadrangle, New York with emphasis on igneous and metamorphic rocks: Boston, Boston University Graduate School, unpublished $\mathrm{PhD}$ thesis, 142 p., 1:24,000.

Harbaugh, A.W., Banta, E.R., Hill, M.C., and McDonald, M.G., 2000, MODFLOW-2000, the U.S. Geological Survey modular ground-water model-User guide to modularization concepts and the ground-water flow process: U.S. Geological Survey Open-File Report 00-92, 121 p.

Heisig, P.M., 2010, Water resources of Rockland County, New York, 2005-07, with emphasis on the Newark basin bedrock aquifer: U.S. Geological Survey Scientific Investigations Report 2010-5245, 130 p.

Kummel, H. B., 1899, the Newark or New Red Sandstone Rocks of Rockland County, NY: New York State Geologist, 18th Ann. Report, p. 9-50.

Leggette, Brashears, and Graham, Inc., 1979, Hydrogeologic assessment of Rockland County, New York: Westport, CT, Leggette, Brashears, and Graham, Inc., 72 p., 5 pl.

Leggette, Brashears, and Graham, Inc., 1992, Spring Valley well field drilling and pump test program, Town of Ramapo, Rockland County, New York: Westport, CT, Leggette, Brashears, and Graham, Inc., 51 p.

Lewis, J.C., 1992, Effect of anisotropy on ground-water discharge to streams in fractured Mesozoic basin rocks: American Water Resources Association Monograph Series 17, p. 94-105.

Lewis-Brown, J.C., Rice, D.E., Rosman, R., and Smith, N.P., 2005, Hydrogeologic framework, ground-water quality, and simulation of ground-water flow at the Fair Lawn well field Superfund site, Bergen County, New Jersey: U.S. Geological Survey Scientific Investigations Report 2004-5280, $109 \mathrm{p}$.

Lowe, K. E., 1959, Structure of the Palisades intrusion and Haverstraw and West Nyack, N. Y.: New York Academy of Science Annals, v. 80, p.1127-1139.

Michalski, A., and Britton, R., 1997, The role of bedding fractures in the hydrogeology of sedimentary rock-evidence from the Newark Basin, New Jersey: Ground Water, v. 35, no. 2, p. 318-327.

Morin, R.H., Senior, L.A., Decker, E.R., 2000, Fractured-aquifer hydrogeology from geophysical logs: Brunswick Group and Lockatong Formation, Pennsylvania: Ground Water, v. 38 , no. 2 , p. $182-192$.

New York State Department of Environmental Conservation, 1992, Analysis of a pump test in a heterogeneous anisotropic bedrock aquifer: Albany, NY, State of New York Department of Conservation, $23 \mathrm{p}$.
Olsen, P.E. 1997, Stratigraphic record of the early Mesozoic breakup of Pangea in the Laurasia-Gondwanda rift system: Earth and Planetary Science Review, v. 25, p. 337-401.

Olsen, P.E., and Rainforth, E.C., 2003, The "Age of the Dinosaurs" in the Newark Basin, with special reference to the lower Hudson Valley: 2001 New York Geological Association Guidebook: Albany NY, New York State Museum, p. 59-176.

Parker, R.A., Houghton, H.F., and McDowell, R.C.,1988, Stratigraphic framework and distribution of early Mesozoic rocks of the northern Newark Basin, New Jersey and New York, in Froelich, A.J., and Robinson, G.R., eds., Studies of the Early Mesozoic Basins of the Eastern United States: U.S. Geological Survey Bulletin 1776, p. 31-39.

Parker, R.A., 1993, Stratigraphic relations of the sedimentary rocks below the Orange Mountain Basalt, northern Newark basin, New Jersey and New York: U.S. Geological Survey Miscellaneous Field Investigations, MF-2208, 1 sheet, scale $1: 100,000$.

Perlmutter, N.M., 1959, Geology and groundwater resources of Rockland County, New York: State of New York Department of Conservation, Water Power and Control Commission, Bulletin GW42, 133 p., 4 pl.

Pittman, W.E., and Talwani, M., 1972, Sea-floor spreading in the North Atlantic: Geological Society of America Bulletin, v. 83 , p. 619-646.

Poeter, E.P., Hill, M.C., Banta, E.R., Mehl, S., and Christensen, S., 2005, UCODE_2005 and six other computer codes for universal sensitivity analysis, calibration and ucertainty evaluation: U.S. Geological Survey Techniques and Methods 6-A11, $283 \mathrm{p}$.

Puffer, J.H., Block, K.A., and Steiner, J.C., 2009, Transmission of flood basalts through shallow crustal sill and the correlation of sill layers with extrusive flows: The Palisades Intrusive System and the basalts of the Newark basin, New Jersey, U.S.A. : Journal of Geology, v.117, p. 139-155.

Rankin, D.W., Drake, A.A., Jr., and Ratcliffe, N.M., 1989, Geologic map of the U.S. Appalachians showing the Laurentian margin and Taconic orogen, in Hatcher, R.D., Jr., Thomas, W.A., and Viele, G.W., eds., The Appalachian-Ouachita orogen in the United States, v. F-2 of The Geology of North America: Boulder, CO., Geological Society of America, plate 2.

Ratcliffe, N. M., 1980, Brittle (Ramapo fault) and phyllonitic ductile shear zones in the basement rocks of the Ramapo seismic zones New York and New Jersey, and their relationship to current seismicity, in Manspeizer, Warren, ed., Field studies of New Jersey geology and guide to field trips: Proceedings of the 52nd annual meeting of the New York Geological Association, p. 278-311. 
Ratcliffe, N.M., 1982, Results of core drilling of the Ramapo fault at Sky Meadow Road, Rockland County, New York, and assessment of evidence for reactivation to produce seismicity: U.S. Geological Survey Miscellaneous Investigations Series Map I-1401.

Ratcliffe, N. M., 1988, Reinterpretation of the relationship of the western extension of the Palisades Sill to the flows at Ladentown, New York, based on new core data, in Froelich, A.J., and Robinson, G.R., eds., Studies of the early Mesozoic basins of the eastern United States: U.S. Geological Survey Bulletin 1776, p. 113-135.

Ratcliffe, N. M., and Burton, W.C., 1985, Fault reactivation models for origin of the Newark basin and studies related to eastern U.S. seismicity, in Robinson, G.R., and Froelich, A.J., eds., Proceedings of the second U.S. Geological Survey workshop on the early Mesozoic basins of the eastern United States, p. 36-45.

Reilly, T.E., Franke, O.L., and Bennett, G.D., 1984, The principle of superposition and its application in groundwater hydraulics: U.S. Geological Survey Open-File Report 84-459, $36 \mathrm{p}$.

Risser, D.W., Conger, R.W., Ulrich, J.E., and Asmussen, M.P., 2005, Estimates of ground-water recharge based on streamflow-hydrograph methods: Pennsylvania: U.S. Geological Survey Open-File Report 2005-1333, 30 p.

Rutledge, A.T., 1998, Computer programs for describing the recession of ground-water discharge from streamflow data - update: U.S. Geological Survey Water-Resources Investigations Report 98-4148, 43 p.

Savage, E. L., 1967, The Triassic sediments of Rockland County, New York: New Brunswick, NJ, Rutgers University, unpublished Ph.D. dissertation, 189 p.

Schlische, R.W., 2002, Progress in understanding the structural geology, basin evolution, and tectonic history of the eastern North American Rift system, in LeTourneau, P.M., and Olsen,P.E., eds., The Great Rift valleys of Pangea in eastern North America, v. 1: Tectonics, structure, and volcanism of supercontinent breakup: Columbia University Press, p. 21-58.

Shapiro, A.M., Hsieh, P.A., Burton, W.C., and Walsh, G.J., 2007, Integrated multi-scale characterization of groundwater flow and chemical transport in fractured crystalline rock at the Mirror Lake Site, New Hampshire, in Hyndman, D.W., Day-Lewis, F.D., and Singha, K. eds., Subsurface Hydrology: Data integration for Properties and Processes: American Geophysical Union Geophysical Monograph Series, v. 171, p. 201-225.
Smoot, J.F., 1991, Sedimentary facies and depositional environments of early Mesozoic Newark Supergroup basins, eastern North America: Paleogeography, Paleoclimatology, Paleoecology, v. 84, p. 369-423.

Smoot, J.F., 2010, Description and distribution of Triassic depositional facies in the Newark Basin, Chapter A, in Herman, G.C., and Serfes, M.E., eds., Contributions to the geology and hydrogeology of the Newark Basin, New Jersey: New Jersey Department of Environmental Protection, Geological Survey Bulletin 77, p. 1-110.

Stewart, M., Cimino, J., and Ross, M., 2007, Calibration of base flow separation methods with streamflow conductivity: Ground Water, v. 45, no. 1, p. 17-27.

Tiedeman, C.R., Lacombe, P.J., and Goode, D.J., 2010, Multiple well-shutdown tests and site-scale flow simulation in fractured rocks: Ground Water, v. 48, no. 3, p. 401-415.

Tindall, J.A., and Kunkel, J.R., 1999, Unsaturated zone hydrology: Upper Saddle River, N.J, Prentice Hall, Inc., $624 \mathrm{p}$.

Todd, D.K., and Mays, L.W., 2005, Groundwater Hydrology: Hoboken, NJ, John Wiley \& Sons, 636 p.

U.S. Census Bureau, State and County Quick Facts, Rockland County, NY, Population estimates for New York counties (excel spreadsheet), accessed October 2007 at http://quickfacts.census.gov/qfd/states/36/36087lk.html.

Vecchioli, John, Carswell, L.D., and Kasabach, H.F., 1969, Occurrence and movement of groundwater in the Brunswick shale at a site near Trenton, New Jersey: U.S. Geological Survey Professional Paper 650-B, p. 154-157.

Voss, C.I., and Provost, A.M., 2002, SUTRA-A model for saturated-unsaturated variable-density ground-water flow with solute or energy transport: U.S. Geological Survey Water-Resources Investigations Report 02-4231, 250 p.

Worzel, L.J., and Drake, C.L., 1957, Structure section across the Hudson River at Nyack, NY from seismic observations, in Lowe, K.E., ed., Modern aspects of the geology of New York City and environs: Annals of New York Academy of Sciences, v. 80, art. 4, p. 1092-1105.

Yager, R.M., Southworth, S., and Voss, C.I., 2008, Simulation of ground-water flow in the Shenandoah Valley, Virginia and West Virginia, using variable-direction anisotropy in hydraulic conductivity to represent bedrock structure: U.S. Geological Survey Scientific Investigations Report 2008-5002, $54 \mathrm{p}$.

Zheng, Chunmiao, and Bennett, G.D., 2002, Applied contaminant transport modeling: New York, John Wiley \& Sons, $621 \mathrm{p}$. 
Appendixes 1, 2, 3, and 4 


\section{Appendix 1.}

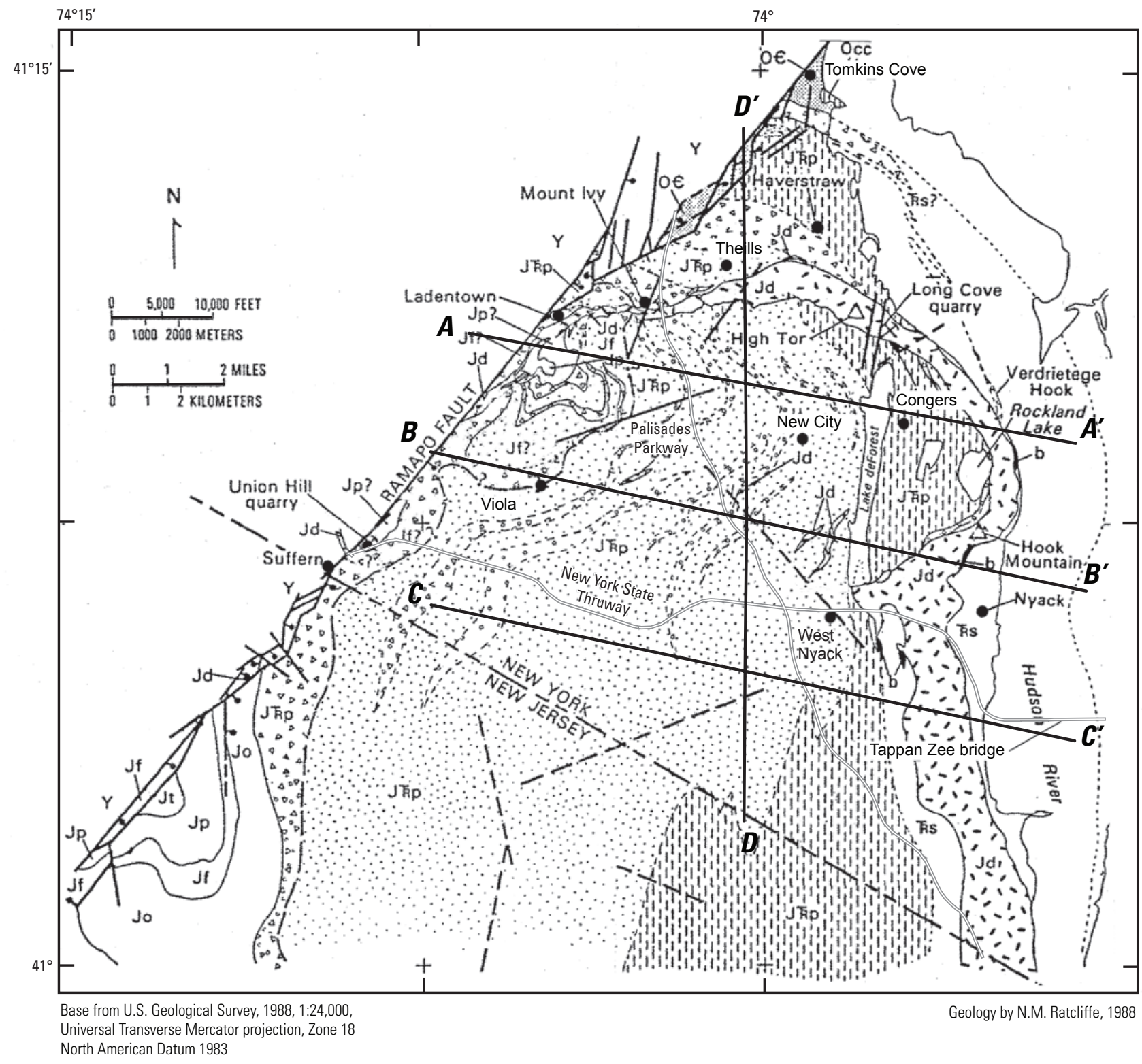

Appendix 1. Generalized bedrock geology of northern Newark basin modified from Ratcliffe (1988) showing geologic sections, stratigraphic units and lithofacies discussed in the text. 


\section{Appendix 1.}
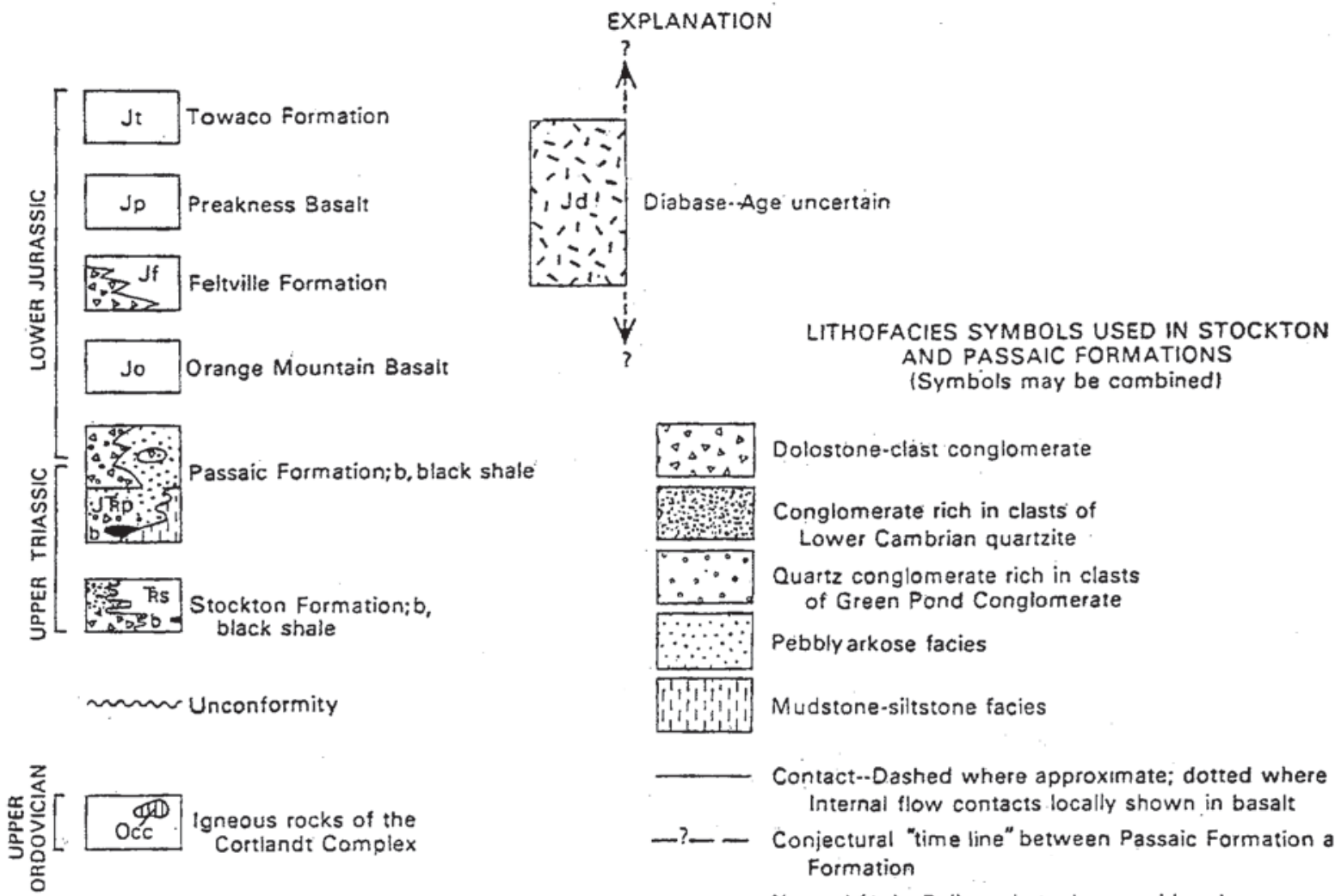

- Contact--Dashed where approximate; dotted where concealed. Internal flow contacts locally shown in basalt

- ? - Conjectural "time line" between Passaic Formation and Feltville Formation

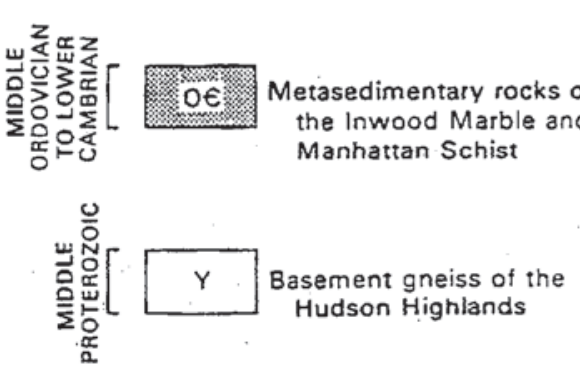

- Normal fault..Ball on downthrown side where displacement is known

- - Conjectural fault

X Quarry

A A' $^{\prime}$ Line of geologic section as shown in figure 4

Appendix 1. Generalized bedrock geology of northern Newark basin modified from Ratcliffe (1988) showing geologic sections, stratigraphic units and lithofacies discussed in the text.-Continued 


\section{Appendix 2. Modifications to SUTRA}

Boundary condition output files

Time-dependent boundary conditions

Drain-boundary nodes

Piecewise-linear unsaturated-flow functions

Head-based simulations with unsaturated flow

Optional output of simulated values to ".Ist" file

More efficient processing of schedules

Miscellaneous 
Appendix 3. Input data for the Time-Dependent Sources and Boundary Conditions Files (.bcs) 
72 Hydrogeology and Simulation of Groundwater Flow in Fractured Rock in the Newark Basin, Rockland County, New York

\section{Appendix 4. Selected SUTRA Subroutines}

Subroutine BCSTEP

Subroutine BOUND

Subroutine BOUND1

Subroutine FOPEN

Subroutine NAFU

Subroutine OUTBCOF

Subroutine OUTBCOP

Subroutine OUTBCOS

Subroutine OUTBCOU

Subroutine PUSWF

Subroutine SOURCE

Subroutine SOURCE1

Subroutine UNSAT 


\section{Appendix 1: Modifications to SUTRA}

This appendix describes the changes made to the SUTRA code to (1) write boundary condition information to a new set of output files, (2) enable specification of time-dependent boundary conditions through one or more input files, (3) enable simulation of drain-boundary nodes at which water can exit the model but cannot enter the model and (for reverse-flow simulations) "antidrain"-boundary nodes at which water can enter the model but cannot exit the model, (4) introduce piecewise-linear unsaturatedflow functions, (5) enable simulation of unsaturated flow when SUTRA input variables have been scaled so that SUTRA effectively solves for head instead of pressure, and (6) effect several relatively minor modifications. These features are not available in the standard version of SUTRA (Voss and Provost, 2002, version 2.1 of 2008), but most of these features will be documented in the forthcoming VERSION 2.2 of SUTRA, with the exception of those pertaining to representation of drains and unsaturated flow. To enable all of the new features described here, the user needs to specifiy "VERSION 2.2" in input parameter SIMULA in dataset 1 of the ".inp" (main input) file.

The modifications are categorized below according to the new features with which they are associated. However, note that some portions of the source code reflect changes associated with multiple new features. For the sake of brevity and clarity, not all Fortran comment lines and inline comments are included in the source code listings.

\section{Boundary condition output files}

Specifications and simulated values at boundary condition nodes can optionally be written to a set of four new output files. Information on fluid source/sink nodes, solute or energy source/sink nodes, specified-pressure nodes, and specified-concentration or temperatures nodes is written to files that, by convention, are given the file extensions ".bcof", ".bcos", ".bcop", and ".bcou", respectively.

If used, filenames for these output files must be added to the "SUTRA.FIL" file. The file types for the ".bcof", ".bcos", ".bcop", and ".bcou" files are "BCOF", "BCOS", "BCOP", and "BCOU”, respectively.

A new dataset, $8 \mathrm{E}$, has been added to the ".inp" (main input) file. It consists of a single line on which five input parameters are listed in the following order: NBCFPR, NBCSPR, NBCPPR, NBCUPR, and CINACT. The first four parameters determine how often output is written to the ".bcof", ".bcos", ".bcop", and ".bcou" files, respectively. For example, if NBCFPR $=5$, then information on fluid sources/sinks is written to the ".bcof" file on every fifth time step. CINACT determines whether output is written for boundary condition nodes that have been rendered inactive: yes if CINACT=" $\mathrm{Y}$ ", and no if CINACT=" $N "$.

Writing of boundary condition information to the ".bcof", ".bcos", ".bcop", and ".bcou" files is handled by new subroutines OUTBCOF, OUTBCOS, OUTBCOP, and OUTBCOU, respectively. These subroutines are listed in Appendix 3. The logic for calling these subroutines has been added to subroutine SUTRA, immediately after the call subroutine OUTELE: 


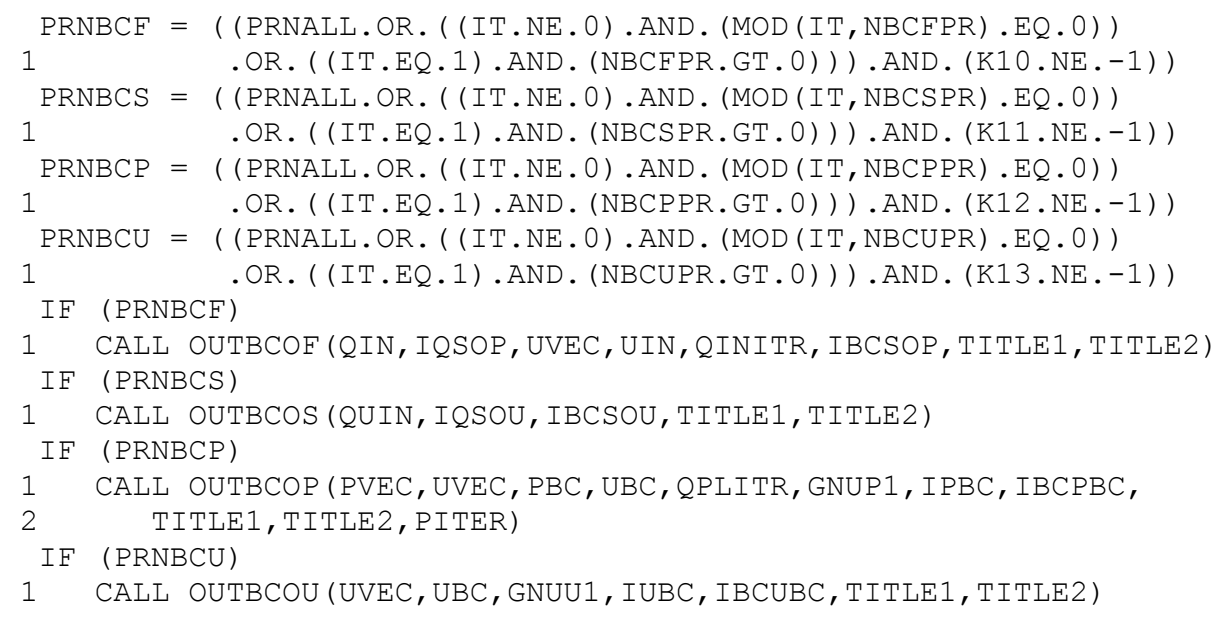

Variables PRNBCF, PRNBCS, PRNBCP, and PRNBCU are declared as LOGICAL in subroutine SUTRA.

Variables ONCEK10, ONCEK11, ONCEK12, and ONCEK13 are declared as LOGICAL and are passed through COMMON block PLT2 to the main program and subroutines OUTBCOF, OUTBCOS, OUTBCOP, OUTBCOU, and SUTRA. They are initialized to ".FALSE." in the main program and subsequently record whether subroutines OUTBCOF, OUTBCOS, OUTBCOP, and OUTBCOU, respectively, have been called at least once. This information is used to determine when to print headers to the corresponding output files, ".bcof", ".bcos", “.bcop", and ".bcou”, respectively.

Print cycle variables NBCFPR, NBCSPR, NBCPPR, and NBCUPR have been added to COMMON block CONTRL and are thereby passed to all program units that contain that COMMON block.

Integer variables K10, K11, K12, and K13 hold FORTRAN unit numbers for the ".bcof", ".bcos", ".bcop", and ".bcou" files, respectively. They have been added to COMMON block FUNITS and are thereby passed to all program units that contain that COMMON block. To accommodate the additional output files, plus the new ".bcs" file type, the dimensions of arrays FNAME and IUNIT have been extended from $(0: 8)$ to $(0: 13)$.

The following code has been added to subroutine INDAT1, immediately following the code that processes dataset $8 \mathrm{D}$, to read and process the new dataset $8 \mathrm{E}$ :

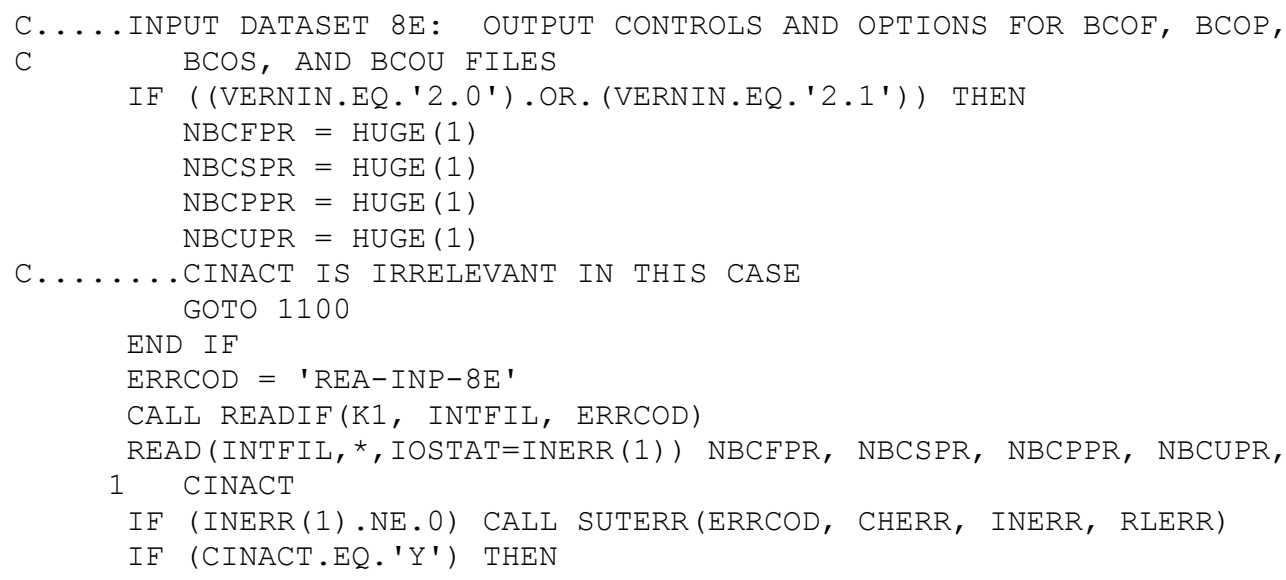




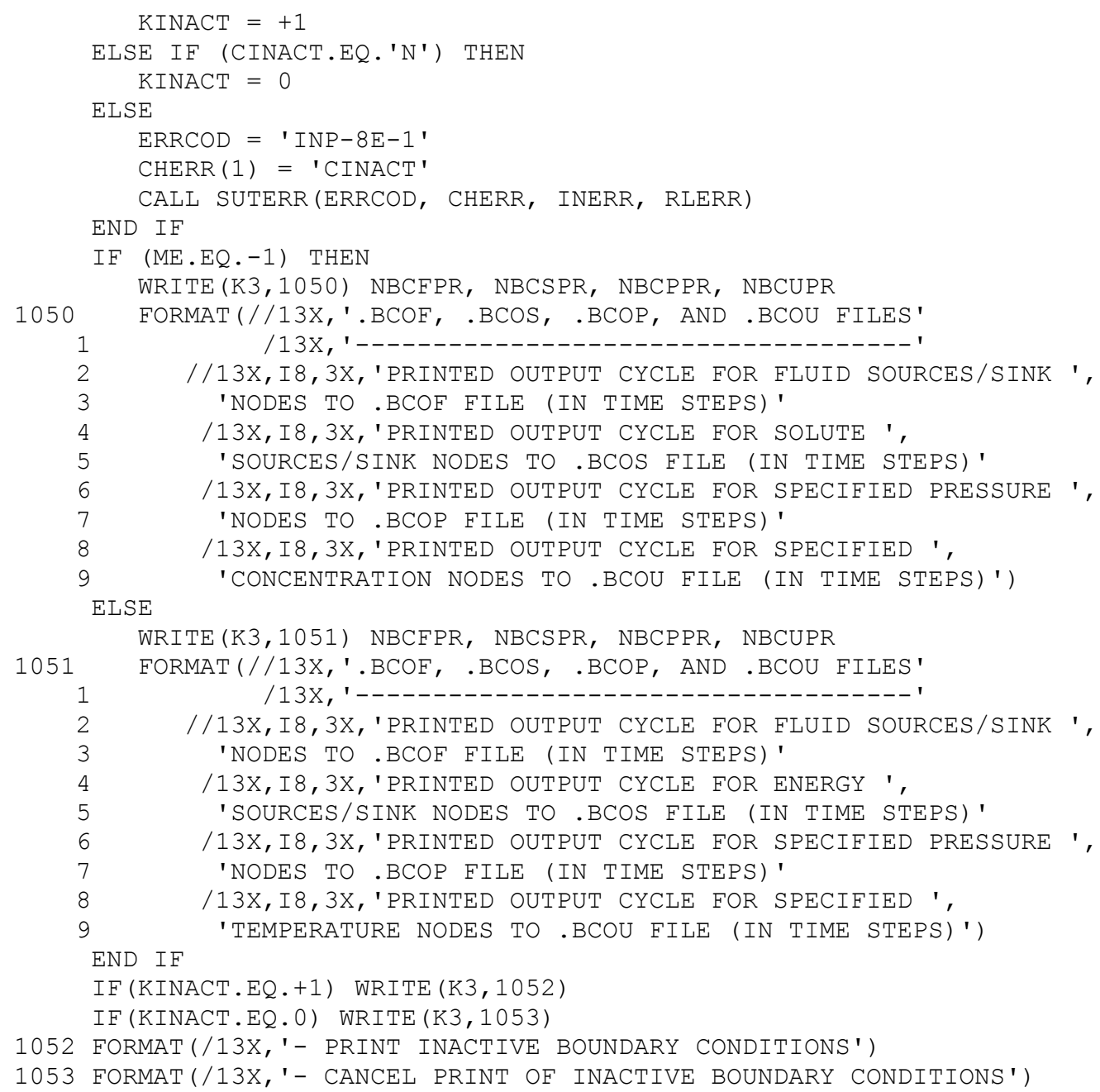

To provide the line label referred to in the statement "GOTO 1100" above, "1100" was appended to the beginning of the first line of the section of INDAT1 that reads dataset 9:

1100 ERRCOD = 'REA-INP-9'

In subroutine INDAT1, 200 was subtracted from certain line labels to accommodate the new code listed above. Specifically, line labels 1182, 1187, 1188, 1189, 1190, 1191, 1193, 1194, 1195, 1196, 1197, and 1199 became 982, 987, 988, 989, 990, 991, 993, 994, 995, 996, 997, and 999, respectively.

Input variable CINACT is declared as a character variable of length 1 in subroutine INDAT1. COMMON block KPRBCS passes KINACT to the main program and subroutines INDAT1, OUTBCOF, OUTBCOP, OUTBCOS, OUTBCOU, OUTLST2, and OUTLST3.

Subroutine FOPEN has been modified in a number of places and is listed in Appendix 3. The modifications account for reading and storage of data, error checking, and opening of files associated with the new ".bco*" output files and ".bcs" input files. 
Subroutine NAFU, which finds the next available Fortran unit, has been modified in a number of places and is listed in Appendix 3. The modifications have to do with the new ".bco*" output files and ".bcs" input files.

Subroutine UNSAT, which calculates unsaturated flow functions, has been modified in a number of places and is listed in Appendix 3. The modifications have to do with the new ".bco*" output files and piecewise-linear unsaturated flow functions.

The section of the main program that outputs file unit assignments has been modified in a number of places and is listed below. It includes modifications associated with the new ".bcs" input files.

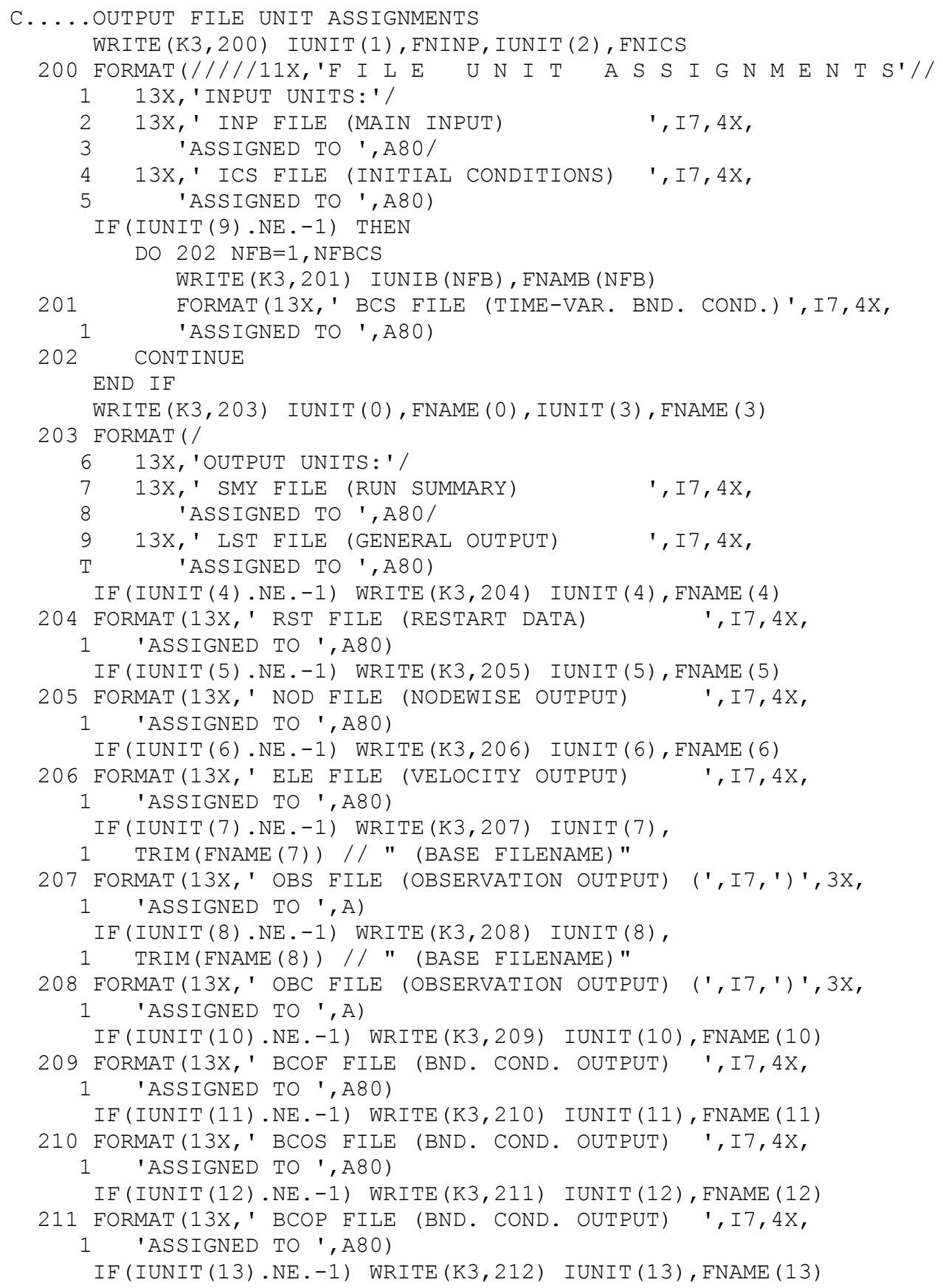




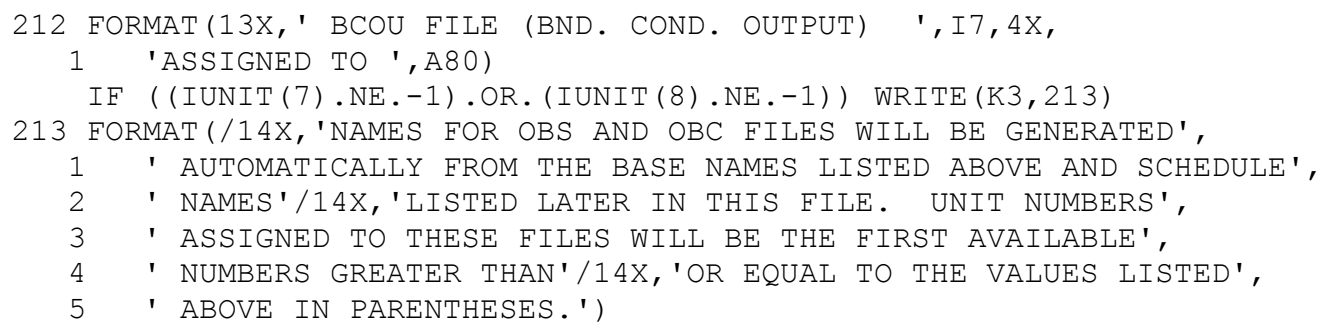

What was formerly line label 210 is now 214 to accommodate the new format statements above.

The error-handling subroutine SUTERR has been updated to account for the new ".bco*" files. The following four lines have been added to explanation of error condition "FIL-5":

$\begin{array}{lll}\operatorname{EX}(11)=' & \text { BCOF (".bcof" output file)' } & \text { ! bcofiles } \\ \operatorname{EX}(12)=' & \text { BCOP (".bcop" output file)' } & \text { ! bcofiles } \\ \operatorname{EX}(13)=' & \text { BCOS (".bcos" output file)' } & \text { ! bcofiles } \\ \operatorname{EX}(14)=' & \text { BCOU (".bcou" output file)' } & \text { ! bcofiles }\end{array}$

For error conditions "FIL-6" and "FIL-7", lines 5-7 of the explanation have been replaced with

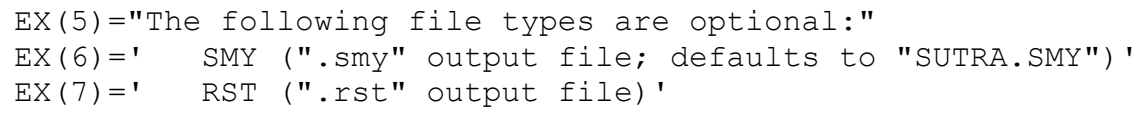

and lines 11 and 12 have been replaced with

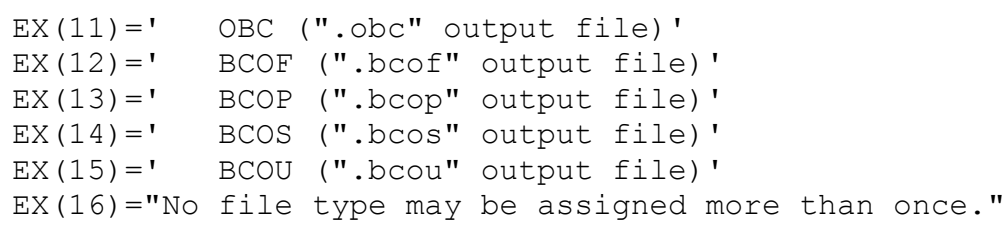

For error conditions beginning with "INP-8A", line 5 of the explanation has been changed to

$$
\operatorname{EX}(5)=" 10 \quad \text { 'N' 'N' 'N' 'Y' 'Y' 'Y' 'Y' 'Y' 'Y' 'Y' 'Y'" }
$$

which also reflects changes made in connection with optional output of pressures, saturations, and concentrations or temperatures to the ".Ist" file. A new error condition, "INP-8E-1", has been added after condition "INP-8D-5":

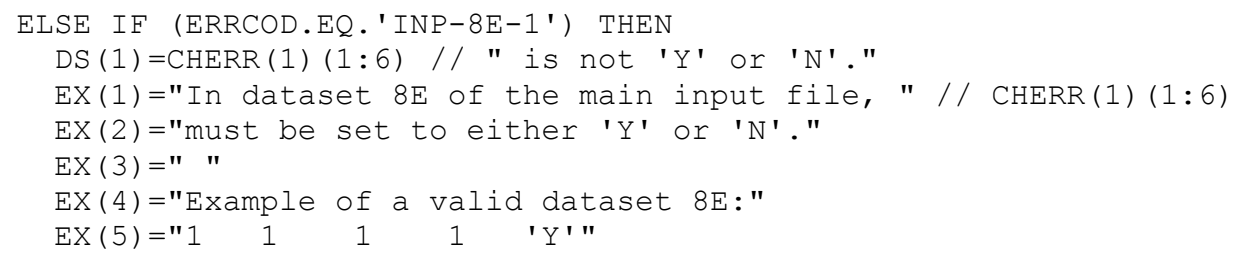

The algorithm that computes the number of digits of matching between computed and specified values is approximate and does not give exact results in some cases. 


\section{Time-dependent boundary conditions}

In the standard version of SUTRA (Voss and Provost, 2002, version of 2008), time-dependent boundary conditions are to be programmed by the user in subroutine BCTIME. In the present version of SUTRA, they can be specified via one or more files that are, by convention, given the file extension ".bcs." The input format for ".bcs" files is described in Appendix 2.

A new module, BCSDEF, defines arrays IUNIB and FNAMB, which are associated with ".bcs" files:

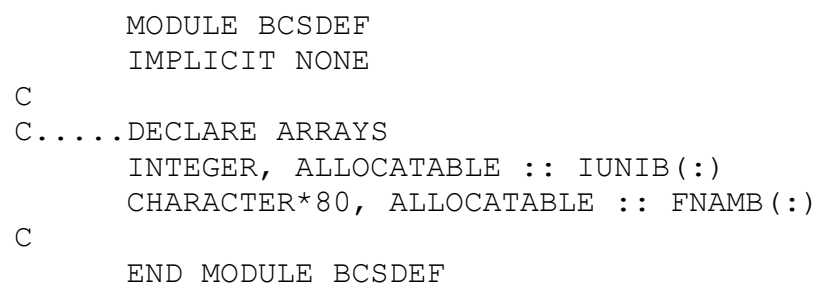

Module BCSDEF is used in the main program and subroutines BCSTEP, FOPEN, NAFU, and READIF. Arrays IUNIB and FNAMB store unit numbers and filenames, respectively, for the ".bcs" files. Both arrays are allocated in subroutine FOPEN.

A new integer variable, NFBCS, stores the total number of ".bcs" files. It is passed to the main program and subroutines BCSTEP, FOPEN, NAFU, and READIF through a new COMMON block, FUNIB.

The new subroutine BCSTEP handles reading and processing of time-dependent boundary conditions specified in ".bcs" files. It is listed in Appendix 3. BCSTEP is called from subroutine SUTRA using the following code, which appears immediately after the call to subroutine BCTIME:

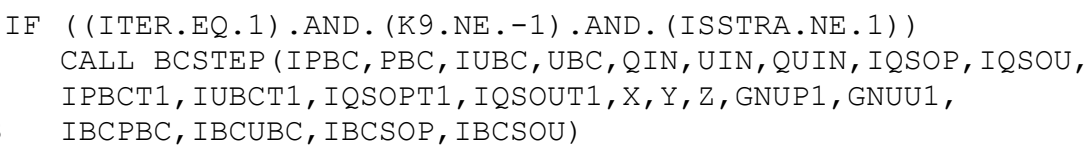

Subroutine BOUND, which reads and organizes input data from datasets 19 and 20 (specified pressures and specified concentrations or temperatures), has been modified in a number of places and is listed in Appendix 3. The modifications have to do with time-dependent boundary ".bcs" conditions and drain nodes.

The new subroutine BOUND1 reads and organizes time-dependent specified pressures and specified concentrations or temperatures from datasets 4 and 5 of the ".bcs" files. It is listed in Appendix 3.

Subroutine SOURCE, which reads and organizes input data from datasets 17 and 18 (sources/sinks of fluid mass, and sources/sinks of solute mass or thermal energy) has been modified in a number of places and is listed in Appendix 3. The modifications have to do with time-dependent boundary ".bcs" conditions.

The new subroutine SOURCE1 reads and organizes time-dependent sources/sinks of fluid mass, and sources/sinks of solute mass or thermal energy from datasets 2 and 3 of the ".bcs" files. It is listed in Appendix 3. 
Subroutine FOPEN, which opens input and output files, has been modified in a number of places and is listed in Appendix 3. The modifications account for reading and storage of data, error checking, and opening of files associated with the new ".bcs" input files and ".bco*" output files.

Subroutine NAFU, which finds the next available Fortran unit, has been modified in a number of places and is listed in Appendix 3. The modifications have to do with the new ".bcs" input files and ".bco*" output files.

Integer variable K9 records the FORTRAN unit numbers for the ".bcs" file currently being read. It has been added to COMMON block FUNITS and is thereby passed to all program units that contain that COMMON block.

Arrays FNAIN, KLIST, and NKS store the names and unit numbers of inserted files and the number of inserted files of each type currently open, respectively. The lead dimension of these arrays has been increased from 2 to 3 to accommodate the new ".bcs" file type. NKS(3) is initialized to zero in the main program before any files are opened.

Subroutine READIF, which handles reading of input data, has been modified in a number of places to account for the new ".bcs" files. The section of code that handles the case when the end of an inserted file has been reached (INERR(1).LT.0) has been updated to

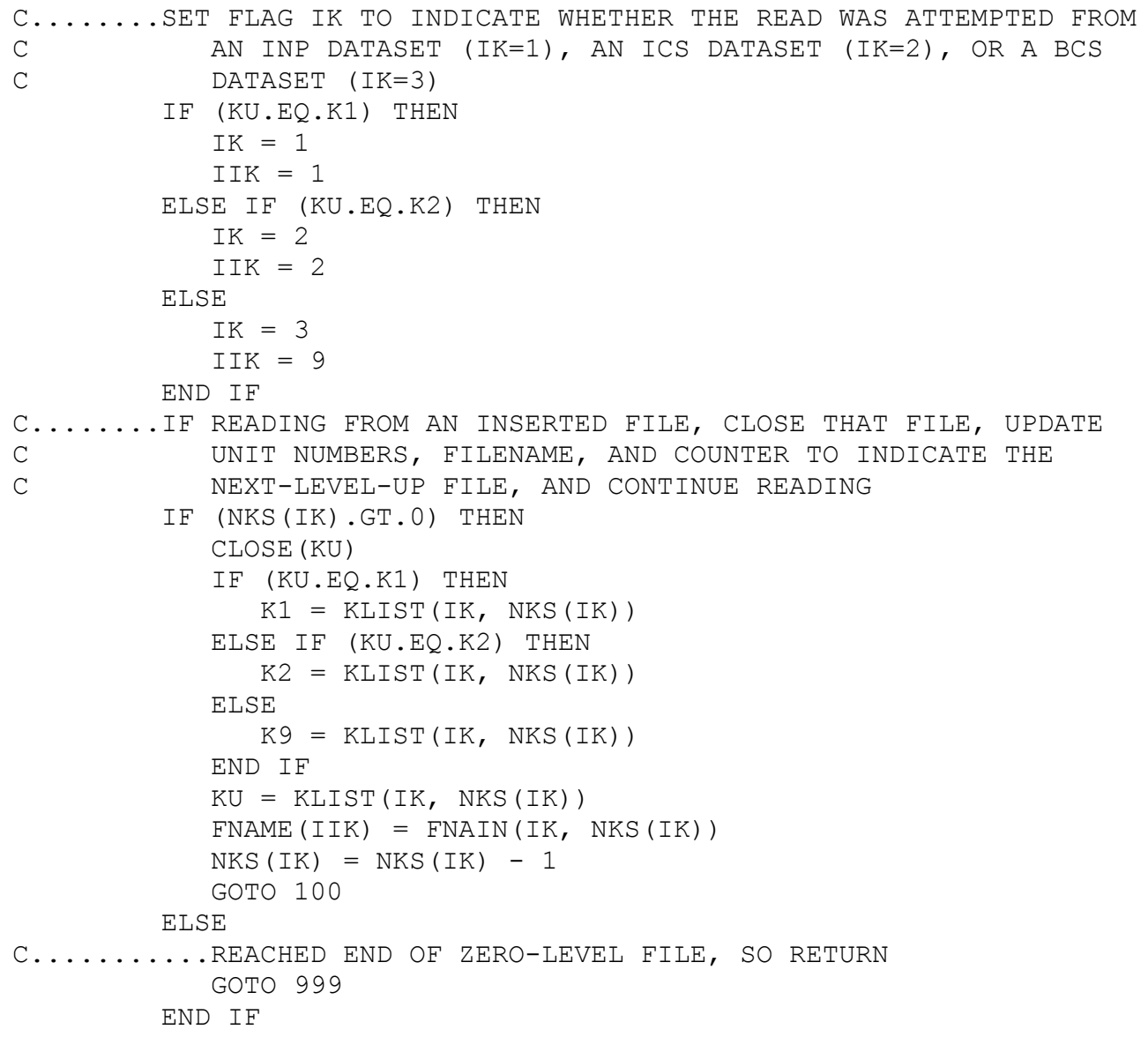


The section of READIF that sets flag IK to indicate the type of file that was read has been updated to

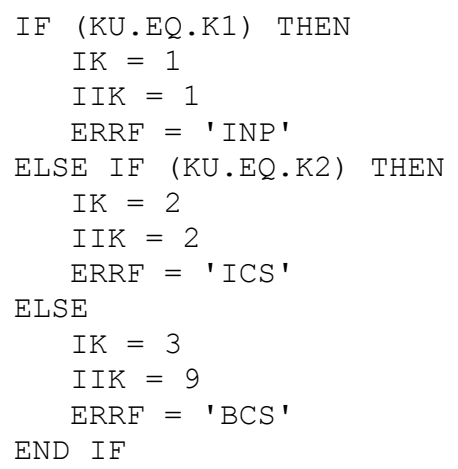

Do loop 565 has been added to READIF to check whether the inserted filename duplicates the name of a ".bcs" file:

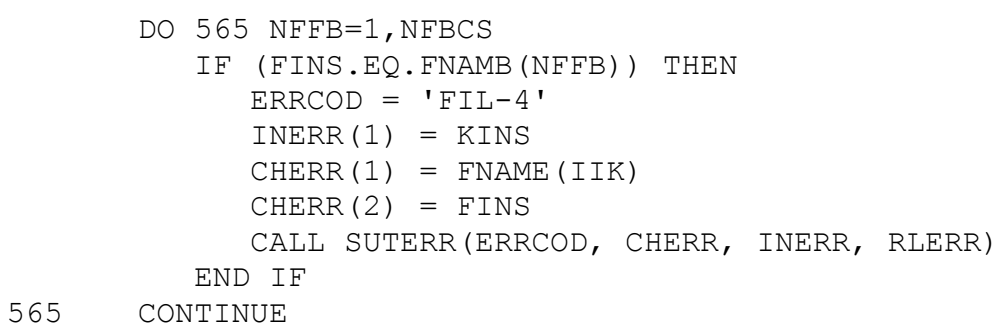

All seven lines in READIF in which CHERR(1) was set to FNAME(IK) have been updated to

$\operatorname{CHERR}(1)=\operatorname{FNAME}(I I K)$

In DO loop 550, the upper limit on the loop index, I, has been increased from 2 to 3 to account for the fact that there are now 3 file types that can include @INSERT statements. In DO loop 560, the upper limit on the loop index, NFF, has been increased from 8 to 13 to account for the increase in the number of file types, including ".bco*" files. And the section of READIF that updates unit number and filenames to indicate the newly inserted file before reading continues has been modified to

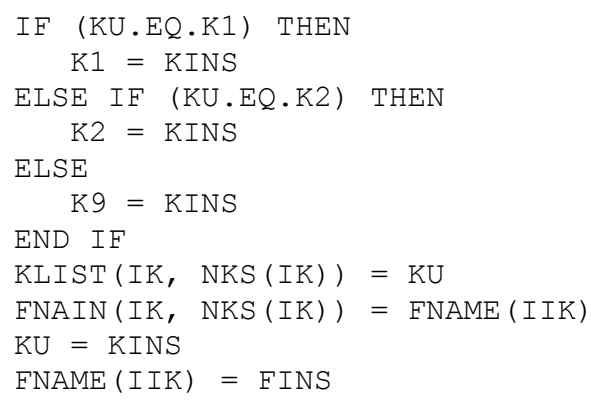

To facilitate activation and deactivation of specified-pressure and specified-concentration or temperature boundary conditions, arrays GNUP1 and GNUU1 have been introduced. These arrays are declared as DOUBLE PRECISION in module ALLARR, allocated with dimension NBCN in the main program, and deallocated in subroutine TERSEQ if ALLO1 is set to ".TRUE.". 
Array GNUP1 has been added to the argument lists of subroutines BC, BCSTEP, BOUND, BUDGET, INDAT2, OUTBCOP, OUTRST, SUTRA, and TERSEQ and has been declared with dimension NBCN in all of these subroutines except TERSEQ. In all calculations that formerly involved GNUP, GNUP has been replaced with GNUP1(IP), where IP is the number of the node at which the calculation is being performed. To facilitate simulation restarts, array GNUP1 is written to the ".rst" file by subroutine OUTRST and read from the ".rst" file by subroutine INDAT2. GNUP1 follows array PBC in the ".rst" file and is written and read in the same way as PBC. Array GNUP1 is also used in connection with drain nodes.

Array GNUU1 has been added to the argument lists of subroutines BC, BCSTEP, BUDGET, OUTBCOU, SUTRA, and TERSEQ and has been declared with dimension NBCN in all of these subroutines except TERSEQ. In all calculations that formerly involved GNUU, GNUU has been replaced with GNUU1(IUP), where IUP is the number of the node at which the calculation is being performed.

INTEGER(1) arrays IBCPBC, IBCUBC, IBCSOP, and IBCSOU have been introduced to record how each boundary condition node has been assigned its latest values. These arrays are defined in module ALLARR, allocated in the main program with dimensions NBCN, NBCN, NSOP, and NSOU, respectively, and deallocated in subroutine TERSEQ if ALLO1 is set to ".TRUE.". They are all passed through the argument lists of and declared in subroutines BCSTEP and SUTRA. In addition, IBCPBC is passed to and declared in subroutine OUTBCOP, IBCPBC is passed to and declared in subroutine OUTBCOP, IBCUBC is passed to and declared in subroutine OUTBCOU, IBCSOP is passed to and declared in subroutines BUDGET and OUTBCOF, and IBCSOU is passed to and declared in subroutines BUDGET and OUTBCOS.

In subroutine BUDGET, IBCSOP and IBCSOU are used in the modified sections of code within DO loops 500 and 3500 , respectively:

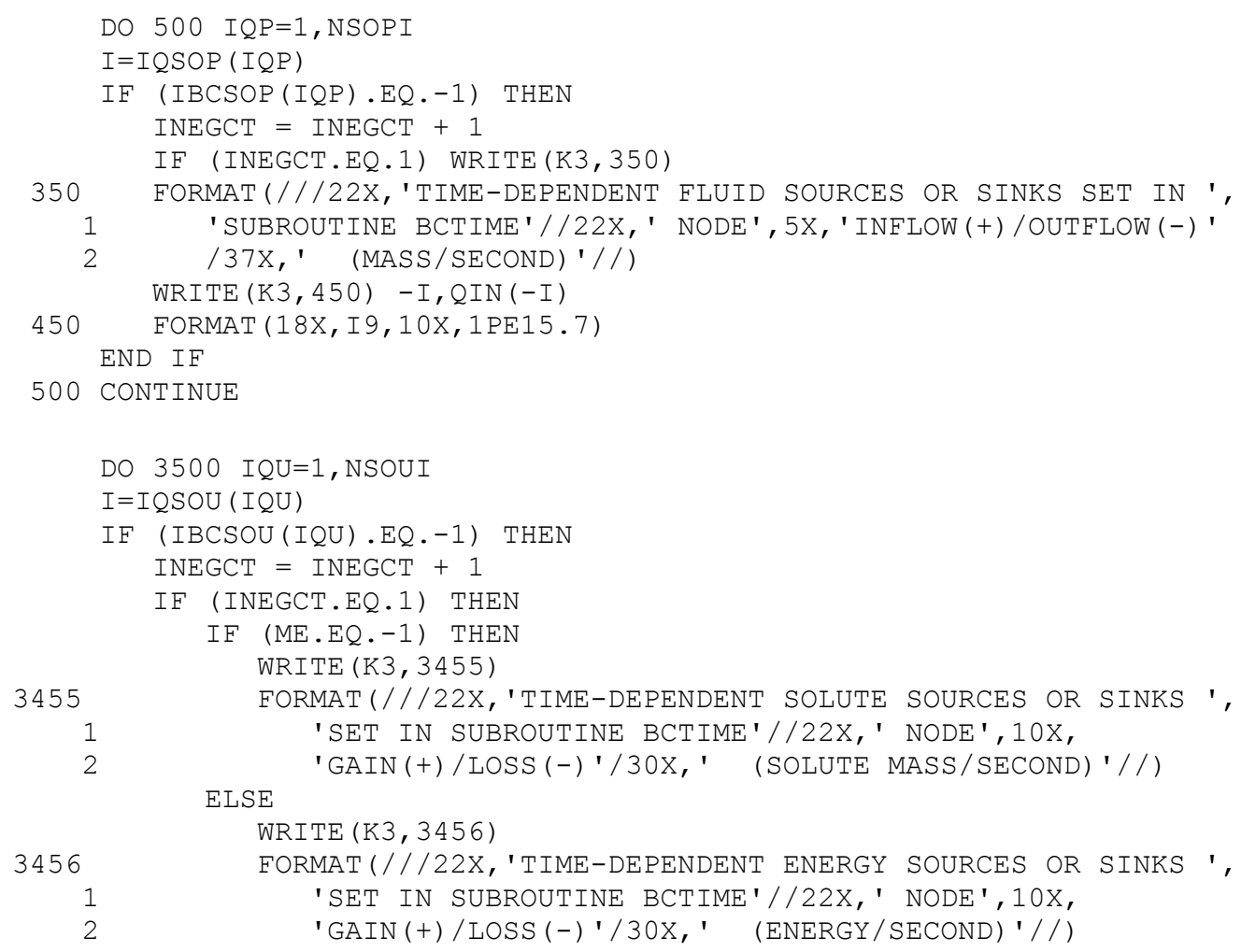




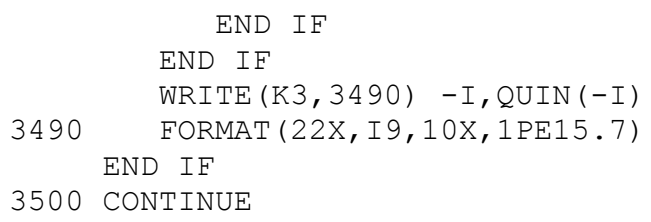

The section of the main program that outputs file unit assignments has been modified in a number of places and is listed in the earlier section that discusses modifications associated with the new ".bco*" output files.

The section of the main program that computes and outputs array memory requirements has been modified in a number of places and is listed below:

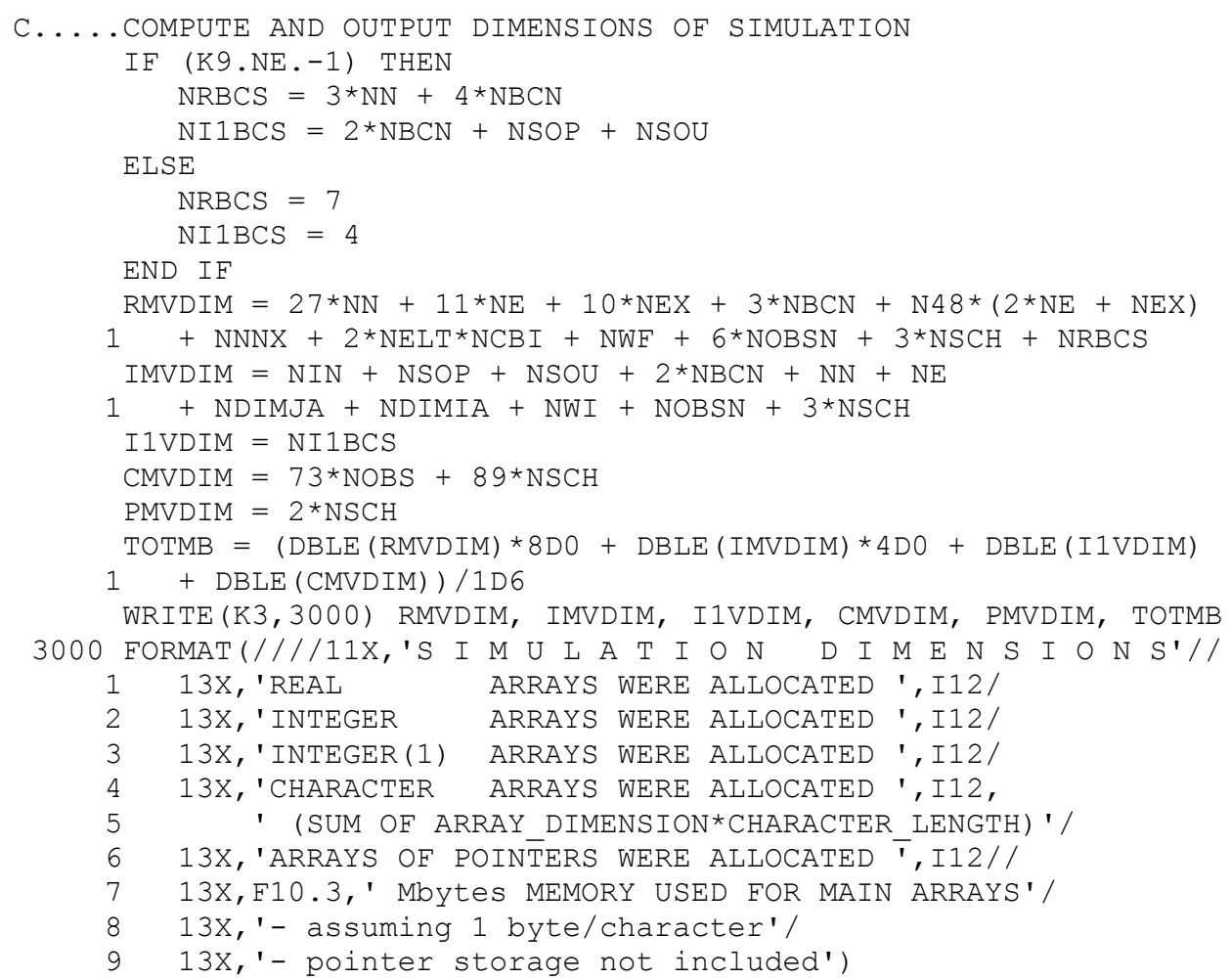

A character variable of length 80 , called FNBCS, has been introduced into the main program. It is set to FNAME(9) after the call to subroutine FOPEN but is not used subsequently. Omitting it likely will have no effect on the results computed by SUTRA.

A number of new error conditions have been added to the error-handling subroutine, SUTERR, in connection with ".bcs" files. They appear immediately after error condition "INP-20-1":

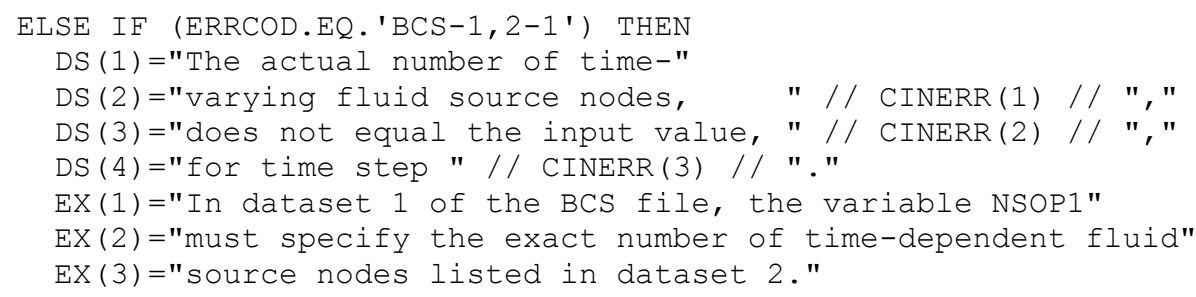




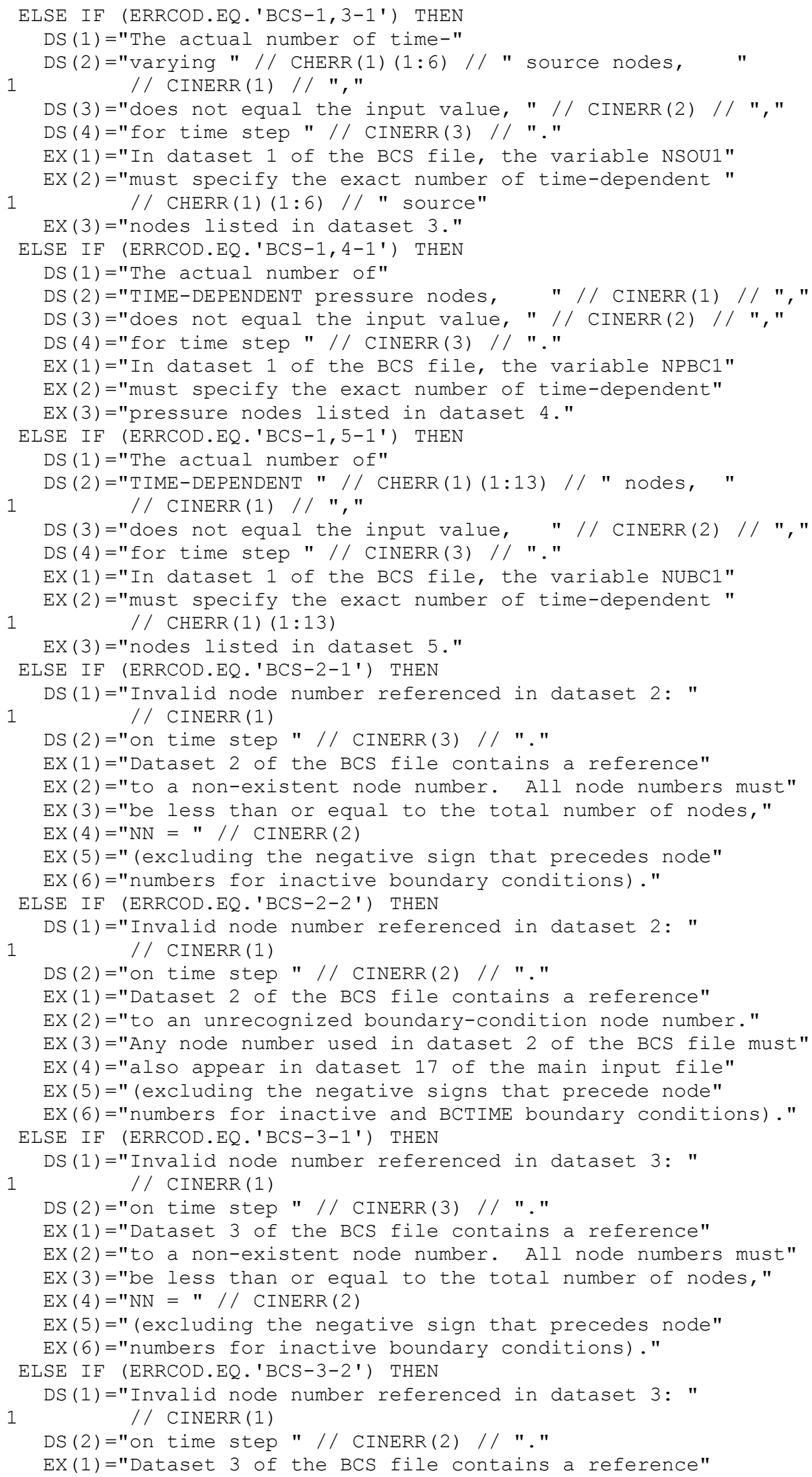




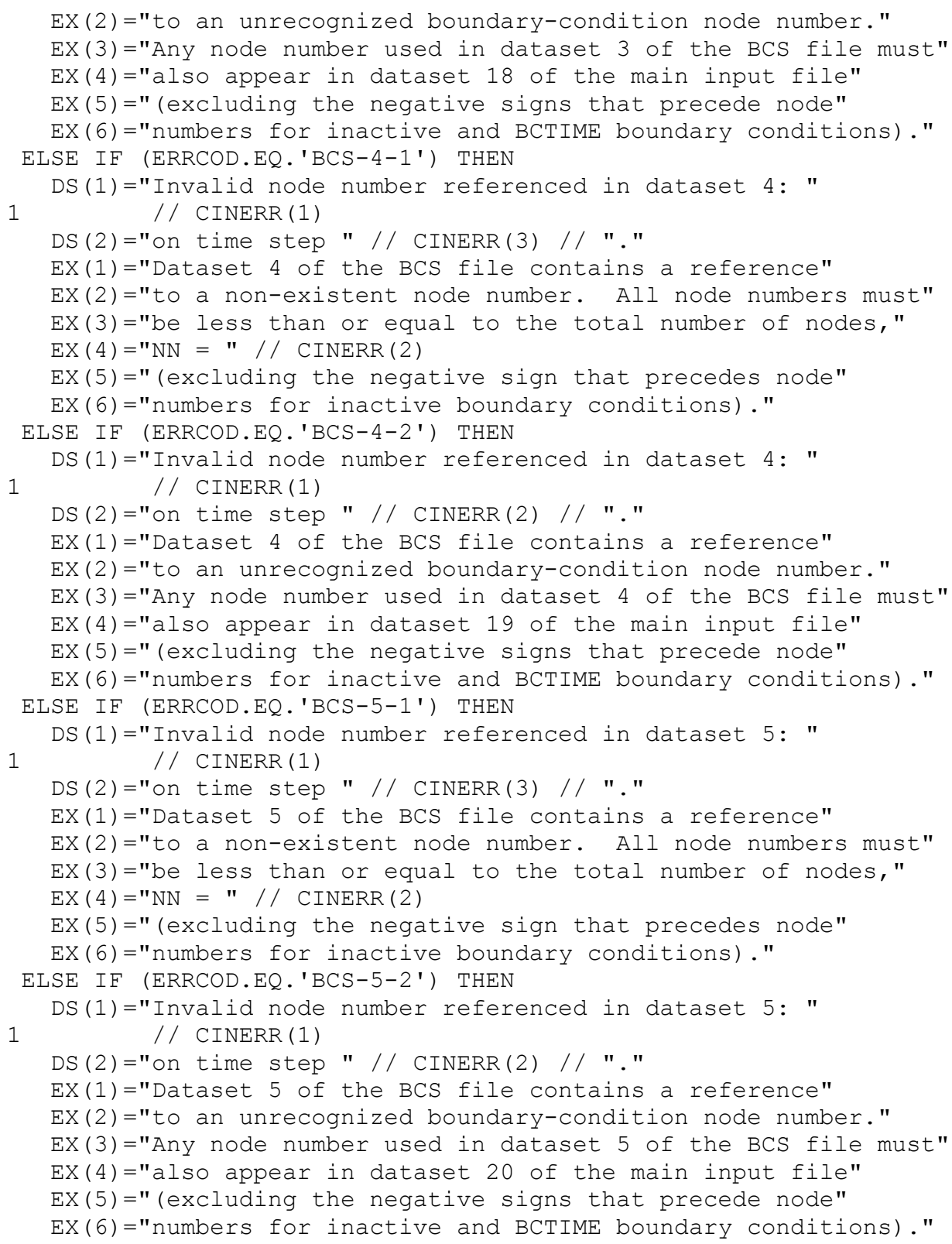

The condition that checks for the type of error just before the error message is written has been expanded to

IF ( (CODE (1).EQ.'INP').OR. (CODE (1).EQ. 'ICS').OR.

1 (CODE (1) EQ.'BCS')) THEN

and the section of code that sets the filename for FORTRAN read errors has been changed to

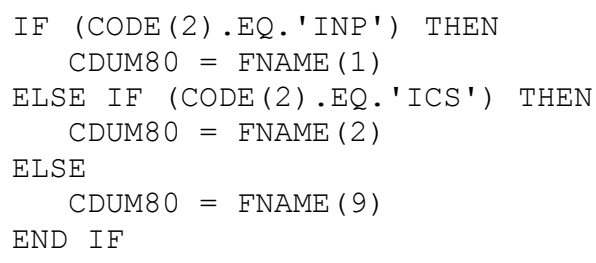




\section{Drain-boundary nodes}

At a drain node, the flow $q_{d r n}[\mathrm{M} / \mathrm{T}]$ in or out of the model is $\mathrm{v}\left(p_{b c}-p\right)$ if $p>p_{b c}$ and zero if $p \leq p_{b c}$, where $p$ $\left[\mathrm{M} /\left(\mathrm{LT}^{2}\right)\right]$ is the last computed value of pressure at the node, $p_{b c}\left[\mathrm{M} /\left(\mathrm{LT}^{2}\right)\right]$ is a specified external pressure, and $v[L T]$ is the conductance of the hydraulic connection between pressures $p$ and $p_{b c}$. Thus, when the pressure at the boundary node, $p$, exceeds the external pressure, $p_{b c}$, a negative flow (out of the model) results. When $p$ is less than or equal to $p_{b c}$, there is no flow in or out of the model at that node.

Drain-boundary conditions are implemented as a variation on specified-pressure boundary conditions. Input of drain-boundary conditions is through SUTRA dataset 19. The input format for this dataset has been modified by adding two parameters.

When a line of dataset 19 is read (for example, corresponding to specified-pressure node number IPU), any information following the original three input parameters (IPBC, PBC, and UBC) is stored in entry IPU of a character array called CMNT19. CMNT19(IPU) is then parsed to extract the values of two new parameters, SPTYPE (character string) and GNUG (double precision array). SPTYPE='SPECP' indicates that the node is an ordinary specified-pressure node; SPTYPE='DRAIN' indicates that the node is a drain. Logical array ISDRAIN is defined to permanently store type information for each node in dataset 19: if node IPU is a drain, then ISDRAIN(IPU)=.TRUE.; otherwise, ISDRAIN(IPU)=.FALSE.. GNUG(IPU) holds the value of the conductance $v$ for node IPU.

The parsing of CMNT19 to extract SPTYPE and GNUG assumes that the information following IPBC, PBC, and UBC consists of two character fields (both read into character string CDUM), followed by an integer value (read into integer IDUM), followed by the values of SPTYPE and GNUG. This corresponds to the form of dataset 19 produced by a version of SutraGUI (Winston and Voss, 2004) that has been modified to include a comment field with specified-pressure boundary conditions. The user-specified entry in the comment field in SutraGUI is assumed to be of the form "SPECP " + gnug' for an ordinary specifiedpressure node and "DRAIN " + gnug' for a drain, where gnug is the numerical value of GNUG for the node.

For reverse-flow simulations, drain nodes are made to behave opposite to the way they normally behave: groundwater can recharge but not discharge at such an "anitidrain" node.

A new module, DRNDEF, defines arrays ISDRAIN and CMNT19, which are associated with drains:

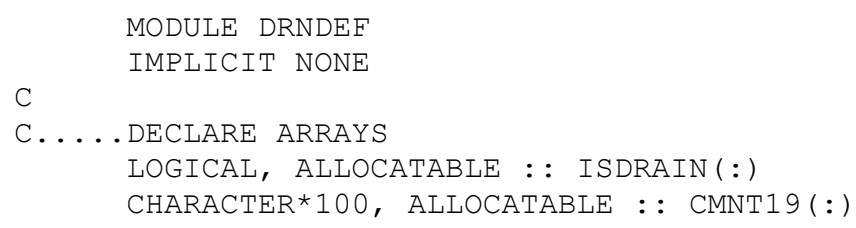


Module DRNDEF is used in the main program, SUTRA_MAIN, and in subroutines BC, BUDGET, SUTRA, and BCTIME. Array ISDRAIN records whether a given specified-pressure node is to be treated as a drain node. Array CMNT19 stores drain information read from dataset 19 of the ".inp" input file. Both arrays are allocated with dimension NBCN in SUTRA_MAIN, right before subroutine INDAT1 is called.

Array GNUP1 has been introduced in connection with ".bcs" boundary conditions and is used to store conductances associated with specified-pressure nodes, including those designated as drain nodes. To prevent recharge at drain nodes, calculations involving array GNUP1 have been modified and are listed below. In subroutine BC:

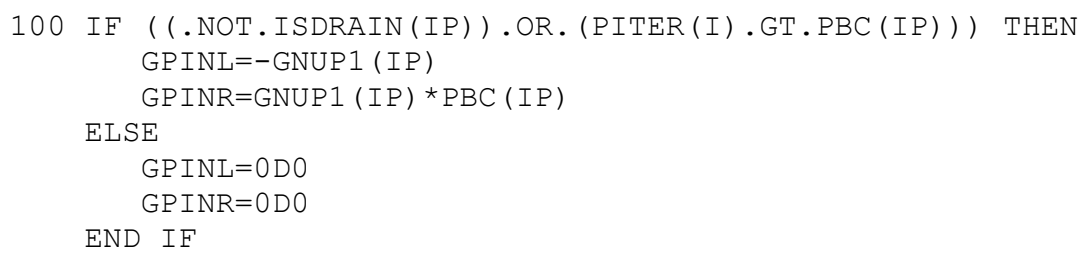

In subroutine BUDGET:

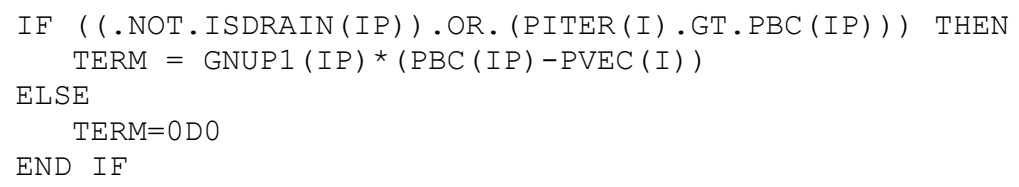

within DO loop 200, and

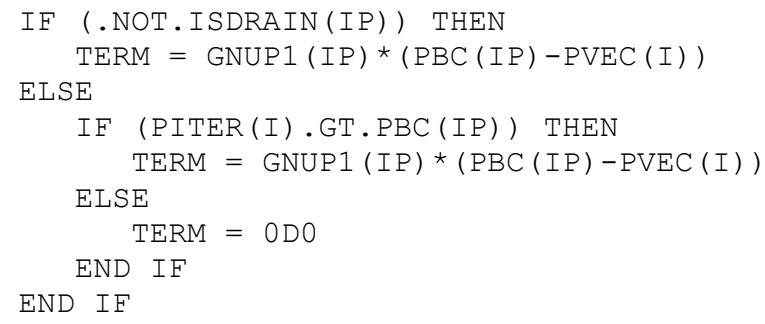

within DO loop 700. The write statement within DO loop 700 has been replaced with

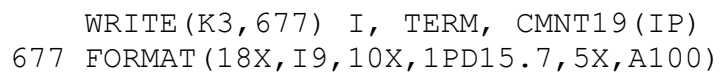

which immediately follows the block IF statement. In subroutine SUTRA, the two lines that update elements of array QPLITR have each been replaced with

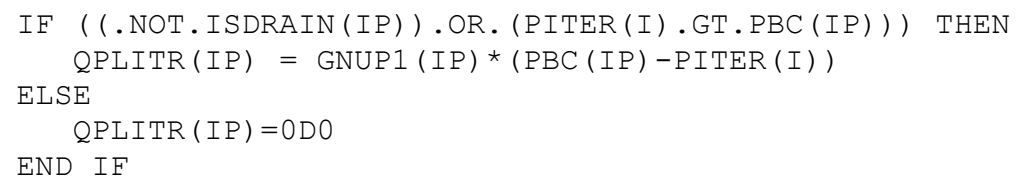


For reverse-flow simulations (antidrains), the ".GT." operator is changed to ".LT." in each of the four block IF statements immediately above.

Array PITER holds the latest iterate of the pressure (head) solution. It is has been added to the argument lists and dimension statements of subroutines BC and BUDGET to facilitate drain calculations.

\section{Piecewise-linear unsaturated-flow functions}

The unsaturated-flow functions are programmed such that saturation is a piecewise-linear function of pressure and relative permeability is a linear function of saturation. Two zones with distinct unsaturated-flow parameters are defined.

In zone 1, the following four parameters are specified by the user: the residual saturation, SWRES1; the air entry pressure, PENT1; the pressure at which the residual saturation is reached, PSWRES1; and the relative permeability at the residual saturation, RKRES1. For pressures greater than or equal to PENT, saturation equals 1 . For pressures less than or equal to PSWRES1, saturation equals the residual saturation. For intermediate pressures, saturation varies linearly between these two bounding values. Relative permeability varies linearly between a value of RKRES1 at a saturation of SWRES1 and a value of 1 at a saturation of 1 . Unsaturated-flow behavior in zone 2 is governed by analogous parameters SWRES2, PENT2, PSWRES2, and RKRES2.

Unsaturated-flow input parameters are specified by the user in a separate file called "plunsat.dat", which must reside in the directory in which the SUTRA simulation is being run. Input consists of two lines. On the first line, SWRES1, PENT1, PSWRES1, and RKRES1 are listed, in that order. On the second line, SWRES2, PENT2, PSWRES2, and RKRES2 are listed, in that order. The following code has been added to the main program, immediately after the element incidence list is read by subroutine CONNEC, to read input data from file "plunsat.dat":

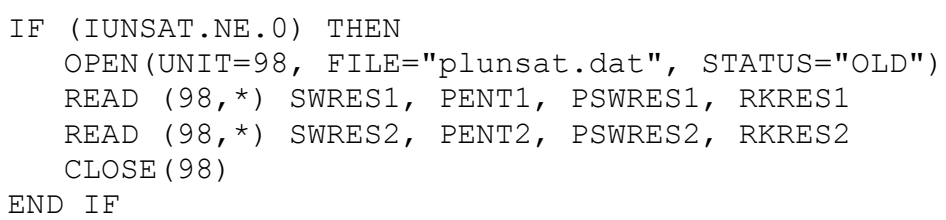

The eight input parameters are declared as REAL and are passed to the main program and subroutine UNSAT through two common blocks:

COMMON /UNSAT1/ SWRES1, PENT1, PSWRES1, RKRES1

COMMON /UNSAT2/ SWRES2, PENT2, PSWRES2, RKRES2

Subroutine UNSAT, which calculates unsaturated flow functions, has been modified in a number of places and is listed in Appendix 3. The modifications have to do with piecewise-linear unsaturated flow functions and the new ".bco*" output files. 


\section{Head-based simulations with unsaturated flow}

For simulations of fully saturated, constant-density flow, SUTRA can be made to effectively solve for hydraulic heads instead of pressures by scaling the input variables appropriately. To allow head-based simulations with unsaturated flow, SUTRA has been modified to make the conversions from head to pressure that are required prior to calling subroutine UNSAT. This capability is supported only in 3D simulations.

To perform 3D, unsaturated, head-based basis function calculations, subroutine BASIS3 must take into account altitude. Accordingly, a new quantity, ZG, has been introduced. ZG is initialized to zero immediately before DO loop 1000, then assembled within the loop using the statement

$Z G=Z G+Z(I) * F(I L)$

ZG is subsequently used in the conversion from head to pressure that precedes the updated calculation of unsaturated flow parameters in BASIS3:

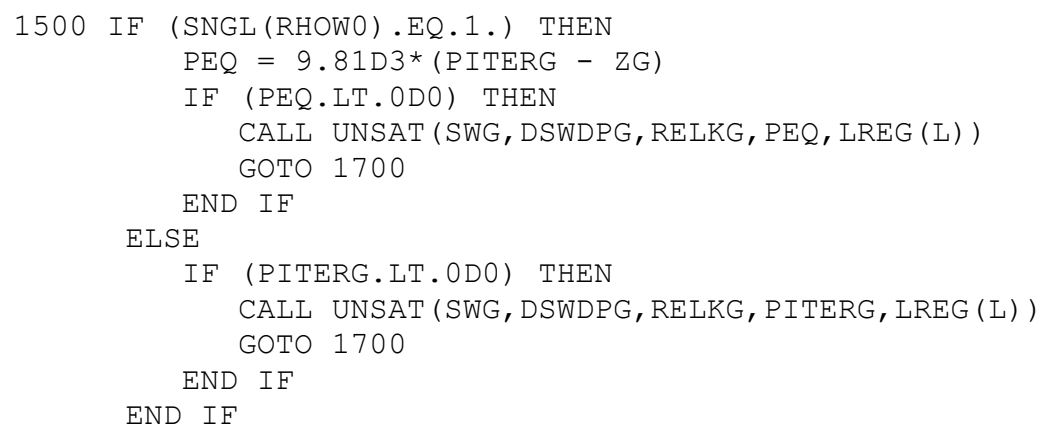

Similar modifications were made to calculations of unsaturated flow parameters throughout the SUTRA source code. In subroutine BUDGET:

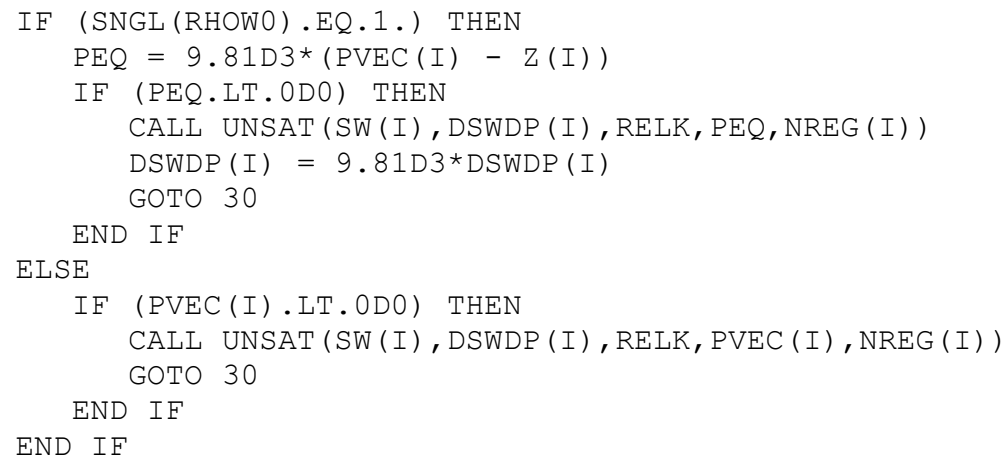

In subroutine INDAT2:

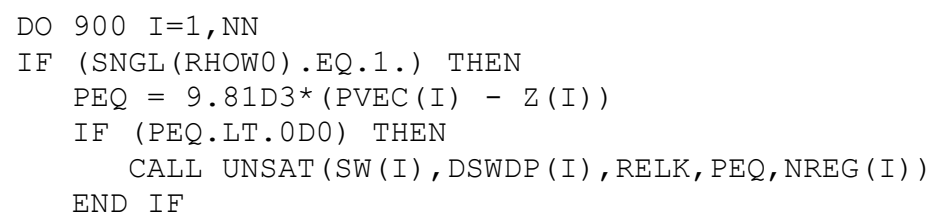




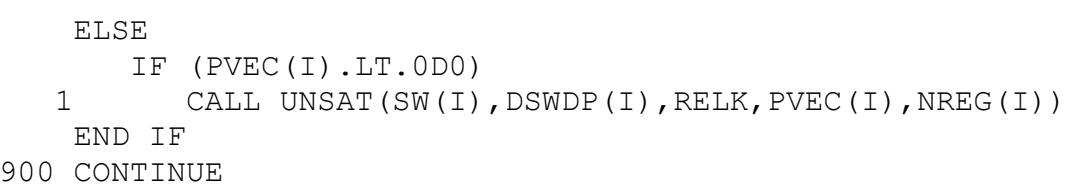

In subroutine NODAL:

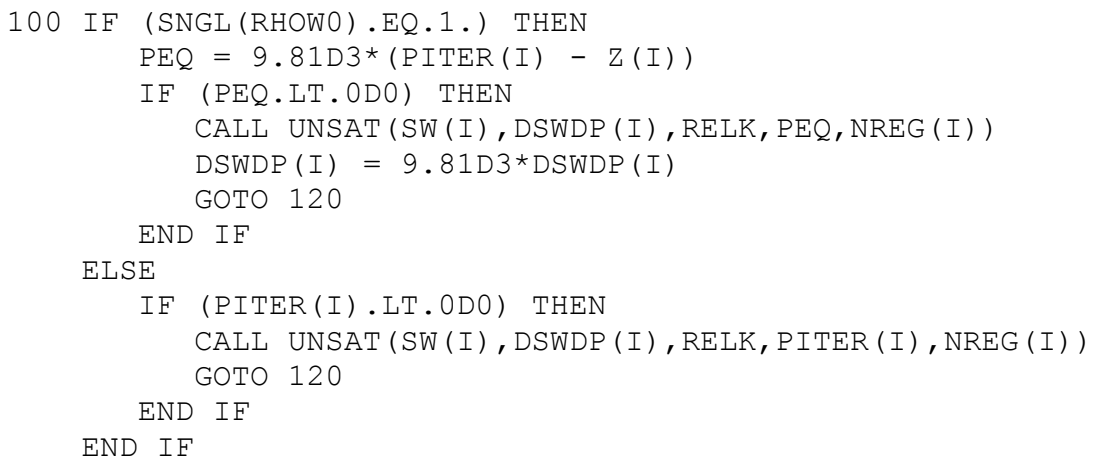

The updates described above require adding the array of node altitudes, $Z$, to the argument lists and dimension statements of subroutines BUDGET, INDAT2, and NODAL. For reverse-flow simulations (antidrains), the four block IF statements listed immediately above are modified by substituting either PITERG for PITERG, -PVEC for PVEC, or -PITER for PITER in both parts of the block IF statement. In the second part of each block IF statement, this is accomplished by setting an intermediate variable, $P E Q$, to -PITERG, -PVEC, or -PITER and passing PEQ to subroutine UNSAT in place of PITERG, PVEC, or PITER.

Accounting for altitude in unsaturated flow parameter calculations also entails passing observation point altitudes to function PUSWF, which interpolates values of pressure, concentration or temperature, and saturation in time. In all calls to PUSWF, observation point altitude, OBSPTS(JJ)\%Z (where $\mathrm{JJ}$ is the observation point number), is inserted in the argument list immediately before variable SFRAC. The corresponding variable within PUSWF is ZG. In module EXPINT, the explicit interface for PUSWF has been updated by inserting variable ZG into the argument list immediately before variable SFRAC. Function PUSWF has been modified in a number of places and is listed in Appendix 3.

The following warning message has been added to subroutine INDAT1:

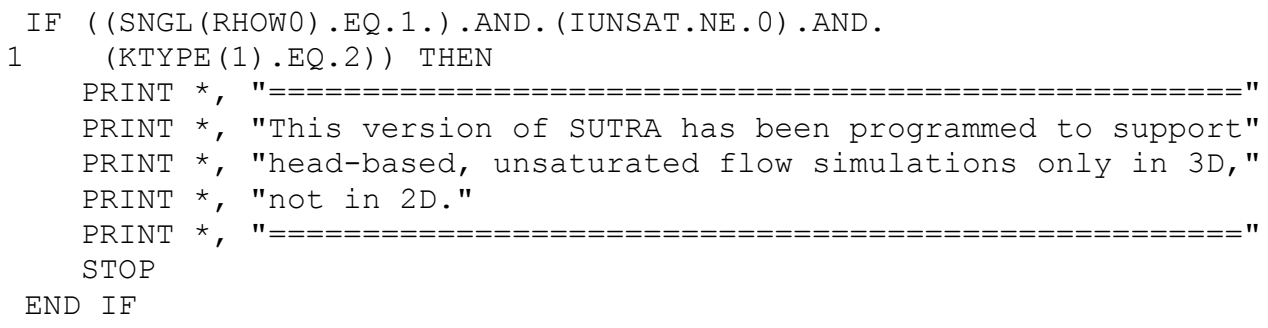




\section{Optional output of simulated values to ".Ist" file}

Input variables CPANDS and CCORT, both character variables of length 1, have been added to ".inp" dataset $8 \mathrm{~A}$ to control whether simulated pressures and saturations, and concentrations or temperatures, are written to the "Ist" output file. CPANDS is listed immediately after CINCID, and CCORT is listed immediately after CVEL in dataset 8A.

These two new variables are declared and read in subroutine INDAT1. The section of code that performs the read has been expanded to

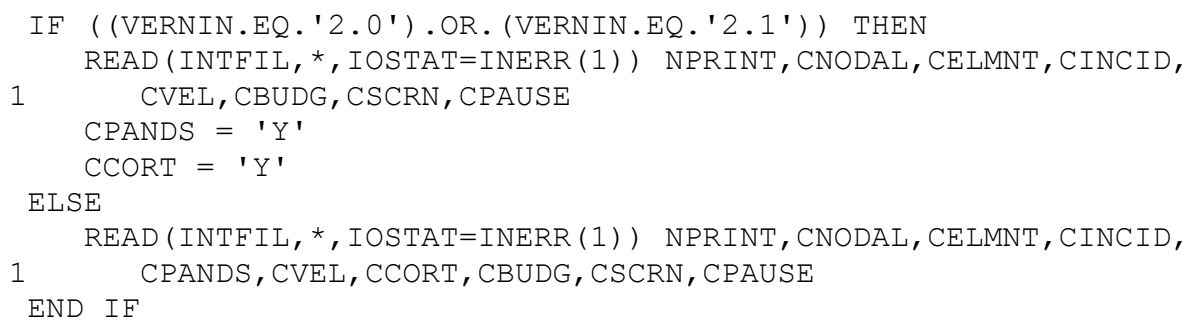

After dataset $8 \mathrm{~A}$ is read, print flags KPANDS and KCORT are set as follows:

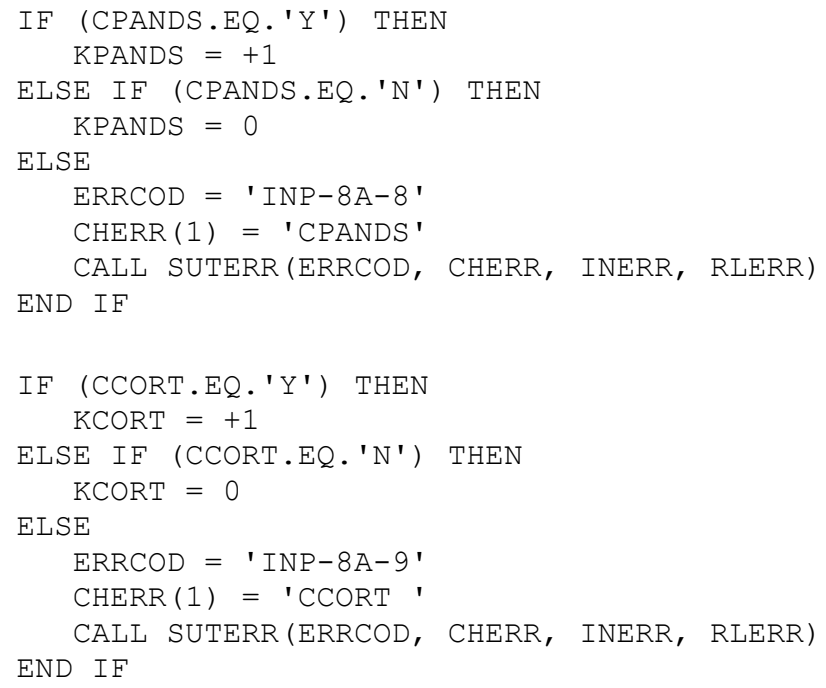

KPANDS and KCORT have been added to COMMON block KPRINT and are thereby passed to all program units that contain that COMMON block.

The section of subroutine INDAT1 that writes print flag information for pressures, saturations, velocities, and concentrations or temperatures to the ".Ist" file has been modified and expanded to

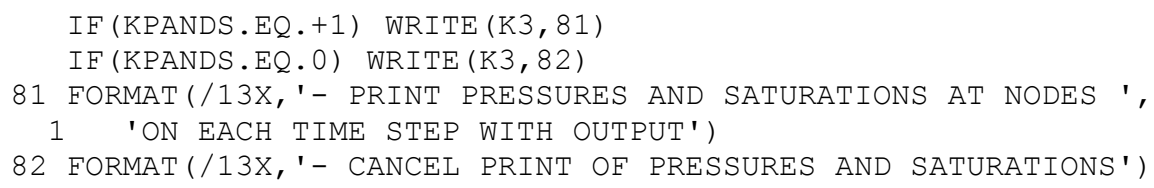




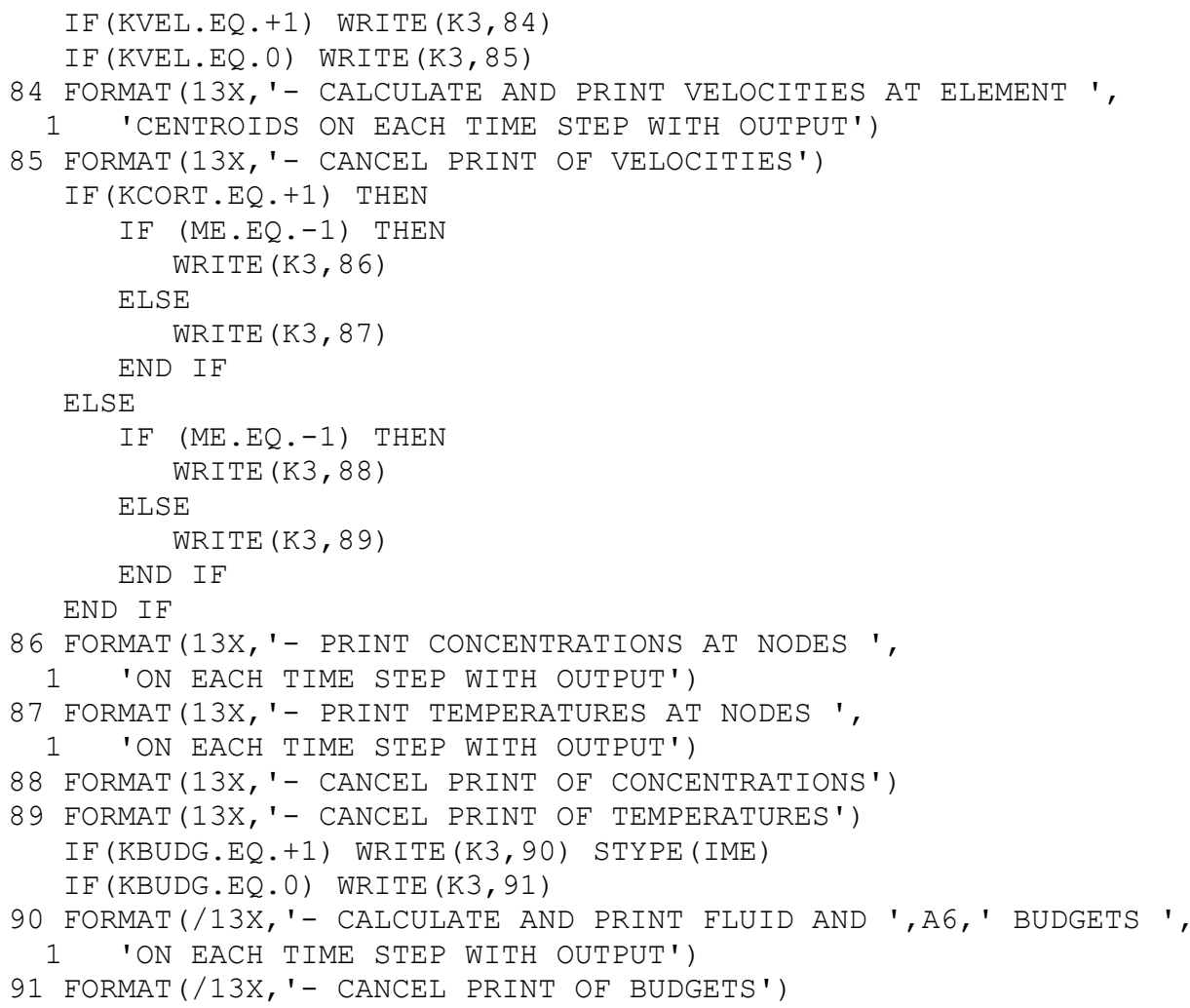

In subroutines OUTLST2 and OUTLST3, the sections of code that write pressures, saturations, and concentrations or temperatures to the ".Ist" file have each been embedded in an IF statement such that writing occurs only if the corresponding print flag is set to 1 .

In the error handling subroutine, SUTERR, the condition that checks for error conditions beginning with "INP-8A" has been expanded to

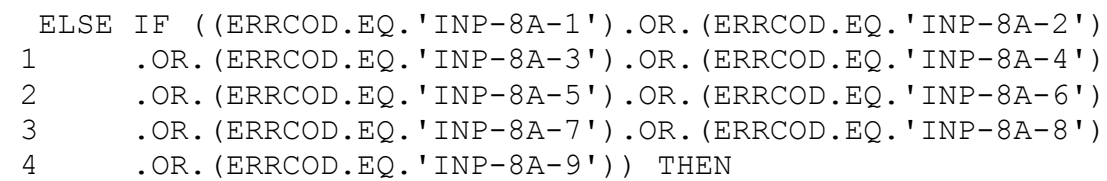

For these error conditions, line 5 of the explanation has been changed to

$$
\operatorname{EX}(5)=" 10 \quad \text { 'N' 'N' 'N' 'Y' 'Y' 'Y' 'Y' 'Y' 'Y' 'Y' 'Y'" }
$$

which also reflects changes made in connection with the new ".bco*" output files. Error messages for conditons "INP-8A-8" and "INP-8A-9" have not been added to subroutine SUTERR.

\section{More efficient processing of schedules}

The efficiency with which schedules are created has been improved by keeping track of the largest time and the last entry in each schedule. In module SCHDEF, two components have been added:

DOUBLE PRECISION : : TLGST 
In subroutine LLDINS, which is used to construct schedules in the form of linked lists, two corresponding arguments, DLGST1 and DLAST, have been added to the argument list, and DLAST has been declared as a pointer of type LLD. In module EXPINT, the explicit interface for LLDINS has accordingly been updated to

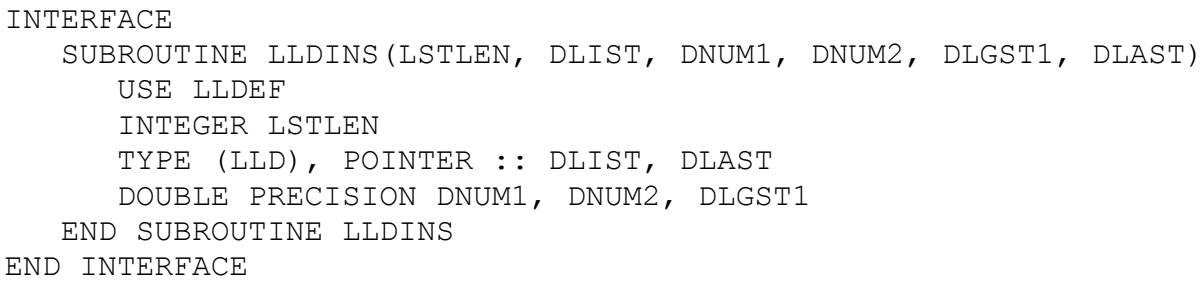

In the section of LLDINS that places entries at the head of the linked list, the statement "GOTO 780" has been replaced with

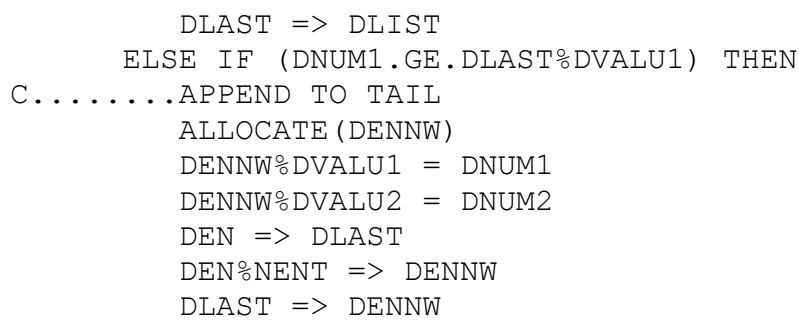

and the section that formerly appended entries to the tail of the list (between the line labeled "770" and the subsequent "END IF") has been deleted.

In subroutine INDATO, SCHDLS(iv)\%SLAST has been added to the ALLOCATE statement and initialized to HUGE(1D0) in DO loops 135, 185, and 800; here, iv stands for the corresponding DO loop index variable (NS or I). In INDATO, all lines of the form "LSTLEN = 0", "SCHDLS(I)\%LLEN = LSTLEN", or "SCHDLS(I)\%LLEN = NTLIST" have been deleted, the line

ITMAX $=$ SCHDLS $(1) \circ L L E N-1$

has been added immediately after the line labeled "580", the two lines that deallocate and allocate SCHDLS(ISCHTS)\%SLIST (schedule "TIME_STEPS") have been replaced with

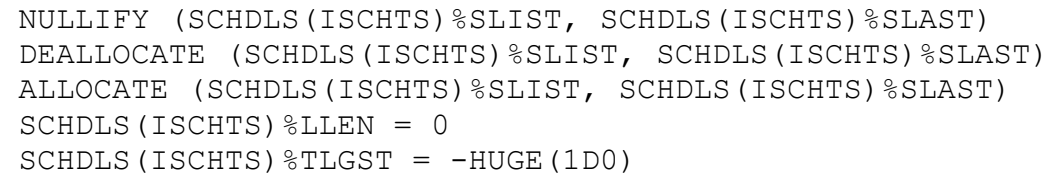

and the two lines that deallocate and allocate SCHDLS(I)\%SLIST within DO loop 845 have been replaced with

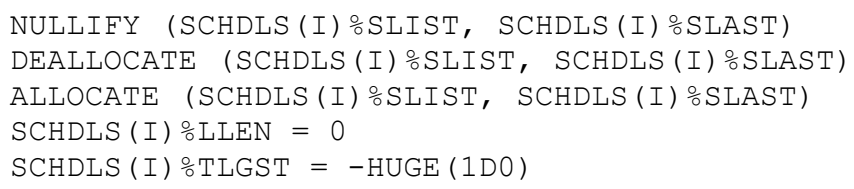


In subroutine INDAT1, all lines of the form "LSTLEN = 0", "SCHDLS(2)\%LLEN = LSTLEN", or "SCHDLS(2)\%LLEN = 0" have been deleted.

In subroutines INDAT0 and INDAT1, all calls to subroutine LLDINS have been modified with the substitution of SCHDLS(ns)\%LLEN for LSTLEN and the addition of SCHDLS(ns)\%TLGST and SCHDLS(ns)\%SLAST to the end of the argument list; here, $n s$ stands for the schedule number specified for SCHDLS()\%SLIST in the call to LLDINS. For example,

CALL LLDINS (LSTLEN, SCHDLS (1) NLIST, TIME, STEP)

has been modified to

CALL LLDINS (SCHDLS(1) LLEN, SCHDLS(1)SLIST, TIME, STEP, $1 \quad \operatorname{SCHDLS}(1) \div \mathrm{TLGST}, \operatorname{SCHDLS}(1) \div \mathrm{SLAST})$

\section{Miscellaneous}

In the main program, parameter VERN, which holds the SUTRA version number, has been set to " 2.2 " in anticipation of the next software release, and the conditional that checks for error condition "INP-2A-4" has been modified to

ELSE IF ( (VERNIN.NE.'2.0 ').AND. (VERNIN.NE.'2.1 ').AND

1 (VERNIN.NE.'2.2')) THEN

In subroutine SUTRA, the condition that determines whether subroutine OUTRST is called has been modified to make the call contingent on the existence of a ".rst" file, which is now optional:

IF ((K4.NE.-1).AND.(ISTORE.NE.0).AND.((ISTOP.NE.0).OR.

1 (MOD(IT,ISTORE).EQ.0)))

2 CALL OUTRST(PVEC,UVEC,PM1,UM1,CS1,RCIT,SW,QINITR,PBC,GNUP1)

In format statement 1500 of subroutine INDAT1, both instances of the formatting code "2(64X)" are replaced with the equivalent code "128X".

In subroutines FINDL2 and FINDL3, COMMON block DIMS is only partially specified

COMMON /DIMS/ NN, NE

and in FORMAT statement 1888 of subroutine SUTERR, the comma follow the formatting code "A38" has been omitted.

There is no evidence that either of these omissions affected the proper functioning of the code when compiled with the Compaq Digital Fortran compiler. 


\section{Appendix 2: Input Data for the Time-Dependent Sources and Boundary Conditions Files (.bcs)}

These input files allow the user to change the values of sources and boundary conditions, and to turn them on or off, at any time step during a simulation. Once made, specifications remain in force until they are changed or turned off. For example, a specified pressure node will have a certain value of prescribed pressure until that value is changed or turned off (rendered inactive) by a subsequent specification.

The ".bcs" files may be omitted if there are no time-dependent sources or boundary conditions (other than those specified in subroutine BCTIME).

The ".bcs" files contains specifications for time-dependent sources and boundary conditions:

- The input formats of datasets $2-5$ parallel those of datasets $17-20$ of the ".inp" (main input) file.

- Specifications made in ".bcs" files take precedence over those made in the ".inp" file and subroutine BCTIME.

- The ".bcs" files are not read if the simulation is purely steady-state (steady flow and steady transport). In that case, the sources and boundary conditions specified in ".inp" datasets $17-$ 20 are used.

- On each time step, the ".bcs" files are processed in the order in which they appear in the "SUTRA.FIL" file.

- On each time step, multiple specifications of the same type at the same node are resolved in favor of the last specification read.

When using time-dependent sources and boundary conditions, whether they are specified in the ".bcs" file or in subroutine BCTIME, the user is responsible for ensuring the following:

- A flow and transport solution must occur on any time step in which the prescribed source rate for a fluid source node changes.

- A transport solution must occur on any time step in which the prescribed source concentration/temperature for a fluid source node changes.

- A transport solution must occur on any time step in which the prescribed source rate for a solute/energy source node changes.

- A flow and transport solution must occur on any time step in which the prescribed pressure for a specified pressure node changes.

- A transport solution must occur on any time step in which the prescribed concentration/temperature of inflowing fluid for a specified pressure node changes.

- A transport solution must occur on any time step in which the prescribed concentration/temperature for a specified concentration/temperature node changes.

Note that inactivating or reactivating a node (by changing its node number from positive to negative, or vice versa, in the ".bcs" file), as a rule, constitutes a change in its specifications. Cycling of flow and 
transport solutions is controlled by NPCYC and NUCYC in dataset 6 of the ".inp" file. Setting NPCYC=NUCYC $=1$ automatically satisfies all requirements listed above by causing a flow and transport solution to occur on every time step.

In each ".bcs" file, datasets 1 - 5 (listed below) are required for each time step on which timedependent source and boundary condition specifications are made in that ".bcs" file.

Time steps must appear in chronological order within each ".bcs" file.

DATASET 1: Time Step Number and Time-Dependent Source and Boundary Condition Counts (one line)

$\begin{array}{lll}\text { Variable } & \text { Type } & \text { Description } \\ \text { ITNBCS } & \text { Integer } & \begin{array}{l}\text { Time step number at which the source and boundary } \\ \text { condition specifications are to be applied. }\end{array} \\ \text { NSOP1 } & \text { Integer } & \begin{array}{l}\text { Exact number of nodes at which a fluid source/sink is } \\ \text { specified for time step ITNBCS. }\end{array} \\ \text { NSOU1 } & \text { Integer } & \begin{array}{l}\text { Exact number of nodes at which an energy or solute mass } \\ \text { source/sink is specified for time step ITNBCS. }\end{array} \\ \text { NPBC1 } & \text { Integer } & \begin{array}{l}\text { Exact number of nodes at which pressure is specified for } \\ \text { time step ITNBCS. }\end{array} \\ \text { NUBC1 } & \text { Integer } & \begin{array}{l}\text { Exact number of nodes at which temperature or } \\ \text { concentration is specified constant for time step ITNBCS. }\end{array}\end{array}$

Note:

NSOP1, NSOU1, NPBC1, and NUBC1 give the number of nodes listed in ".bcs" datasets 2, 3, 4, and 5 , respectively. 
DATASET 2: Time-Dependent Fluid Sources and Sinks (one line for each of NSOP1 fluid source nodes as specified in ".bcs" DATASET 1, plus one line)

OMIT when there are no fluid sources/sinks to be specified for time step ITNBCS (NSOP1=0). Specifications made in this dataset take precedence over those made in ".inp" dataset 17 (and subroutine BCTIME).

Variable Type Description

Lines 1 to NSOP1:

IQCP1 Integer Number of node to which source/sink data on this line refers. Specifying the node number with a negative sign renders the fluid-source/sink condition inactive at node IQCP1 during time step ITNBCS, which sets the source/sink rate to zero and gives the user the option of suppressing output for the inactive source node by setting CINACT='N" in ".inp" dataset 8E.

Any node listed in this dataset must also be listed in ".inp" dataset 17.

QINC1 Real Fluid source (or sink) at node IQCP1 during time step ITNBCS, $\mathrm{Q}_{\text {IN. }}[\mathrm{M} / \mathrm{s}]$.

A positive value is a source of fluid to the aquifer. May be omitted if the source node is inactive (IQCP1<0).

UINC1 Real Temperature or solute concentration (mass fraction) of fluid entering the aquifer at node IQCP1 during time step ITNBCS, $\mathrm{U}_{\mathrm{IN}} \cdot\left[{ }^{\circ} \mathrm{C}\right]$ or $\left[\mathrm{M}_{\mathrm{s}} / \mathrm{M}\right]$.

May be omitted if if the source node is inactive $(\mathrm{IQCP} 1<0)$ or if QINC1 $\leq$.

Last line:

Integer Placed immediately following all NSOP1 fluid source node lines. Line must begin with the integer 0 . 
DATASET 3: Time-Dependent Energy or Solute Mass Sources and Sinks

(one line for each NSOU1 energy or solute source nodes as specified in ".bcs" DATASET 1, plus one line)

O M IT when there are no energy or solute sources/sinks to be specified for time step ITNBCS (NSOU1=0).

Specifications made in this dataset take precedence over those made in ".inp" dataset 18 (and subroutine BCTIME).

Variable Type Description

Lines 1 to NSOU1:

IQCU1 Integer Number of node to which source/sink data on this line refers. Specifying the node number with a negative sign renders the solute/energy-source/sink condition inactive at node IQCU1 during time step ITNBCS, which sets the source/sink rate to zero and gives the user the option of suppressing output for the inactive source node by setting CINACT='N' in “.inp" dataset 8E.

Any node listed in this dataset must also be listed in ".inp" dataset 18.

QUINC1 Real Source (or sink) of solute or energy at node IQCU1 suring time step ITNBCS, $\psi_{\mathrm{IN}}$. $[\mathrm{E} / \mathrm{s}]$ for energy transport, $\left[\mathrm{M}_{\mathrm{s}} / \mathrm{s}\right]$ for solute transport.

A positive value is a source to the aquifer. May be omitted if the source node is inactive (IQCU1<0).

Last line:

Integer Placed immediately following all NSOU1 energy or solute mass source node lines. Line must begin with the integer 0 . 
DATASET 4: Time-Dependent Specified Pressures (one line for each of NPBC1 specified pressure nodes as indicated in ".bcs" DATASET 1, plus one line)

O M I T when there are no pressures to be specified for time step ITNBCS (NPBC1=0).

Specifications made in this dataset take precedence over those made in ".inp" dataset 19 (and subroutine BCTIME).

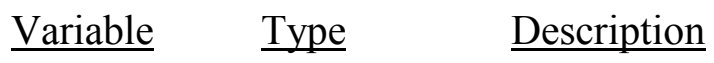

Lines 1 to NPBC1:

IPBC1 Integer Number of node to which specified pressure data on this line refers. Specifying the node number with a negative $\underline{\text { sign }}$ renders the specified-pressure condition inactive (it is not applied) at node IPBC1 during time step ITNBCS, which gives the user the option of suppressing output for the inactive boundary condition by setting CINACT=' $N$ ' in “.inp" dataset 8E.

Any node listed in this dataset must also be listed in ".inp" dataset 19.

PBC1 Real Pressure value specified at node IPBC1 during time step ITNBCS. $\left[\mathrm{M} /\left(\mathrm{L} \cdot \mathrm{s}^{2}\right)\right]$.

May be omitted if the boundary condition is inactive $(\mathrm{IPBC} 1<0)$.

UBC1 Real Temperature or solute concentration of any external fluid that enters the aquifer at node IPBC1 during time step ITNBCS. $\left[{ }^{\circ} \mathrm{C}\right]$ or $\left[\mathrm{M}_{\mathrm{s}} / \mathrm{M}\right]$.

May be omitted if the boundary condition is inactive $(\mathrm{IPBC} 1<0)$.

Last line:

Integer $\quad$ Placed immediately following all NPBC1 specified pressure lines. Line must begin with the integer 0 . 
DATASET 5: Time-Dependent Specified Concentrations or Temperatures

(one line for each of NUBC1 specified concentration or

temperature nodes indicated in ".bcs" DATASET 1, plus one line)

O M I T when there are no concentrations or temperatures to be specified for time step ITNBCS (NUBC1=0).

Specifications made in this dataset take precedence over those made in ".inp" dataset 20 (and subroutine BCTIME).

$\underline{\text { Variable }}$ Type $\quad \underline{\text { Description }}$

Lines 1 to NUBC1:

IUBC1 Integer Number of node to which specified concentration or temperature data on this line refers. Specifying the node number with a negative sign renders the specifiedconcentration/temperature condition inactive (it is not applied) at node IUBC1 during time step ITNBCS, which gives the user the option of suppressing output for the inactive boundary condition by setting CINACT $={ }^{\prime} \mathrm{N}$ ' in “inp" dataset $8 \mathrm{E}$.

Any node listed in this dataset must also be listed in ".inp" dataset 20.

UBC1 Real Temperature or solute concentration value specified at node IUBC1 during time step ITNBCS. $\left[{ }^{\circ} \mathrm{C}\right]$ or $\left[\mathrm{M}_{\mathrm{s}} / \mathrm{M}\right]$. May be omitted if the boundary condition is inactive $(\mathrm{IUBC} 1<0)$.

Last line:

Integer Placed immediately following all NUBC1 specified temperature or concentration lines. Line must begin with the integer 0 . 


\section{Appendix 3: Selected SUTRA Subroutines}

This appendix contains listings of selected SUTRA subroutines that have been modified extensively, as well as new SUTRA subroutines.

\section{Subroutine BCSTEP}

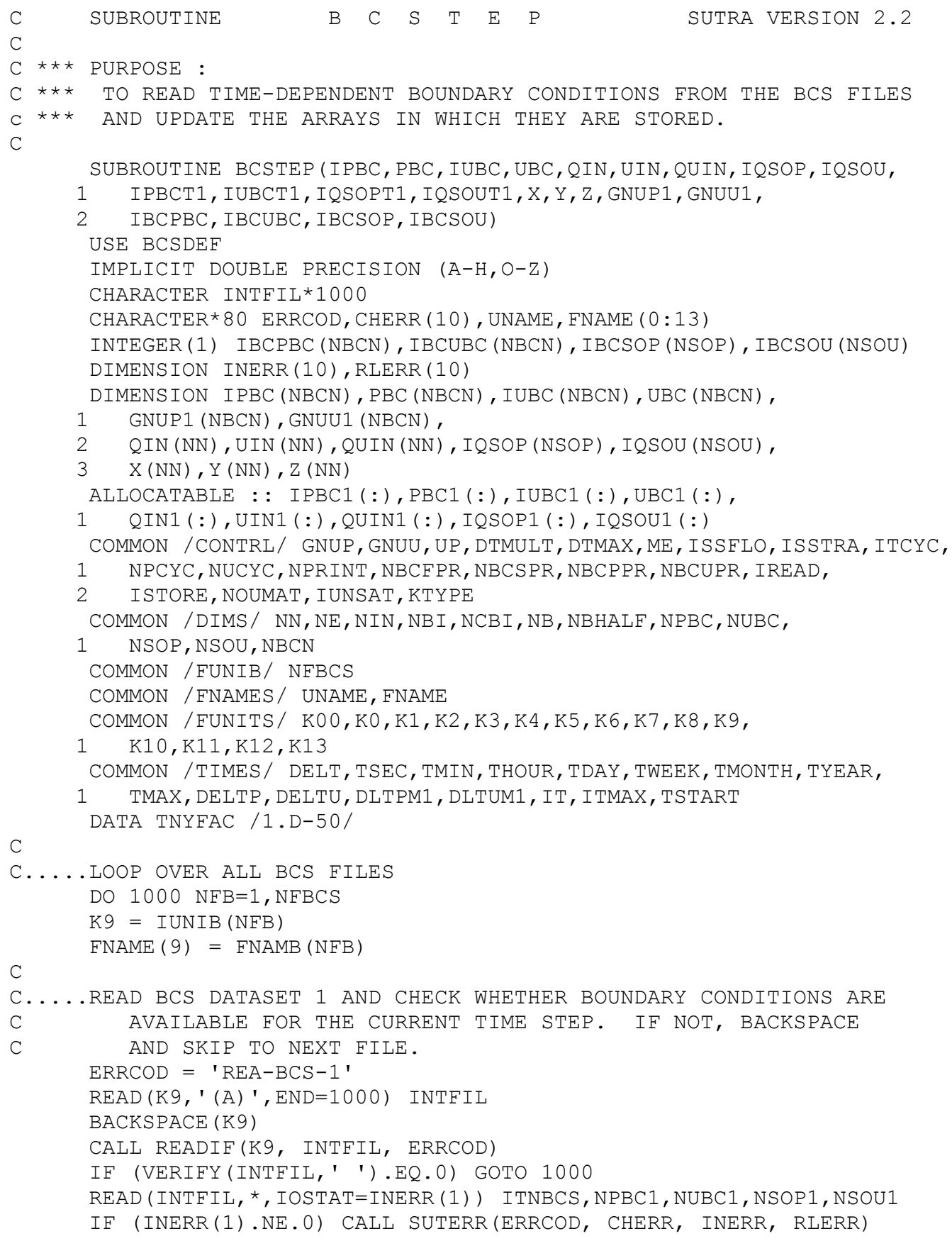




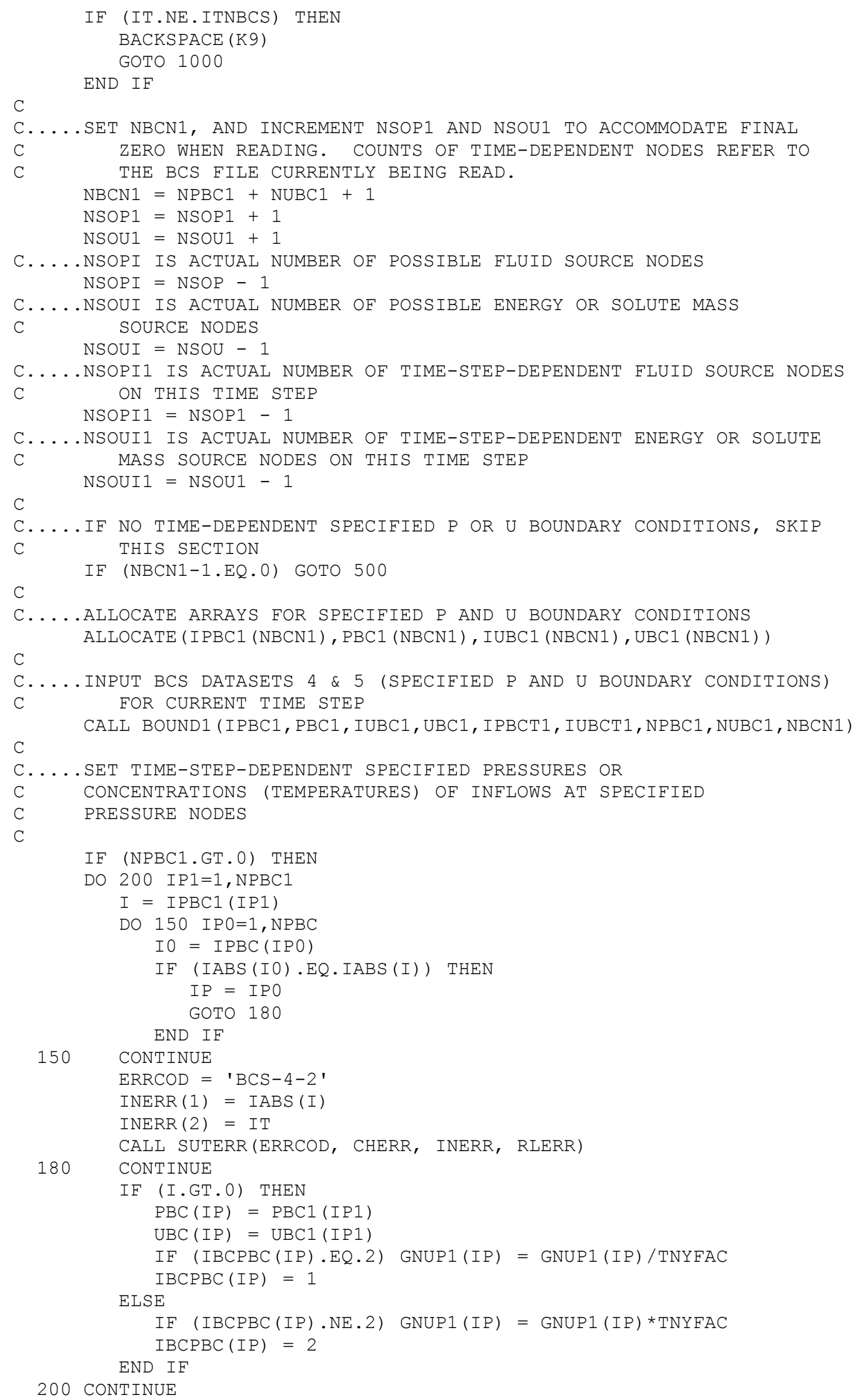




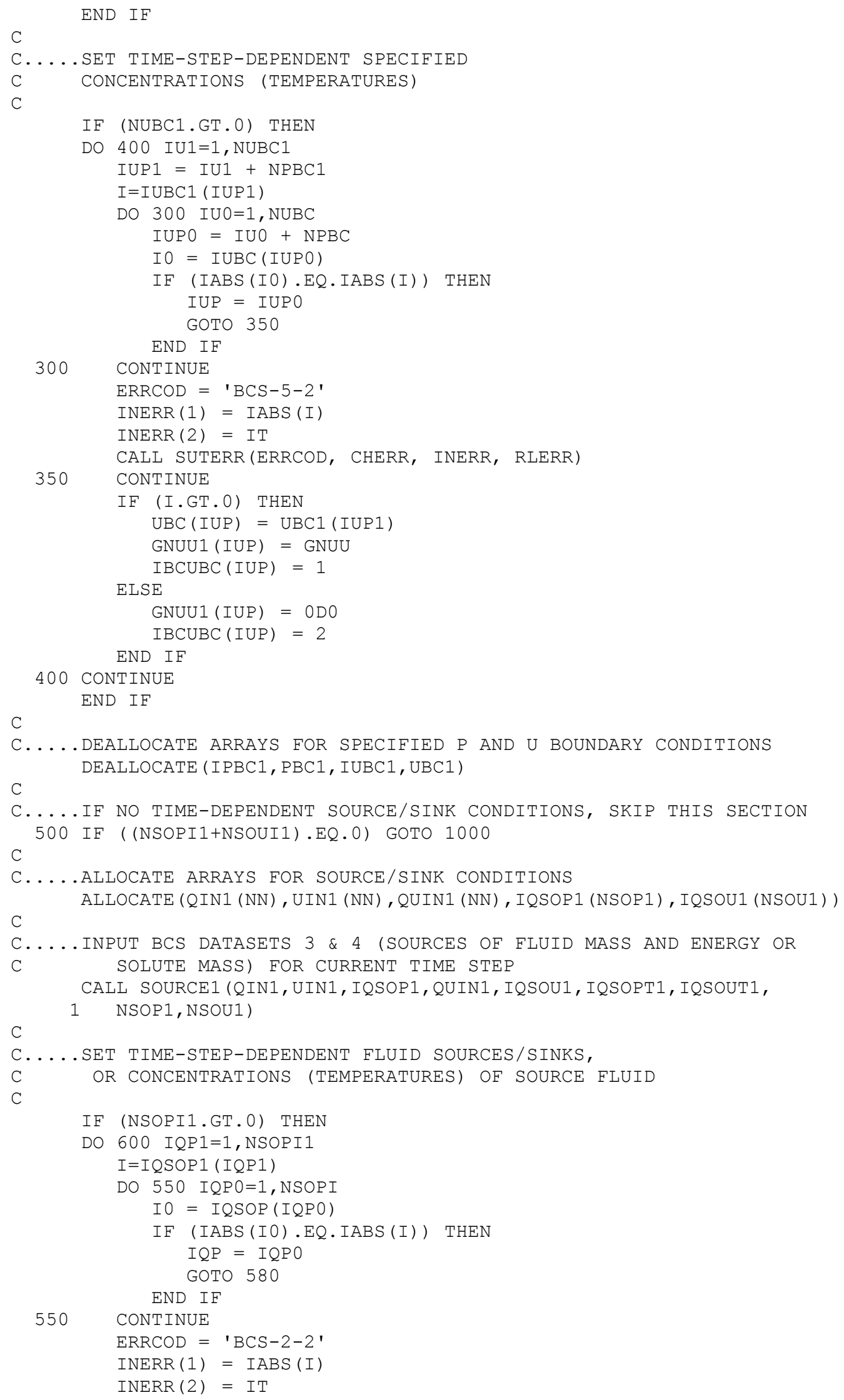




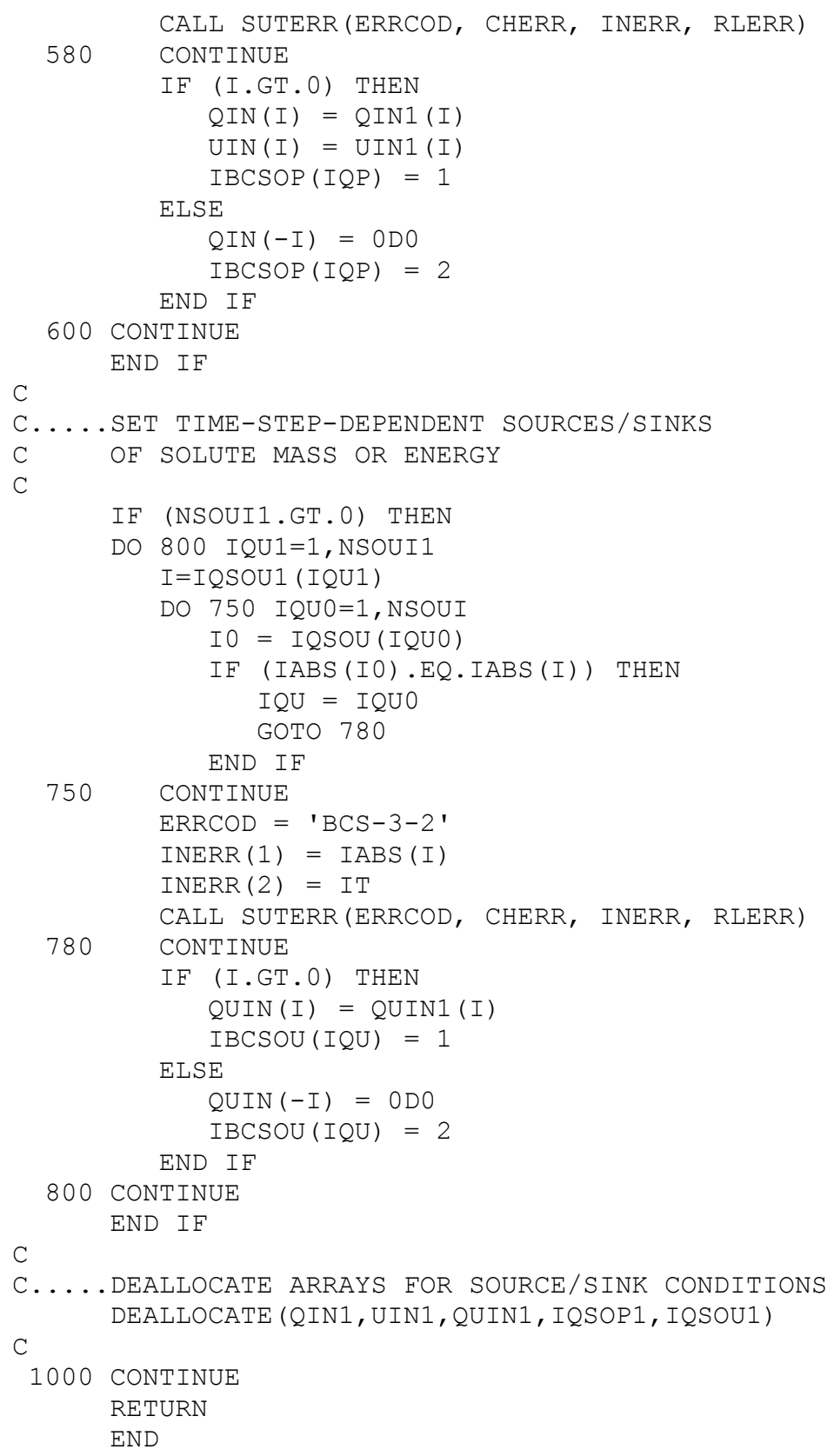

\section{Subroutine BOUND}

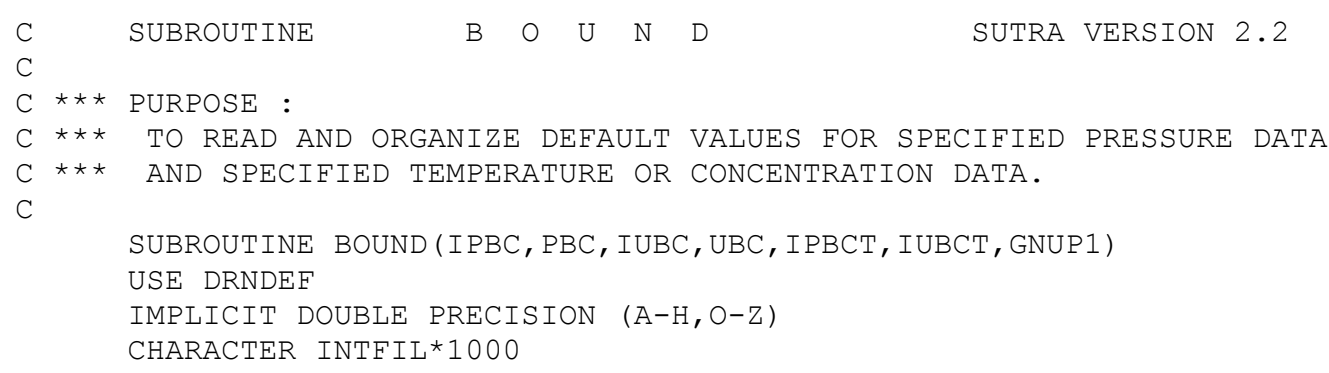




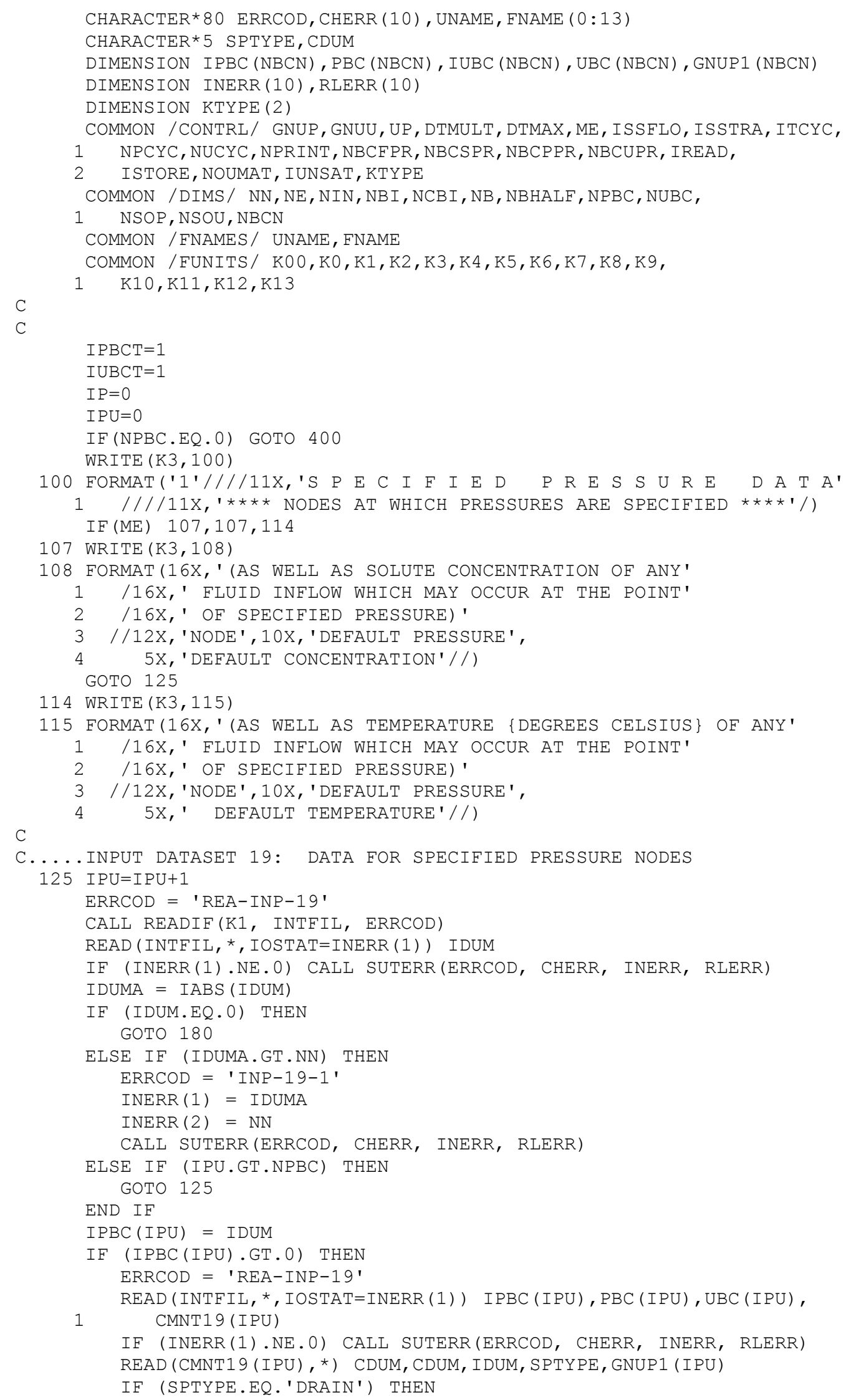




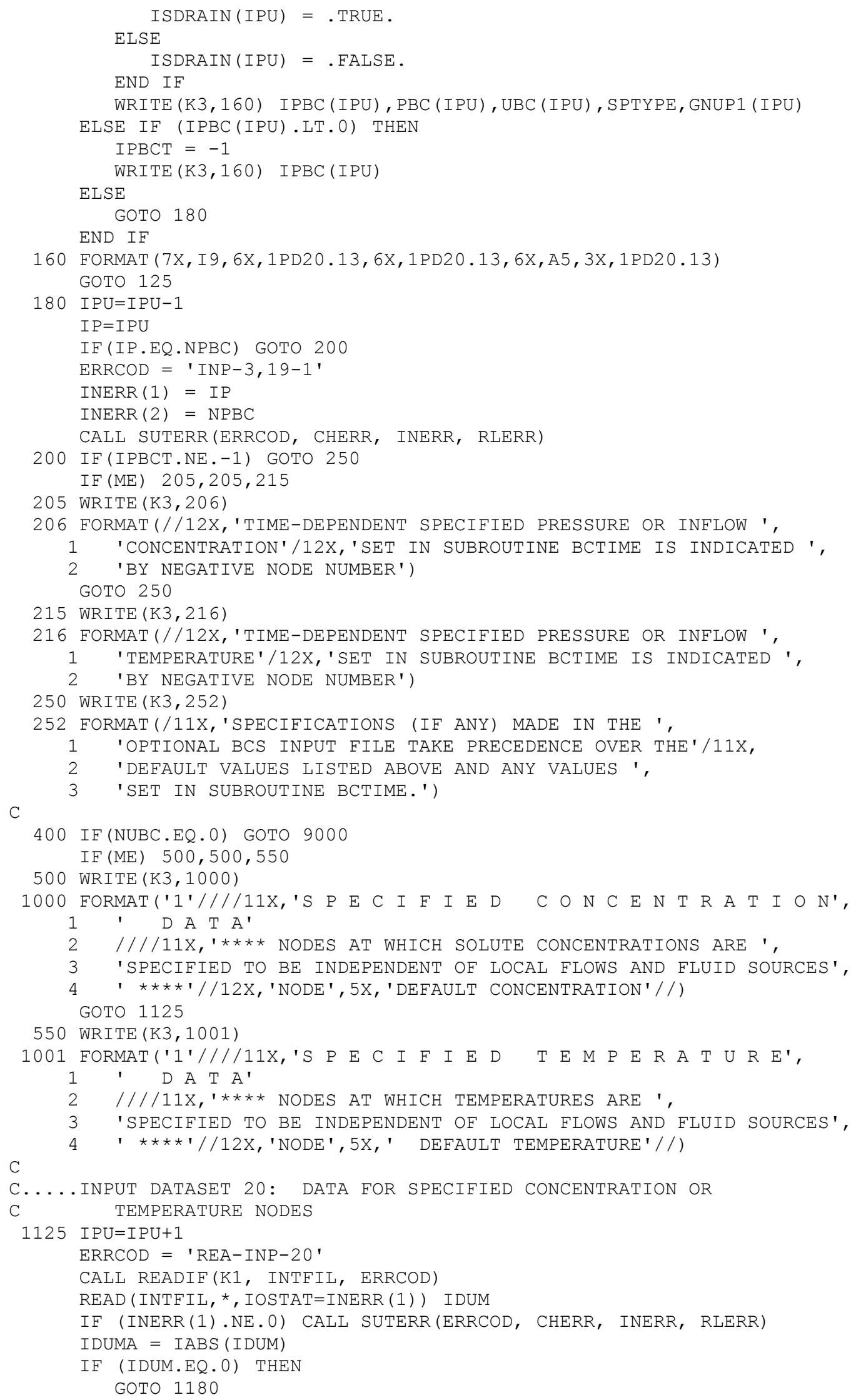




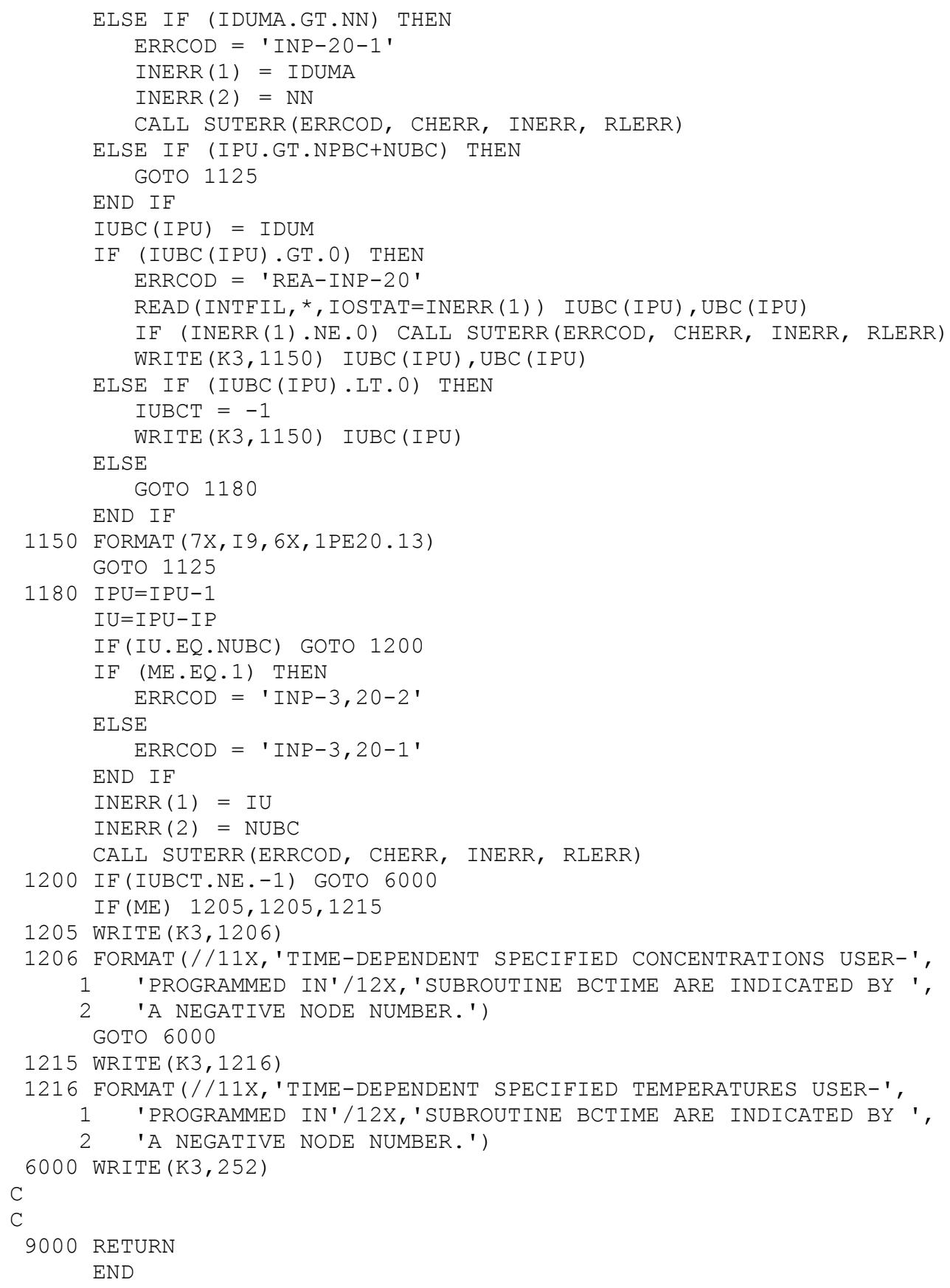

\section{Subroutine BOUND1}

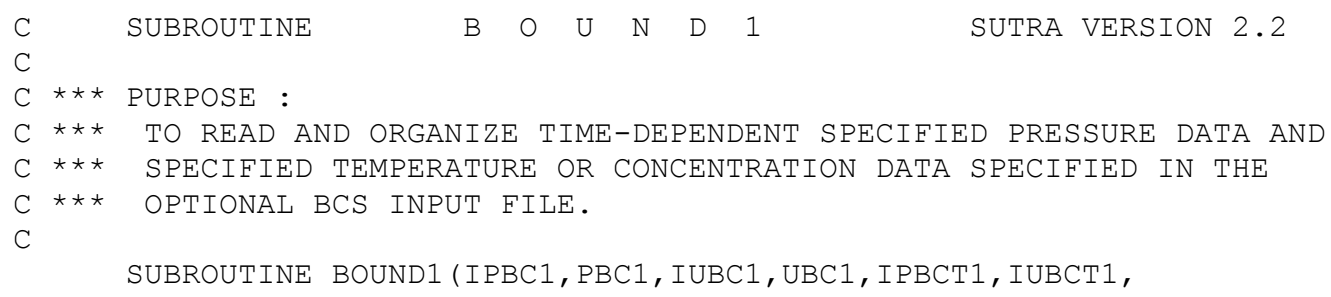


$1 \quad \mathrm{NPBC} 1, \mathrm{NUBC} 1, \mathrm{NBCN} 1$ )

IMPLICIT DOUBLE PRECISION (A-H,O-Z)

CHARACTER INTFIL * 1000

CHARACTER $* 80$ ERRCOD, CHERR (10), UNAME, FNAME $(0: 13)$

DIMENSION IPBC1 (NBCN1), PBC1 (NBCN1), IUBC1 (NBCN1), UBC1 (NBCN1)

DIMENSION INERR (10), RLERR (10)

DIMENSION KTYPE (2)

COMMON /CONTRL/ GNUP, GNUU, UP, DTMULT, DTMAX, ME, ISSELO, ISSTRA, ITCYC,

1 NPCYC, NUCYC, NPRINT, NBCFPR, NBCSPR, NBCPPR, NBCUPR, IREAD,

2 ISTORE, NOUMAT, IUNSAT, KTYPE

COMMON /DIMS / NN, NE, NIN, NBI, NCBI, NB, NBHALF, NPBC, NUBC,

$1 \quad \mathrm{NSOP}, \mathrm{NSOU}, \mathrm{NBCN}$

COMMON / FNAMES / UNAME, FNAME

COMMON / FUNITS/ K00, K0,K1, K2, K3, K4, K5, K6, K7, K8, K9,

$1 \mathrm{~K} 10, \mathrm{~K} 11, \mathrm{~K} 12, \mathrm{~K} 13$

COMMON /TIMES/ DELT, TSEC, TMIN, THOUR, TDAY, TWEEK, TMONTH, TYEAR,

C

1 TMAX, DELTP, DELTU, DLTPM1, DLTUM1, IT, ITMAX, TSTART

$\mathrm{C}$

$I P=0$

$I P U=0$

$\operatorname{IPBCT} 1=+1$

C

IUBCT1 $=+1$

$\mathrm{C}$

IF (NPBC1.EQ.0) GOTO 400

C.... INPUT BCS DATASET 4: DATA FOR SPECIFIED PRESSURE NODES

$\operatorname{IPBCT} 1=-1$

125 IPU $=$ IPU +1

ERRCOD = 'REA-BCS-4'

CALL READIF (K9, INTFIL, ERRCOD)

READ (INTFIL, *, IOSTAT=INERR (1)) IDUM

IF (INERR (1).NE.0) CALL SUTERR (ERRCOD, CHERR, INERR, RLERR)

IDUMA $=$ IABS $($ IDUM $)$

IF (IDUM.EQ.0) THEN

GOTO 180

ELSE IF (IDUMA.GT.NN) THEN

$\mathrm{ERRCOD}=$ 'BCS-4-1'

$\operatorname{INERR}(1)=$ IDUMA

$\operatorname{INERR}(2)=\mathrm{NN}$

$\operatorname{INERR}(3)=I T$

CALL SUTERR (ERRCOD, CHERR, INERR, RLERR)

ELSE IF (IPU.GT.NPBC1) THEN GOTO 125

END IF

$I P B C 1(I P U)=I D U M$

IF (IPBC1 (IPU) . GT. 0) THEN

ERRCOD = 'REA-BCS-4'

$\operatorname{READ}($ INTFIL, *, IOSTAT=INERR (1) )

1 IPBC1 (IPU), PBC1 (IPU), UBC1 (IPU)

IF (INERR (1).NE.0) CALL SUTERR (ERRCOD, CHERR, INERR, RLERR)

ELSE IF (IPBC1 (IPU).LT.0) THEN CONTINUE

ELSE

GOTO 180

END IF

GOTO 125

$180 \mathrm{IPU}=\mathrm{IPU}-1$

$I P=I P U$

IF (IP.EQ.NPBC1) GOTO 400

$\mathrm{ERRCOD}=$ 'BCS-1, 4-1'

$\operatorname{INERR}(1)=\operatorname{IP}$

$\operatorname{INERR}(2)=$ NPBC1 


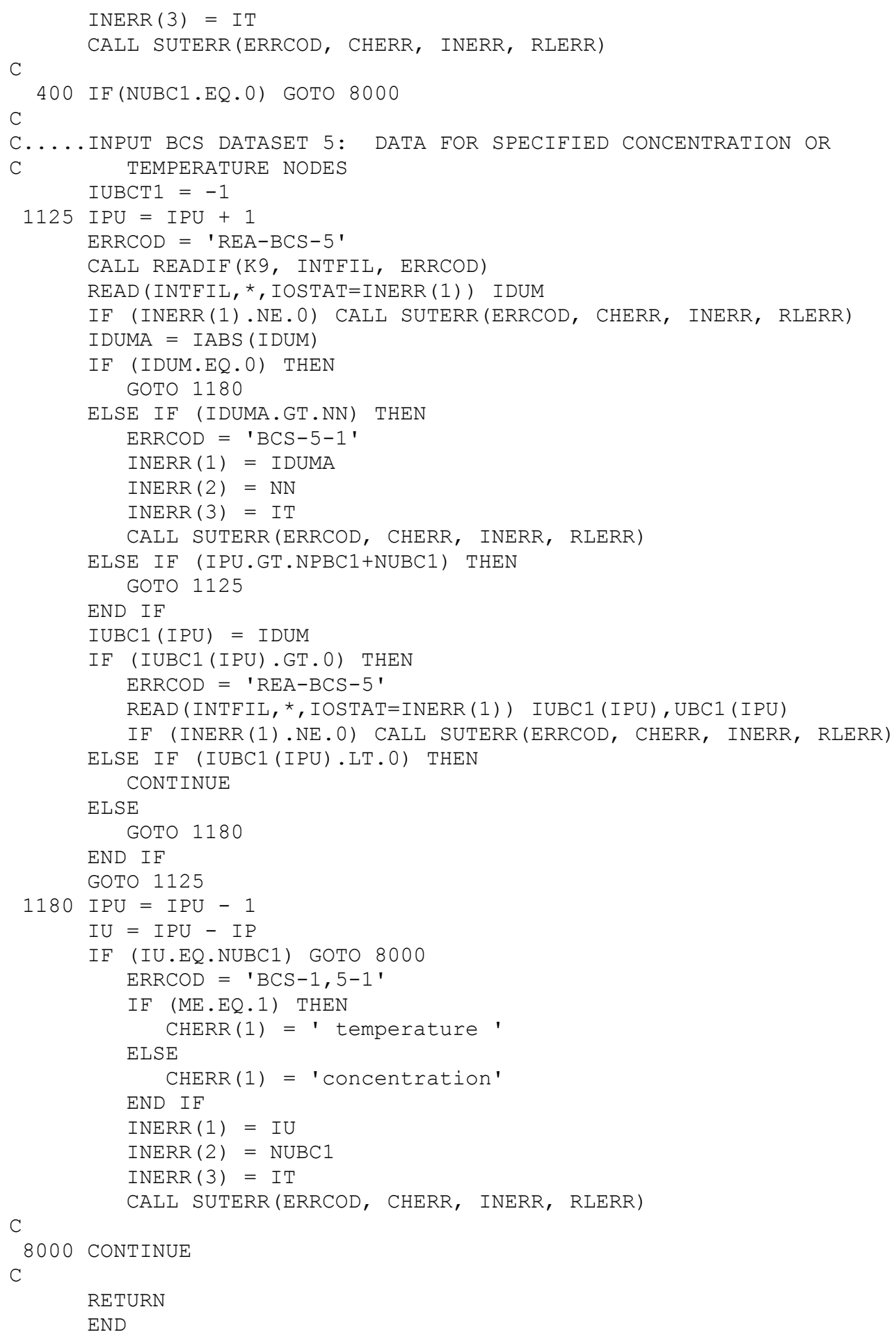

\section{Subroutine FOPEN}

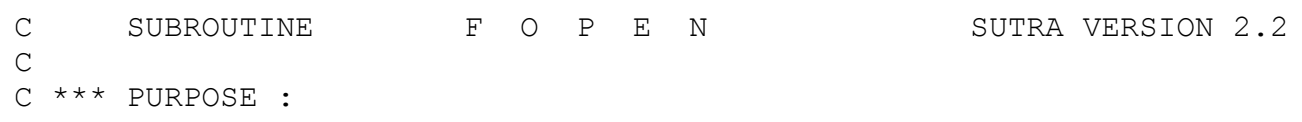




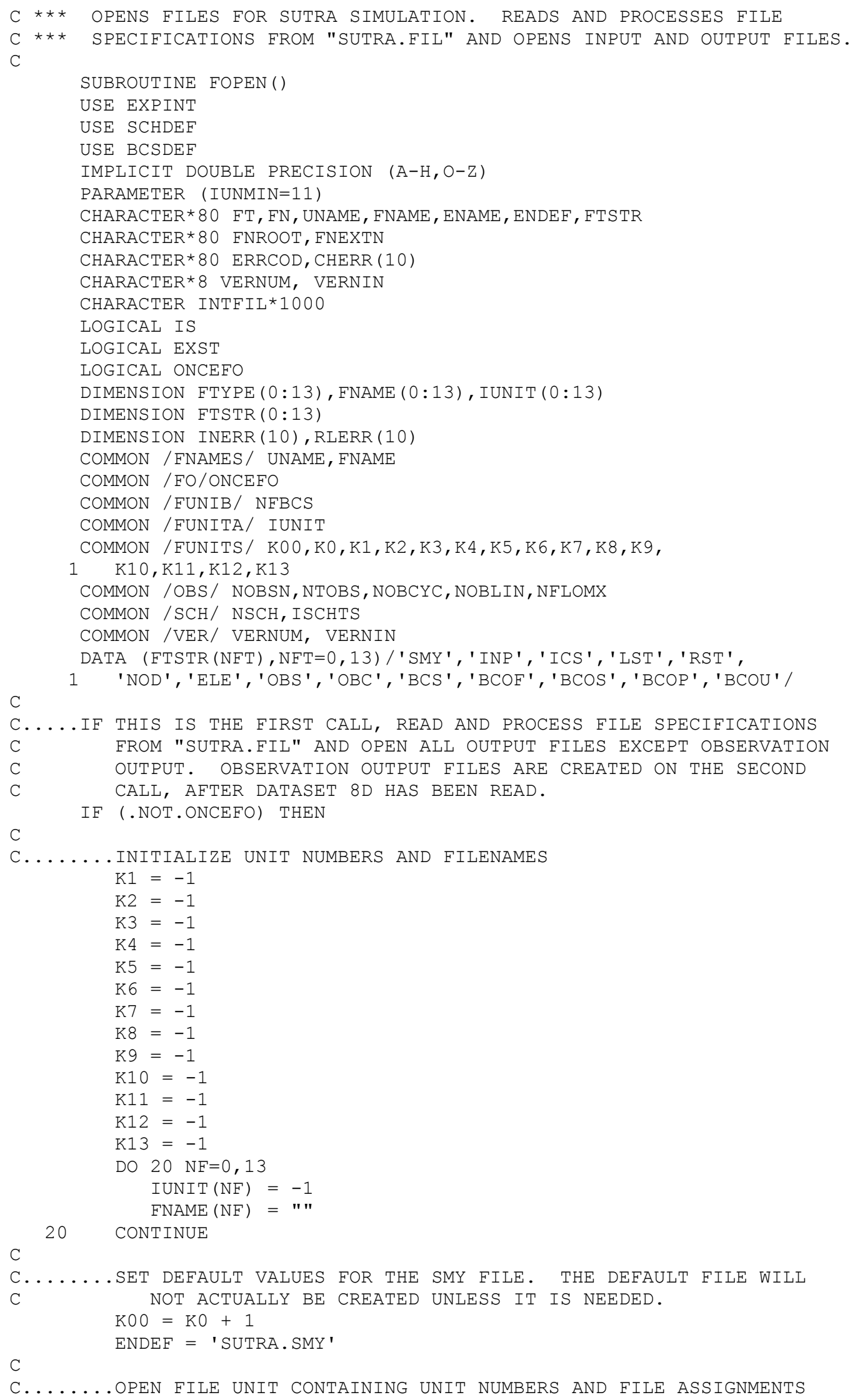




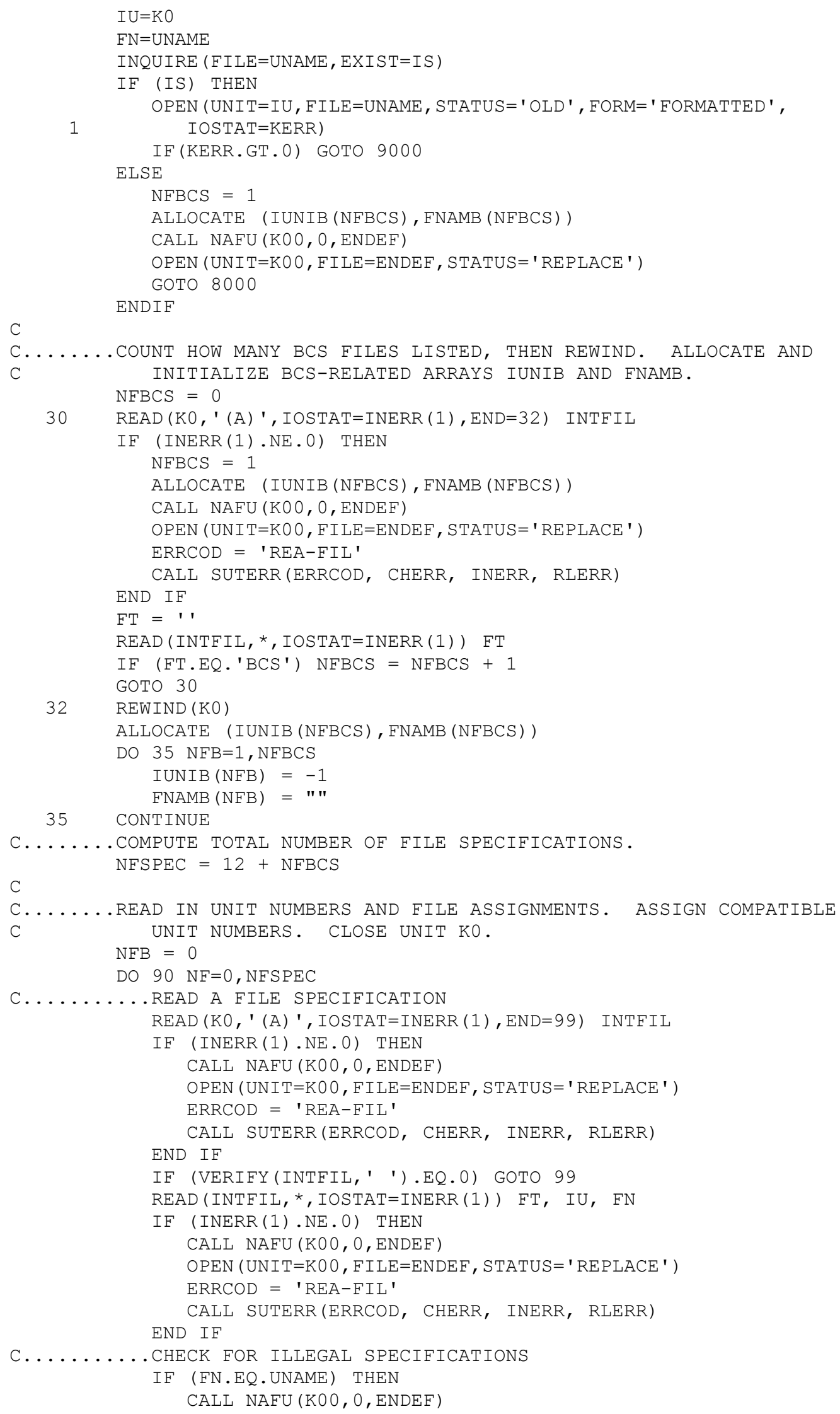




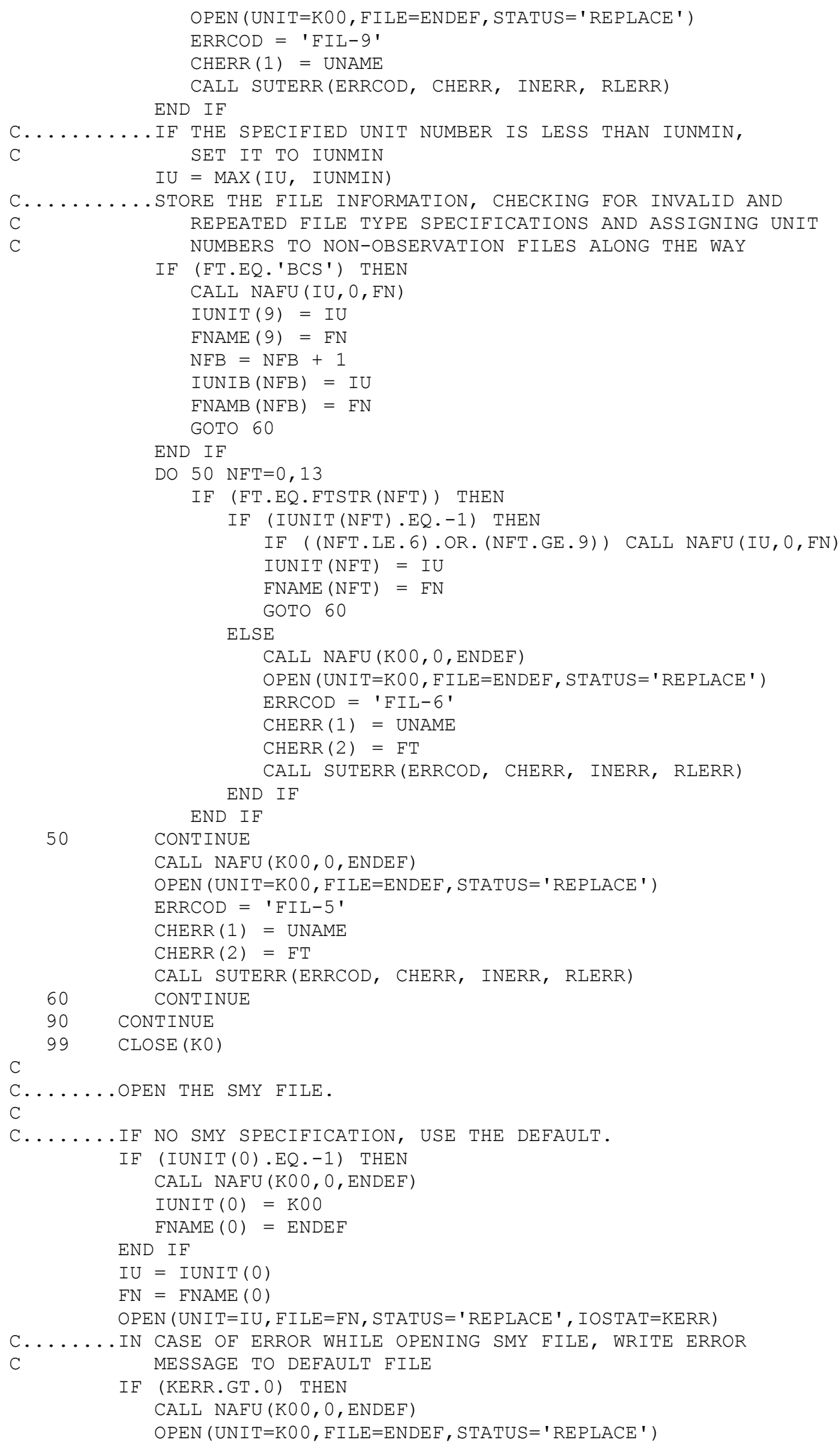




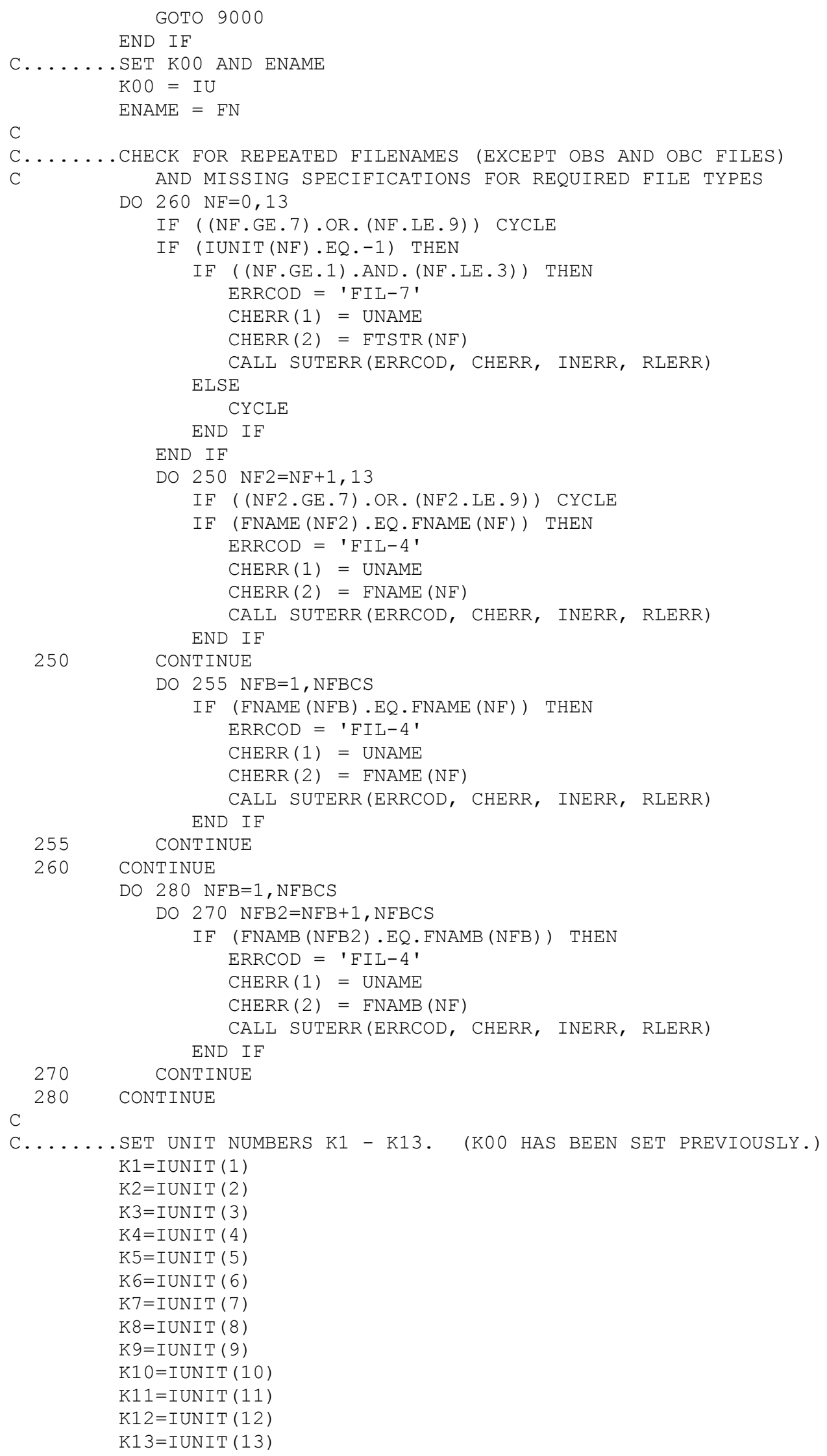




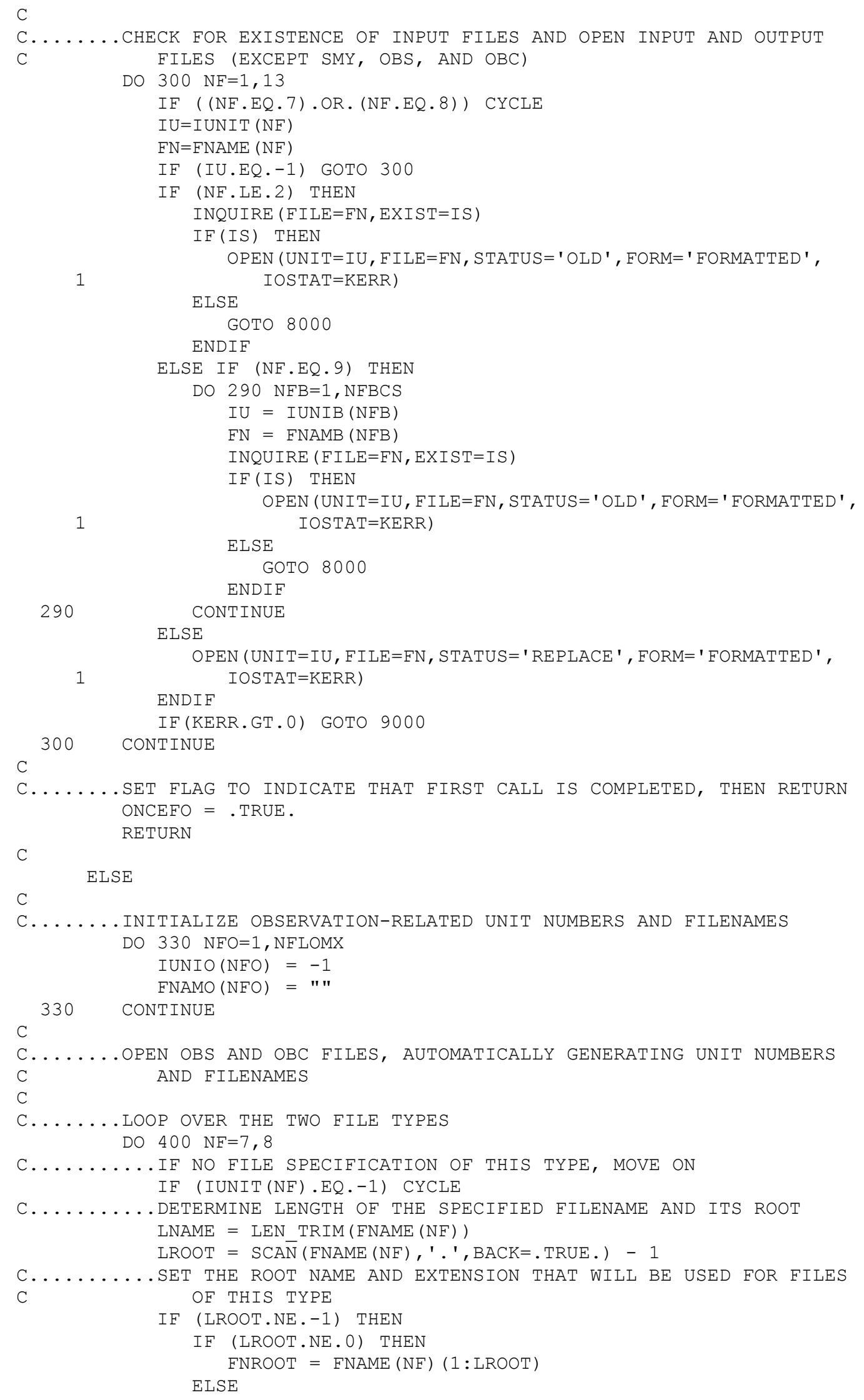




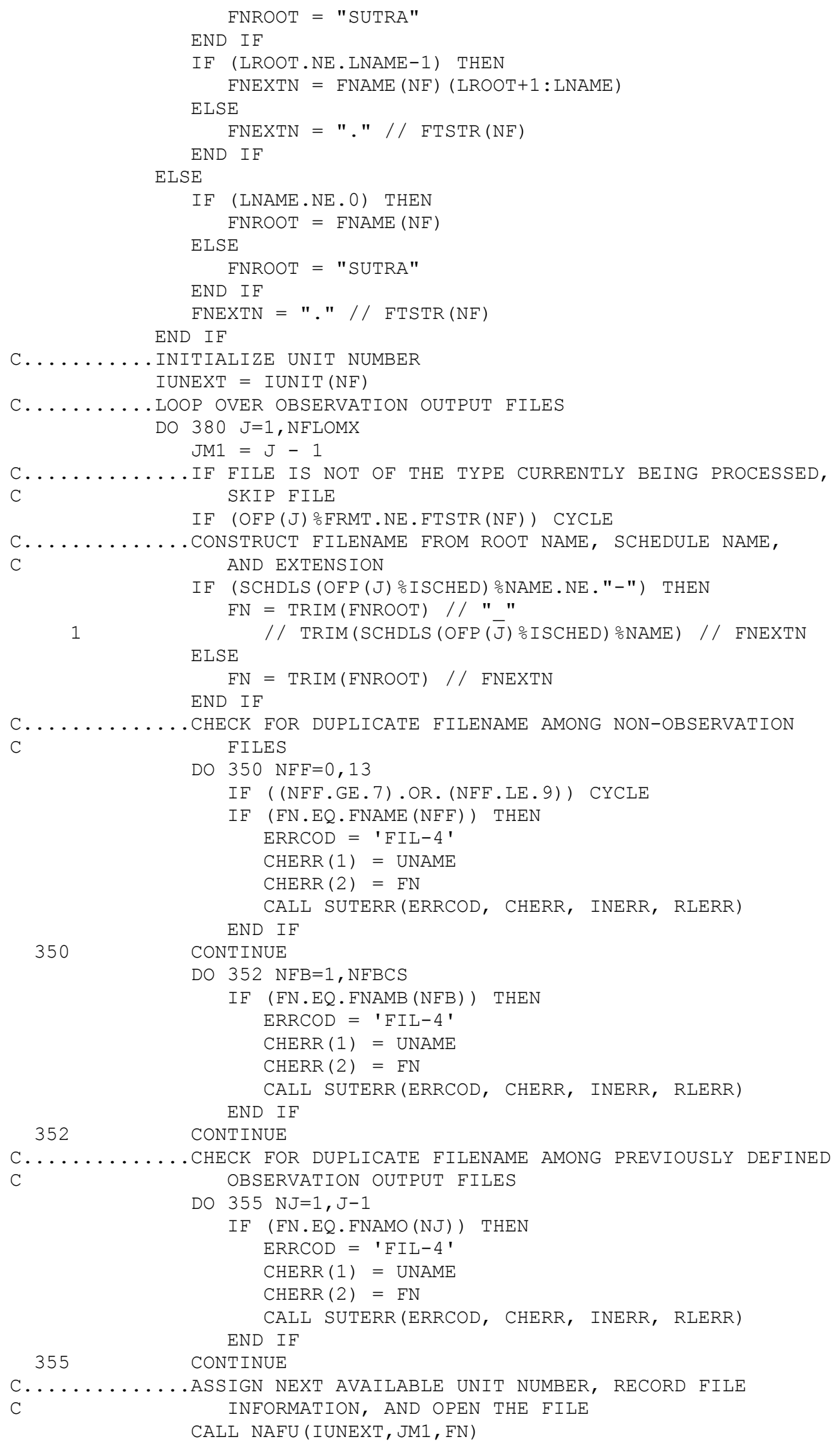




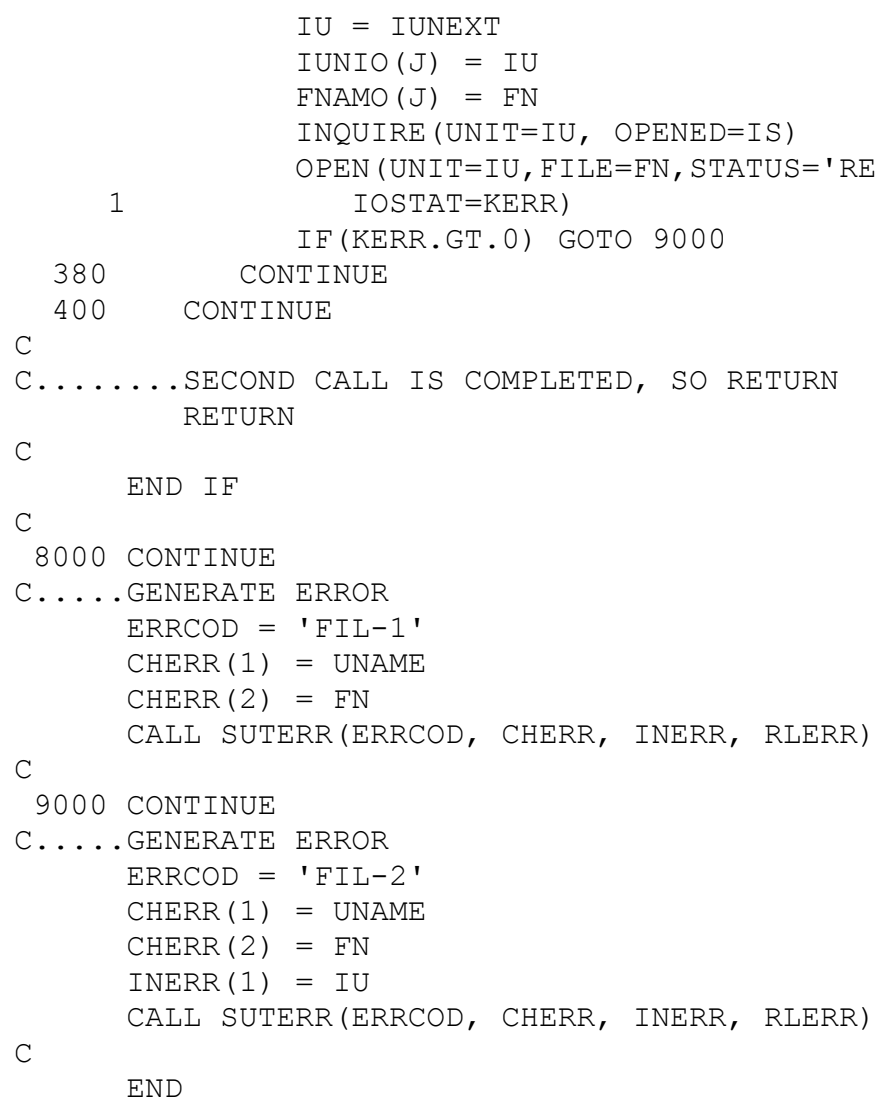

\section{Subroutine NAFU}

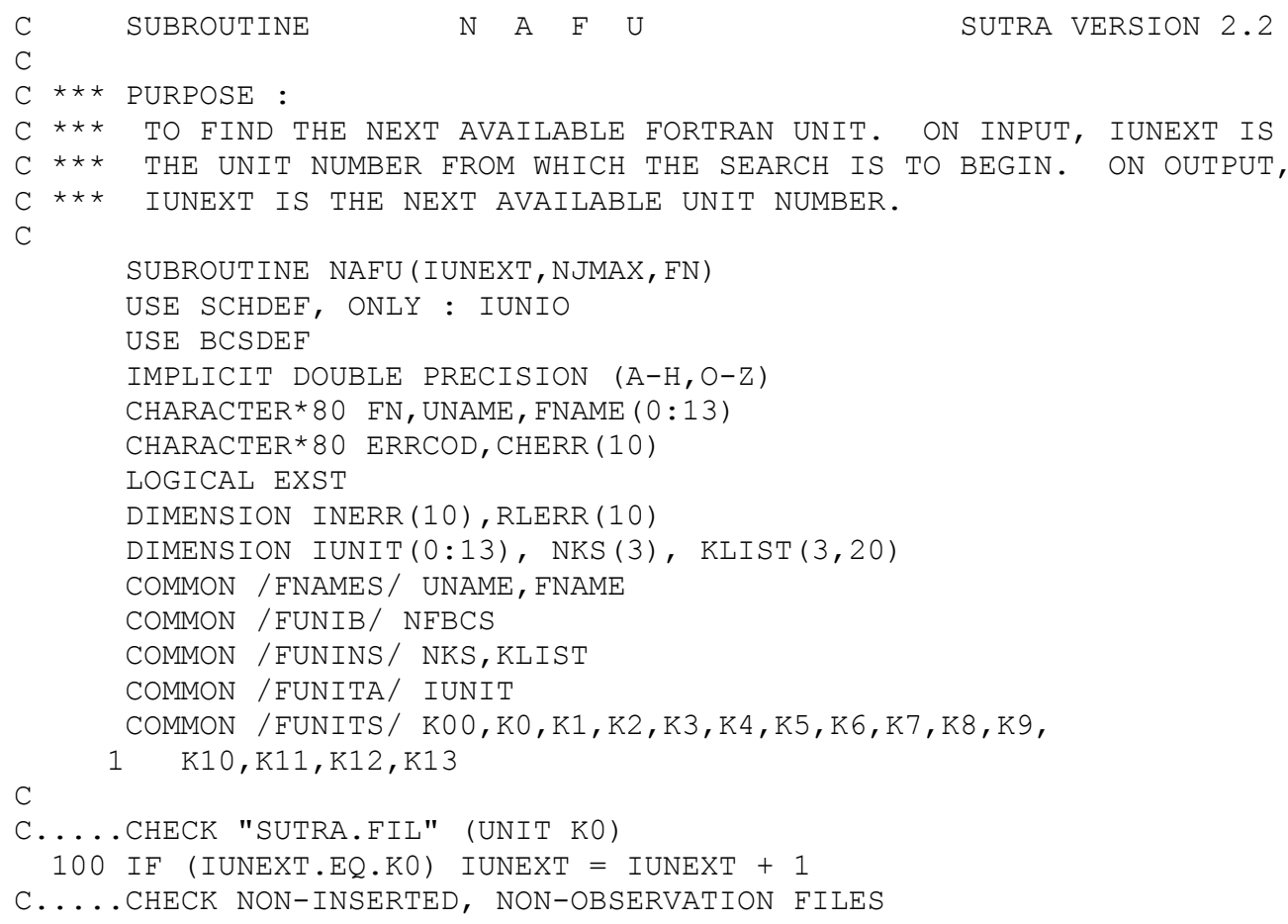




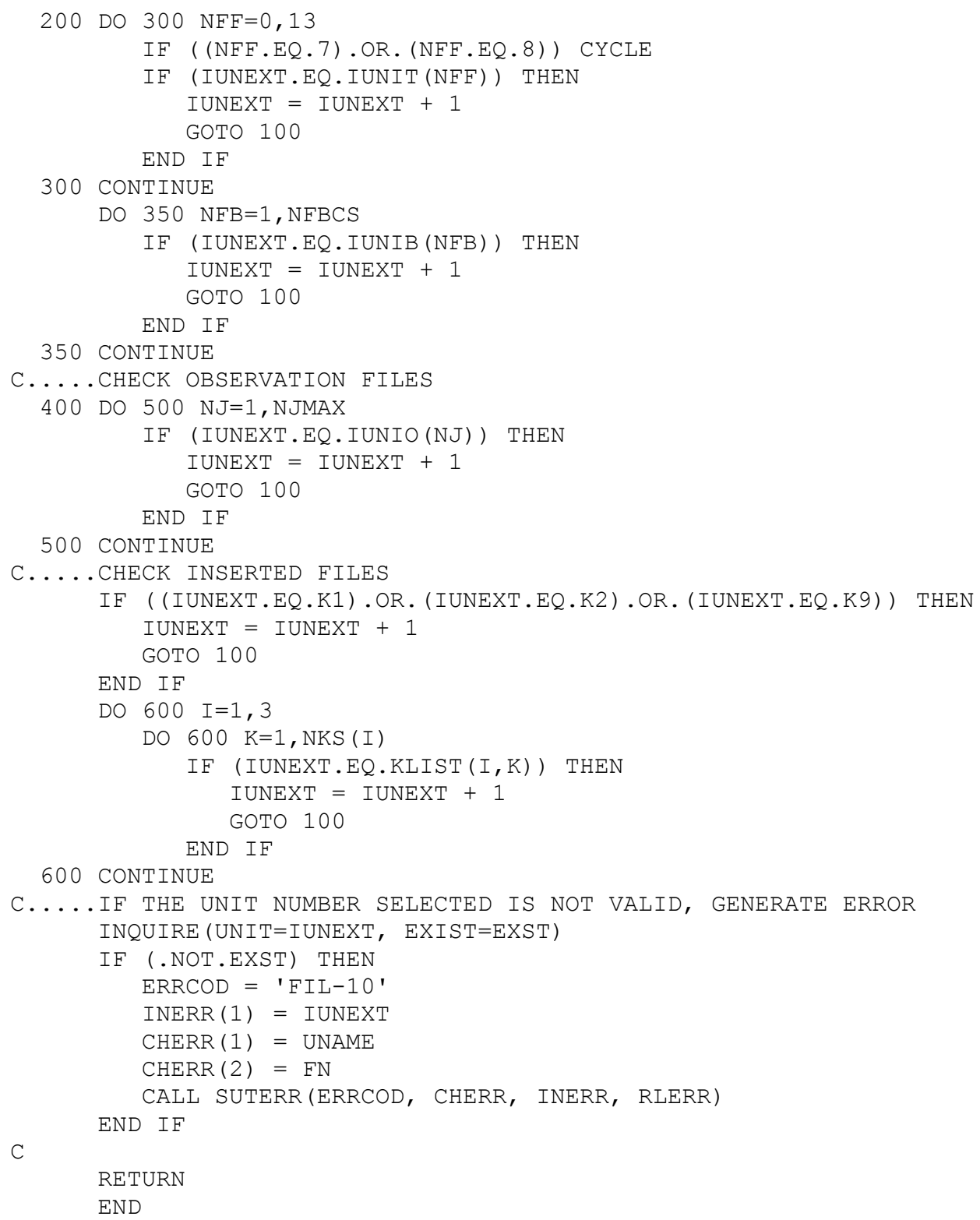

\section{Subroutine OUTBCOF}

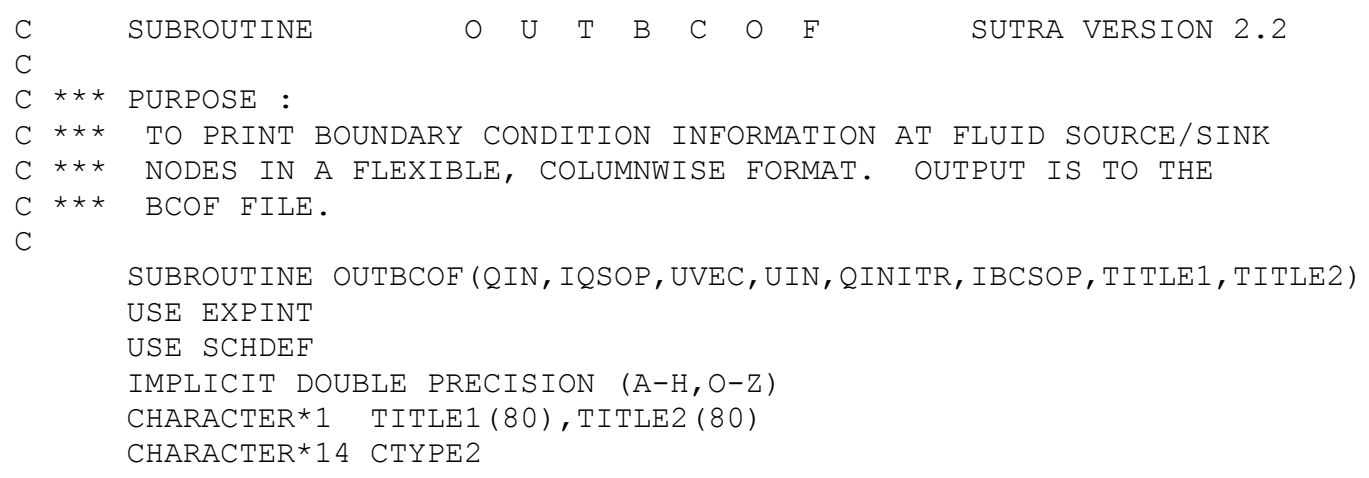




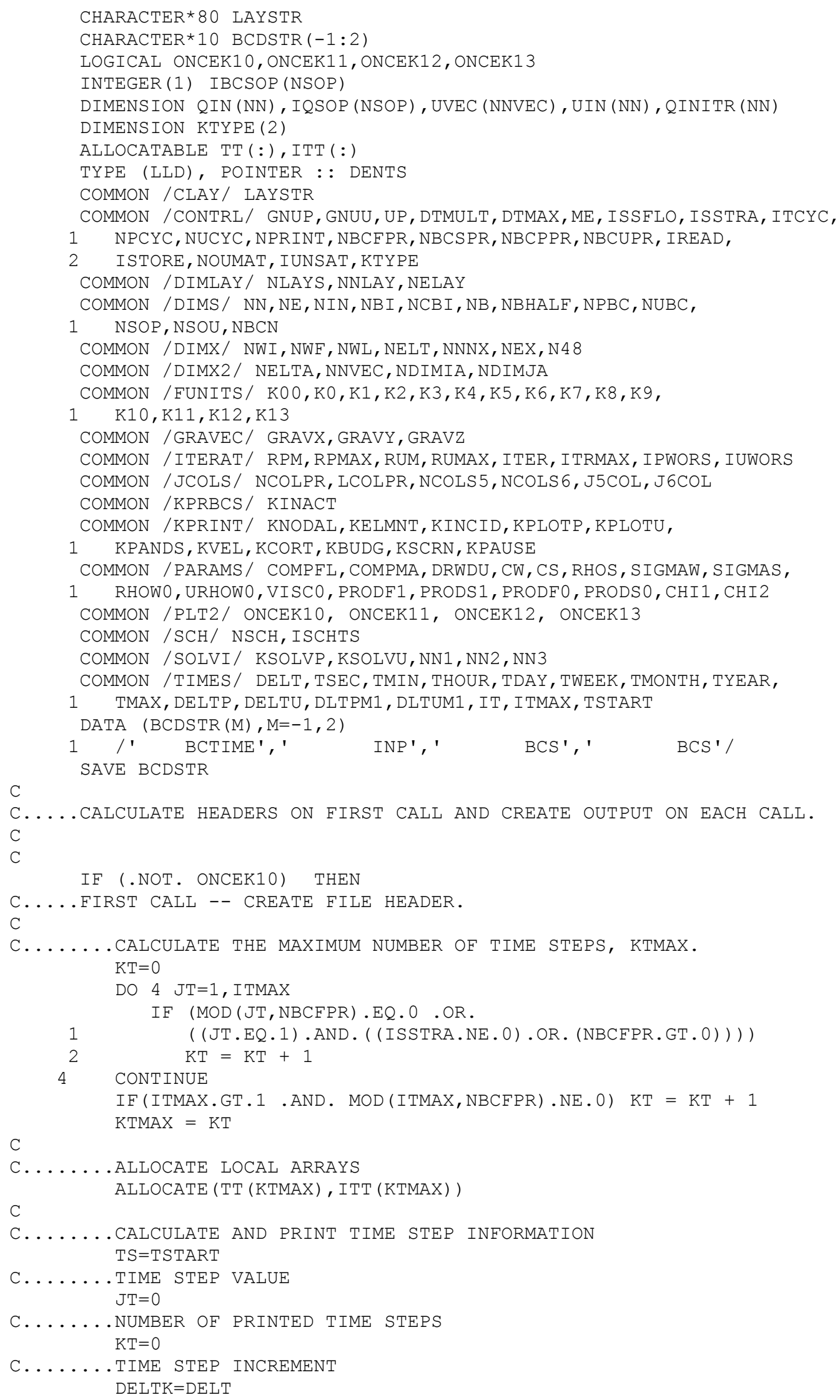




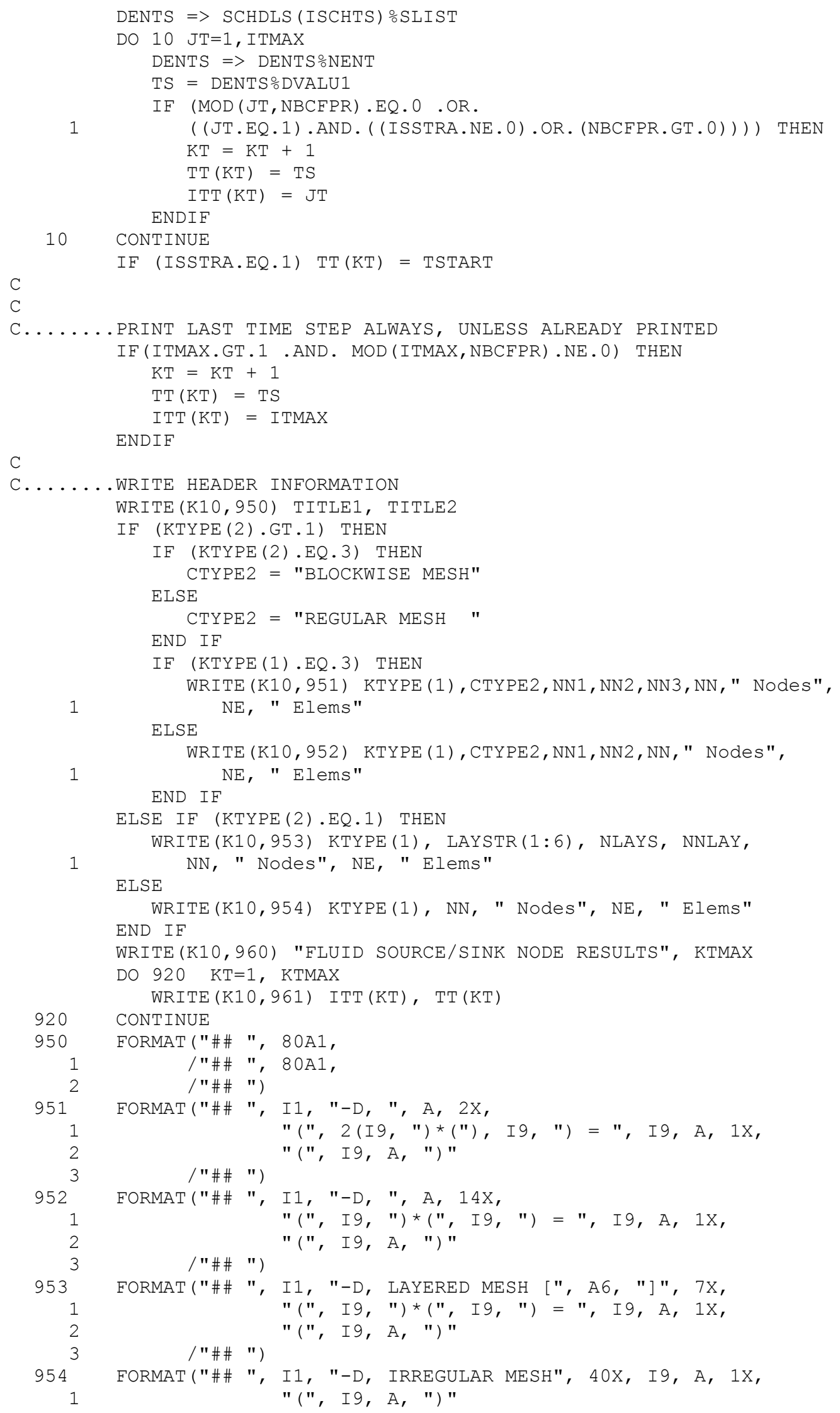




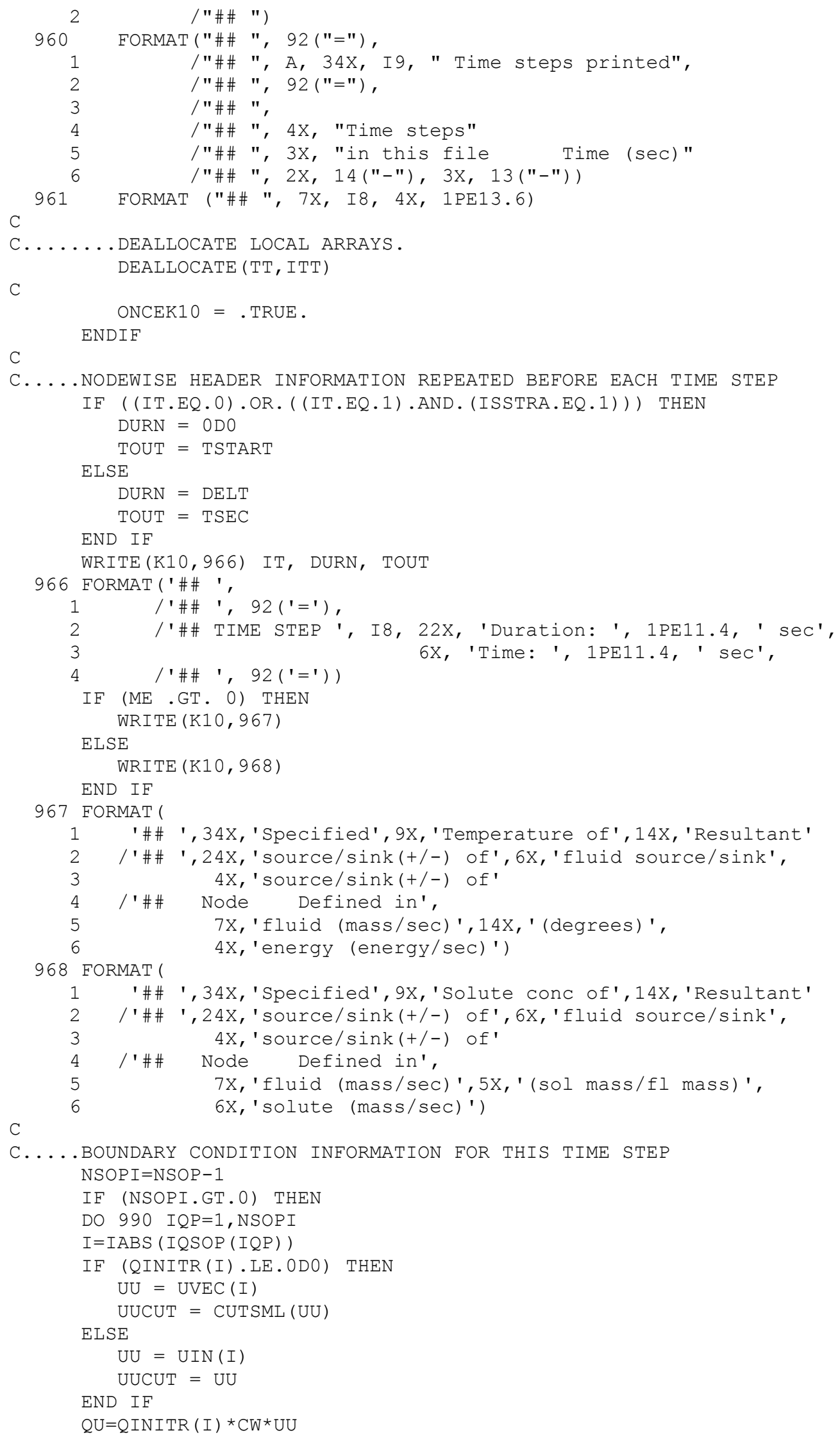




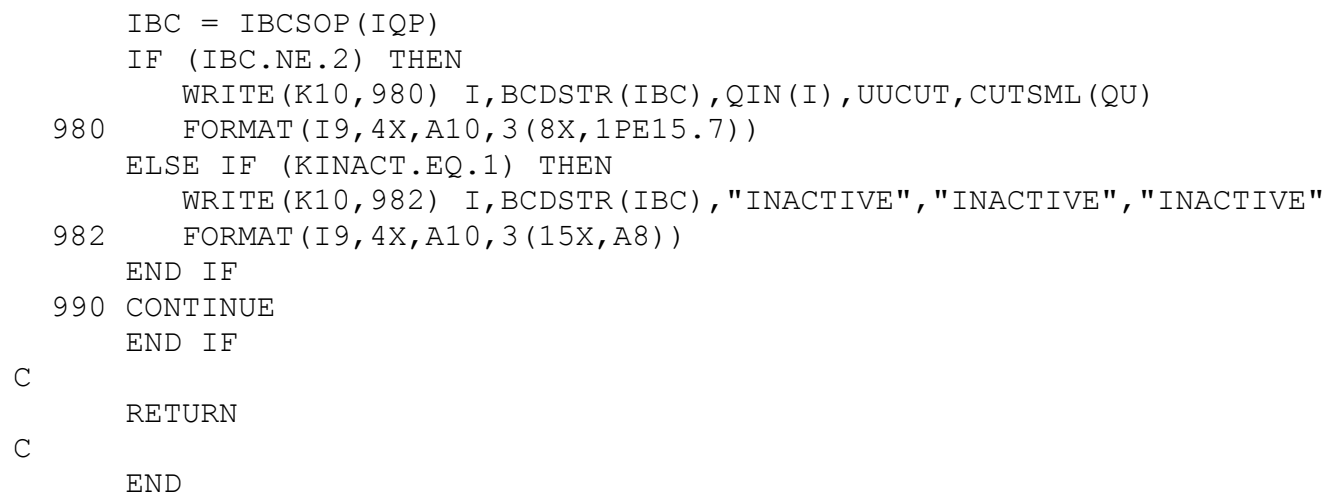

\section{Subroutine OUTBCOP}

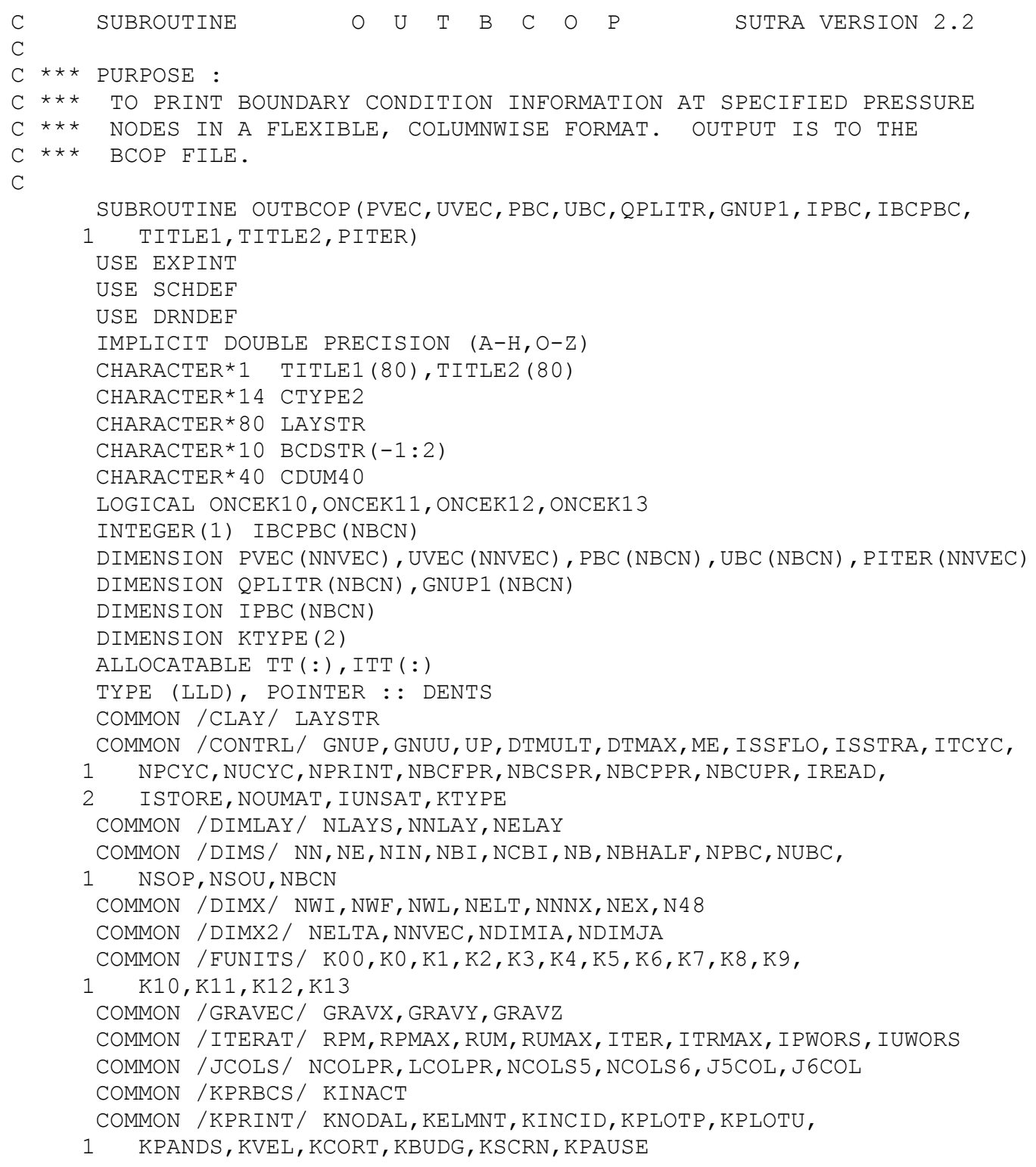




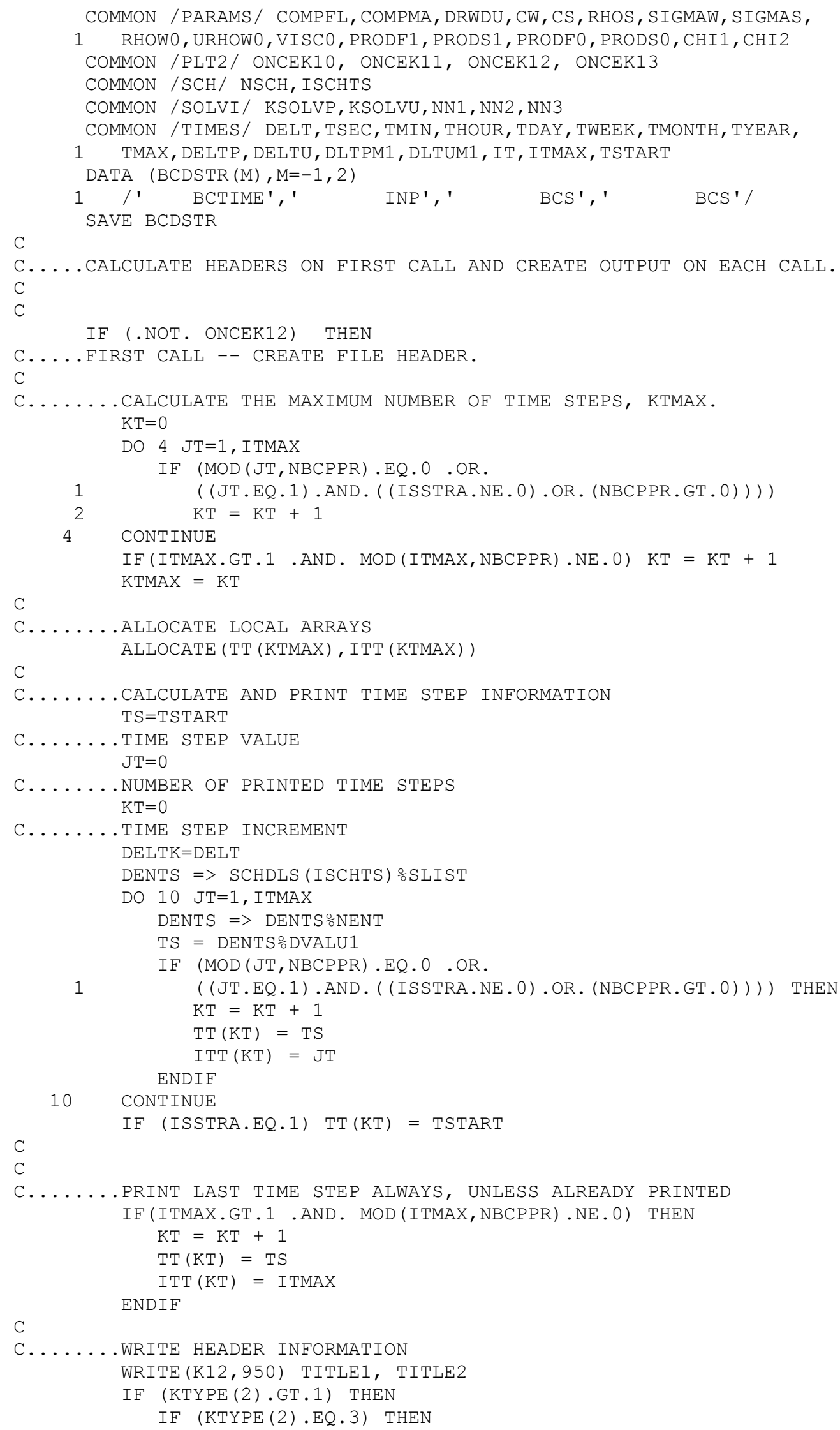




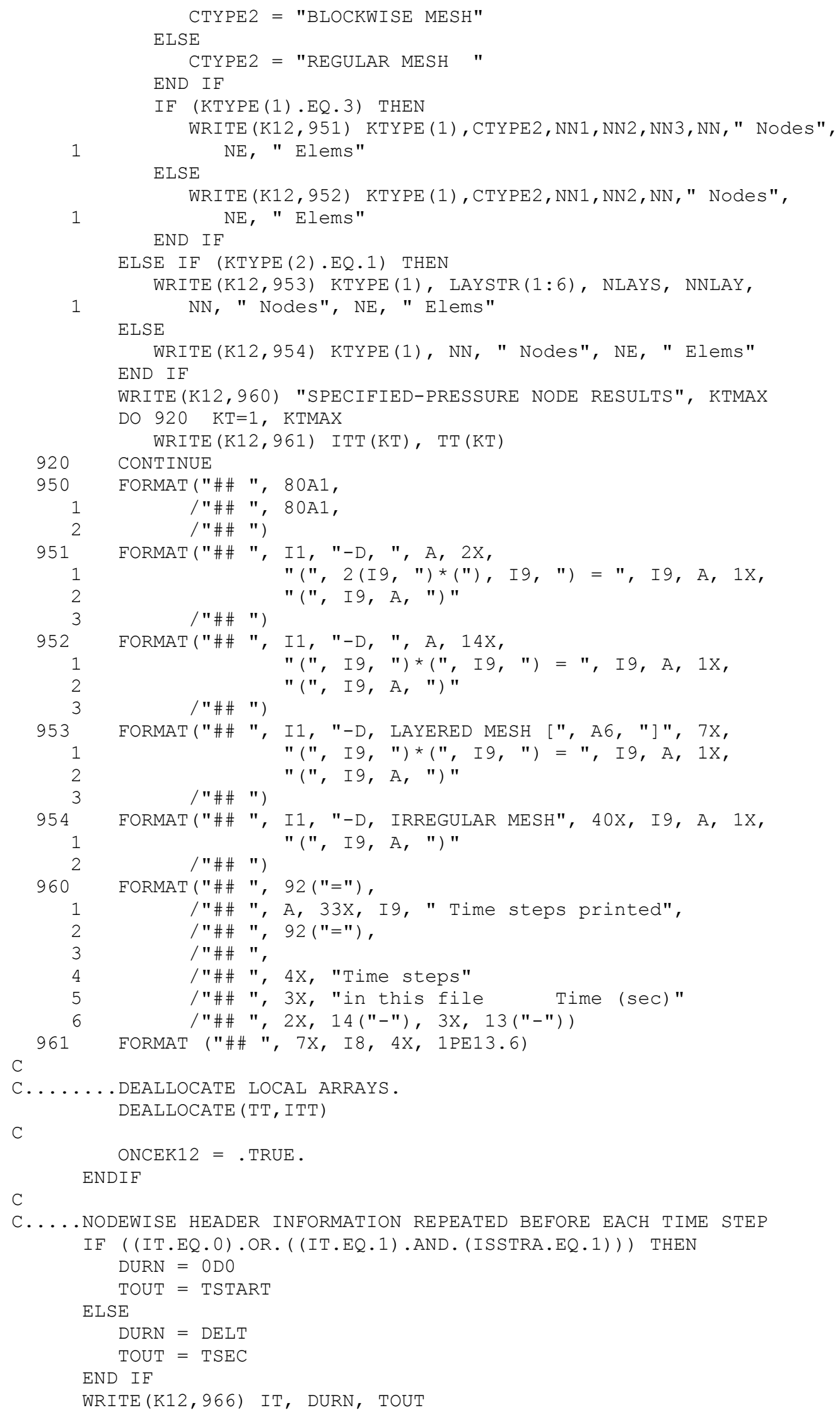




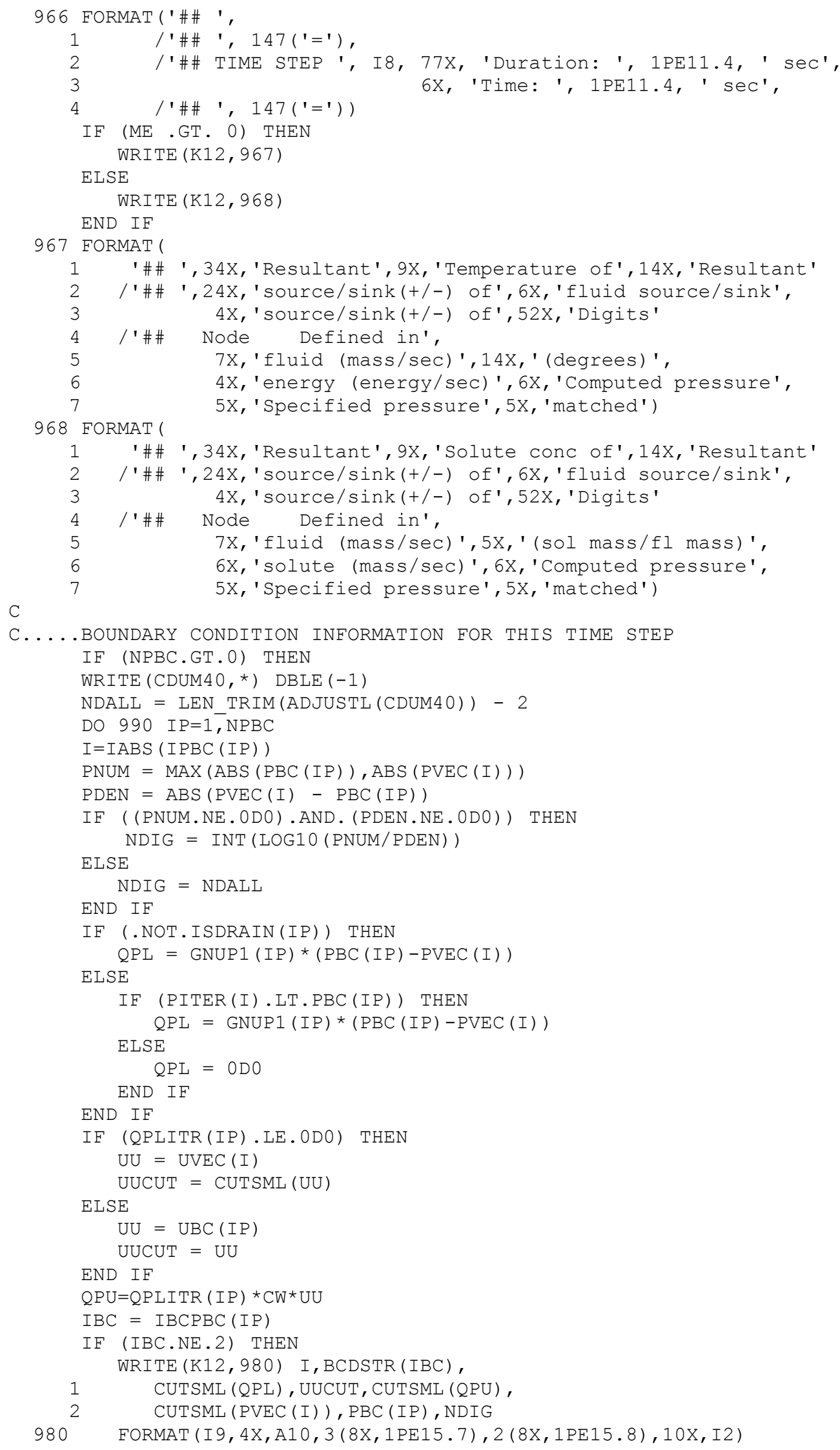




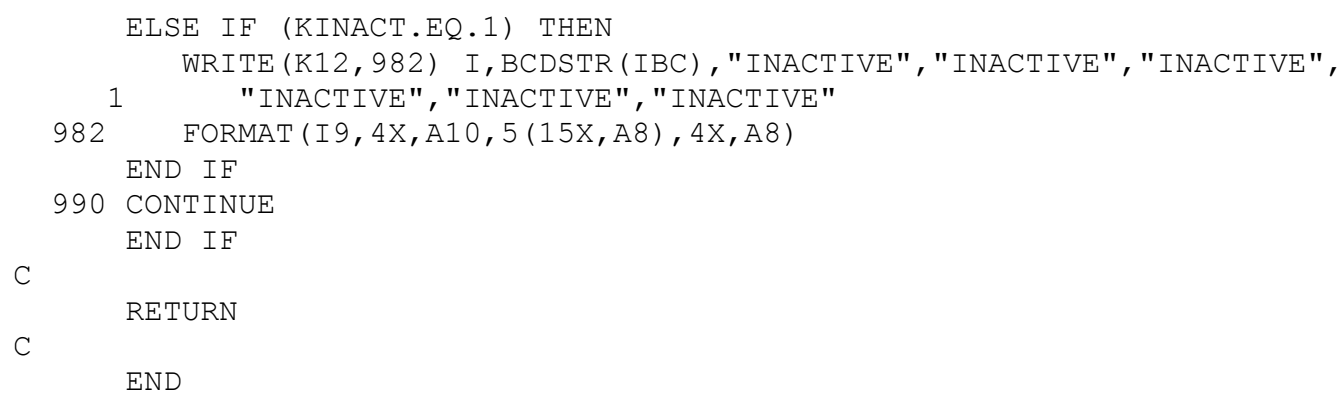

\section{Subroutine OUTBCOS}

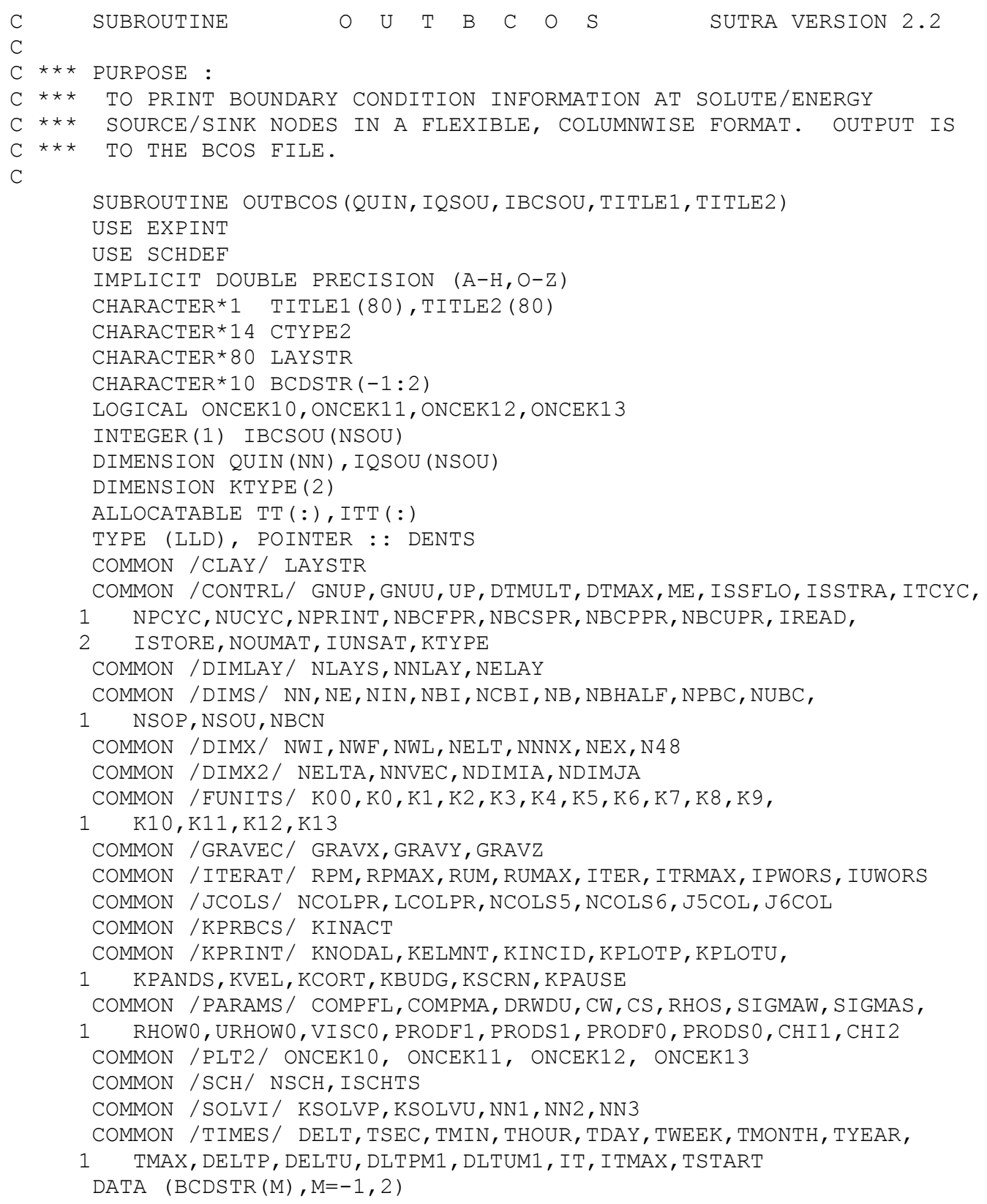




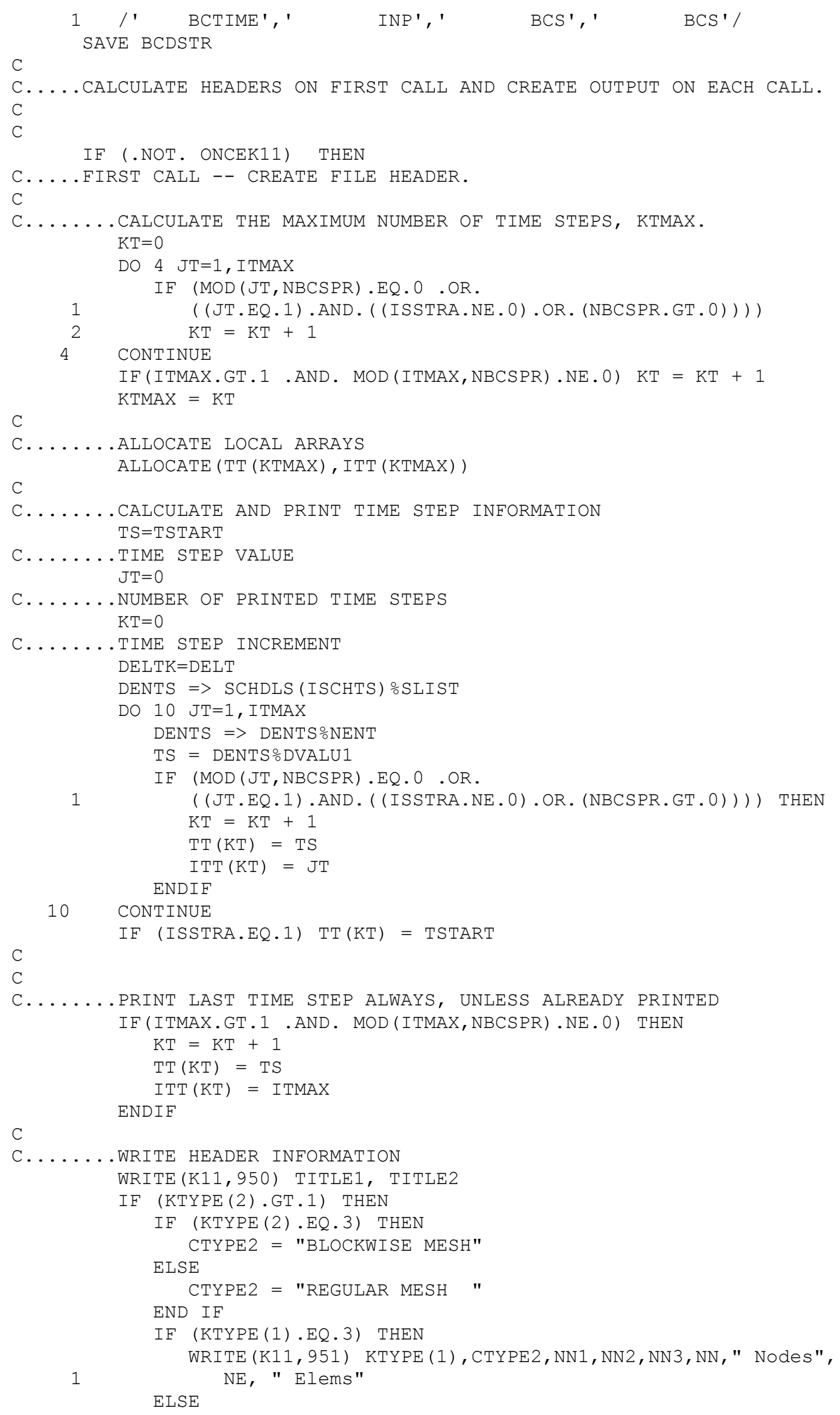




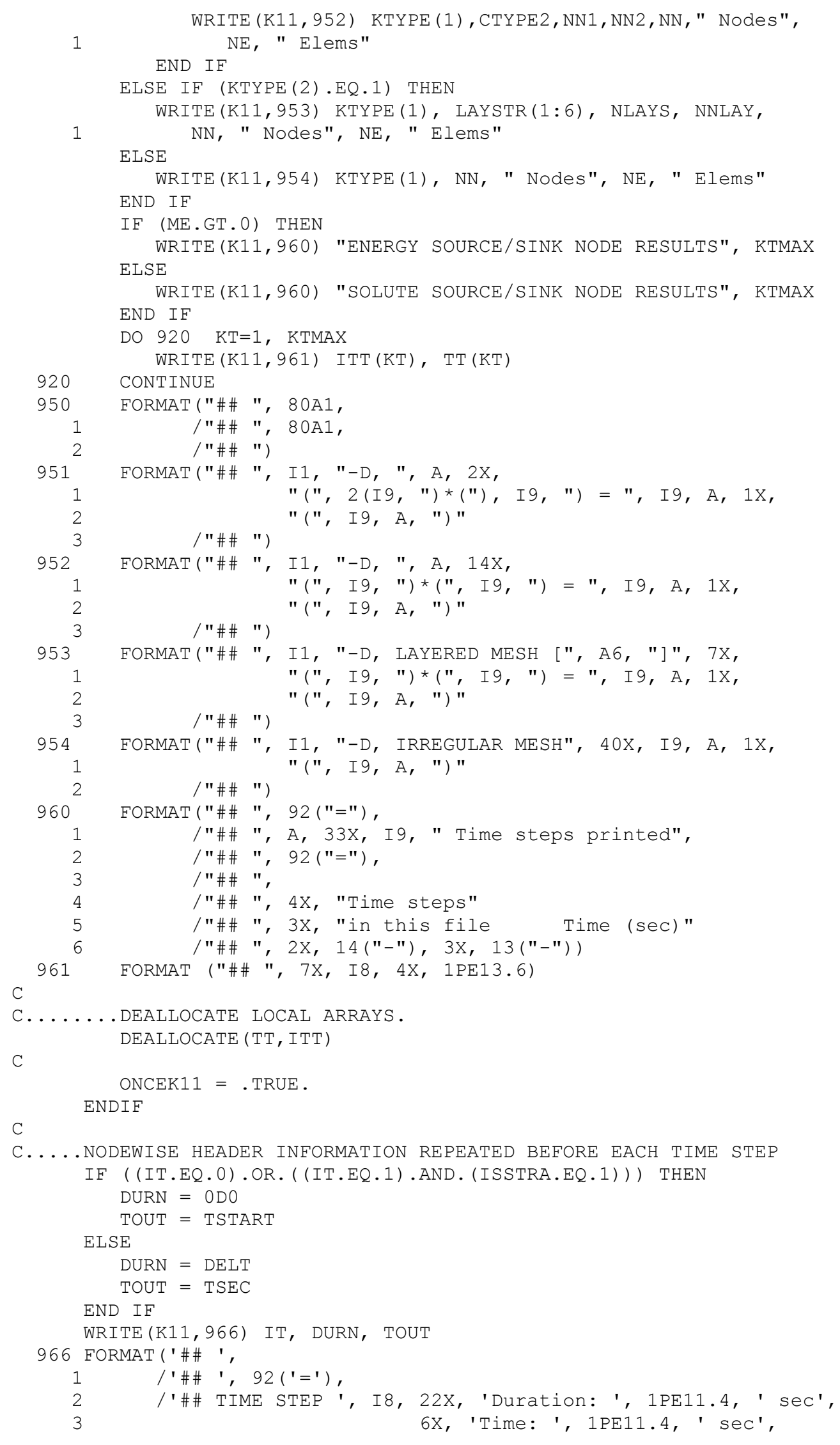




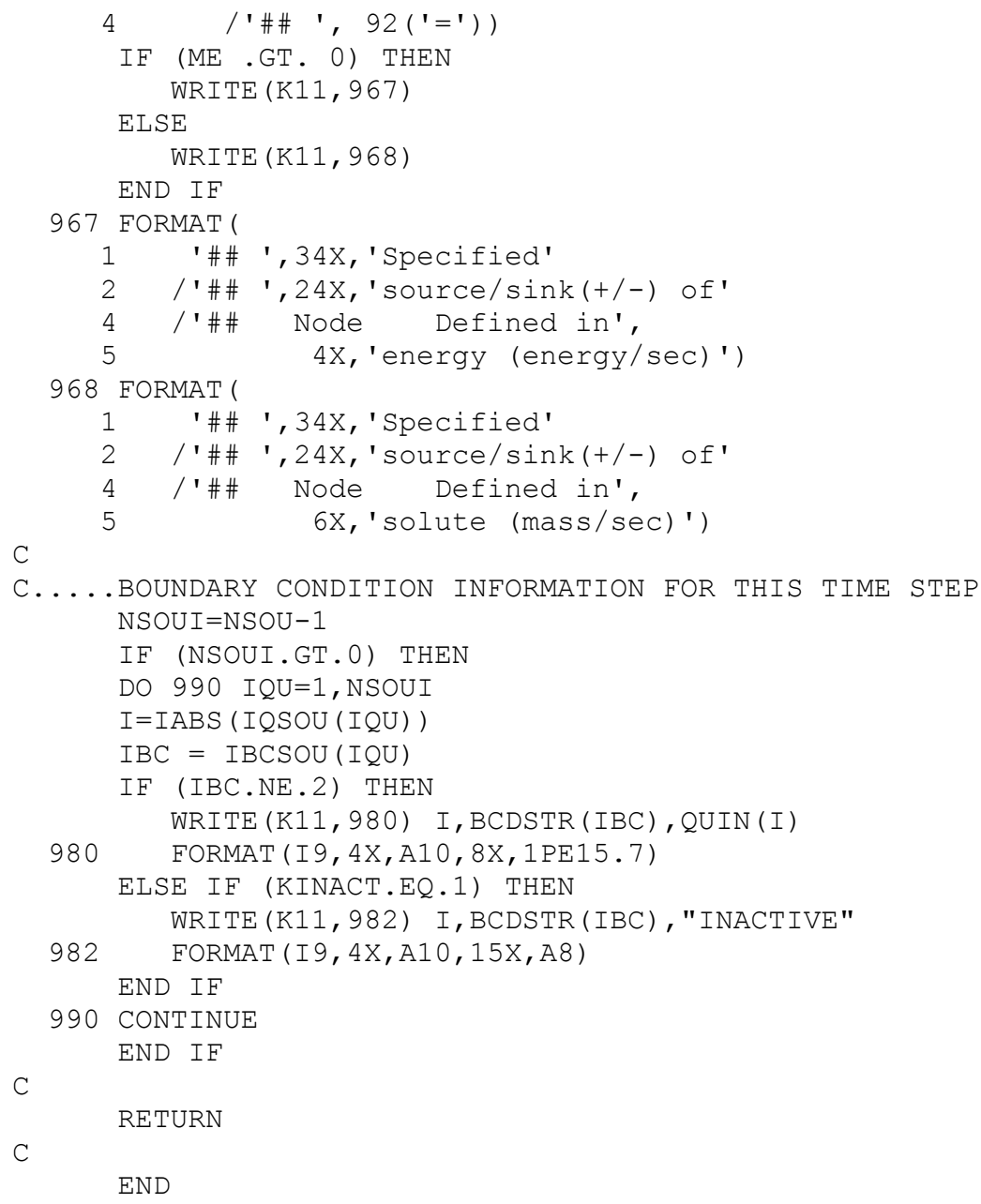

\section{Subroutine OUTBCOU}

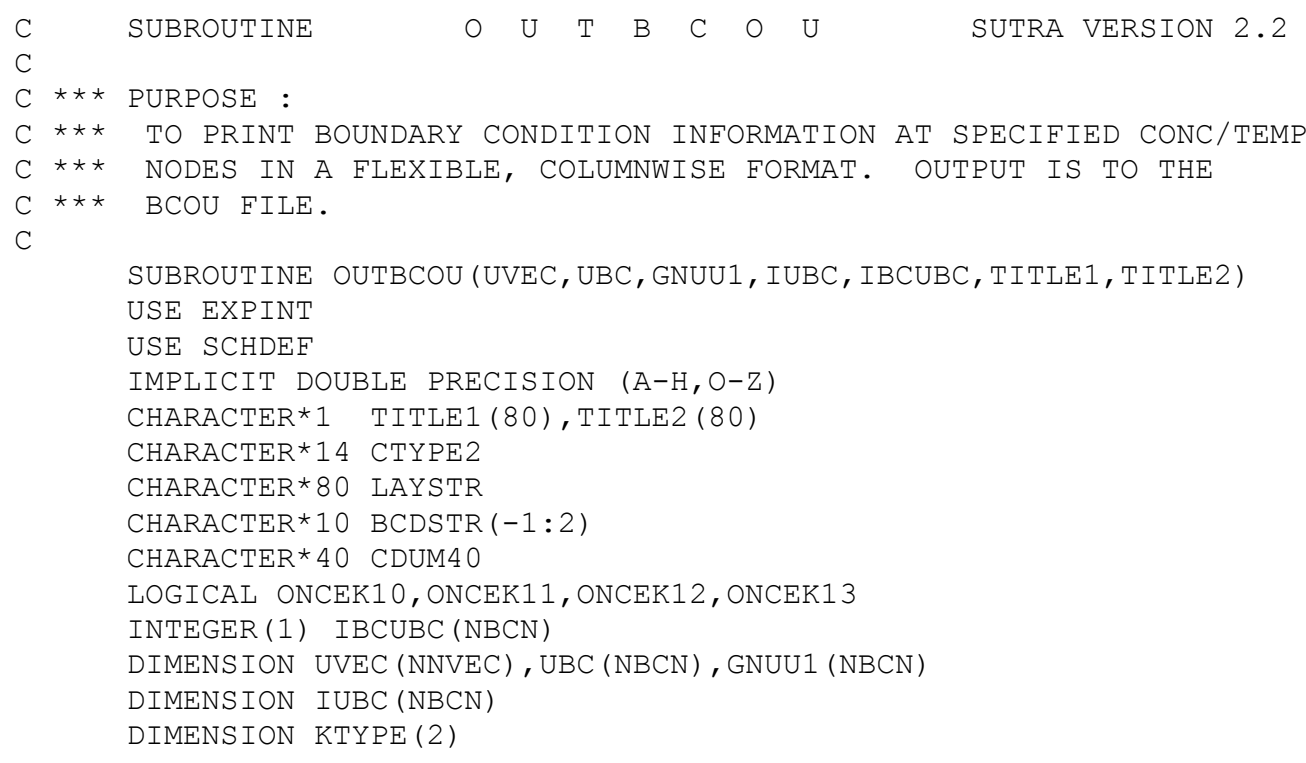




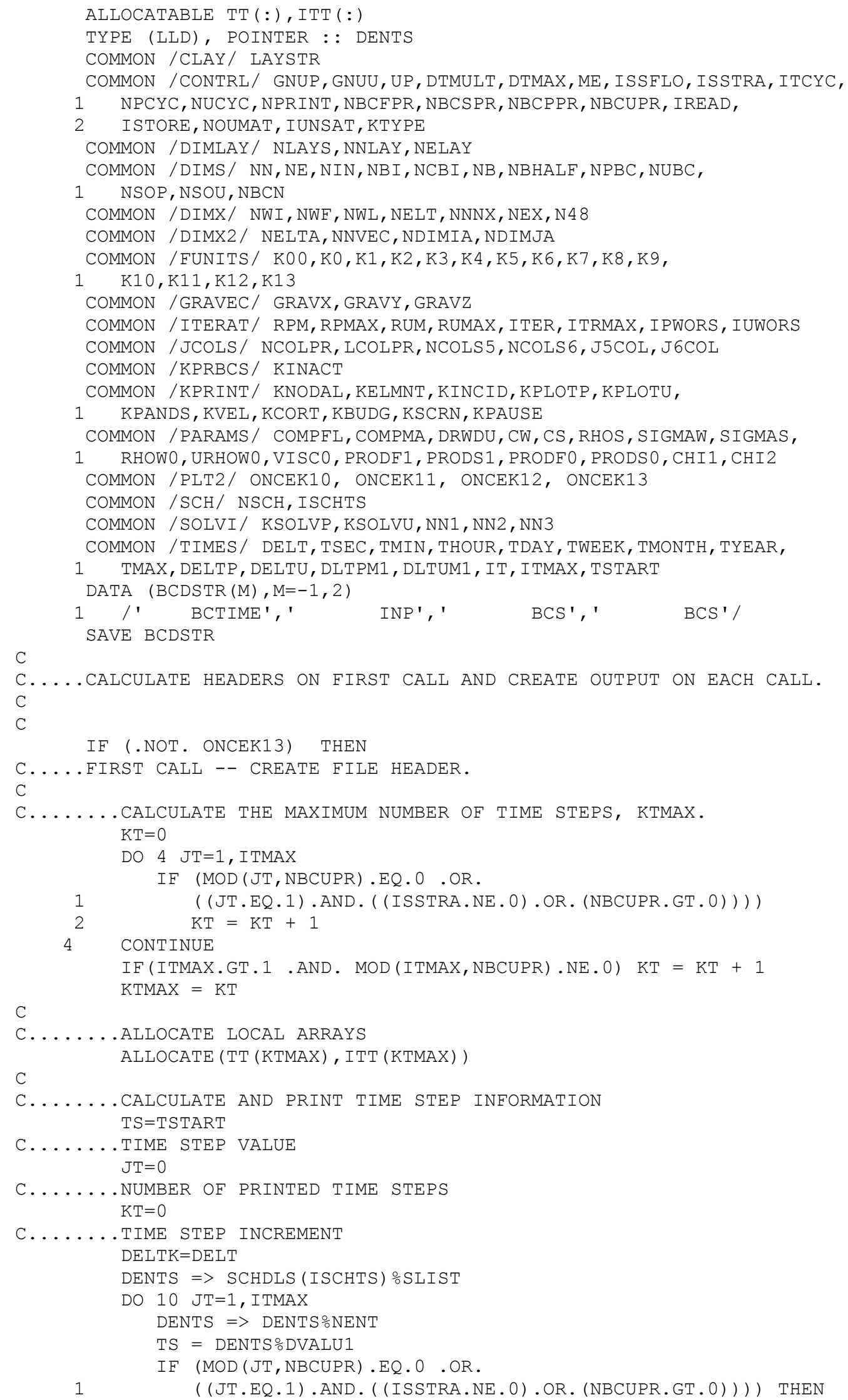




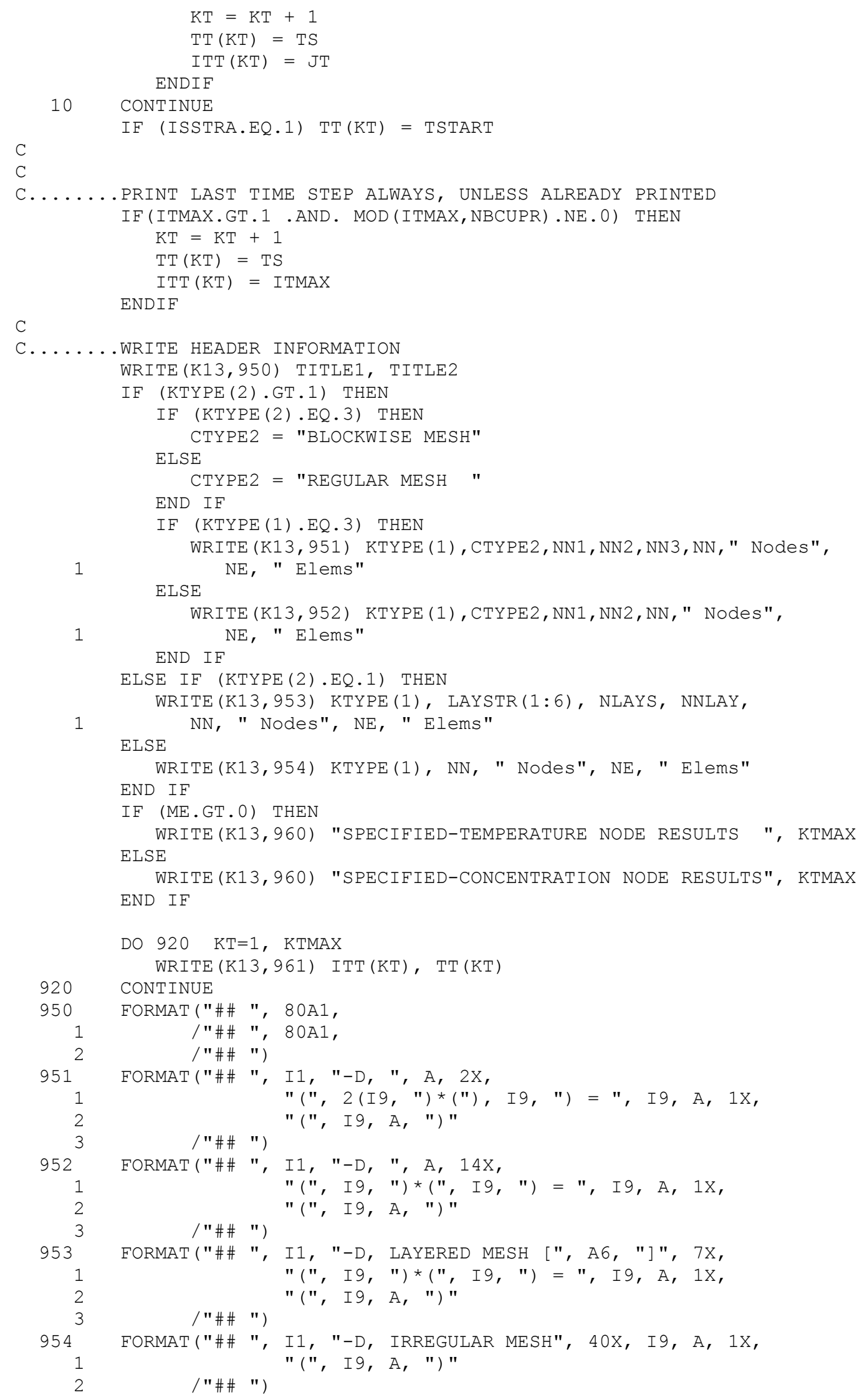




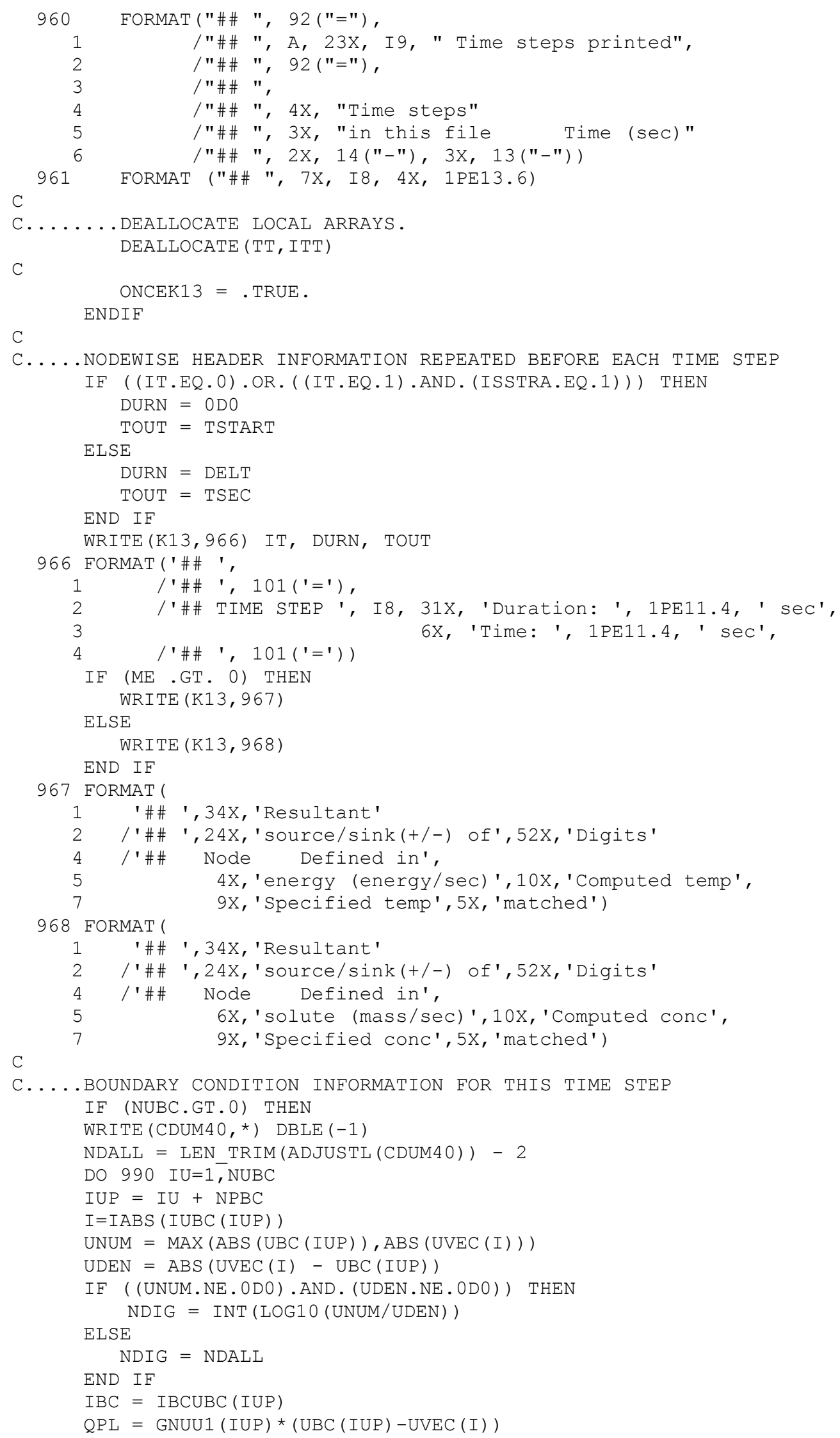




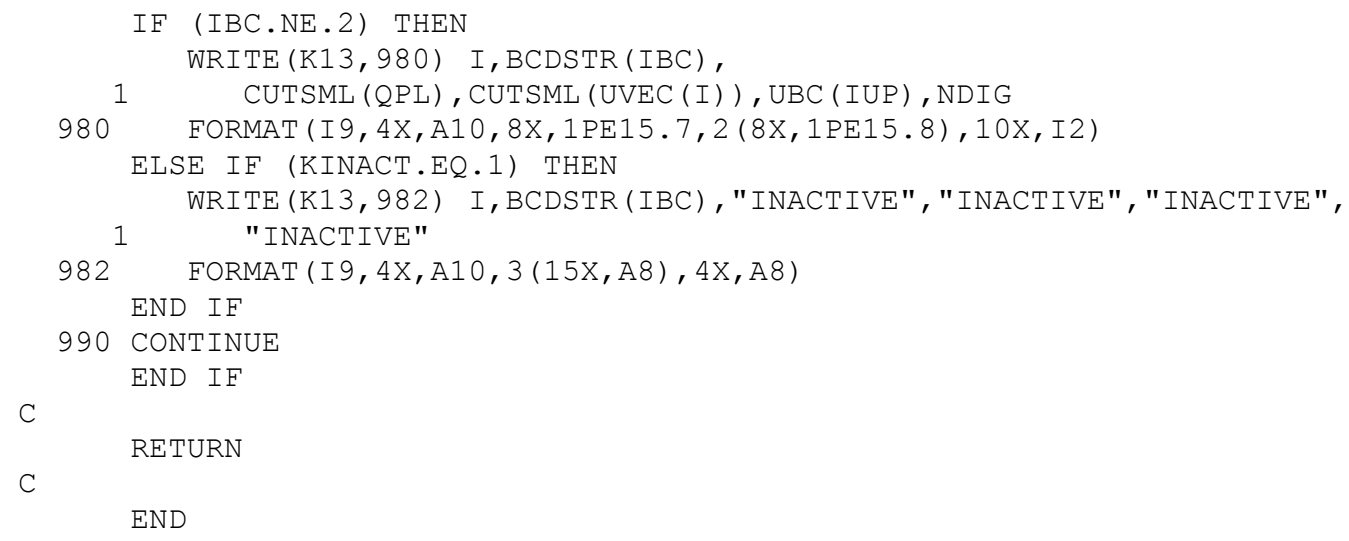

\section{Function PUSWF}

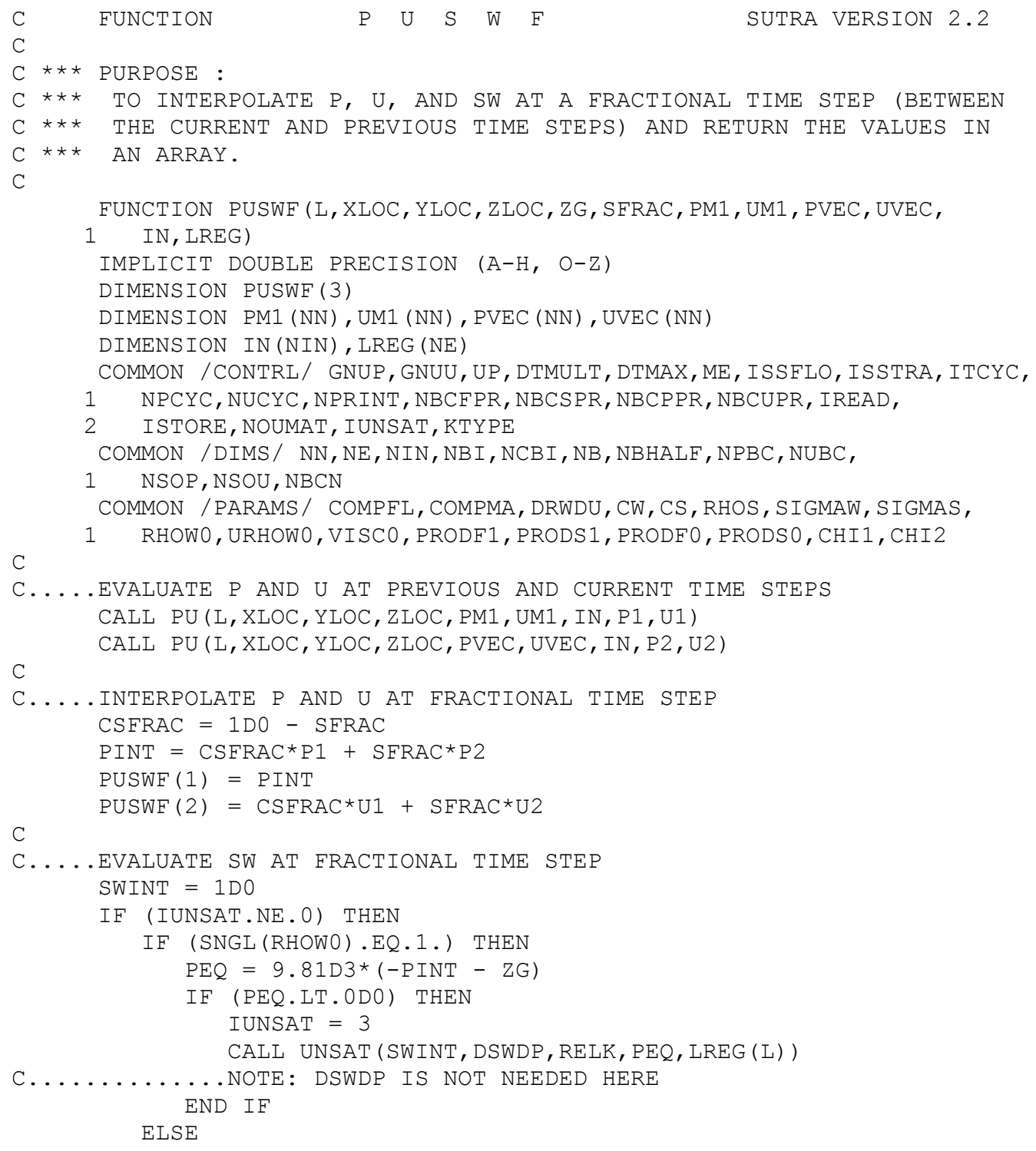




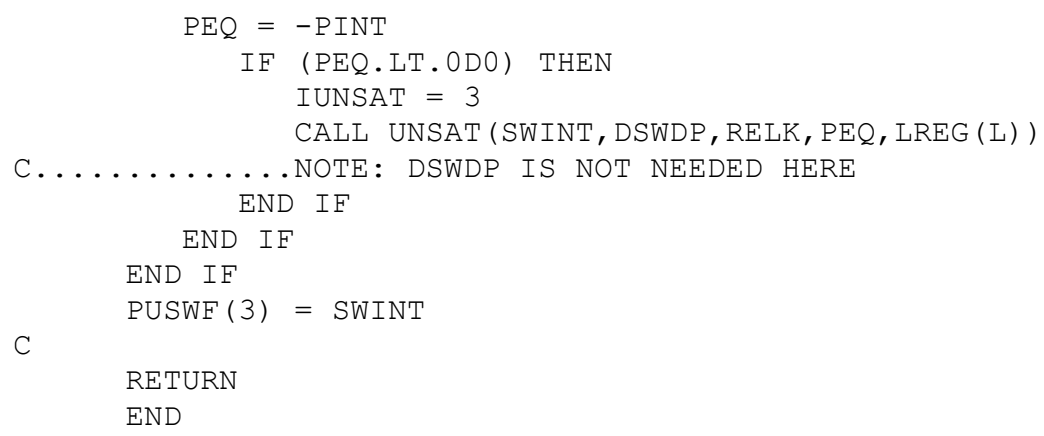

\section{Subroutine SOURCE}

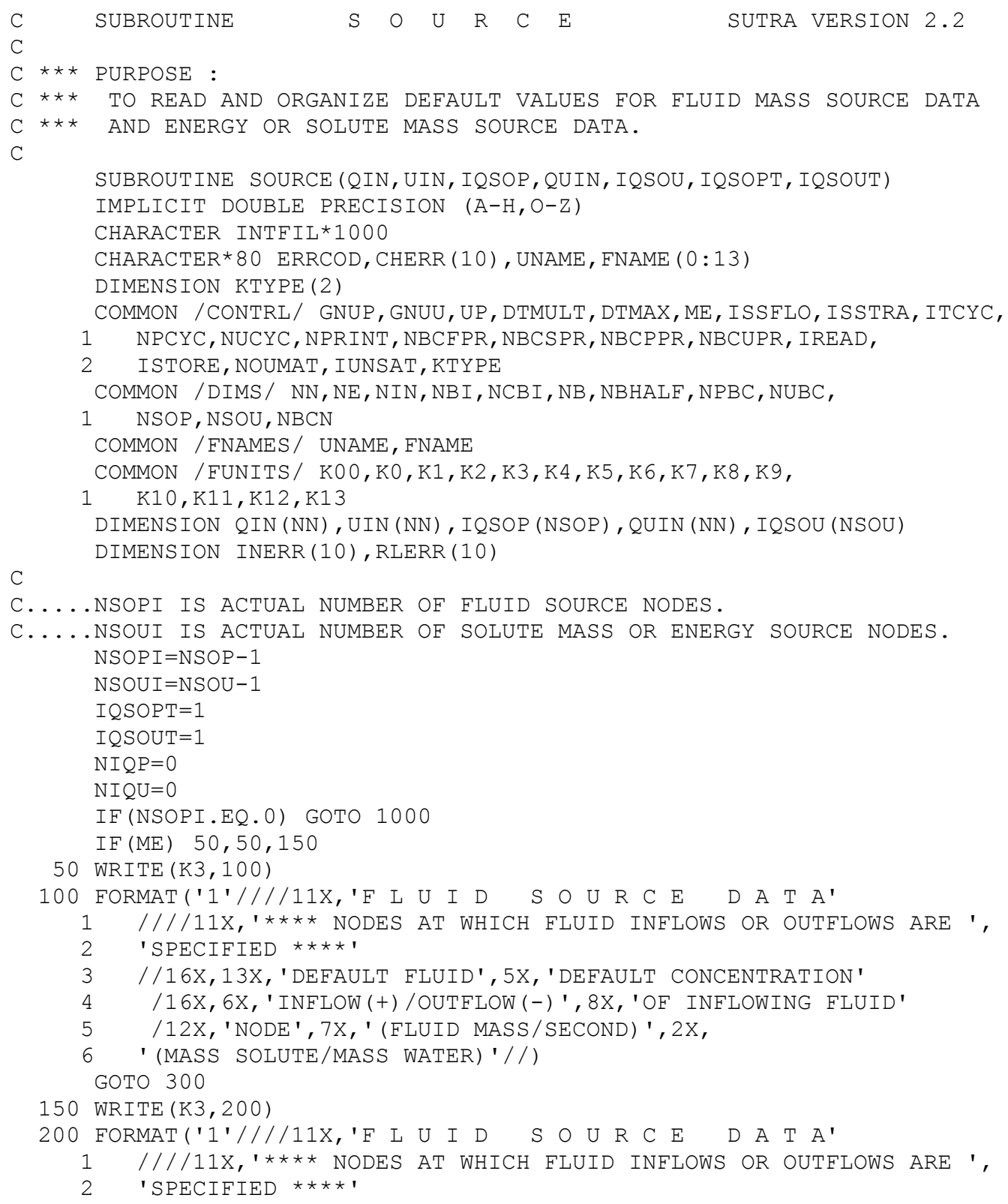




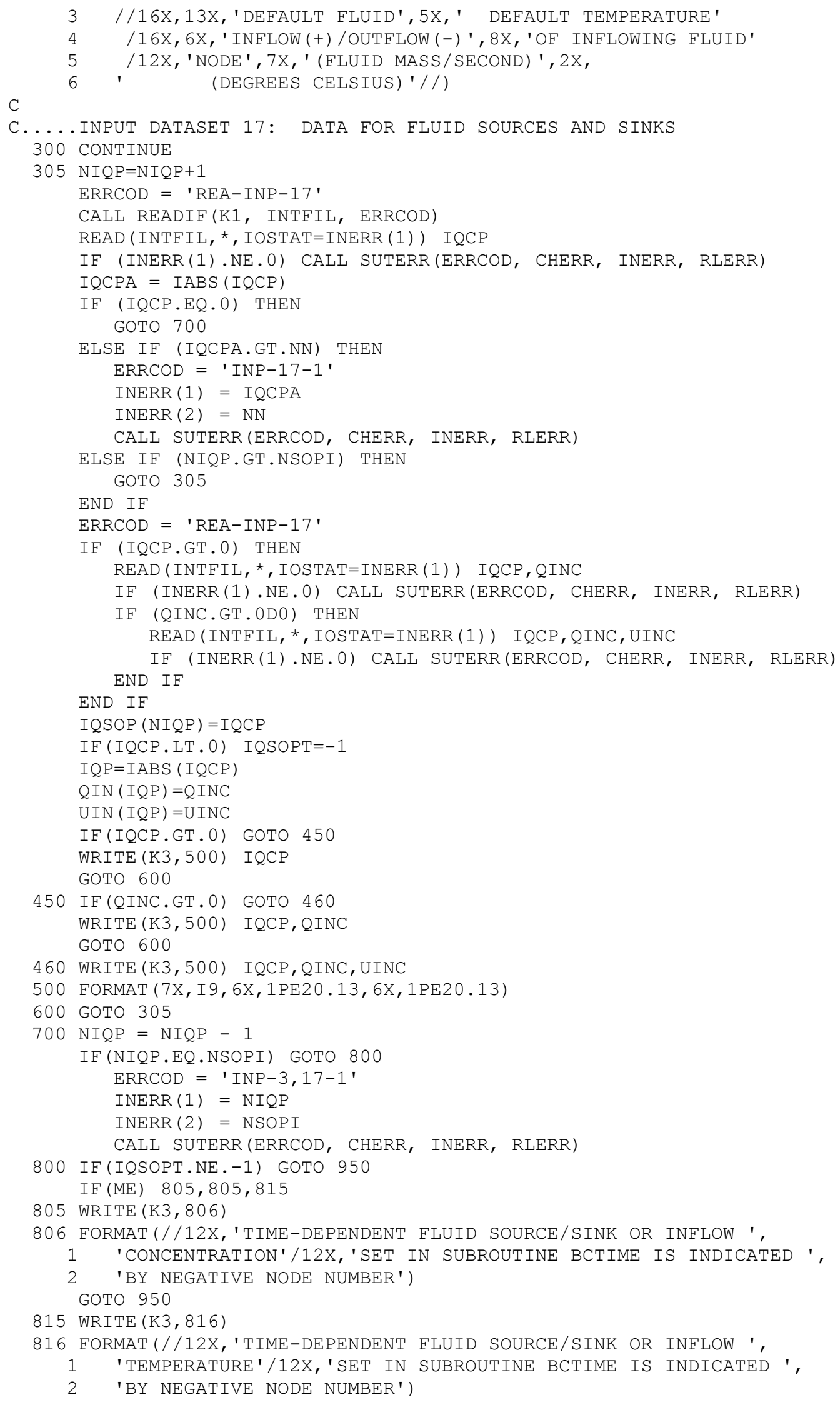




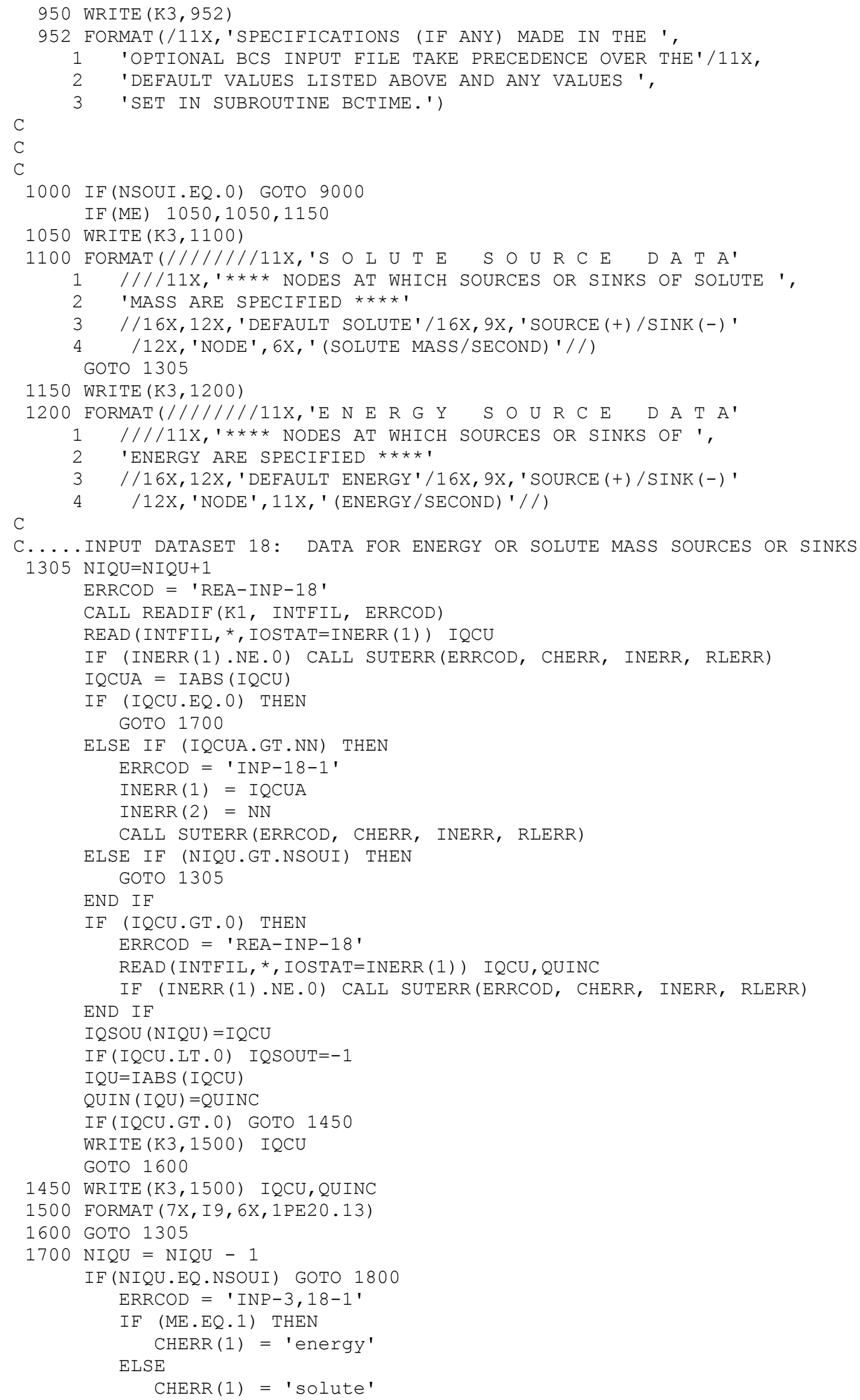




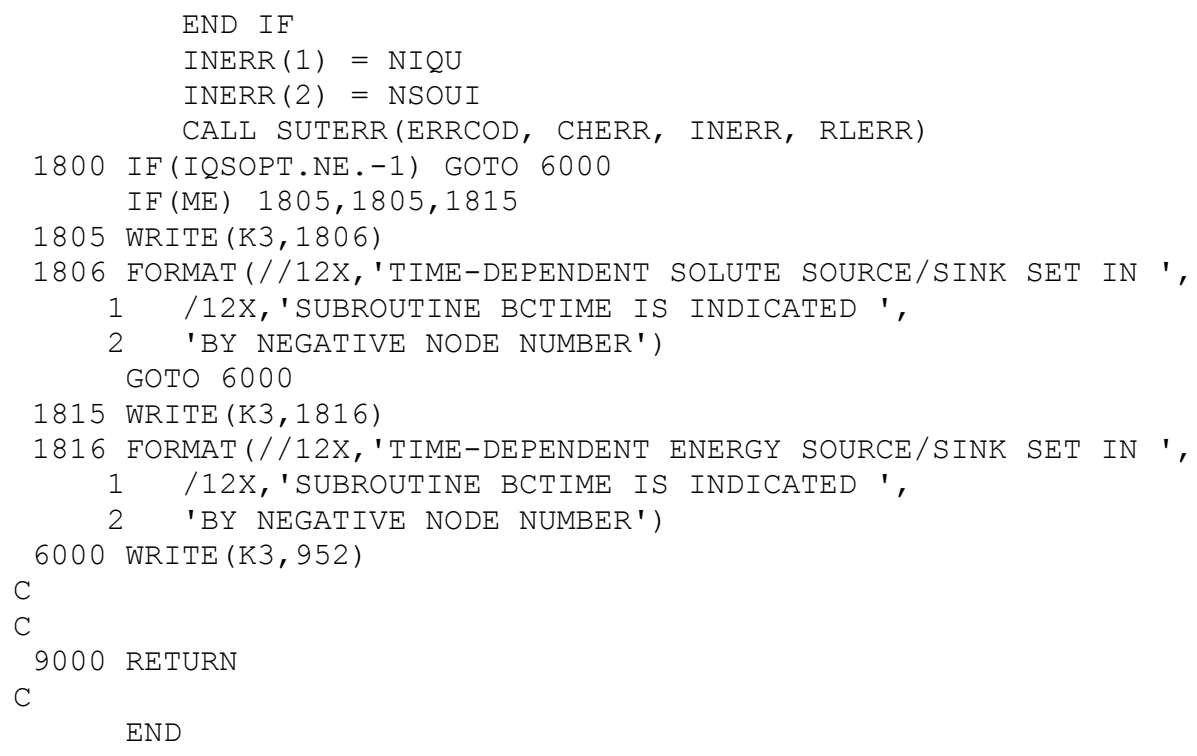

\section{Subroutine SOURCE1}

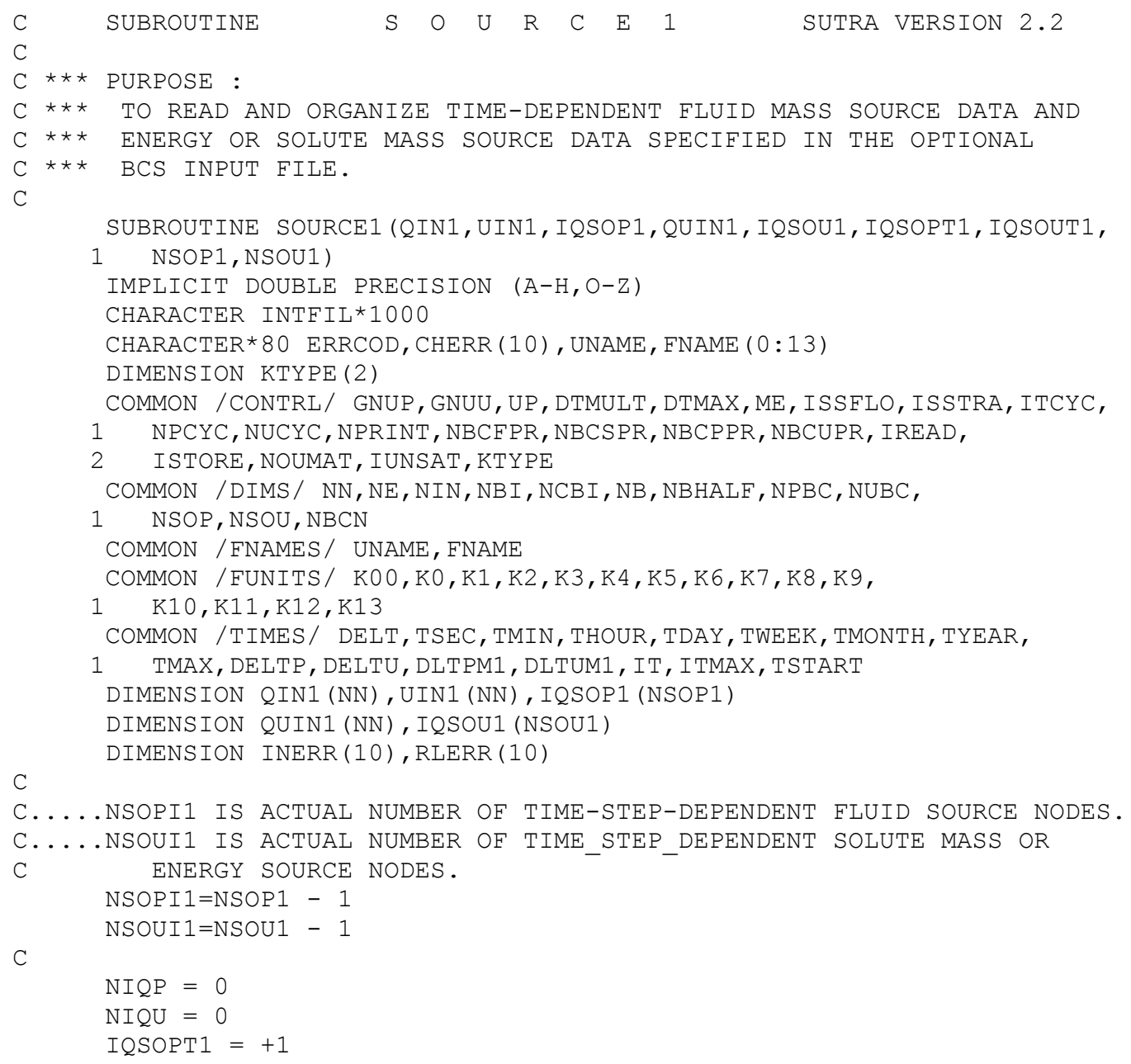




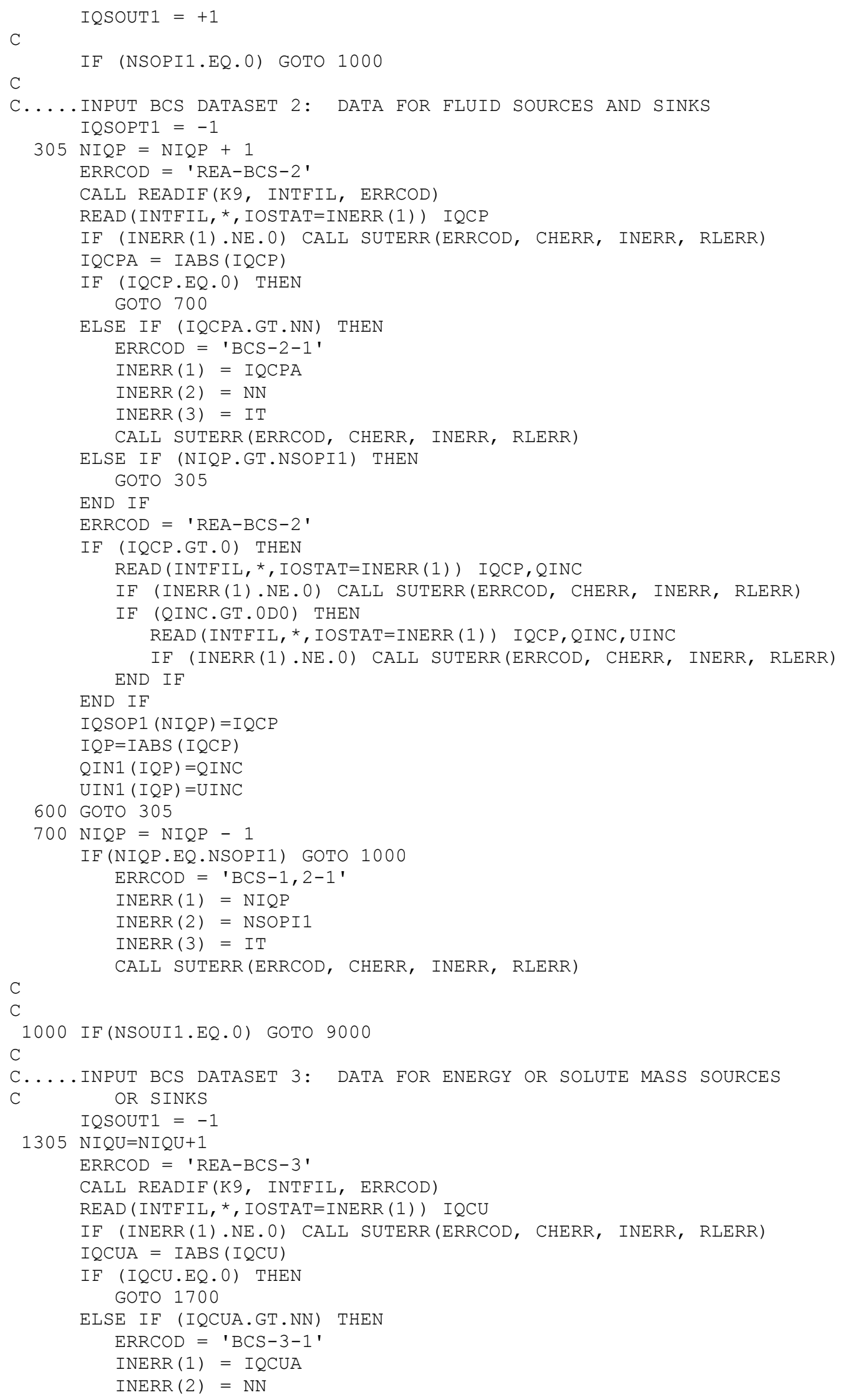




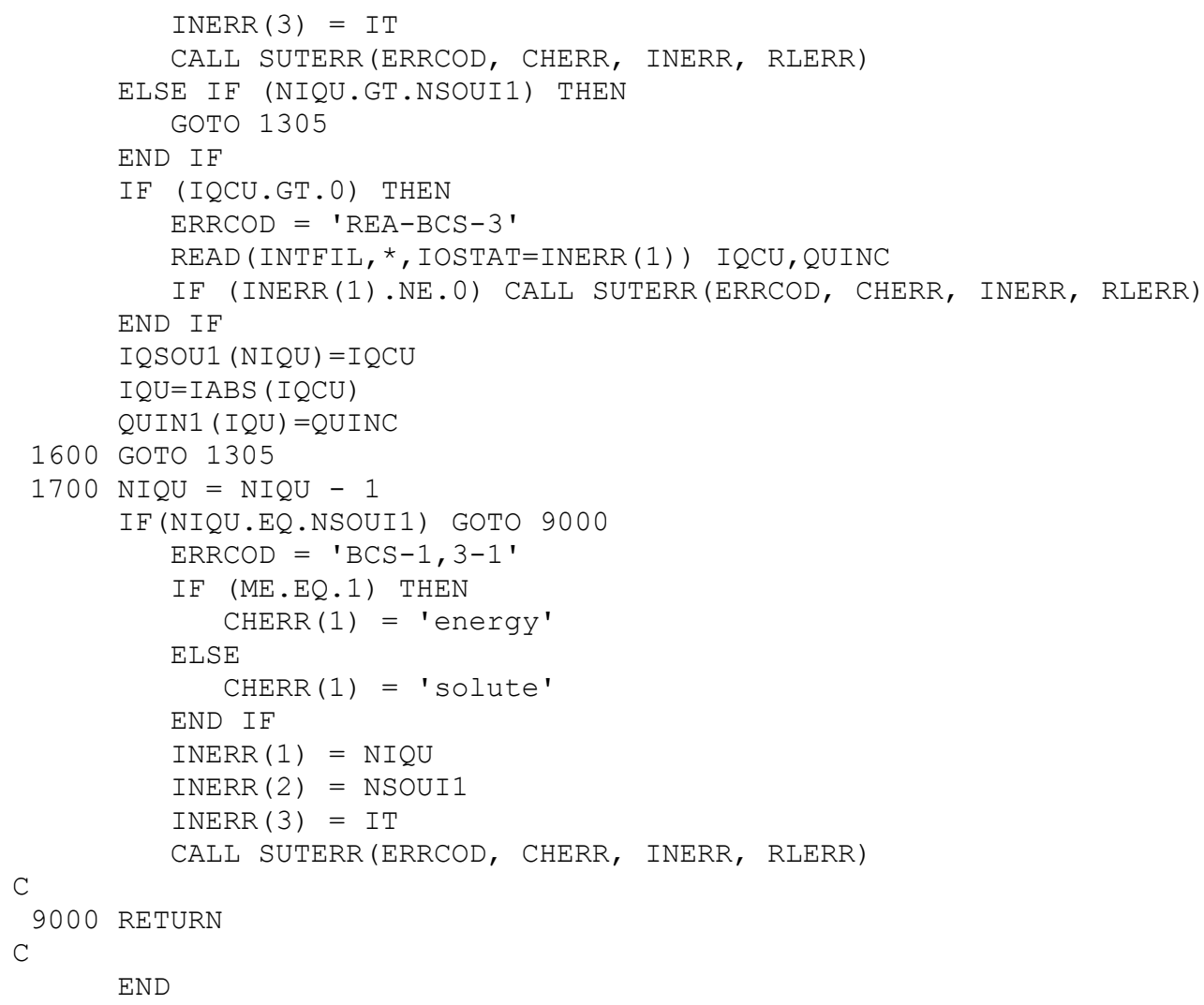

\section{Subroutine UNSAT}

To save space, selected comment lines have been deleted from the listing below.

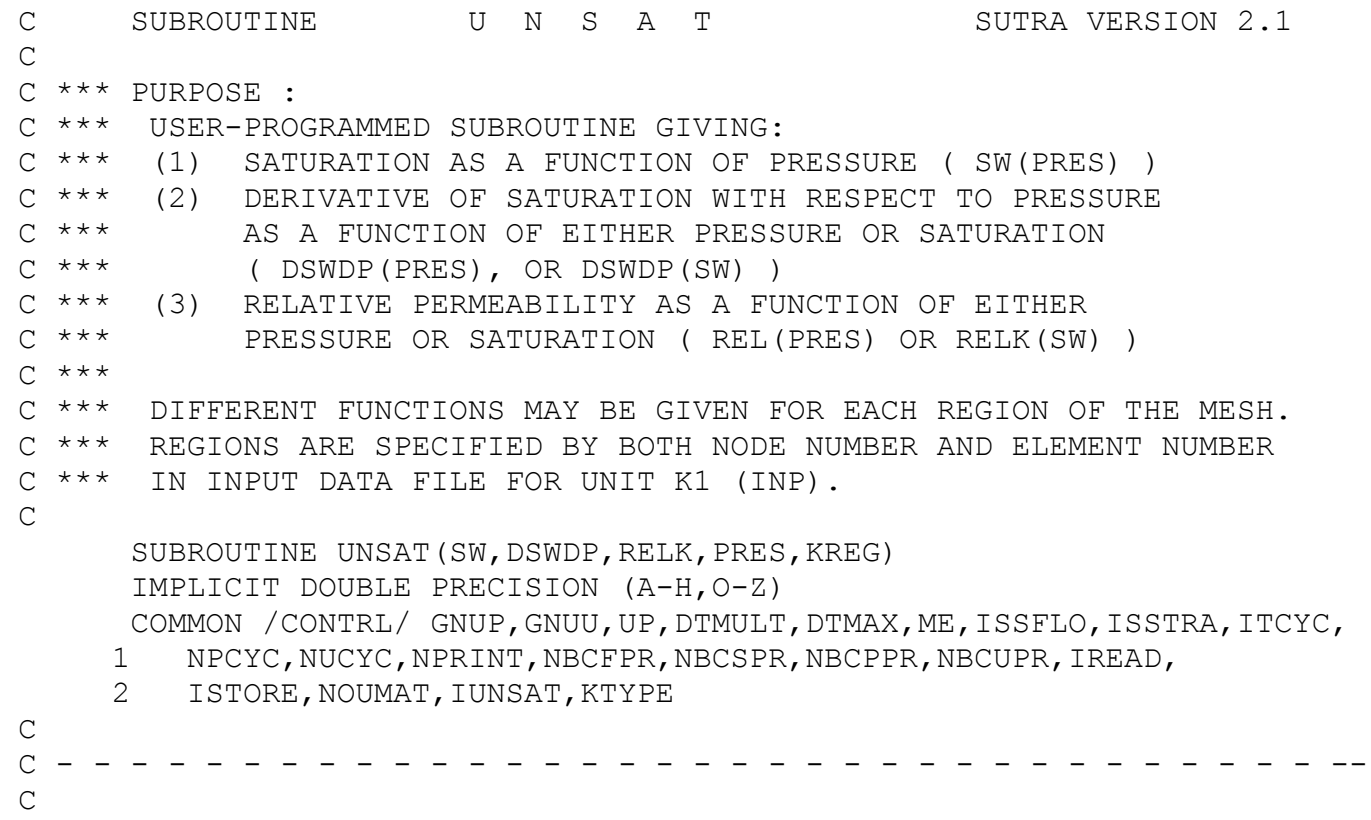


C SWRES IS RESIDUAL SATURATION, PENT IS AIR ENTRY PRESSURE, C PSWRES IS PRESSURE AT RESIDUAL SATURATION, RKRES IS RELATIVE

C PERMEABILITY AT RESIDUAL SATURATION

C

C

REAL SWRES, PENT, PSWRES, RKRES, SLOPES, SLOPEK

REAL SWRES1, SWRES2, PENT1, PENT2, PSWRES1, PSWRES2, RKRES1, RKRES2

COMMON /UNSAT1/ SWRES1, PENT1, PSWRES1, RKRES1

COMMON /UNSAT2/ SWRES2, PENT2, PSWRES2, RKRES2

C

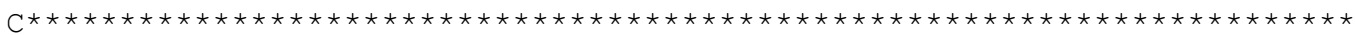

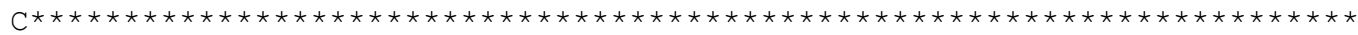

$\mathrm{C}$

C SET PARAMETERS FOR CURRENT REGION, KREG $\operatorname{GOTO}(10,20)$, KREG

10 SWRES $=$ SWRES1

PENT $=$ PENT 1

PSWRES $=$ PSWRES 1

RKRES $=$ RKRES 1

GOTO 100

20 SWRES=SWRES2

$\mathrm{PENT}=\mathrm{PENT} 2$

PSWRES $=$ PSWRE 2

RKRES $=$ RKRES2

100 CONTINUE

SLOPES $=(1$. - SWRES $) /($ PENT - PSWRES $)$

SLOPEK $=(1 .-$ RKRES $) /(1 .-$ SWRES $)$

C

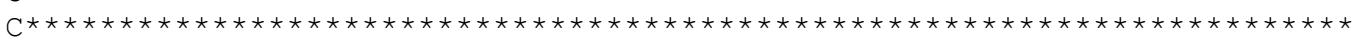

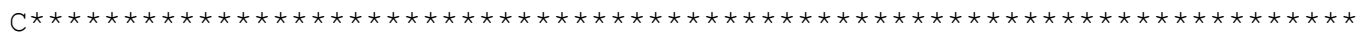
C.....SECTION (1):

C SW VS. PRES (VALUE CALCULATED ON EACH CALL TO UNSAT)

C CODING MUST GIVE A VALUE TO SATURATION, SW.

C

C PIECEWISE LINEAR CURVE

IF (PRES . LE. PSWRES) THEN $\mathrm{SW}=\mathrm{DBLE} \quad(\mathrm{SWRES})$

ELSE IF (PRES . GE . PENT) THEN $\mathrm{SW}=1 . \mathrm{DO}$

ELSE

$\mathrm{SW}=\operatorname{DBLE}(1 \cdot+\operatorname{SLOPES} *(\operatorname{PRES}-\mathrm{PENT}))$

END IF

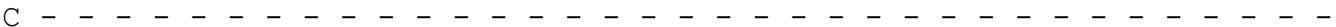

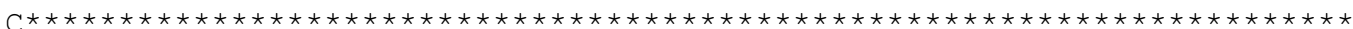

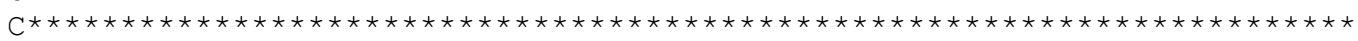

C

C

IF (IUNSAT-2) $600,1200,1800$

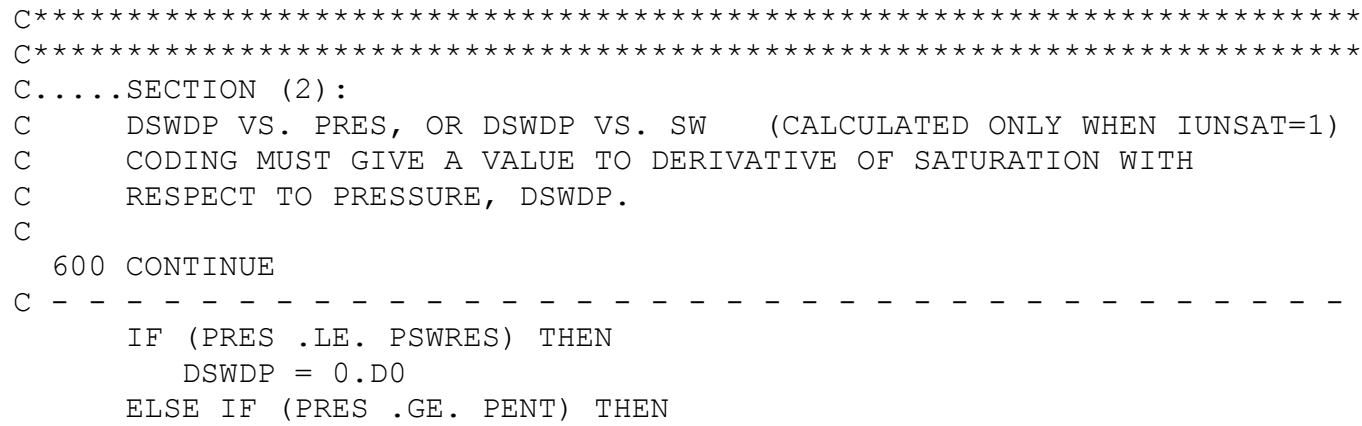




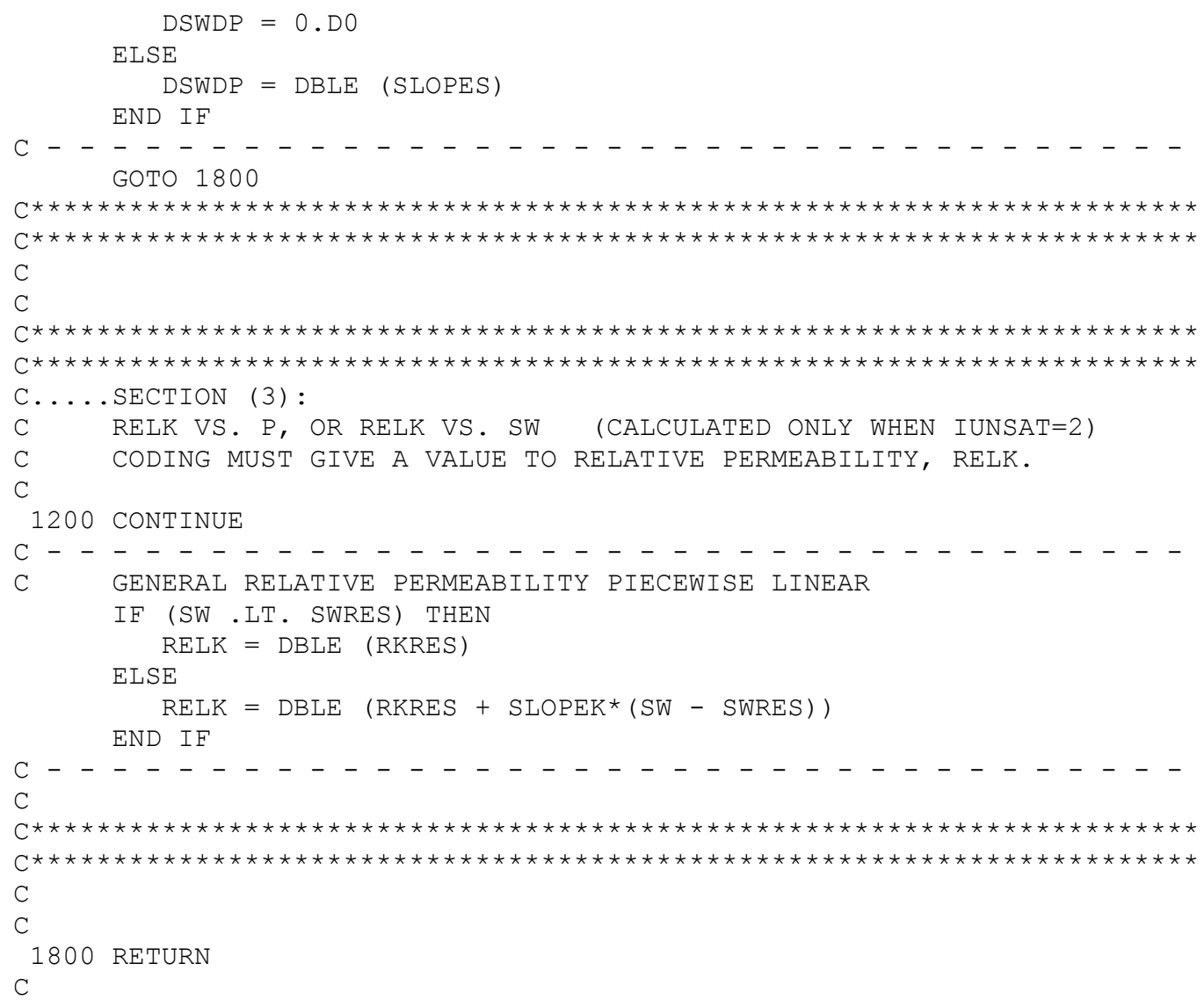

END 
Prepared by the Pembroke Publishing Service Center

For additional information write to:

New York Water Science Center

U.S. Geological Survey

30 Brown Rd.

Ithaca, NY 14850

Information requests:

(518) 285-5602

or visit our Web site at: http://ny.water.usgs.gov 
